\title{
An Evaluation of Energy Storage Options for Nuclear Power
}

Justin Coleman

Shannon Bragg-Sitton, Ph.D.

Eric Dufek, Ph.D.

UT Team:

Sam Johnson

Joshua Rhodes, Ph.D.

Todd Davidson, Ph.D.

Michael E. Webber, Ph.D.

June 2017

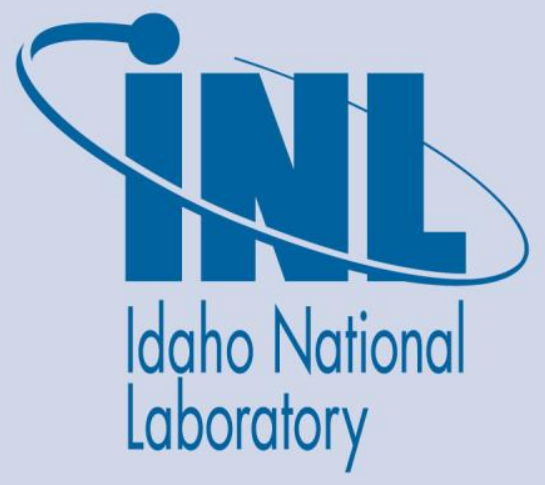

The INL is a U.S. Department of Energy National Laboratory operated by Battelle Energy Alliance 


\section{DISCLAIMER}

This information was prepared as an account of work sponsored by an agency of the U.S. Government. Neither the U.S. Government nor any agency thereof, nor any of their employees, makes any warranty, expressed or implied, or assumes any legal liability or responsibility for the accuracy, completeness, or usefulness, of any information, apparatus, product, or process disclosed, or represents that its use would not infringe privately owned rights. References herein to any specific commercial product, process, or service by trade name, trade mark, manufacturer, or otherwise, does not necessarily constitute or imply its endorsement, recommendation, or favoring by the U.S. Government or any agency thereof. The views and opinions of authors expressed herein do not necessarily state or reflect those of the U.S. Government or any agency thereof. 


\title{
An Evaluation of Energy Storage Options for Nuclear Power
}

\author{
Justin Coleman \\ Shannon Bragg-Sitton, Ph.D. \\ Eric Dufek, Ph.D. \\ UT Team: \\ Sam Johnson \\ Joshua Rhodes, Ph.D. \\ Todd Davidson, Ph.D. \\ Michael E. Webber, Ph.D. \\ June 2017 \\ Idaho National Laboratory \\ Nuclear Science and Technology \\ Idaho Falls, Idaho 83415
}

http://www.inl.gov

Prepared for the

U.S. Department of Energy

Office of Nuclear Energy

Under DOE Idaho Operations Office

Contract DE-AC07-05ID14517 


\section{SUMMARY}

\section{Overview}

Energy supply, distribution, and demand are continuing to evolve as new generation sources come online and new appliances are installed. A larger percentage of the United States (U.S.) energy mix is provided by variable energy sources such as wind and solar each year, and distributed generation is becoming more common. In parallel, an evolution in consumer products such as electrical vehicles, information technology devices for residential and industrial applications, and appliances is changing how energy is consumed. As a result of these trends, nuclear power plants (NPPs) are being called upon to operate more flexibly than ever before. Furthermore, advanced nuclear power plants (A-NPPs) might operate as part of an electricity system that looks very different than when the current NPP fleet was constructed.

A-NPPs face the possibility that they will need to operate in an environment where flexibility (e.g., fast ramping) is more highly valued than stability (e.g., baseload generation for conventional demand curves). The current fleet of NPPs is struggling to remain economical in competitive markets in an era of historically low natural gas prices and renewable sources with very low marginal costs. These factors, overlaid with an ambiguous national policy related to nuclear energy and a decision-making context that struggles with multi-decade capital investments, raise key questions and present significant challenges to the economics of nuclear power in the evolving grid.

Multiple factors could improve the economics of A-NPPs, including: (1) minimizing the need for active safety systems, (2) minimizing adoption of oneoff reactor designs, (3) establishing policies that credit low carbon emitting technologies, and (4) integrating energy storage technologies that increase revenue and reduce costs through a combination of ancillary services, market hedging, and reduced costs via stable operation. This report focuses on Item (4), containing an overview, synthesis, and examination of energy storage options that could be integrated with nuclear generation.

Figure 1 provides an overview of the 2015 energy mix by sector, which shows that NPPs are currently used exclusively for electricity generation that is ultimately consumed in the residential, commercial, and industrial sectors. Some areas for NPP energy growth in the future include power generation for electrified transportation and thermal generation for storage and industrial applications. Currently, most industrial thermal energy users combust fossil resources (i.e., coal or natural gas) to meet the energy needs of the processes, but heat from nuclear operations could also be used in certain specific applications. 


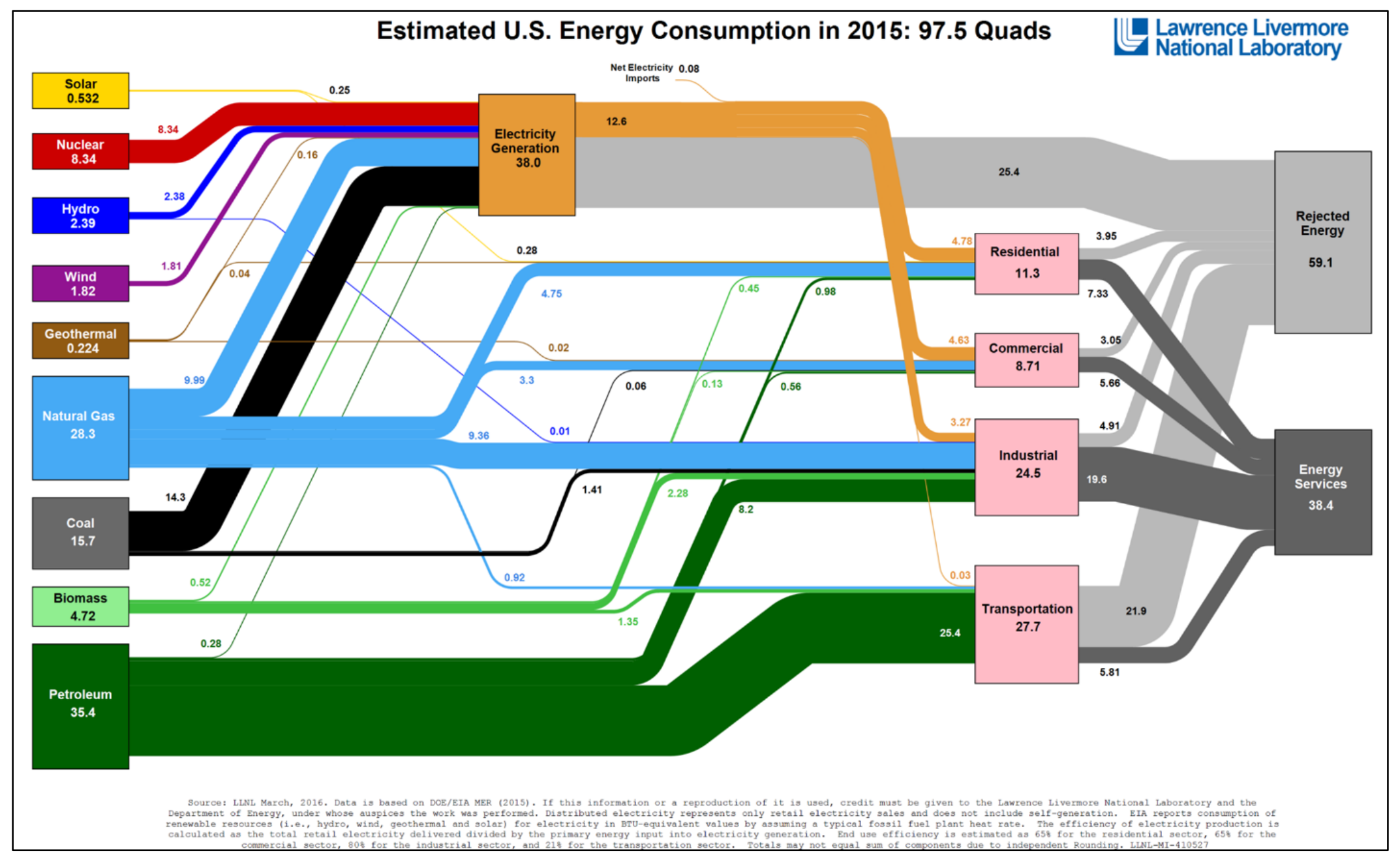

Figure 1. Estimated U.S. energy consumption in 2015 [1]. 
Figure 2 shows U.S. greenhouse gas (GHG) emissions by sector. Figure 1 shows that electricity and heat contributed the most to GHG emissions in 2015, specifically in the residential, commercial, and industrial sectors. The next largest contributor for 2015 was the transportation sector. In 2016, it is anticipated that the transportation sector will surpass the power sector as the leading source of $\mathrm{CO}_{2}$ emissions. Incorporating a higher fraction of A-NPPs along with solar and wind in place of coal and natural gas as source of heat and power will help decarbonize the U.S. energy mix.

\section{Current Electricity Grid}

In traditional grid balancing areas, thermal generators fueled by coal and nuclear energy have been called upon to provide baseload power, while natural gas combined cycle, boilers, and combustion turbine systems have been used for mid-merit dispatch and to meet peaking requirements. Areas with abundant water and suitable geography also often use hydroelectric sources for either baseload or backup power. This suite of options is used with different dispatching schemes to match the electrical supply to hourly, daily and seasonal swings in load (electrical demand).

This conventional system is already very variable, as load is difficult to predict with great precision and there are many common-mode effects that strain the system. For example, weather systems, such as a heat wave, can increase demand by driving up the use of air conditioning while simultaneously reducing the efficiency of thermal power plants. The addition of renewable generators might increase this variability as they contribute to uncertainty in the net load that needs to be met by dispatchable baseload and peaking plants. Despite the complexity of the U.S. electricity system, which is nationally comprised of more than one thousand major power plants and millions of miles of transmission and distribution lines, it has worked with great reliability even with increasing usage. This performance could be attributed to the fact that the U.S. electricity system is divided into multiple interconnects and operating regions that are supported by a vast number of grid operators who are dedicated to maintaining the resilience of the grid. However, this regional apportionment of responsibility has also led to contrasting policies regarding the electricity grid in the U.S. and other constraints such as different market dynamics that could ultimately increase the complexity of the U.S. electricity system.

\section{Evolving Energy Grid}

Despite the past reliability of electrical systems in the U.S., the generation, transmission and distribution system is undergoing rapid transition. New devices such as electric vehicles, web-enabled information technology devices, and electrified manufacturing could cause demand to increase for electricity despite rapid efficiency gains elsewhere in society. These devices are also beginning to reduce the dependency of variations in demand on weather. At the same time, rapid penetration of variable renewable generators, such as wind and solar energy, historically low natural gas prices that have driven down wholesale electricity prices, and a policy environment that is ambiguous about the role of nuclear power in decarbonizing the grid, have resulted in a challenge for many legacy NPPs to stay economically viable in some regions. Hence, the continued operation of these plants and construction of new NPPs have an uncertain outlook. 


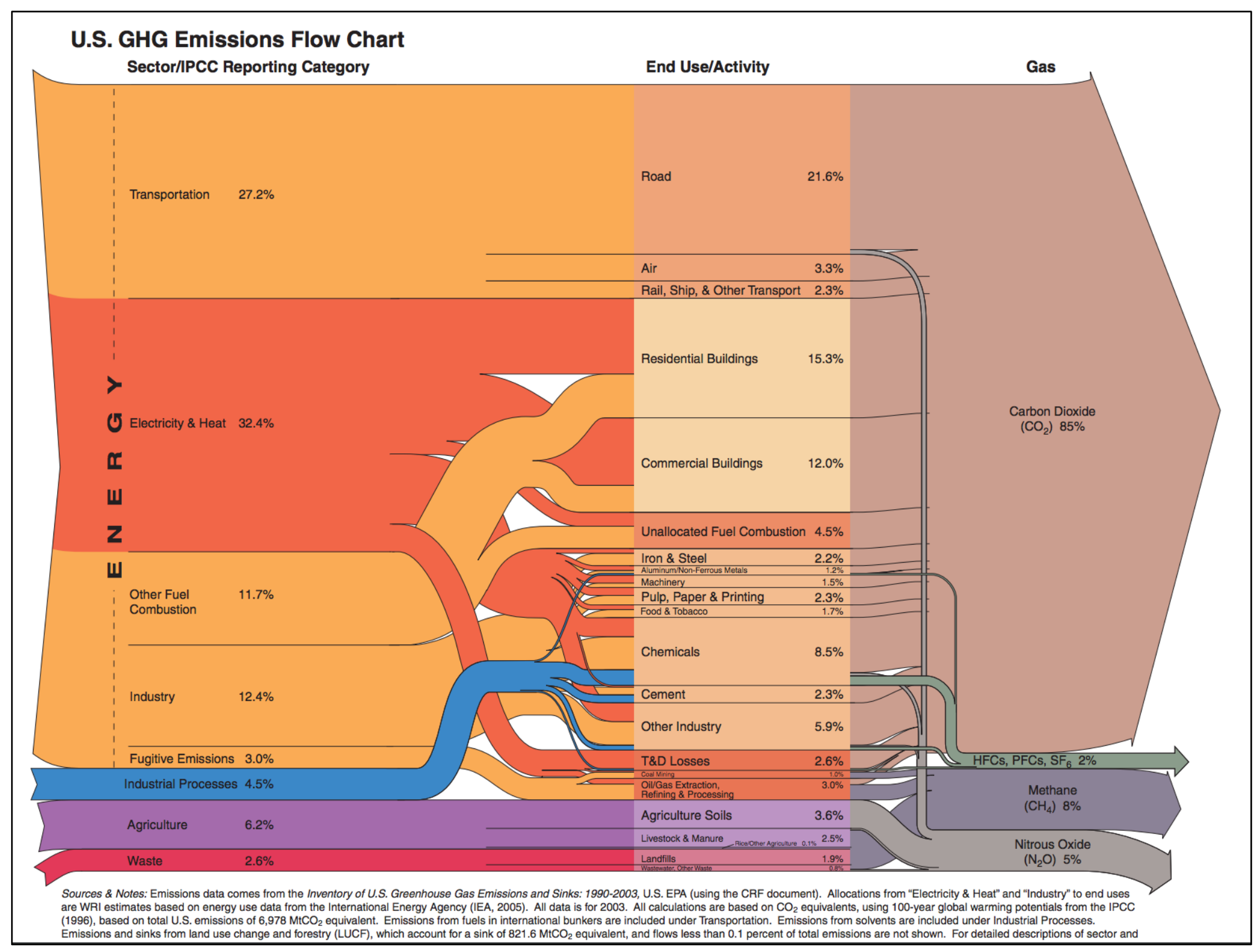

Figure 2. U.S. GHG emissions flow chart [2]. 
NPPs have had difficulty adapting to the shifting grid dynamics due to regulatory constraints and limited experience ramping electricity production and operating flexibly in the U.S. By contrast, NPPs in France have been flexibly operating for years because their power plants have been designed for that operational role, since France has a very high percentage of baseload generators on the grid rather than variable renewable energy sources (VRES). In regulated markets like the Southeastern U.S., nuclear power is still experiencing some growth. However, the high capital cost and uncertain policy context puts nuclear power at a disadvantage in the restructured (i.e., deregulated) markets that exist throughout the majority of the country.

\section{Potential Energy Future}

This report examines whether incorporating energy storage technologies can mitigate some of the challenges currently faced by nuclear utilities. Energy storage would enable NPPs to respond nimbly to market variability, and it could also position NPPs to participate differently in restructured markets. Deregulated markets have led to the introduction of ancillary service markets that enable energy storage technologies to generate revenue by providing grid services such as backup power, frequency regulation up, frequency regulation down, fast response reserves, and so forth. Integrating these technologies with nuclear generators might further enhance the market competitiveness of an NPP. In addition, significant use of energy storage technologies might provide broader benefits to the electric grid as a whole, potentially reducing the need for peaking plants and improving the economic performance of baseload plants. However, under current market conditions, many energy storage technologies, both thermal and electrical, are economically challenged and face significant barriers to investment. Thus, while the economic competitiveness of nuclear power might benefit from integration with energy storage, the converse - that the economic competitiveness of energy storage could also benefit from integration with nuclear power - might also be true. Therefore, more information regarding the performance metrics, policy and market conditions, and compatible revenue streams of the available energy storage technologies is needed to clarify the advantages provided by these technologies and the challenges these technologies still face.

\section{Energy Storage Technology Selection}

In summation, NPPs are being called upon to operate flexibly, which has introduced a difficult economic situation for plant operators. In addition, advanced NPPs coupled with solar and wind technologies using energy storage might help meet GHG emissions targets. This report explores the possibility that a wide variety of energy storage devices could be integrated with A-NPPs to provide flexibility. A down-selection tool was developed as a part of this research to help the user decide which technology is most appropriate. Some of the key factors considered by the tool include: environmental impact, geographic availability, cost requirements, technology maturity, and technology performance.

The down-selection tool is capable of systematically considering data gathered in this report to generate a few top-level technology recommendations. Selected output from the decision tool is displayed in Figure 3. By assembling a database of information concerning the available energy storage technologies 
under development or in use for grid stabilization in the U.S., this report and decision tool could provide a way for developers to acquaint themselves with a particular storage technology before choosing to build a new installation.

\begin{tabular}{||c|c|c|c|c|c|c|}
\hline Technology Characteristics & PSH & CAES & Flywheels & Li-ion & $\begin{array}{c}\text { Hot and Cold } \\
\text { Water }\end{array}$ & $\begin{array}{c}\text { Molten } \\
\text { Salts }\end{array}$ \\
\hline Environmental Impact & 6.39 & 6.39 & 8.89 & 5.83 & 10.00 & 6.11 \\
\hline Technology Maturity & 10.00 & 10.00 & 7.78 & 7.78 & 7.78 & 10.00 \\
\hline Geographic Availability & 1.00 & 1.00 & 1.00 & 1.00 & 1.00 & 1.00 \\
\hline Cost Requirements & 1.00 & 1.00 & 0.00 & 1.00 & 1.00 & 1.00 \\
\hline Cost Difference $(S)$ & $6.00 \mathrm{E}+06$ & $8.50 \mathrm{E}+06$ & $-1.00 \mathrm{E}+07$ & $0.00 \mathrm{E}+00$ & $9.40 \mathrm{E}+06$ & $9.30 \mathrm{E}+06$ \\
\hline Space Requirements & 1.00 & 1.00 & 1.00 & 1.00 & 1.00 & 1.00 \\
\hline Weight Requirements & 1.00 & 1.00 & 1.00 & 1.00 & 1.00 & 1.00 \\
\hline Potential Additional Storage Capacity $(\mathrm{kWh})$ & $5.00 \mathrm{E}+11$ & $2.00 \mathrm{E}+12$ & $2.00 \mathrm{E}+13$ & $7.50 \mathrm{E}+10$ & $2.00 \mathrm{E}+13$ & $8.00 \mathrm{E}+10$ \\
\hline Potential Additional Power Capacity $(\mathrm{kW})$ & $5.00 \mathrm{E}+11$ & $5.00 \mathrm{E}+11$ & $1.00 \mathrm{E}+15$ & $7.50 \mathrm{E}+11$ & $\mathrm{NA}$ & $\mathrm{NA}$ \\
\hline Application Compatibility Factor & 1.00 & 1.00 & 0.00 & 0.50 & 1.00 & 1.00 \\
\hline Levelized Cost of Storage, Lower-End $(\mathrm{S} / \mathrm{MWh})$ & 188 & 192 & 276 & 321 & $\mathrm{NA}$ & $\mathrm{NA}$ \\
\hline Levelized Cost of Storage, Upper-End $(\mathrm{S} / \mathrm{MWh})$ & 274 & 192 & 989 & 658 & $\mathrm{NA}$ & $\mathrm{NA}$ \\
\hline
\end{tabular}

Figure 3. Selection from the decision tool for energy storage technologies.

To obtain the output shown above in Figure 3, a generic scenario for the state of New York was supplied to the decision tool. New York's political and economic climate will be discussed in later sections as a part of the Northeastern regional electricity market. According to the chart displayed above, New York has both favorable policy conditions and a moderately dynamic electricity market. In this scenario, a typical energy storage capacity, power output, and budget were selected and no technologies were eliminated from consideration due to space, weight, or geographic requirements. The results for a few of the most common energy storage technologies are displayed above in Figure 3, and the displayed chart shows that only flywheels and hydrogen production were ruled out due to cost requirements and an inability to perform energy arbitrage services, which was selected as the desired grid-scale application. Of the remaining compatible storage technologies, a developer using the tool could then select a technology for their application based on the technology characteristics that they find to be the most important. If cost was selected as the most important characteristic, then pumped storage hydropower would be the top recommended technology due to its relatively low levelized cost of storage.

In addition to the overview of energy storage, this report lays out the preliminary steps for grid modeling and optimization work that could offer greater specificity on the profitability of energy storage technologies integrated with electricity generating units. Future work could also guide current users of energy storage technologies while identifying economic ways to improve system operations. This decision tool could be expanded to determine the best energy storage technologies in every region of the U.S. based on a variety of criteria, such as levelized cost or performance. In conclusion, energy storage technologies could enable NPP use in the residential, commercial, industrial, and 
transportation sectors, which could both maximize the amount of revenue available to the nuclear power industry and significantly reduce GHG emissions. 


\section{CONTENTS}

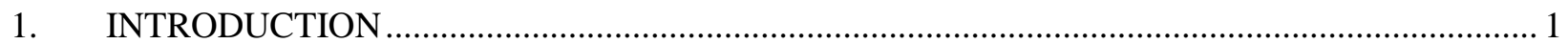

$1.1 \quad$ Purpose

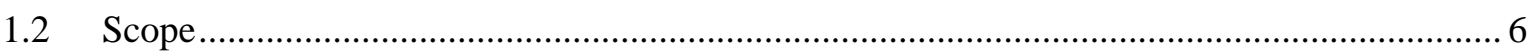

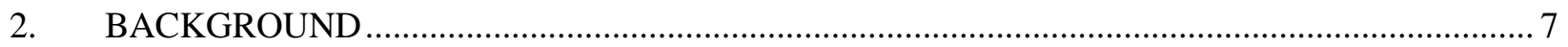

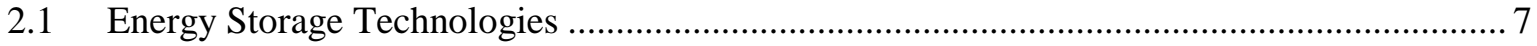

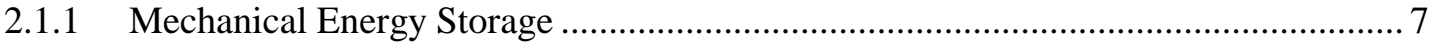

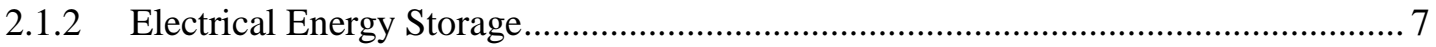

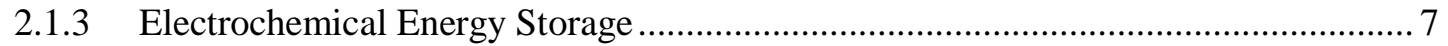

2.1.4 Chemical Energy Storage

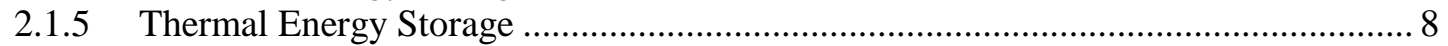

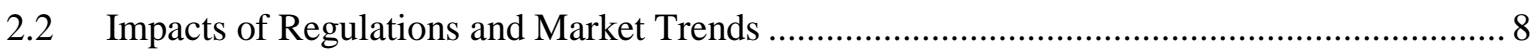

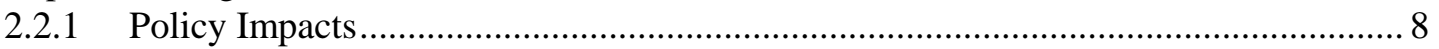

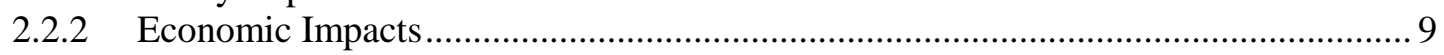

2.3 Overview of the Grid and Modern Electricity Markets ................................................... 10

2.3.1 Operation of the Electric Grid............................................................................. 10

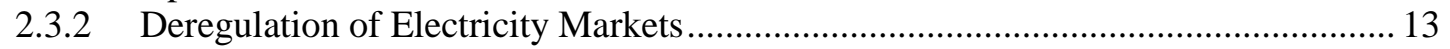

2.3.3 Regional Evolution of Electricity Markets ............................................................. 14

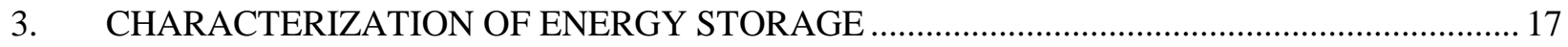

3.1 Performance Parameters for Energy Storage ................................................................... 17

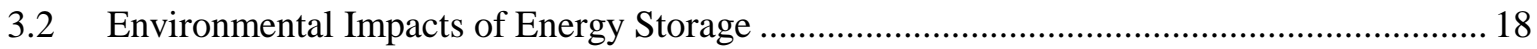

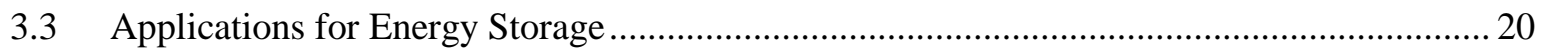

3.4 End-User Energy Management Strategies ................................................................. 21

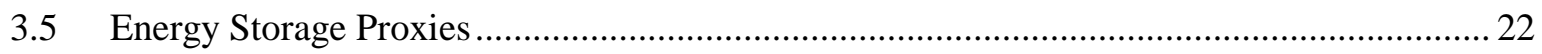

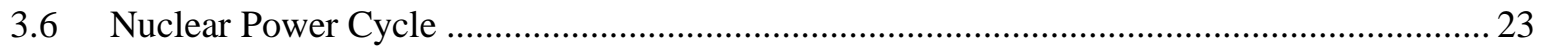

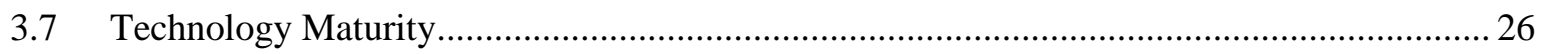

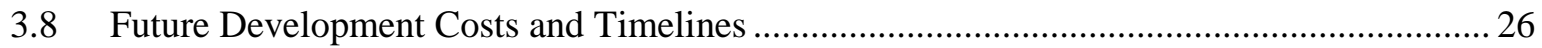

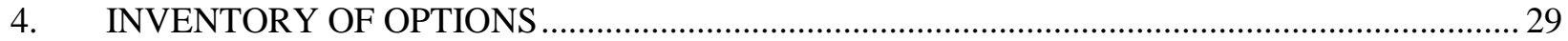

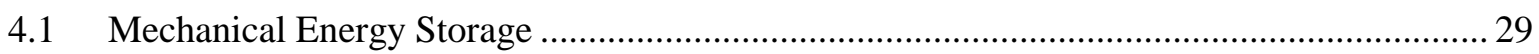

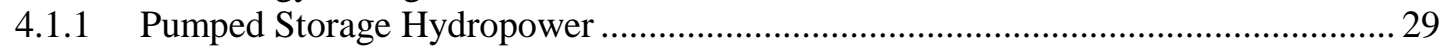

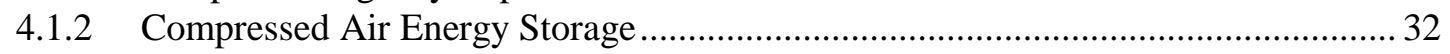

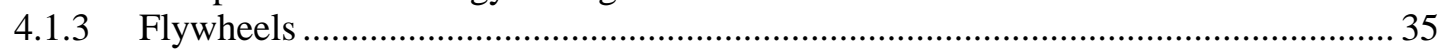

4.2 Electrical Energy Storage

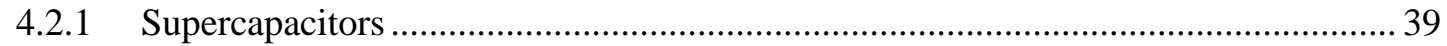

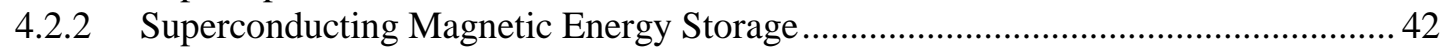

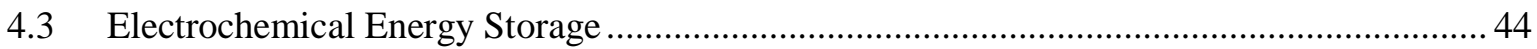

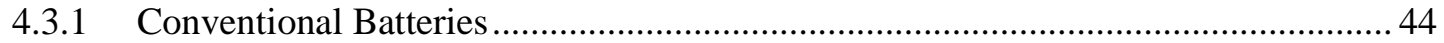

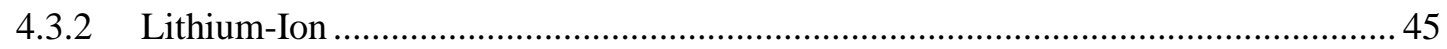

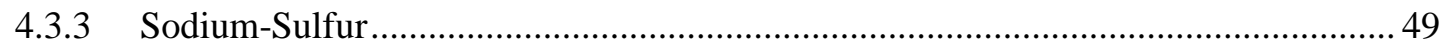

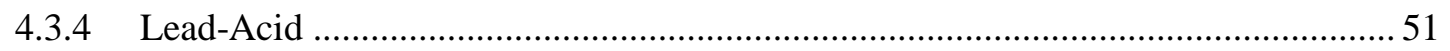

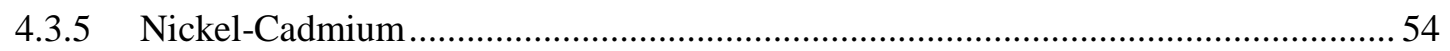

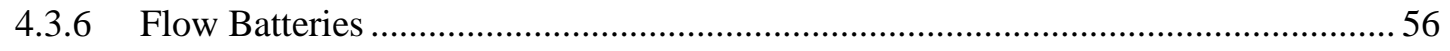




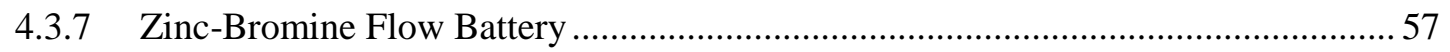

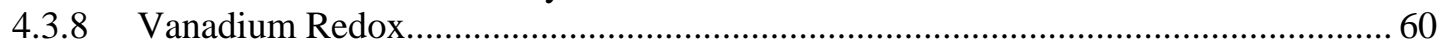

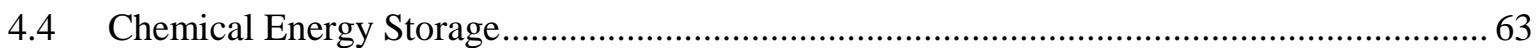

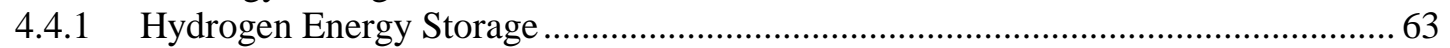

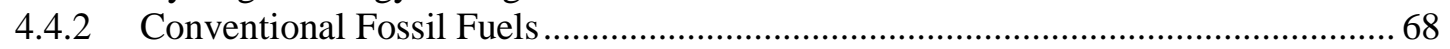

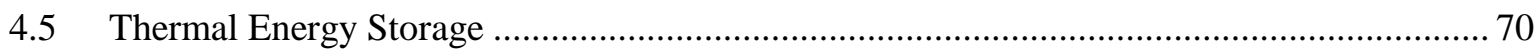

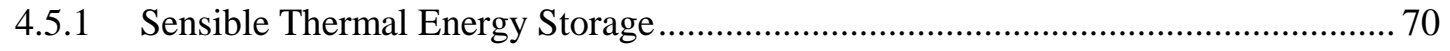

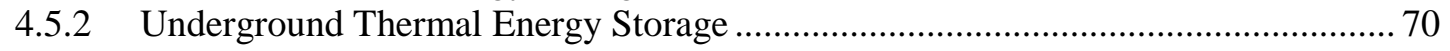

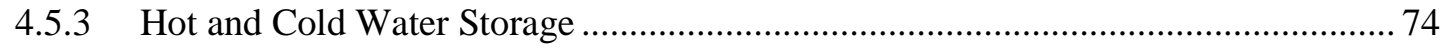

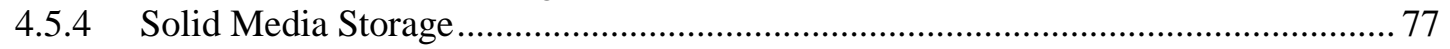

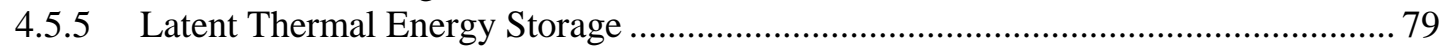

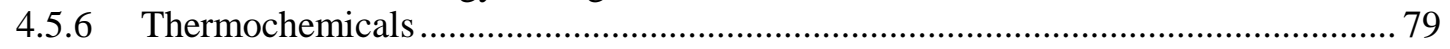

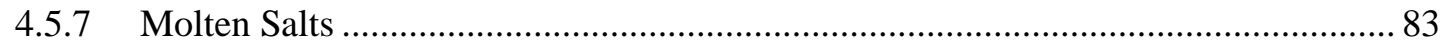

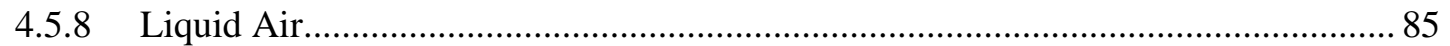

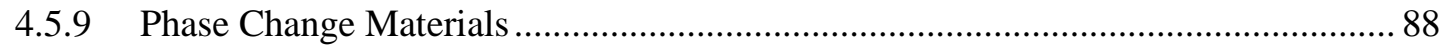

5. DECISION TOOL DEVELOPMENT (Methods and Analytical Approach) ............................... 91

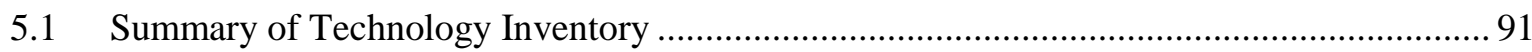

5.1.1 Comparison of Performance Parameters................................................................ 91

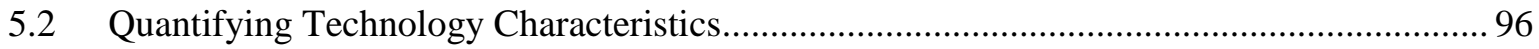

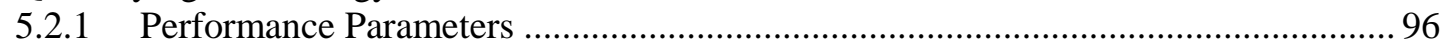

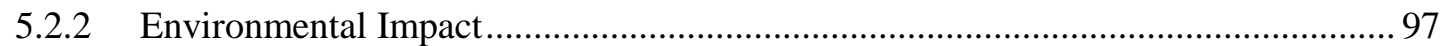

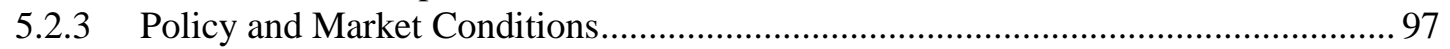

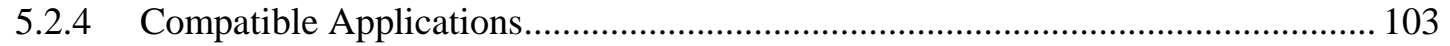

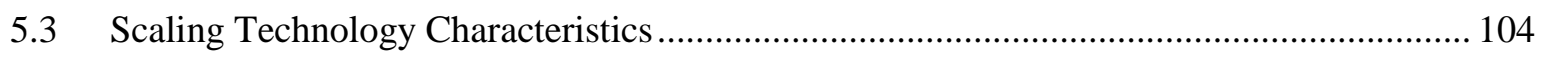

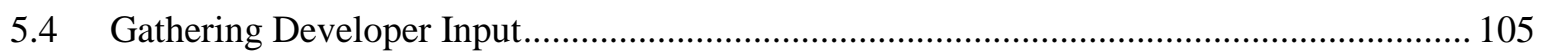

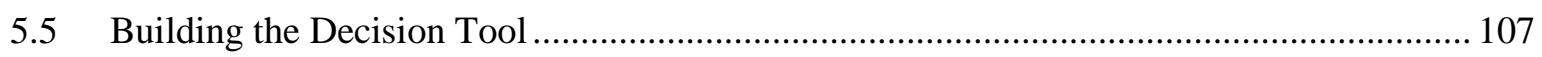

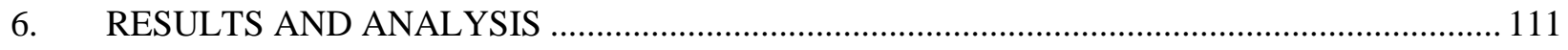

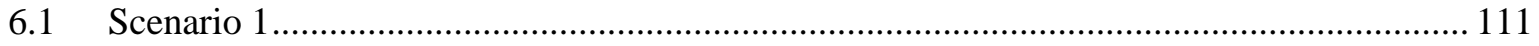

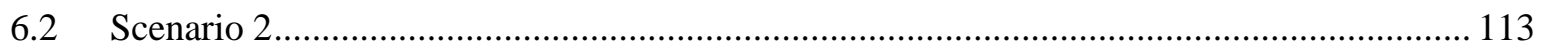

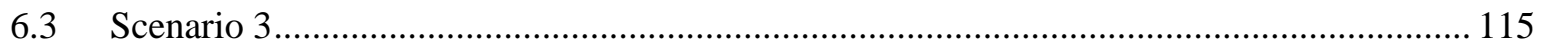

6.4 Analysis of the Impacts of Energy Storage Integration ............................................... 117

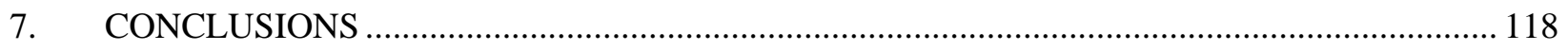

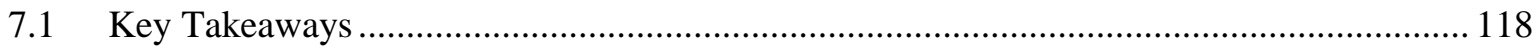

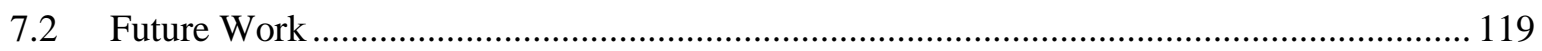

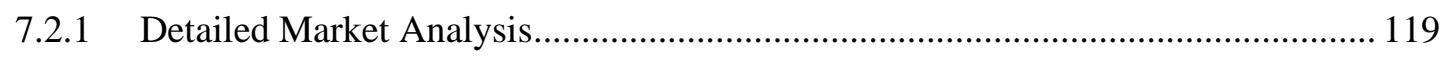

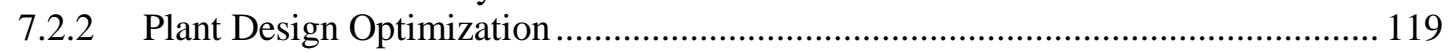

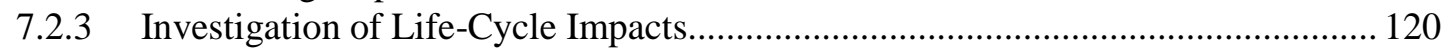

7.2.4 Refinement of Performance Metrics .................................................................. 120

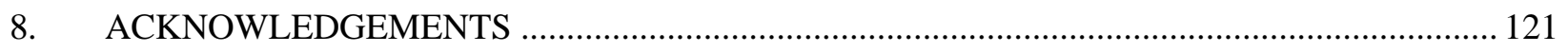

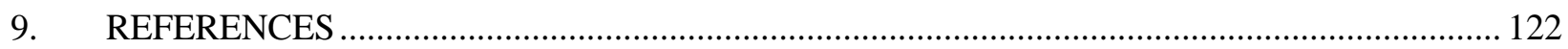




\section{FIGURES}

Figure 1. Estimated U.S. energy consumption in 2015. Error! Bookmark not defined.

Figure 2. U.S. GHG emissions flow chart. Error! Bookmark not defined.

Figure 3. Selection from the decision tool for energy storage technologies. vii

Figure 4. Nuclear power plants in the decommissioning process in the U.S......................................... 1

Figure 5. Growth in natural gas production from shale in the U.S. ..................................................... 3

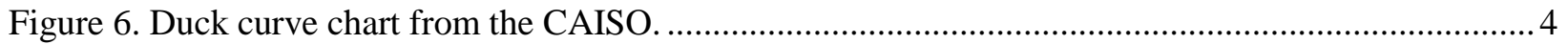

Figure 7. Incidence of negative electricity prices in the Electricity Reliability Council of Texas

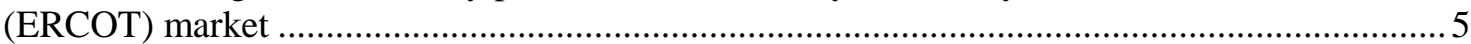

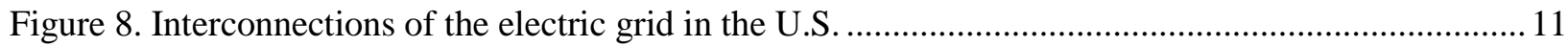

Figure 9. New generation mix projection for four policy scenarios ..................................................... 12

Figure 10. Map of states that have pursued electricity market deregulation........................................... 13

Figure 11: Map of regional electricity markets in the U.S................................................................ 14

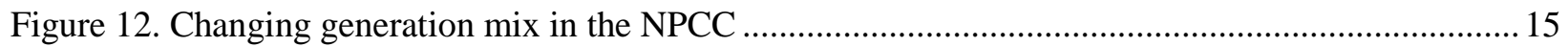

Figure 13. Basic diagram representing the nuclear power cycle ..........................................................2 24

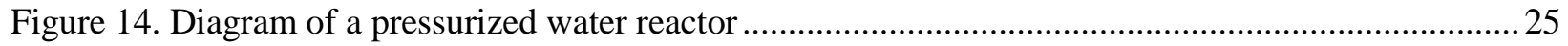

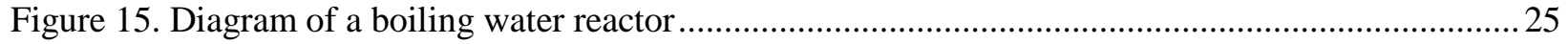

Figure 16. Correlation between maturity level, development costs, and technology risk .......................28

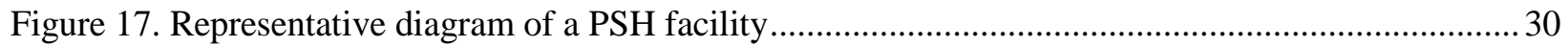

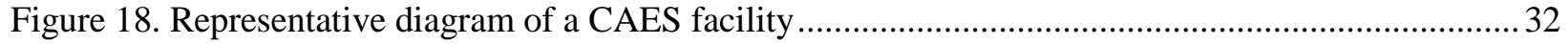

Figure 19. Potentially suitable geologic formations for underground CAES from the Electric Power Research Institute (EPRI) ................................................................................... 34

Figure 20. Representative diagram of a flywheel energy storage system ...............................................36

Figure 21. Charging and discharging process for a supercapacitor .......................................................40

Figure 22. Representative diagram of a SMES system........................................................................ 43

Figure 23. Representative diagram of a lithium-ion battery …............................................................. 45

Figure 24. Representative diagram of a sodium-sulfur battery .............................................................. 49

Figure 25. Representative diagram of a lead-acid battery...................................................................52

Figure 26. Representative diagram of a nickel-cadmium battery ..........................................................54

Figure 27. Representative diagram of a zinc-bromine flow battery ......................................................57

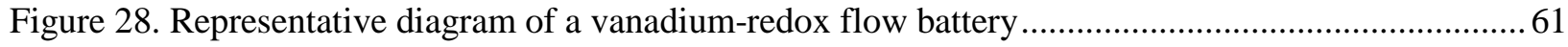

Figure 29. Production and uses for a hydrogen energy storage system .................................................64

Figure 30. Representative diagram of an aquifer TES system for building heating and cooling ..............71

Figure 31. Representative diagram of hot and cold water energy storage tanks................................... 75

Figure 32. Example of a concrete thermal energy storage module .......................................................... 77 
Figure 33. Representative diagram of a thermochemical energy storage system .................................... 80

Figure 34. Representative diagram of a molten salt TES system for a CSP plant ................................... 84

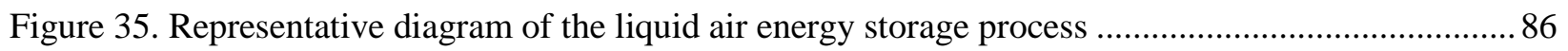

Figure 36. Representative diagram of an ice thermal energy storage system ......................................... 88

Figure 37. Comparing energy density and cost of storage for various technologies ...............................99

Figure 38. Comparing specific energy and cost of storage for various technologies .............................. 93

Figure 39. Comparing power density and cost of power for various technologies...................................94

Figure 40. Comparing specific power and cost of power for various technologies ..................................95

Figure 41. Comparing the cost of power for thermal energy storage technologies ..................................96

Figure 42. Regions used to determine market variability ............................................................... 102

Figure 43. Energy arbitrage to capture peak demand pricing in Scenario 1........................................111

Figure 44. Stoplight chart with selected electricity storage technologies for Scenario 1. ...................... 113

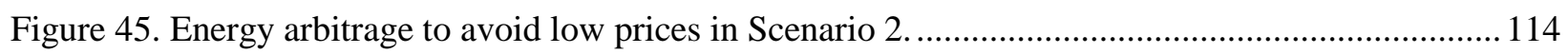

Figure 46. Spotlight chart with selected thermal energy storage technologies for Scenario 2. ................ 115

Figure 47. Mechanical, electrical, and electro-chemical energy storage technologies for

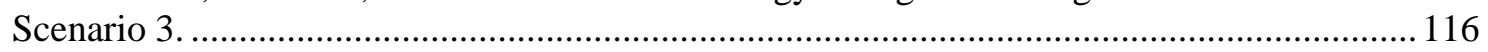

Figure 48. Flow batteries and thermal energy storage technologies for Scenario 3. ............................. 117

\section{TABLES}

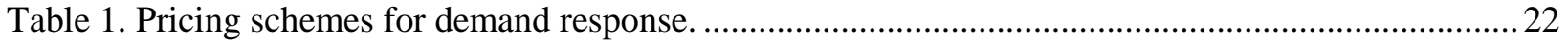

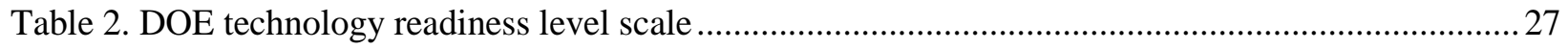

Table 3. Performance parameters for mechanical energy storage systems................................................ 37

Table 4. Environmental impacts of mechanical energy storage systems............................................... 37

Table 5. Compatible applications for mechanical energy storage systems................................................ 39

Table 6. Performance parameters for electrical energy storage systems. ............................................... 41

Table 7. Environmental impacts for electrical energy storage systems. ................................................4 41

Table 8. Compatible applications for electrical energy storage systems. ............................................. 42

Table 9. Performance parameters for conventional battery systems.......................................................46

Table 10. Environmental impacts of conventional battery systems...................................................... 47

Table 11. Environmental impacts of conventional battery systems....................................................... 48

Table 12. Compatible applications for conventional battery systems...................................................56

Table 13. Performance parameters for flow battery systems............................................................58

Table 14. Environmental impacts of flow battery systems. .....................................................................59

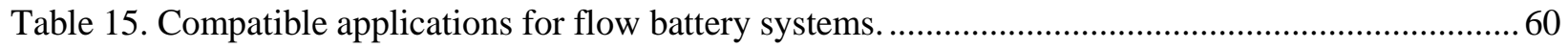

Table 16. Performance parameters for chemical energy storage systems...............................................65 


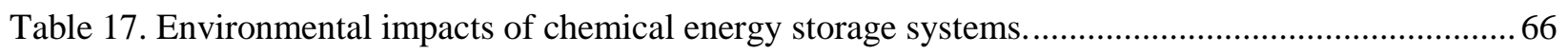

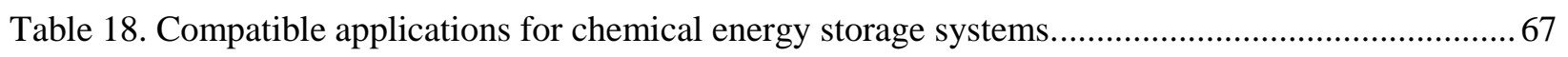

Table 19. Performance parameters for sensible thermal energy storage systems.................................... 72

Table 20. Environmental impacts of sensible thermal energy storage systems. ...................................... 73

Table 21. Applications compatible with sensible thermal energy storage systems. .................................74

Table 22. Performance parameters for latent thermal energy storage systems...................................... 81

Table 23. Environmental impacts of latent thermal energy storage systems. .......................................... 82

Table 24. Compatible applications for latent thermal energy storage systems...................................... 83

Table 25. Quantification of relevant performance parameters..............................................................97

Table 26. Quantification of relevant environmental impacts.................................................................. 98

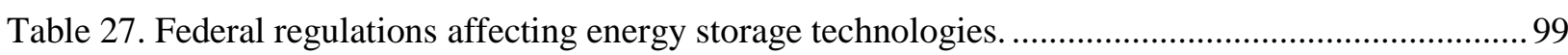

Table 28. State policies and initiatives affecting energy storage technologies..................................... 100

Table 29. Market trends and regulations affecting energy storage technologies. .................................. 101

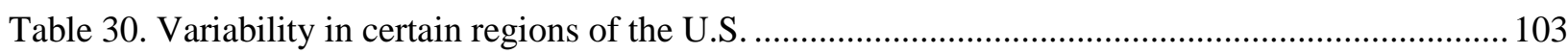

Table 31. Quantification for level of compatibility with grid-scale applications. .................................. 103

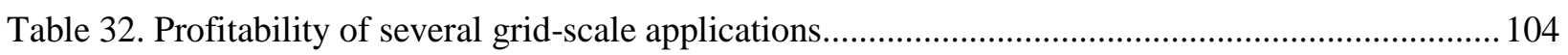

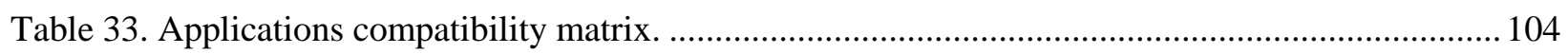

Table 34. Requirements for energy arbitrage to capture peak demand pricing for Scenario 1................112

Table 35. Requirements for energy arbitrage to avoid low prices in Scenario 2 . .................................. 114

Table 36. Requirements for frequency regulation in Scenario 3. ....................................................... 116 


\section{ACRONYMS}

ARRA American Recovery and Reinvestment Act of 2009

A-NPP Advanced Nuclear Power Plant

BWR boiling water reactor

CAES compressed air energy storage

CAISO California Independent System Operator

CPUC California Public Utility Commission

CSP concentrating solar power

DOE Department of Energy

EIA Energy Information Administration

EPA Environmental Protection Agency

EPRI Electric Power Research Institute

ERCOT Electricity Reliability Council of Texas

FERC Federal Energy Regulatory Commission

GHG greenhouse gas

IEA International Energy Agency

ISO Independent System Operator

ISO-NE New England Independent System Operator

ITC investment tax credit

LAES Liquid Air Energy Storage

LCOS Levelized Cost of Storage

MISO Midcontinent Independent System Operator

NERC North American Electricity Reliability Council

NPCC Northeast Power Coordinating Council

NPP nuclear power plant

NRC Nuclear Regulatory Commission

NYISO New York Independent System Operator

O\&M operating and maintenance

PCM phase change material

PIER Public Interest Energy Research

PSH pumped storage hydropower

PUC Public Utility Commission

PV photovoltaic

PWR pressurized water reactor 
RTO Regional Transmission Organization

SMES superconducting magnetic energy storage

SMUD Sacramento Municipal Utilities District

TCS thermochemical storage

TES thermal energy storage

TRA Technology Readiness Assessment

TRL Technology Readiness Level

U.S. United States

UTES underground thermal energy storage

UWR Universal Waste Rule

VRB vanadium redox battery

VRES variable renewable energy sources

VSR variable supply resource 


\section{An Evaluation of Energy Storage Options for Nuclear Power}

\section{INTRODUCTION}

Despite the fact that nuclear power plants (NPPs) generate electricity without producing emissions and operate at a high capacity factor, nuclear power appears to be in decline in the United States (U.S.). Many existing NPPs are being shut down, although a few reactors are being built in the Southeast. As a whole, nuclear power generation in the U.S. peaked in 2010 and proceeded to decline slightly between then and 2014 [3]. One of the primary reasons for this downturn might be the rising cost of building NPPs, which has led to an increased marginal cost of generating electricity. Additionally, legacy NPPs for which capital costs are less of a concern are simply unable to compete with electricity produced using low-cost natural gas. In restructured energy markets where NPPs compete directly with natural gas plants and subsidized renewable energy sources like wind and solar power, NPPs have at times been forced to sell power at a loss in recent years [4]. As a result, 19 reactors are currently in various phases of decommissioning by the Nuclear Regulatory Commission (NRC), with five of these plants retiring in the past decade [4]. These plants are identified in Figure 1.

\section{U.S. Commercial Nuclear Power Reactors Undergoing Decommissioning and Permanently Shut Down Formerly Licensed To Operate}

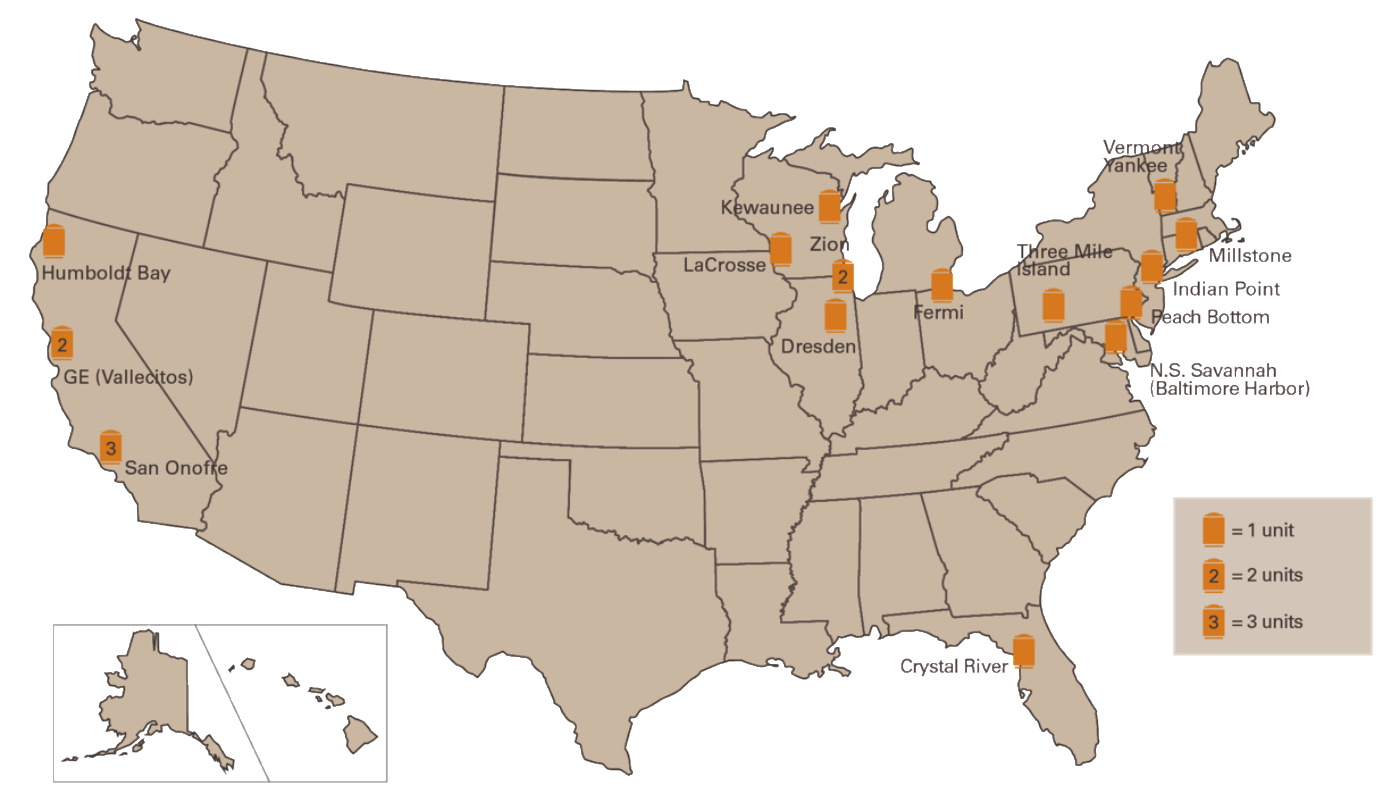

Reactor Decommissioning Sites

As of July 2015

Figure 1. Nuclear power plants in the decommissioning process in the U.S. [5]. 
Furthermore, three additional plants in Illinois and upstate New York could face closure within the next decade [4]. In fact, some projections have identified 37 reactors in total that will soon become economically infeasible [3]. While costs for new NPPs in the U.S. have increased, in South Korea costs for new NPPs have steadily decreased [6]. If the issues that have caused construction costs to increase in the U.S. can be addressed, nuclear power could have an important role to play in the country's decarbonized energy future. In this report, energy storage is explored as a potential solution to the economic challenges faced by NPPs and as a method for enhancing the flexibility of NPPs and increasing their market competitiveness. Although the construction costs for NPPs could fall in the future, potentially lessening the need for energy storage technologies to enhance profitability, the long-term benefits of integrating energy storage with the electric grid are also explored in this report.

\subsection{Purpose}

The rising investment costs for NPPs, along with historical events that have increased the perceived risk of generating electricity with nuclear energy, have contributed to the difficulty of building new NPPs [3]. However, nuclear power provides environmental and performance benefits and therefore should be given serious consideration as an ongoing part of the energy mix. The U.S. made commitments in December of 2015 as a part of the Paris Agreements to reduce greenhouse gas emissions in the country to 26-28\% below 2005 levels by 2025. Furthermore, the Clean Power Plan was proposed in June of 2014, with the goal of reducing power sector emissions to $30 \%$ below 2005 levels by 2030 . Although this plan is currently under review by the Supreme Court, if this measure passes, electricity generation from NPPs could become increasingly important as environmental restrictions could potentially limit electricity generation from coal and natural gas fired power plants [7]. However, as the economic viability of NPPs across the country has declined, nuclear power developers face several technical and economic challenges to constructing new plants that would help the U.S. comply with its targets.

One of the most significant economic challenges faced by NPPs is falling wholesale electricity prices in restructured energy markets. Although NPPs have remained economically viable in regulated regions like the Southeast, where the only new NPP construction projects over the past couple of decades have appeared, falling prices have undermined the profitability of NPPs in the deregulated energy markets that serve the majority of consumers in the U.S. While falling prices are disadvantageous for NPPs, they also have the positive effect of invigorating the economy and providing financial relief to the consumer. Multiple factors have contributed to falling electricity prices, but two are particularly relevant: low natural gas prices and low marginal costs for renewable power generation. This report will seek to identify ways by which NPPs can work with storage technologies for market competition in a low price environment.

The falling price of natural gas has introduced significant downward pressure on electricity prices as developers have seized the opportunity presented by abundant domestic natural gas resources and have ramped up the construction of natural gas fired power plants as well as the extraction of fuel across the country. The growth of natural gas production came about as a result of the shale revolution, or the discovery of vast natural gas resources in shale formations in the U.S. The revolution was driven by great technological strides such as the development of horizontal drilling and hydraulic fracturing methods that expedited the process of extracting fuel from these formations. The resulting growth of natural gas production from shale formations in the U.S. is illustrated below in Figure 2. Over the period from 2006 to 2016 , monthly dry shale gas production increased by approximately $2000 \%$. This rise in productivity

has introduced over 40 billion cubic feet per day to the market in 2016, comprising approximately $50 \%$ of all conventional and unconventional domestic natural gas production [8]. 


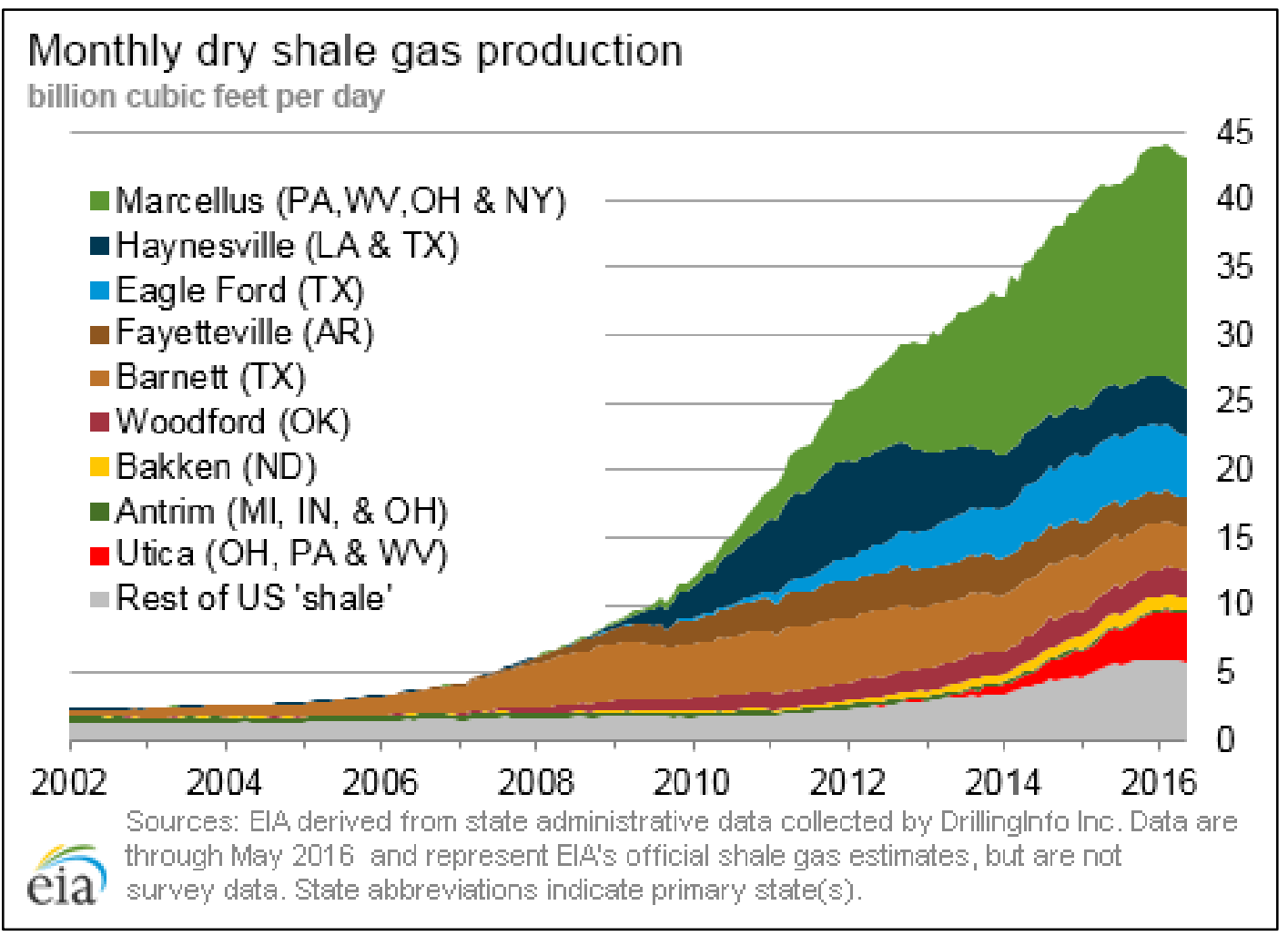

Figure 2. Growth in natural gas production from shale in the U.S. [8].

The ensuing growth in the supply of natural gas caused the annual average Henry Hub natural gas spot price to drop from $\$ 8.86$ per million Btu in 2008 to a low of $\$ 2.50$ per million Btu in early 2012 . These lower fuel prices have been a primary driver for lower wholesale electricity prices as natural gas power plants are able to bid in to the market at lower marginal costs. This drop in electricity prices has contributed significantly to the unfavorable economic conditions for NPPs, since their marginal costs have grown because of higher safety compliance costs in the wake of the Fukushima disaster [9].

The increasing penetration of VRES, in particular wind and solar power, on the grid has increased the variability of the electricity supply and introduced another element of volatility to regional electricity markets across the country, which has presented additional challenges for nuclear power. However, the increased penetration of VRES has also helped reduce greenhouse gas emissions in the U.S. The variability of these energy sources is driven by meteorological and astronomical conditions, which means their output varies by weather, time of day, position of the earth relative to the sun, and so forth. It is possible that these electricity generating units will not provide the amount of electricity forecasted for that day, which is in contrast with conventional power plants that are dispatchable. Additionally, as the percentage of electricity generation from solar power grows, conventional power plants are being asked to ramp more quickly as the sun sets and demand begins to peak in the early evening. The California Independent System Operator (CAISO) has dubbed this phenomenon the "Duck Curve," shown below in Figure 3 [10]. NPPs often have trouble ramping up their production of electricity at the rates that are being predicted by the CAISO in Figure 3 due to technical limitations in the existing fleet of reactors in the U.S. Economic limitations also inhibit NPPs from operating flexibly in response to electricity generation from VRES, since the resulting reduced capacity factor increases the difficulty of capital recovery [11]. 


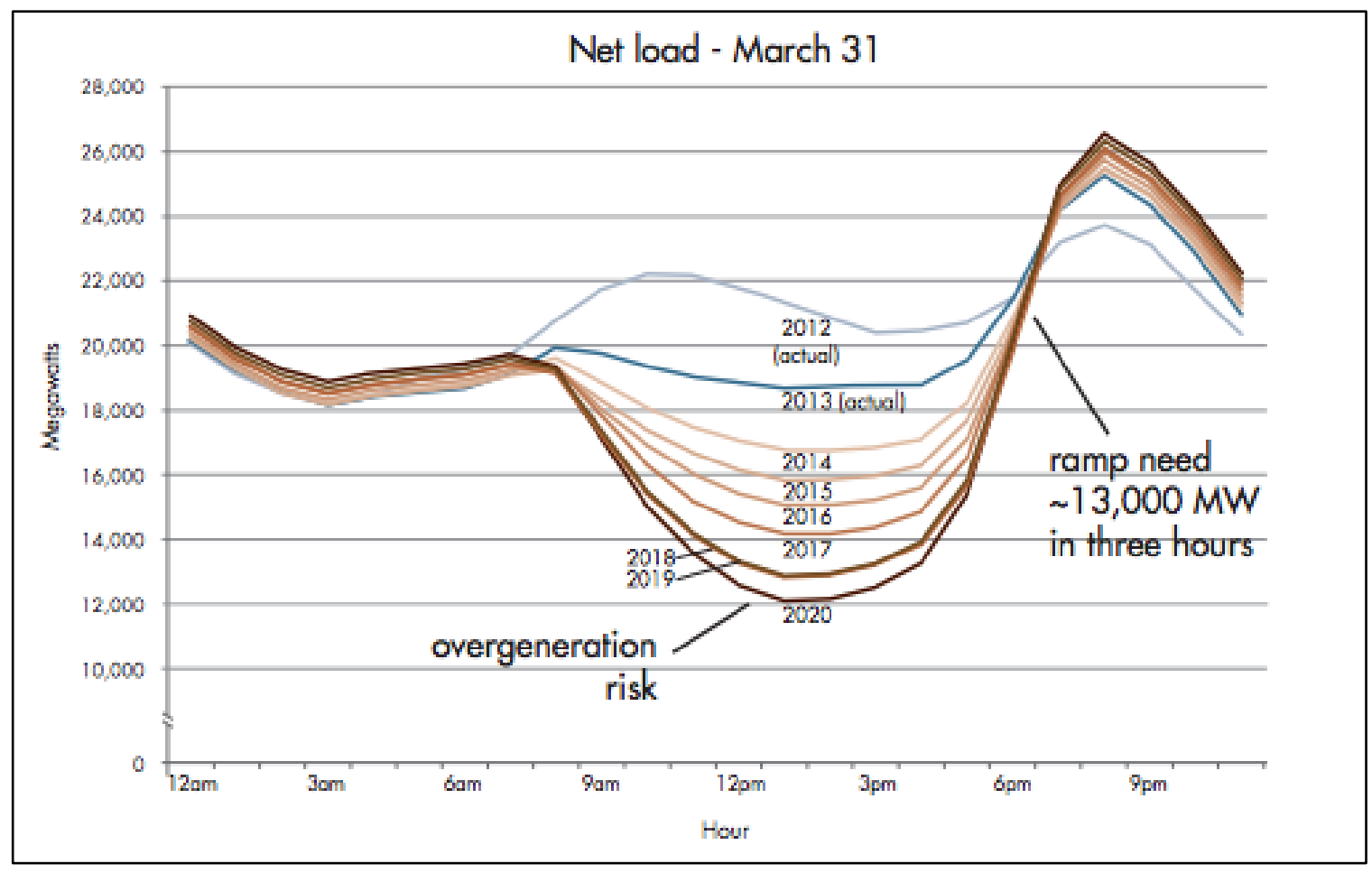

Figure 3. Duck curve chart from the CAISO [10].

The growth of electricity generation from VRES in the U.S. has been driven by three primary factors: federal tax incentives, state goals, and technical advancements that have led to decreased manufacturing costs. The first production tax credit for renewable energy was established by the Energy Policy Act of 1992, and applied principally to wind power. The production tax credit provided tax benefits to wind powered facilities based on the amount of energy provided by the facility for the first 10 years of the lifetime of the plant. Similarly, an investment tax credit (ITC) was established for solar power by the Energy Policy Act of 2005. This tax incentive provided a 30\% tax refund to new solar power plant constructions. The success of the wind and solar power industry has been closely tied to the expiration and renewal of these tax benefits for much of the industry's history. In December of 2015, the Consolidated Appropriations Act of 2016 was passed, which extended both of these tax incentives for 5 years after their initial deadlines [12]. These external market drivers are a large part of the reason for the installation of new capacity, and the free fuel (wind and sunshine) explains why renewables have such a low marginal cost. Another driver of the growth of VRES in the U.S. are the renewable portfolio standards that have been passed in 29 states as of 2016 [13]. These state goals require constituent utilities to install a specified capacity or sell a specified amount or percentage of electricity from renewable energy sources by a set deadline, often 15-20 years in the future. The third and final driver of market adoption for the growth of VRES is the rapid rate of technological innovation in the industry. Specifically, the costs of solar photovoltaic (PV) panels have continued to fall, with the cost of installed solar projects dropping more than $50 \%$ between 2009 and 2015. The efficiency of solar panels has also steadily increased over the years [14]. In addition, the efficiency of wind turbines has continued to rise, from $22 \%$ before 1998 to a market average of 33\% in 2014 [15]. These factors have combined to push the wholesale market price of electricity lower. For example, the exponential growth of wind capacity in the state of Texas between 2006 and 2009 resulted in occasional periods of negative real-time electricity prices in the wholesale market as shown in Figure 4, although the addition of transmission lines to reach the Competitive Renewable Energy Zones has reduced such occurrences [16]. Thus, the deregulation of energy markets in the U.S. has introduced market competition from natural gas and VRES that has driven down the cost of electricity and created an uncertain economic climate for NPPs. 


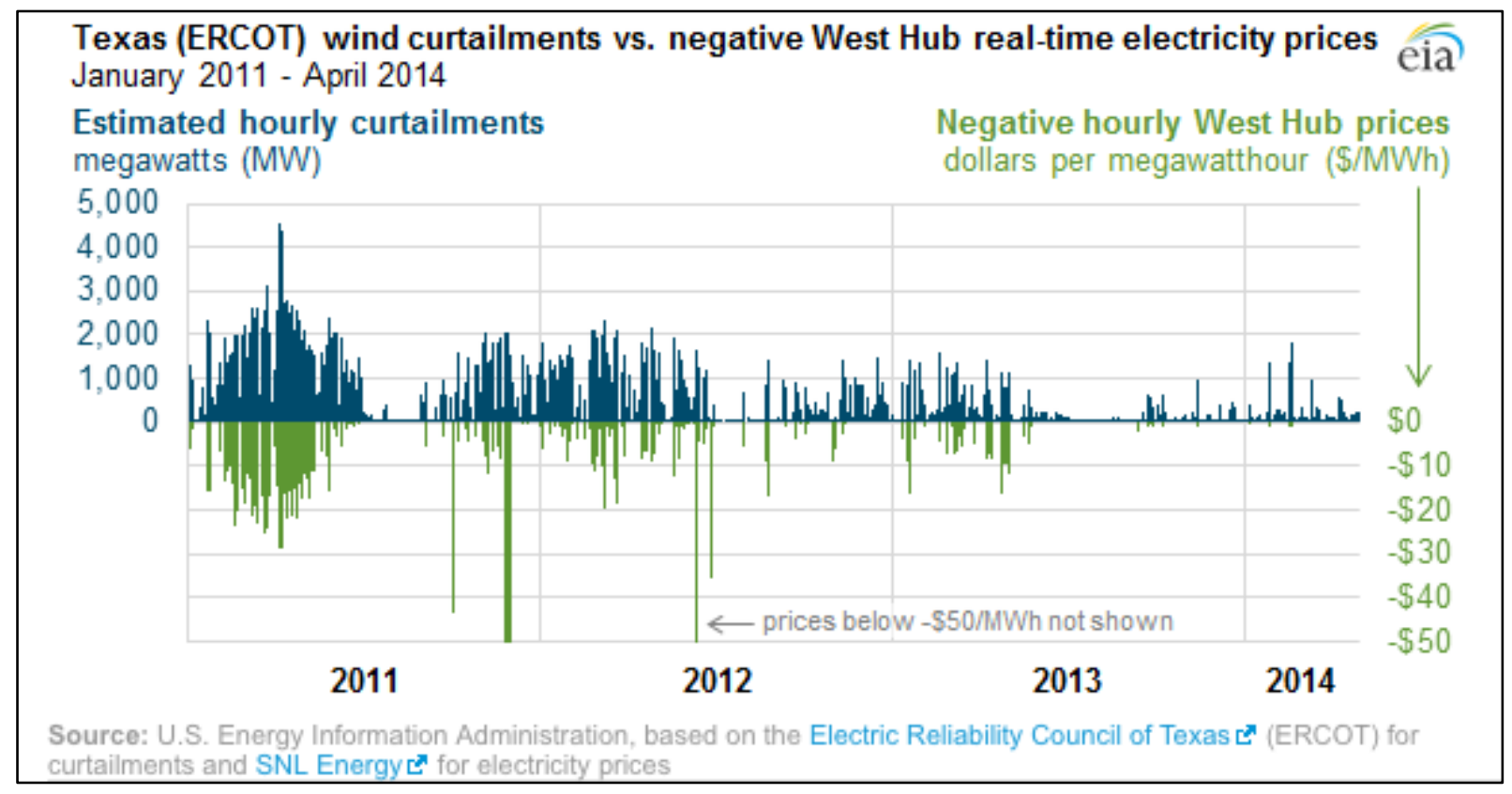

Figure 4. Incidence of negative electricity prices in the Electricity Reliability Council of Texas (ERCOT) market [16].

Although restructured energy markets pose several challenges for NPPs, the consequences of market deregulation are not all negative. The process of market restructuring in the U.S. has formed new markets for ancillary services that strengthen grid reliability. In addition, the introduction of variability to the grid from renewable energy sources has expanded the need for these services. Although these services have always been important, ancillary service markets provide utilities with a way to generate revenue by providing these benefits to the grid. Ancillary services encompass a variety of specialized services that are required for maintaining the integrity of the electric grid in the U.S. and securing a stable power supply for consumers. The specific services provided and their exact definitions vary depending on the particular energy market that an electricity generating unit is operating in. These services are typically purchased from market participants in line with the North American Electricity Reliability Council (NERC) reliability standards that require energy markets in the U.S. to retain a certain capacity of each ancillary service at all times to maintain the resiliency of the grid. Although energy and ancillary service markets are kept separate, it is possible for a generator to sell electricity in the wholesale market while simultaneously selling ancillary services as long as the capacity for these two services do not overlap. A few ancillary services that are common to energy markets in the U.S. are frequency regulation, spinning reserves, and non-spinning reserves [17]. Several key ancillary services that are critical to operating the modern electricity system will be discussed in this report.

The hypothesis this report seeks to examine is that energy storage is an effective solution to the economic difficulties faced by NPPs operating in modern electricity markets. Grid-scale energy storage could provide NPPs with the means to operate flexibly and avoid low electricity prices while simultaneously increasing the amount of energy sold during peak demand periods. Energy storage can also effectively provide the valuable ancillary services the grid needs, enhancing the revenue streams of NPPs. In addition, energy storage technologies could provide system-wide benefits to the grid by increasing the efficiency of balancing supply and demand and reducing the need for excess generating capacity. In fact, recent research has shown that NPPs capable of flexible operation could play a major role in the decarbonization of the grid in the U.S. [18]. 


\subsection{Scope}

In their report Grid Energy Storage, the U.S. Department of Energy (DOE) identified four key barriers that have delayed the widespread deployment of energy storage technologies. These barriers are the need for validated performance and safety, an inequitable regulatory environment, insufficient industry acceptance, and the high costs of energy storage systems. The economic value of energy storage systems is complicated by the fact that the services provided by energy storage can theoretically be provided by alternate methods and systems. For example, instead of investing in expensive energy storage technologies, a power plant could instead choose to direct electricity towards more profitable services such as desalination or the production of chemicals during periods of low demand. As a result, the high costs of energy storage systems are often not competitive with some of these non-storage solutions. Many of these alternative options are examined in this report. Investment in further product development is needed to bring the costs of the energy storage technologies investigated in this report down to a competitive level. The immaturity of the energy storage industry has also resulted in a lack of significant performance testing and validation. Consequently, investors are hesitant to back energy storage development initiatives [19]. An inequitable regulatory environment also limits the economic value proposition for energy storage. Thus, it is currently difficult for energy storage technologies to receive remuneration for all of the benefits they provide to the grid. This is partly due to market rules that prohibit transmission and generation markets from mixing in deregulated zones [20]. A greater understanding of the most profitable use profiles for energy storage technologies is needed for both regulated and deregulated markets. These first three barriers identified by DOE have contributed to an uncertain view of energy storage among electric utilities in the U.S. To encourage investment, further product development, pilot testing, regulatory advancements, and system analyses are needed to determine the most effective and profitable use of energy storage technologies [19]. This report aims to discuss these barriers to energy storage development. 


\section{BACKGROUND}

Although the idea of integrating energy storage with nuclear power is not new, there are no current examples of successful direct implementation in the world today. There are some energy storage technologies have been used successfully to provide support to the grid, such as pumped storage hydropower (PSH) and compressed air energy storage (CAES) facilities, among others. Both of these energy storage systems are often used to store large amounts of energy produced during periods of low demand to sell during peak demand periods. However, many other energy storage technologies have not yet been tested or implemented on as large of a scale. This report will identify energy storage methods that can be used for applications such as hedging and providing ancillary services like frequency regulation to the grid.

\subsection{Energy Storage Technologies}

In this report, energy storage technologies were categorized based on the form of energy they store (e.g., mechanical energy, electrical energy, electrochemical energy, chemical energy, and thermal energy). These categories were used to distinguish between the many different energy storage technologies. The following technologies were divided into these categories.

\subsubsection{Mechanical Energy Storage}

Mechanical energy storage accounts for $99 \%$ of the installed energy storage capacity world-wide in the form of pumped storage hydropower, which entails pumping water uphill to an elevated reservoir and then releasing the stored water through a turbine to produce electricity at a later time. The widespread commercialization of pumped storage hydropower facilities is due to the simplicity, cost competitive implementation, and the fact that mechanical energy storage technologies are often much larger in scale than other energy storage technologies. The types of mechanical energy storage considered in this report include: PSH, CAES, and flywheels. These storage technologies convert electrical energy from the grid into either potential energy (PSH and CAES) or kinetic energy (flywheels) and then convert this energy back into electricity when discharging [20].

\subsubsection{Electrical Energy Storage}

Electrical energy storage technologies are those technologies that store electricity with either magnetic or voltage potential fields. Although electrochemical energy storage technologies also store electrical energy, it is stored in the form of chemical reactions instead. Therefore, technologies utilizing chemical reactions were included in a separate category, electrochemical energy storage. For this report, two electrical energy storage technologies will be considered: supercapacitors and superconducting magnetic energy storage (SMES). Supercapacitors store energy in an electric field between two high surface area electrodes separated by an ion-permeable membrane. Supercapacitors can quickly charge and discharge the energy they hold (high power output), but they cannot store as much energy per unit mass as other forms of energy storage, such as lithium ion batteries. SMES systems store energy in a magnetic field using supercooled, superconducting materials that provide little to no resistance to electric currents [20].

\subsubsection{Electrochemical Energy Storage}

The most common form of electrochemical energy storage is a battery. Several battery types are in various stages of development in the U.S. and are already being used in some locations to provide ancillary services to the grid. This category could be further sub-divided into the categories of conventional batteries and flow batteries. Both types of battery will be thoroughly explored in this report. The specific battery technologies that were examined in this report include: lithium-ion, sodium-sulfur $(\mathrm{NaS})$, lead-acid, nickel-cadmium ( $\mathrm{NiCd})$, zinc-bromine ( $\mathrm{ZnBr}$ ) flow batteries, and vanadium redox flow 
batteries. Each of these batteries operates differently and has unique storage characteristics that will be discussed in full detail [20] [21] [22].

\subsubsection{Chemical Energy Storage}

Chemical energy storage works by storing energy in chemical bonds that can later be broken to release the stored energy. A few of the primary types of chemical energy storage already qualify as types of electrochemical or thermal energy storage (i.e., batteries and thermochemical energy storage). However, one important technology that has not been mentioned already is hydrogen energy storage. In this form of energy storage, electricity that has been generated by a power plant can be used to produce hydrogen through electrolysis. The chemical energy stored in the hydrogen bonds can then be used later in a fuel cell or combustion turbine to produce useful work [23]. Conventional fossil fuels are also a form of chemical energy storage.

\subsubsection{Thermal Energy Storage}

Thermal energy storage (TES) technologies store energy in the form of heat. The use of TES differs greatly from the use of electrical energy storage. Electrical energy storage technologies can easily provide services to the grid since no conversion between types of energy is necessary to transfer the energy from the grid to the storage technology, although an AC/DC converter and transformer might be required. In contrast, thermal energy storage technologies are mostly used at power plants to store thermal energy before it is converted to electrical energy or for industrial applications like heating and cooling buildings. The thermal energy storage technologies considered in this report include: underground thermal energy storage, hot and cold water storage tanks, solid media storage, thermochemicals, and phase-change materials. Of the various phase-change materials considered in this report, molten salts and liquid air were focused on in greater detail than the others [20] [24].

\subsection{Impacts of Regulations and Market Trends}

When considering the technicalities of integrating energy storage with nuclear power, it is important to consider how regulations surrounding energy storage and the economics of integrating energy storage affect the process. Many regulations and current market trends are advantageous to energy storage, while many act as potential barriers to widespread energy storage deployment [25].

\subsubsection{Policy Impacts}

Energy storage technologies that store electricity and are grid-connected are subject to regulations. These regulations are set by three primary entities: The Federal Energy Regulatory Commission (FERC), Independent System Operators (ISOs), and Public Utility Commissions (PUCs). Each of these entities oversees a different area of control. FERC monitors energy transfer across state lines, ISOs monitor transmission and generation in the area in which they operate, and PUCs regulate the activities of utilities within their respective state, including capacity acquisition, which can apply to the integration of energy storage [21].

As energy storage technologies continue to develop, several states have begun to introduce legislation to catalyze the growth of energy storage. In fact, the DOE Global Energy Storage Database, which is maintained by the Office of Electricity Delivery and Energy Reliability, has catalogued 23 individual policy initiatives related to energy storage. Fifteen of these policy measures have been passed by state bodies spanning six different states [26]. These policies encourage the growth of energy storage primarily through the means of financial incentives, the development of policy pathways, and the introduction of energy storage portfolio standards or the revision of the state's current renewable portfolio standards to emphasize energy storage. For example, the California Public Utility Commission (CPUC) recently adopted a $1.325 \mathrm{GW}$ target for energy storage integration by 2020 and exempted developers from fees 
associated with the development of energy storage systems. Several states, including Hawaii, New Jersey, and New York have also considered introducing tax credits for energy storage systems similar to those for wind and solar. In Texas, energy storage resources have been redefined as generation assets, which increases the economic viability of energy storage projects by placing the burden of interconnection costs on the utility. In addition to these specific actions, many states have also formed committees and task forces to develop legislative and regulatory tools to spur energy storage growth. However, it should be noted that many of these policies have been proposed and passed with the specific purpose of integrating energy storage with renewable energy sources. In fact, specific sizing and metering requirements have been imposed on energy storage systems receiving fee exemptions in California to ensure that the stored energy comes from renewable sources. Therefore, some of the regulations that favor energy storage technologies in the U.S. might not directly benefit NPPs [27].

Legislation that does not specifically apply to the development of energy storage systems can still impact energy storage integration. For example, subsidies for solar and wind in the form of investment and production tax credits have led to the rise of variable renewable energy on the grid. Although the legislation initiating these subsidies did not specifically apply to energy storage, increased generation from renewable sources has led to the increased need for energy storage systems. Additionally, renewable portfolio standards and goals established by state legislatures have a similar effect.

There are also a few federal policies under consideration that could impact the growth of energy storage. A federal renewable portfolio standard has been considered, although a proposal has never passed through Congress. Additionally, the Clean Power Plan was proposed by the Environmental Protection Agency (EPA) in 2015 and represents the first major effort by the EPA to reduce carbon emissions from power plants in the U.S. [28]. The Clean Power Plan would further incentivize the growth of renewable energy sources and would likely make it difficult for some technologies such as coal power plants to stay profitable [29]. This initiative has the potential to increase the penetration of VRES, creating an even greater opportunity for energy storage. Furthermore, U.S. Representative Mike Honda of California recently proposed a bill in the House of Representatives known as the Energy Storage for Grid Resilience and Modernization Act, or H.R. 5350. This bill proposes that the federal government provide energy storage installations with the same $30 \%$ investment tax credit currently available to wind and solar power projects. This tax incentive would apply to both individuals and businesses seeking to purchase energy storage systems. If this bill passes, this initiative would greatly enhance the cost competitiveness of energy storage technologies [30].

\subsubsection{Economic Impacts}

The market potential for energy storage could be the most important factor impacting widespread deployment of energy storage technologies. Until energy storage is more cost-effective than other available options for increasing the flexibility of electricity generating facilities or helps utilities comply with regulatory requirements, energy storage will likely not become a viable solution [19]. The market potential for energy storage depends on a few variables: the specific technology being considered, the region in which the technology is being deployed, and the services provided by the technology. In this report, the economic impact of each of these parameters will be considered.

Historically, energy storage technologies have competed with natural gas plants or other peaking and backup power plants as a solution to the variation in the demand for electricity throughout the day. However, the additional operational benefits provided by energy storage were rarely considered. As electricity markets begin to deregulate, wholesale markets for energy and ancillary services have been created. With the introduction of wholesale markets for ancillary services, the economic value of the benefits provided by energy storage could be determined, allowing stakeholders to have a clearer picture of the financial returns that can be gained from their investment [31]. 
As the penetration of renewable energy sources on the grid continues to increase, generation from wind and solar resources will have to be curtailed if base-load generators are not able to economically reduce their output. Although this problem could also be solved through the addition of more transmission lines to geographically shift renewable electricity generation to match demand and reduce curtailments, this process could be prohibitively expensive if the distances are extensive. In some instances, energy prices have fallen below the marginal cost to produce electricity for a base-load coal or NPP due to the over-generation of renewables, but the power plant operators choose to sell energy at a loss to avoid reducing the output of the plant if the shutdown and startup costs exceed the lost (or negative) revenue. However, curtailing the generation from renewable energy sources to prevent this situation is environmentally inefficient, since the energy from wind and solar is generated emissions-free. This conflict presents an opportunity for energy storage to provide a way for base-load generators to reduce their exposure to lower wholesale prices when renewable energy sources are over-producing and potentially increase their output above their original nameplate capacity when prices are higher. Although wind and solar integration studies for ERCOT and the Western and Eastern Interconnects have revealed that the flexible generation already available can adequately respond to the variability introduced by renewable energy sources, the conflict between base-load generation and the curtailment of renewable energy generation reveals that there might be a more cost-effective solution. Specifically, a future grid that utilizes energy storage as an enabling technology for base-load generators might be more costeffective [31].

The market for energy storage still poses many challenges, although the monetization of services provided to the grid by energy storage technologies vastly improves the market potential for energy storage. However, in many circumstances the economic benefits provided by energy storage still do not exceed the high costs of installation. Therefore, stakeholders should seek to aggregate the benefits of energy storage whenever possible. Energy storage used only to store electricity produced during off-peak hours to sell during on-peak hours is rarely profitable [32]. However, several barriers to the aggregation of benefits must also be overcome [33]. A technology's ability to combine services and increase profitability will be closely examined in this report.

\subsection{Overview of the Grid and Modern Electricity Markets}

To identify the opportunities available to energy storage, it is important to understand the basics of the electric grid in the U.S. as well as the basic structure of wholesale electricity markets throughout the country. This section will provide an overview of the electric grid in the U.S. and identify specific ways in which future regulations could fundamentally change how the grid operates. Furthermore, the history of energy market deregulation in the U.S. will be briefly discussed and the New England ISO will be singled out as a restructured market that is facing challenges representative of what many more of the energy markets in the U.S. will also soon have to address. The way that energy storage technologies interact with electricity markets has been changing in recent years as markets have deregulated, and this is a large part of the reason why interest in energy storage technologies has increased. The effect of changing regional energy markets and the benefits provided to the grid by each energy storage technology will be examined in this report.

\subsubsection{Operation of the Electric Grid}

The electric grid is a complex network of power plants and transmission lines that spans across the entire U.S. and Canada, distributing energy to a variety of end users. The grid is divided into three parts, the Western Interconnect, Eastern Interconnect, and ERCOT. While these interconnects might exchange small amounts of DC power, they are not connected by traditional AC power lines. The divisions between these interconnections are illustrated below in Figure 5. Since electricity must be generated at the exact amount that it is consumed, the grid requires careful monitoring to maintain reliability. Power plants provide the grid with many services outside of power generation to enhance the reliability of the grid. 
These additional benefits are called ancillary services. Two of the ancillary services that will be considered in this report are spinning reserves and frequency regulation. Frequency regulation, which is the process of matching momentary fluctuations in electricity generation and demand to maintain the grid's frequency and comply with NERC standards that ensure grid reliability. It is important that the amount of power supplied to the grid always matches the instantaneous demand for electricity so that no generated electricity goes unused. Furthermore, the grid frequency must always be maintained at $60 \mathrm{~Hz}$. When the frequency of electricity on the grid is not $60 \mathrm{~Hz}$, it can cause unnecessary wear to the generation assets connected to the grid. Spinning reserves are another form of ancillary services. Presently, spinning reserves refer to power plants that are on, but not providing power to the grid. These power plants must be able to provide power in a matter of seconds to account for lost generation in the event of an unexpected outage. Many of the ancillary services provided by power plants could also be provided by energy storage. Not only can energy storage technologies respond much more quickly than power plants in many circumstances, with energy storage, no fuel is spent while the power plant is on and not providing energy to the grid [33] [34].

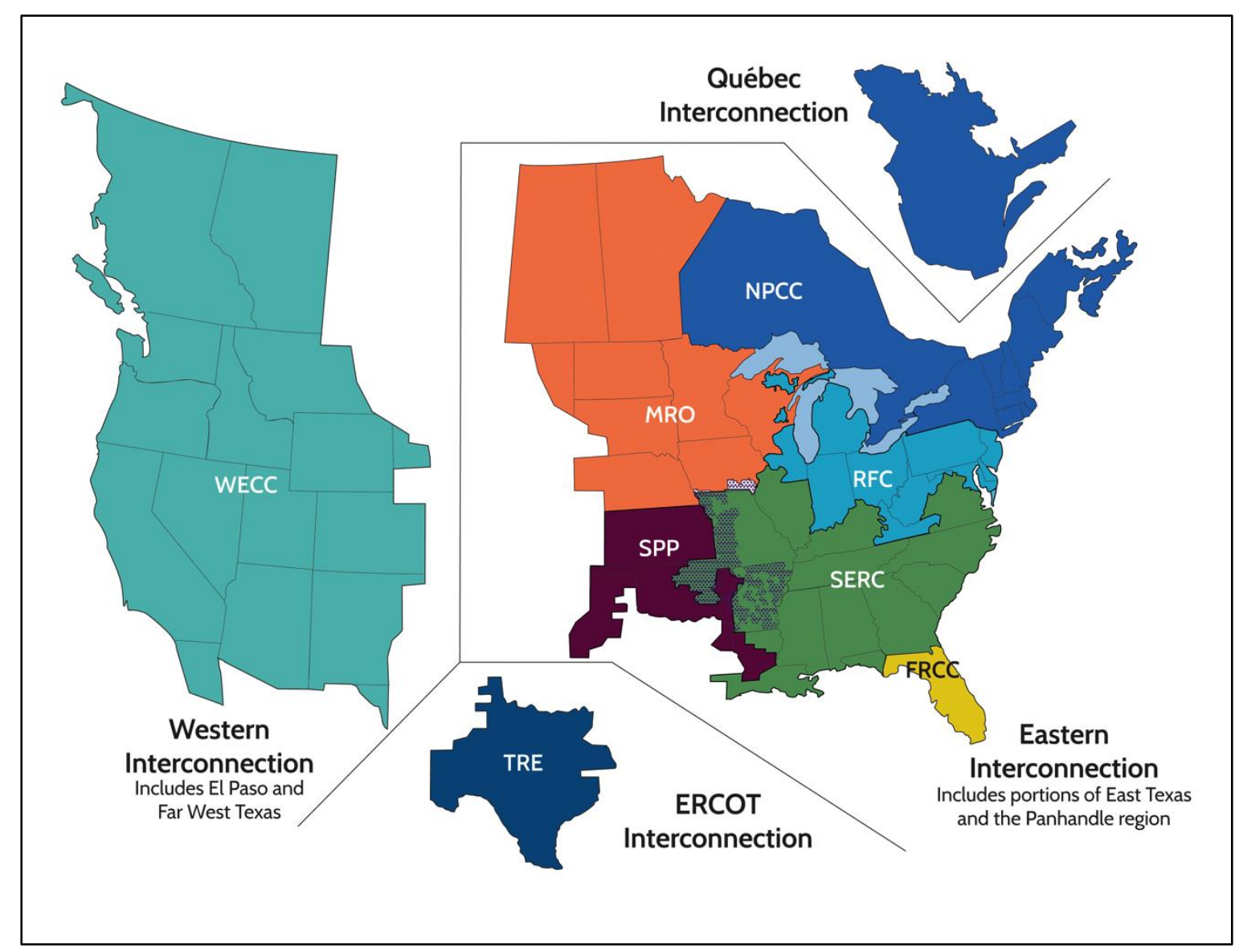

Figure 5. Interconnections of the electric grid in the U.S. [35].

Energy storage could also provide additional benefits to the grid to reduce costs and increase grid resilience that cannot be provided by power plants. Historically, energy storage has been used to provide power plants with arbitrage capabilities, enabling the power plant to store energy when marginal costs or electricity prices are low and sell the stored energy when marginal costs or electricity prices are high. The advancement of energy storage technologies has also created new opportunities for cost reductions by allowing utilities to use a transmission upgrade deferral. Instead of repairing or replacing transmission 
assets, the installation of energy storage can reduce wear and extend the life of the aging assets. An example of this occurred in the city of Presidio, Texas in 2010. A 4 MW, $32 \mathrm{MWh} \mathrm{NaS}$ battery system was constructed to replace the city's aging transmission line, which was causing numerous power outages. This project was funded by ERCOT as a "necessary transmission upgrade" and the costs were passed on to all rate-paying consumers in ERCOT's market through a "postage stamp transmission rate" fee [36]. Energy storage can also act as an enabling technology for base-load generating units that are not able to load follow or ramp effectively to adapt to the integration of variable renewable energy sources (VRES). This benefit offered by energy storage is particularly attractive for NPPs. Since NPPs are typically unable to quickly modulate their power output, energy storage gives a power plant the ability to respond to the variability in demand and fast ramping rates caused by the intermittency of renewable energy sources [33].

In addition to the influx of renewables, regulations recently proposed by the EPA as a part of the Clean Power Plan that limit $\mathrm{CO}_{2}$ emissions from power plants could also have a major impact on the makeup of the grid. In 2015, coal-fired power plants accounted for more than $80 \%$ of the nearly $18 \mathrm{GW}$ of retired capacity. About $30 \%$ of these retirements were caused by the implementation of the EPA's Mercury and Air Toxins Standards [37]. If the Clean Power Plan is not struck down by the Supreme Court, even more coal power plants will likely retire. The Energy Information Administration (EIA) projects that approximately $90 \mathrm{GW}$ of coal-fired capacity and $62 \mathrm{GW}$ of older natural gas and oil capacity could retire by 2040 if the Clean Power Plan is approved [38]. The EPA and EIA have both projected that renewables and newer natural gas plants will overtake the majority of the generation share currently held by coal, while the generation share held by nuclear power will remain relatively constant [39] [40]. Figure 6 shows projections for three separate policy scenarios as presented in the EIA's Annual Energy Outlook 2015. The first scenario assumes the Clean Power Plan remains unchanged, the second scenario assumes that the standards set forth by the Clean Power Plan are tightened between 2030 and 2040, and the third scenario assumes that new nuclear generating units will be treated similarly to renewable generation for compliance purposes. A reference case is also included.

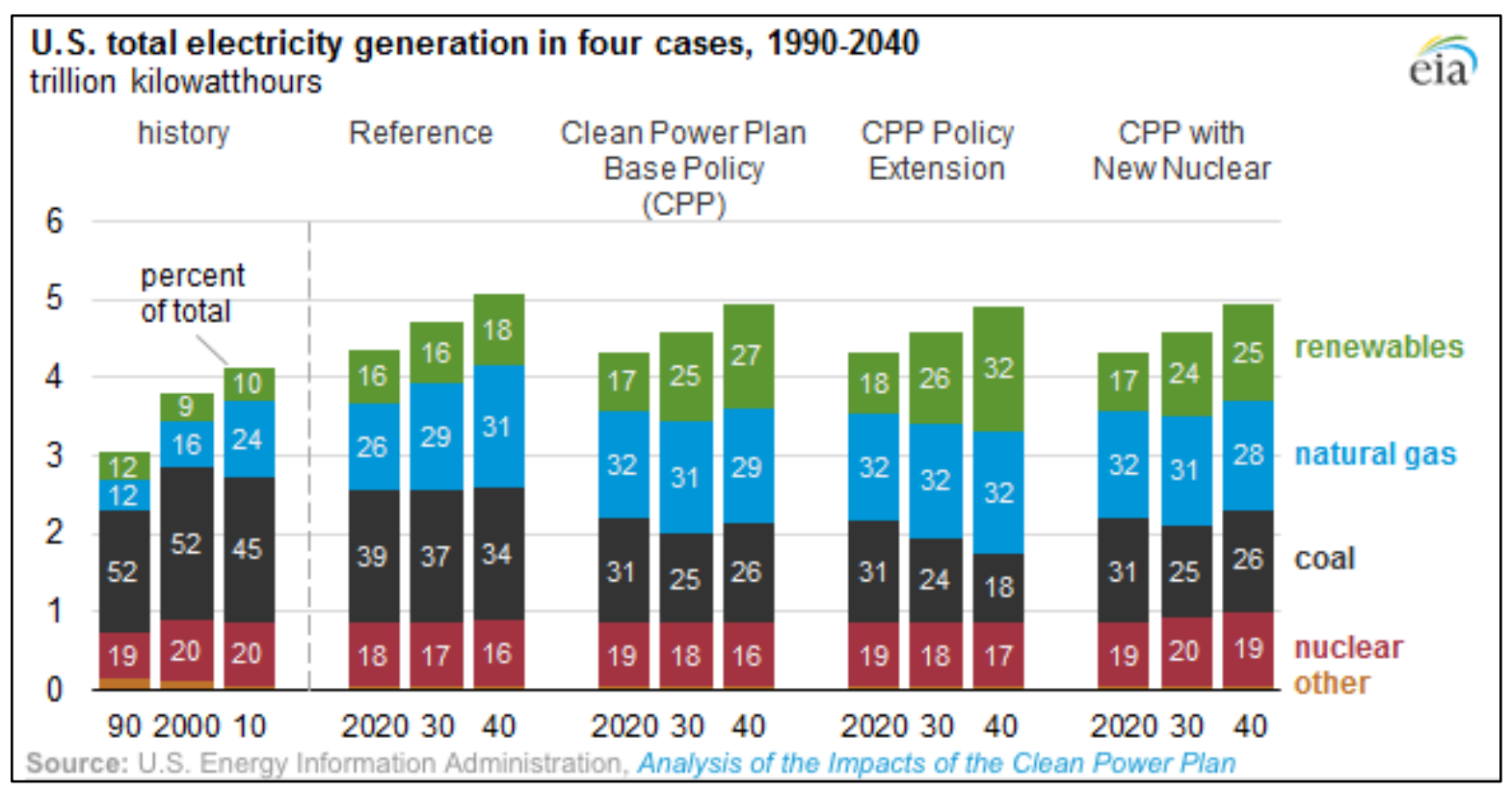

Figure 6. New generation mix projection for four policy scenarios [40]. 
The retirement of power plants throughout the U.S. could present new opportunities for energy storage. Although the construction of natural gas power plants will increase initially to achieve compliance with the Clean Power Plant and other emissions standards, over time renewable generation will gain an increasingly large share of the generation mix, based on EIA's projections. Thus, load variability will continue to increase and the need for flexible generation will increase as well.

\subsubsection{Deregulation of Electricity Markets}

When utilities first began to form, they were unregulated and sold power to consumers in an open market. However, in the 1920s state PUCs began to form with the goal of delivering equitable services and preventing monopolies from forming and overcharging consumers. Likewise, in 1935 Congress passed the Public Utility Holding Company Act to regulate holding companies that had developed and operated utilities in multiple states. However, the Arab Oil Embargo in the 1970s and the Power Plant and Industrial Fuel Use Act of 1978 encouraged developers to invest in power plants that used domestically sourced fuels like coal or uranium. These fuels were more expensive than natural gas and oil and led to a rise in retail electricity prices. In the 1980s, utilities were regularly seeking out rate increases and it became apparent that regulation was not working efficiently. In 1994, California concluded that deregulating the electricity market in the state would stimulate its economy. Many other states quickly followed suit. Figure 7 illustrates the progress of deregulation in the U.S. [41].

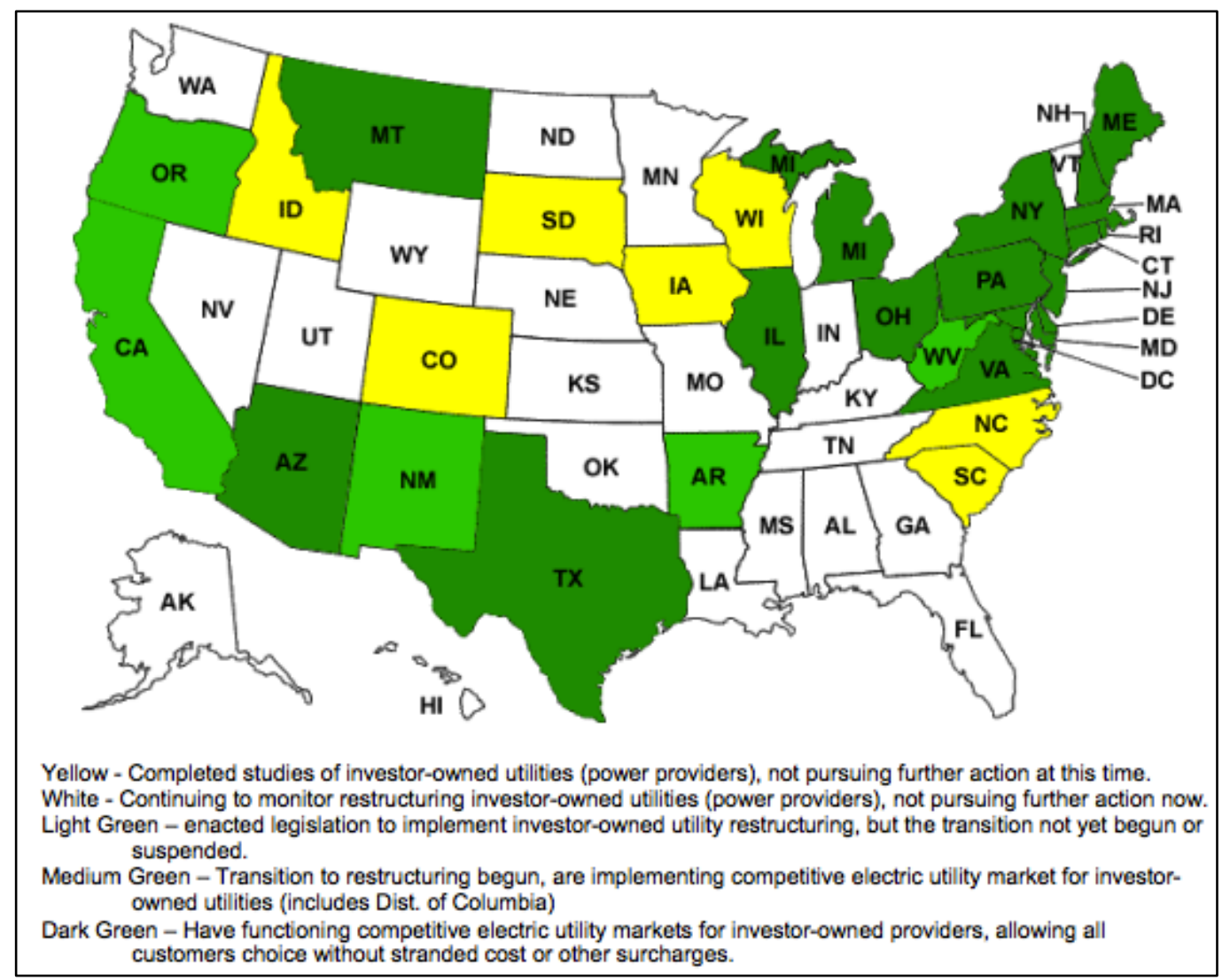

Figure 7. Map of states that have pursued electricity market deregulation [41].

In a deregulated market, market forces have replaced regulated generation rates. Instead of individual utilities determining the price of electricity based on operating costs, energy is sold in a power exchange. Power plants supply hourly bids to the power exchange based on the marginal cost of producing 
electricity for that plant and bids are then sorted into a bid stack. Bids are accepted until the consumer demand is met, starting with the lowest cost producer. All electricity producers (i.e., sellers) are paid the same price as the final bid that is accepted, which is called the market-clearing price. Since many renewable energy sources are paid subsidies by the federal government, like wind and solar, the marketclearing price can sometimes fall below the marginal price of generating electricity for some base-load suppliers like nuclear power. This consequence of deregulation is one reason why energy storage could help to increase the economic viability of NPPs.

Deregulation has also led to the creation of ancillary service markets, where sellers trade capacity to provide system resilience rather than energy. The ancillary service market is where many of the services provided by energy storage are sold. Therefore, the restructuring of electricity markets to allow consumers to purchase power from any energy supplier on the grid has played a primary role in making energy storage technologies profitable. Stored energy can now be sold in a competitive, wholesale market that is open to new market entrants. However, some aspects of restructured electricity markets are also limiting to energy storage technologies. For example, FERC has required transmission-owning utilities to separate all power trading and transmission operations in an effort to eliminate market manipulation. As a consequence, energy storage technologies are prevented from operating in both generation and transmission markets, reducing the number of services that energy storage technologies can provide and restricting the profitability of these technologies [41].

\subsubsection{Regional Evolution of Electricity Markets}

Although large swaths of the U.S. are still served by regulated energy markets, in 2009 restructured electricity markets existed in more than 30 states and served two-thirds of the U.S. population [42]. Traditional markets primarily exist in the Northwest, Southwest, and Southeast regions of the U.S., as shown in Figure 8. Utilities in these regions are often vertically integrated, owning the generation, transmission, and distribution resources in that area. Additionally, federal systems are prominent in these regions, including the Bonneville Power Administration in the Northwest, the Western Area Power Administration in the Southwest, and the Tennessee Valley Authority in the Southeast. The rest of the U.S. is served by a combination of Regional Transmission Organizations (RTOs) and ISOs. ISOs and RTOs operate in restructured electricity markets in which utility services have been unbundled to promote equitable transmission access and maintain system reliability. Seven ISOs and RTOs currently operate in the U.S.: CAISO, Midcontinent ISO (MISO), ERCOT, Southwest Power Pool, New York ISO (NYISO), and New England ISO (ISO-NE). A region map is in provided in Figure 8 [43].

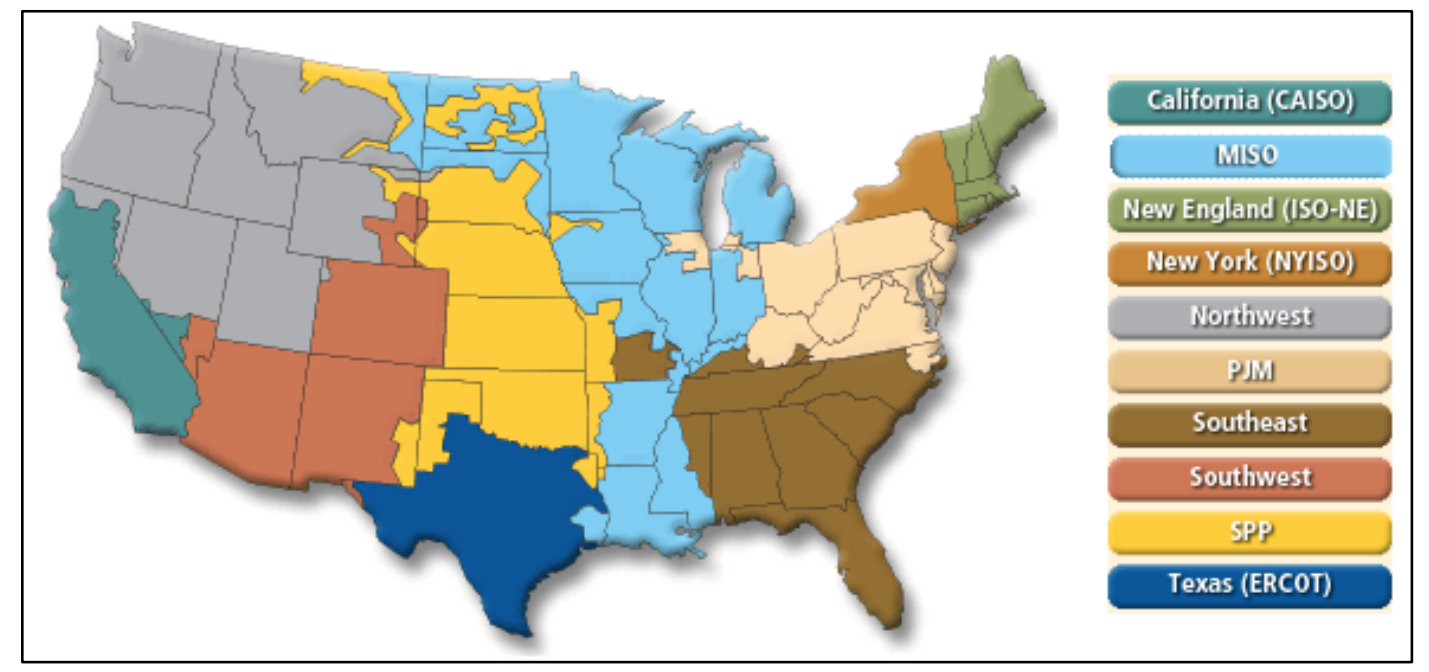

Figure 8: Map of regional electricity markets in the U.S. [44]. 
Each electricity market in the U.S. is evolving in different ways that can be attributed to many factors, such as different renewable portfolio standards, generation mixes, and levels of market competition. Renewable portfolio standards, alongside federal subsidies for wind and solar, have been particularly impactful in driving the evolution of electricity markets. These policies mandate that affected utilities sell a certain percentage or amount of electricity from renewable energy sources. According to the National Conference of State Legislatures, 29 states have adopted renewable portfolio standards [13].

The U.S. can also be divided into the eight reliability regions defined by NERC. Of these regions, the Northeast Power Coordinating Council (NPCC), which encompasses the New York and New England ISOs, might be changing the most rapidly. Specifically, the New England ISO's generation mix shows a continued reduction in coal use since 2012, accompanied by growth in the generation shares held by natural gas and renewable energy sources. The changing generation mix in the NPCC region is displayed below in Figure 9. Although no significant growth in generation from natural gas and renewable energy resources is observed in this region, the transition away from coal-fired generation is happening quickly. This is largely due to legislation such as the Regional Greenhouse Gas Initiative and Mercury and Air Toxins Standards. These regulations, combined with market competition from low-priced natural gas and mandated renewable energy sources, have reduced the economic viability of many coal power plants. Additionally, electricity demand has fallen from its peak in 2005, which has also contributed to a larger market share for natural gas and renewable electricity generation, as displayed in Figure 9 [45].

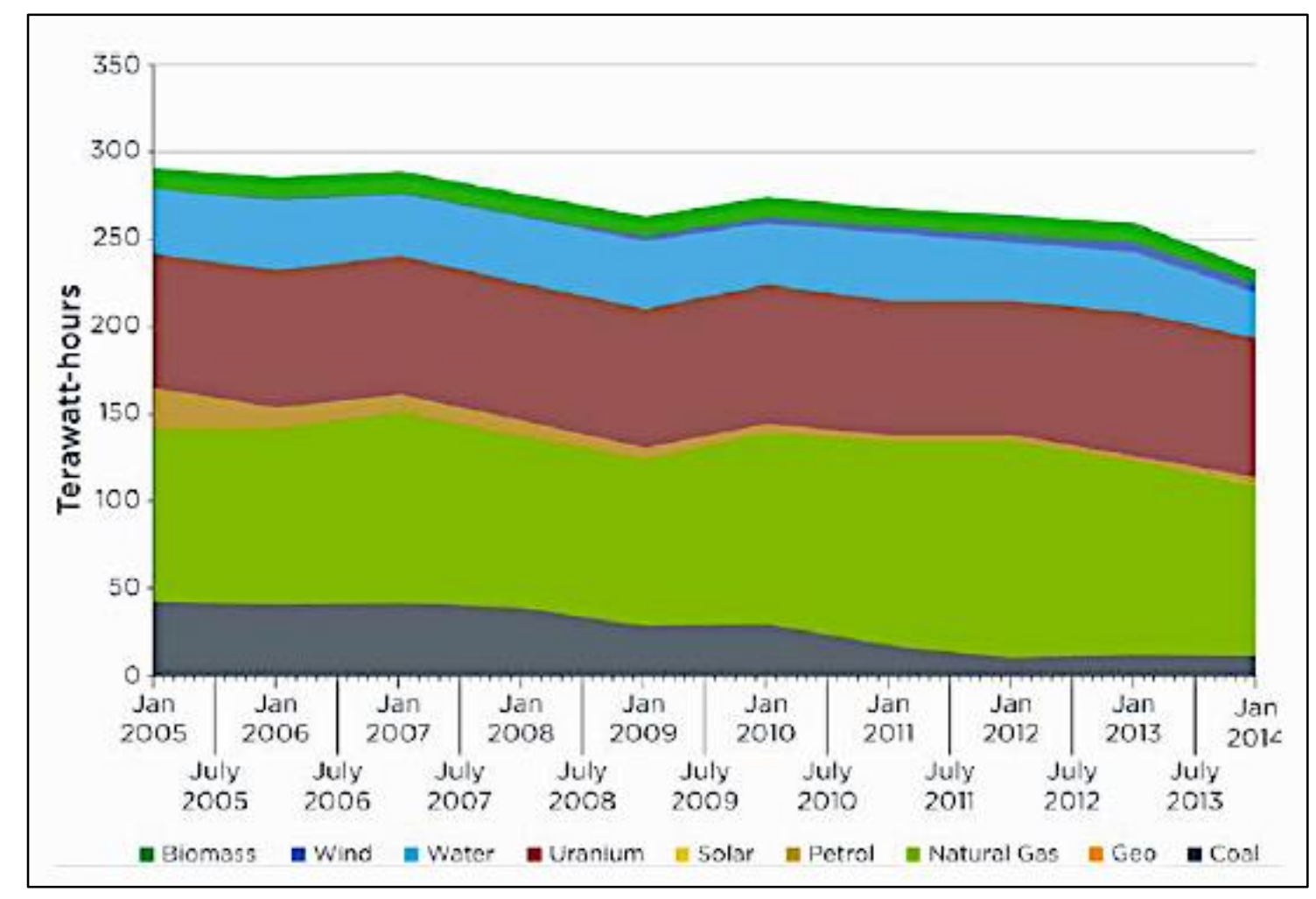

Figure 9. Changing generation mix in the NPCC [45].

The ISO-NE's changing generation mix follows trends predicted by the EIA for the generation mix in the U.S. as a whole. Changes in the ISO-NE electricity market could be instructive for the rest of the nation. Looking to the future, the New England ISO is expecting three waves of change. First, about $80 \%$ of new capacity built in the region since 1997 has been powered by natural gas and this trend is expected 
to continue. Second, over $30 \%$ of all proposed new generation in the region is renewable energy generation from wind and solar power, driven by the renewable portfolio standards in place in all of the ISO-NE's member states. Third, the ISO-NE predicts that up to $20 \%$ of generation could come from entities not connected to the transmission network, such as retail customers and local distribution utilities [46].

This transformation has already presented the New England ISO with new and unexpected challenges that regional electricity markets nationwide could also face in the next couple of decades. First, the development of natural gas power plants has outpaced the construction of fuel transportation infrastructure. Thus, in the winter when heating demands claim a majority of the regional supply of natural gas, the region's coal and nuclear generating resources must be available since gas fired power plants are lacking available fuel. However, coal and nuclear generators are being forced out by competition from natural gas and renewable energy sources as gas pipelines and transmission infrastructure are expanded. Second, the addition of more generation from stochastic wind and solar resources in the region could increase the need for flexible generation. Until new technologies are developed, this flexible generation will come from natural gas. However, adding more natural gas firming power could diminish the environmental benefits of adding generation from renewable energy sources. Third, due to federal subsidies that exist outside of the wholesale electricity market, renewable energy generators are able to sell electricity at prices below their actual operating costs. This phenomenon exerts economic pressure on traditional resources like coal and nuclear power that are unable to cost-effectively curtail their output in the short term [46].

The trends and challenges seen in the New England ISO electricity market are not unique and provide valuable insight into the future of electricity markets in the U.S. Furthermore, each of the challenges experienced by the ISO-NE could be addressed by energy storage coupled with electricity generation from nuclear power. Flexible generation from NPPs could address the variability being introduced to the grid by renewables by providing valuable ancillary services, such as quick ramping. Additionally, these services could be provided without detracting from the environmental benefits offered by renewable energy sources. Energy storage could also enable NPPs to store energy when prices are below operating costs in order to mitigate some of the economic pressure applied by subsidized renewable energy sources. Finally, if nuclear power is made more resilient to the changing market by the addition of energy storage, then NPPs could provide valuable reliability when there are shortages in the supply of natural gas or adverse price fluctuations. 


\section{CHARACTERIZATION OF ENERGY STORAGE}

Each energy storage technology examined in this report has advantages and disadvantages. Thus, the energy storage technology that best increases the operational flexibility of an NPP could change depending on the details of each individual plant's situation. Several parameters were identified to compare and contrast the storage technologies considered in this report, including technical specifications and compatible services that the storage technology can provide to the electric grid. These parameters were used to determine how well a particular storage technology fulfills a developer's individual requirements. Furthermore, although energy storage is the focus of this report, there are other ways to augment the flexibility of an NPP. These alternative methods are addressed in this report to provide perspective, because if energy storage is not a more profitable solution than these methods, then there is little reason to pursue energy storage as an option. Understanding the arena that energy storage technologies operate in as well as the general principles of operation for NPPs is foundational to determining which energy storage technologies are the most compatible with NPPs.

\subsection{Performance Parameters for Energy Storage}

Many parameters could be used to determine the suitability of an energy storage technology for integration with nuclear power, but this report will attempt to identify a few of the most significant metrics. Additionally, it should be noted that some of the parameters used to assess energy storage technologies differ depending on the type of energy that is being stored. For instance, with electrical energy storage technologies, the cycle life of the technology is an important parameter, since these technologies are often cycled multiple times per day. Conversely, for thermal energy storage technologies, the storage output temperature is an important parameter since the stored energy must be converted from heat to electricity before the energy can be delivered to the grid [20] [22]. The parameters used to compare and contrast energy storage technologies in this report are defined below:

- Energy and Power Capacity: Energy capacity is the amount of energy a technology is able to store. Power capacity is the rate at which the technology can discharge stored energy. These quantities are typically supplied by the manufacturer of the technology and are referred to as the rated capacity. The energy and power capacity of a particular technology can vary depending on the size of the energy storage system that is installed. Therefore, the capacity ranges provided in this report are based on actual energy storage installations in the marketplace.

- Energy and Power Capacity Cost: The cost of an energy storage technology is typically defined per kilowatt or kilowatt-hour of storage capacity provided by that technology. If the cost is defined per unit of power capacity, then the total cost of the technology has been divided by the rated capacity of the technology to discharge stored energy at a specified rate. If the cost is defined per unit of energy capacity, then the total cost has been divided by the total storage capacity of the technology. The capacity cost of a technology refers to the capital expenditure costs for that technology. The energy and power capacity costs for a particular energy storage technology can vary widely. For example, $\mathrm{PSH}$ facilities often have low energy capacity costs due to their use of pre-existing natural reservoirs. However, PSH facilities also often have high power capacity costs related to the installation of expensive power generation equipment [47].

- Operating and Maintenance (O\&M) Costs: The operating and maintenance costs of a technology are critical for determining the technology's financial feasibility and the services that the technology can provide. O\&M costs included fuel, labor, and replacement hardware costs, for example. These costs are ongoing, whereas the capital costs of a technology are only charged one time as an initial investment. The operating and maintenance costs of the technologies in this report are measured per $\mathrm{kW}$ on an annual basis. 
- Discharge Time: The discharge time of an energy storage technology is the amount of time required for that technology to discharge its rated capacity. This report provides a range of discharge times for a typically sized installation. It should be noted that this parameter is somewhat variable since it is dependent on the power level at which the energy storage technology is operating. This parameter is also dependent on the size of the energy storage system installed. Although not identical, the discharge time characteristics of a particular technology can often provide insight to the rate at which the technology can be charged.

- Response Time: The response time of an energy storage technology refers to the elapsed time between when power is requested from the technology and when power is delivered by the technology. The response times in this report refer to the performance of the energy storage technology itself, and do not take into account the response time of the connected power electronics. With grid-connected energy storage technologies, the corresponding power electronics typically act as a limiting factor on the storage technology's response time.

- Storage Degradation Rate: The storage degradation rate for a technology measures the daily parasitic loss from the energy stored by that technology. This quantity is recorded as the percentage of the technology's storage capacity that is discharged in one day. This parameter could also impact a technology's levelized cost.

- Round-Trip Efficiency: The round-trip efficiency of an energy storage technology refers to the ratio of energy discharged by the technology to the amount of energy charged to the device.

- Energy and Power Density: The energy and power density of a technology refers to the energy or power capacity per unit volume of the technology.

- Specific Energy and Power: The specific power and energy of a technology refers to the energy or power capacity per unit mass of the technology.

- Cycle Life: The cycle life of an energy storage technology is defined as the number of times the technology can be charged and discharged before the technology fails to deliver sufficient energy and power during discharge in relation to its initial rated capacity. Cycle life is often associated with electrochemical energy storage technologies such as lithium-ion batteries that undergo component damage as the batteries are charged and discharged regularly. The cycle life of a storage technology is dependent on several factors, including the depth of discharge, discharge rate, the temperature and humidity of the surrounding area, and the shelf life of the technology components. The depth of discharge for an energy storage technology refers to the percentage of the technology's energy capacity that is discharged per cycle. A greater depth of discharge reduces the cycle life of the storage technology [48].

- Technology Lifetime: The lifetime of a technology refers to the number of years that the technology can provide services before failing to operate effectively at its rated capacity. However, many technologies will never operate at their rated capacity, which extends their lifetime. The lifetimes included in this report correspond to a typical use profile for each of the considered energy storage technologies. This use profile can change depending on the services provided by the technology.

- Storage Output Temperature: In thermal energy storage technologies, energy is stored in a medium at a certain temperature. If the energy is stored at a higher temperature, then this energy has a higher energetic quality, allowing the thermal energy to be converted to electrical energy with a greater efficiency.

\subsection{Environmental Impacts of Energy Storage}

Different energy storage technologies have varying levels of environmental impact. One example of this impact is that every energy storage technology decreases the efficiency of the electric grid as a whole because all storage technologies have a round-trip efficiency of less than $100 \%$. As a result, more energy 
is required to match the demand for electricity when energy storage is used [49]. This impact of increased energy consumption as a function of the round-trip efficiency of a technology is one example of how energy storage can have increased environmental impacts. The environmental impacts factors that were used in this report to compare and contrast the various energy storage technologies are defined below:

- Land and Water Impact: Some energy storage technologies, such as PSH, require a large amount of land to act as a natural storage reservoir. Additionally, some storage technologies can have a negative effect on the surrounding water resources, such as underground thermal energy storage. The land and water impact of the energy storage technologies in this report was assessed to be either non-existent, not very significant, somewhat significant, significant, or very significant.

- Emissions Produced During Operation: Most energy storage technologies are capable of storing and discharging energy without producing greenhouse gas emissions. However, a few storage technologies produce emissions during operation. For instance, CAES requires the combustion of fossil fuels to provide the additional heat needed to operate the technology. Additionally, the vegetation that gathers in the reservoir of a PSH facility produces greenhouse gases as it decomposes. Whether or not greenhouse gas emissions are produced during the operation of the energy storage technology was considered when determining each technology's environmental impact.

- Hazardous Materials: Hazardous chemicals and materials are often used to build many of the electrochemical energy storage technologies investigated in this report. Although these materials can have severe effects on the health of human workers or local wildlife in the event of a release, these materials are safely contained within the battery's structure. However, since these materials impact their immediate environment, the distance between the energy storage installation and nearby populations can have a mitigating effect. Many of these materials also degrade slowly and can continue to have a negative impact on the environment if they are not properly disposed of or recycled. The environmental impact factor for each energy storage technology's use of hazardous materials was determined by assessing whether the technology contained hazardous materials, contained recyclable hazardous materials, or did not contain any hazardous materials.

- Hazardous Fumes: This environmental impact factor specifically refers to fumes that have a localized effect on the health of nearby power plant workers and wildlife populations, excluding greenhouse gases. The production of hazardous fumes is most commonly associated with electrochemical energy storage technologies, although other energy storage technologies such as molten salts can also produce this effect. For example, hydrogen gas is formed when charging a leadacid battery, which can be highly explosive in concentrated amounts [50]. Although there are several factors that affect how hazardous the fumes produced by a particular energy storage technology can be, such as the chemical species, quantity emitted, distance between the population and the emissions source, and the time since emission, analyzing each of these factors is outside of the scope of this report. Therefore, the environmental impact factor for each technology was determined only by assessing whether or not the technology produced hazardous fumes that could have a negative impact on populations in the technology's immediate vicinity.

- Short-Term Safety Concerns: This environmental impact factor refers to safety concerns that are separate from the health hazards associated with the use of hazardous materials and the emission of hazardous fumes. As an example, the spinning components in flywheels have the potential to cause serious damage in the event of a catastrophic failure. In 2015, a large-scale flywheel system being tested by the Quantum Energy Storage Corporation exploded, sending four workers to the hospital [51]. Although this does not have a long-term impact on the environment in the same way as hazardous materials and fumes, these issues do introduce immediate safety concerns in the surrounding environment of the energy storage technology. Additional instances of nonenvironmental safety concerns include the potential for spontaneous combustion with many of the electrochemical energy storage technologies considered in this report when exposed to non-routine 
conditions and the strong magnetic fields produced by SMES systems. Using this definition, each energy storage technology in this report was assessed to either have several, some, minimal, or no safety concerns.

- Resource Depletion: Many of the electrochemical energy storage technologies considered in this report use rare-earth metals in their construction to obtain superior energy storage characteristics. However, the reserves for some of these rare-earth metals are more plentiful than others. Also, although a technology might currently use rare-earth metals, that material could be replaceable, which would minimize that storage technology's environmental impact. The energy storage technologies featured in this report were distinguished by the rate at which the reserves of any component rareearth metals are being depleted. Insignificant resource depletion indicates that no rare-earth metals are used in the construction of that energy storage technology. Likewise, somewhat significant resource depletion indicates that the reserves for that energy storage technology's component materials have more than 150 years of viability remaining. Finally, energy storage technologies with very significant resource depletion have only 20-50 years of remaining reserves [22].

- Geographic Requirements: The geographic requirements of an energy storage technology were not considered when calculating the technology's overall environmental impact. However, this metric is still important, since it is impossible to install some of the energy storage technologies considered in this report without access to the required geographic features. Thus, whether or not an energy storage technology has specific geographic requirements was recorded within this analysis so that technologies that are incompatible with a developer's location can be identified.

\subsection{Applications for Energy Storage}

Another important point of comparison for energy storage technologies are the specific benefits that the technology can provide to the grid as a source of revenue or increased efficiency for an NPP. A technology's ability to provide a particular service is dependent on the parameters laid out previously. As a result, the services offered by electrical and thermal energy storage technologies are often different. This report will identify which applications are compatible with each storage technology to assess the technology's viability. However, several of the services that energy storage technologies provide benefit the grid as a whole, but do not provide any direct benefit to an individual NPP. Only the applications that directly benefit individual power plants are included in this report [20] [21] [22] [31] [33]. The storage applications that were considered are defined below:

- Energy Arbitrage: Energy arbitrage refers to the process of storing energy when prices are low and selling that stored energy when the price of energy is higher. Base-load generators can simulate a flexible output by using energy storage, allowing them to take advantage of changing prices for electricity.

- Frequency Regulation: Frequency regulation is the practice of balancing the momentary differences between generation and demand. This service is required by NERC mandatory reliability standards in an effort to maintain the grid's frequency at $60 \mathrm{~Hz}$. Frequency regulation is typically automated and occurs on a minute-by-minute basis. Energy storage can provide frequency regulation services by discharging when demand exceeds supply and charging when supply exceeds demand.

- Load Following: While frequency regulation is required to balance momentary differences between the supply and demand of electricity, load following is required to match larger trends in supply and demand. Load following is characterized as power output that changes every several minutes. As the load changes throughout the day, the generation of electricity must increase to match demand. However, since power is purchased hourly, load following services are needed to follow the load between auctions. 
- Voltage Support: Grid operators must maintain stable voltage levels in the transmission and distribution system. However, reactance produced by electronic equipment connected to the grid threatens to cause unacceptable voltage fluctuations. Reactive power must be injected to the grid to offset these fluctuations. Residential PV systems are a growing source of reactance on the grid.

- Spinning, Non-Spinning, and Supplemental Reserves: Reserves are needed to supply power to the grid in case any part of the supply suddenly becomes unavailable. In the U.S., 15-20\% of the normal electricity supply capacity is usually available in reserves at any time. However, the reserves that are available to the grid cannot all respond to an outage immediately. Spinning reserves are generators that are online, but not supplying power to the grid, spinning reserves can respond to an outage within 10 seconds to 10 minutes. Non-spinning reserves are generators that are offline, but can respond within 10 minutes. Non-spinning reserves can also be power plants that are not operating at full capacity and can ramp up in response to an outage. Supplemental reserves are the slowest to respond and can come online within approximately one hour, depending on the type of power plant. Energy storage technologies can often simulate spinning reserves due to quick response times.

- Black Start Capabilities: Black start capabilities are needed to energize the grid when the grid collapses and all other reserve capacity fails to back up the grid. Black start capabilities can provide power to consumers and restart power plants without drawing power from the grid. Energy storage technologies are well-suited to provide this service to the grid.

- Variable Supply Resource Integration: Energy storage can be used to optimize the output from VRES to increase the value of the transmitted electricity. In particular, energy storage can provide two valuable services to renewable energy sources. Energy storage can be used for capacity firming, or enabling the use of an intermittent supply resource as a constant power source. In this report, this parameter refers to an energy storage technology's ability to assist with the integration of VRES with the electric grid.

- Process Heat Applications: The heat from an NPP could be stored with a thermal energy storage technology and used to power an external process that requires heat. For example, energy storage technologies can be used in combined heat and power plants to temporally align the consumer demand for electricity and heat.

- Seasonal Storage: Energy storage technologies can be used to store energy for long periods of time to compensate for the seasonal changes in supply and demand. For example, a thermal energy storage technology can be used to store heat in the summer to be used in the winter when this resource becomes more necessary.

\subsection{End-User Energy Management Strategies}

The primary motivation for integrating energy storage technologies with NPPs is to increase the flexibility of NPPs in response to the high penetration of VRES. However, demand-side energy management strategies can also be used to provide the grid with the necessary operational flexibility to accommodate large amounts of generation from renewable energy sources. Demand-side strategies are included in this report since they offer a potential alternative to the installation of energy storage technologies. However, these strategies are not the primary focus of this report [21] [52]. The most common strategies used by electricity customers are explained below:

- Demand Charge Management: Although residential customers typically pay a flat rate for electricity, large commercial and industrial customers are often charged using real-time pricing [53]. Moreover, commercial and industrial customers are assessed demand charges based on their usage during peak demand periods that are specified by the utility. A couple of different energy management strategies can be used by commercial and industrial customers to reduce these demand charges. 
- Peak Shaving: The most significant demand charges are based on the end-user's maximum load during the peak demand period specified by the utility for a given month. Peak shaving systems are installed to generate electricity during these periods so that the end-user can reduce their demand to the grid and electricity costs. Facilities that use this energy management strategy could experience subsequent net energy savings of 10-30\% [54].

- Load Shedding: Demand charges are also assessed using a tiered rate structure, creating an incentive for an end-user to maintain their load below a certain level during peak demand periods. If the end-user's load exceeds this level, non-critical loads are turned off to avoid increased electricity costs.

- Peak Shifting: This energy management strategy is similar to energy arbitrage, where an energy storage technology is used to store low-priced energy to sell during peak demand periods. With peak shifting, utility customers shift high impact loads from peak demand periods to low-demand periods when electricity prices are lower.

- Demand Response: While demand charge management and peak shifting are energy management strategies used by utility customers to reduce costs, demand response is a tool utilized by utilities to motivate electricity customers to implement these strategies. A utility can use demand response methods to more effectively align the generation from VRES with consumer demand. Two demand response mechanisms are generally used by utilities to increase system reliability.

- Price-Based Programs: Utilities can use price signals to discourage electricity use during peak demand periods. The three pricing schemes most often used by utilities for demand response are time-of-use pricing, critical peak pricing, and real-time pricing (Table 1).

Table 1. Pricing schemes for demand response.

\begin{tabular}{|c|c|}
\hline Pricing Scheme & Definition \\
\hline Time-of-Use Pricing & $\begin{array}{c}\text { Different prices for electricity usage are } \\
\text { assigned for different blocks of time }\end{array}$ \\
\hline Critical Peak Pricing & $\begin{array}{c}\text { Very high prices are charged } \\
\text { for a limited amount of time }\end{array}$ \\
\hline Real-Time Pricing & $\begin{array}{c}\text { Rates change in response to wholesale } \\
\text { market prices on an hourly basis }\end{array}$ \\
\hline
\end{tabular}

- Incentive or Event-Based Programs: Utilities can also provide financial incentives to consumers in return for the ability to control equipment owned by the consumer during peak demand periods. This enables the utility to reduce the load for that period of time and avoid using peaking capacity. Additionally, utilities can alert consumers during peak demand periods to opportunities to receive financial compensation for reducing their load voluntarily. Examples of this type of program include emergency demand response programs, capacity markets, and ancillary service markets.

\subsection{Energy Storage Proxies}

Energy storage technologies are the primary focus of this report, but power plants can also use lowpriced energy to generate revenue by providing goods and services other than electricity. Using lowpriced energy in this way simulates the effect of storing the energy to sell at a later time for a higher price. These indirect methods for increasing the operational flexibility of an NPP are referred to as energy storage proxies in this report. A few key energy storage proxies that are currently used or could be used by NPPs are considered below: 
- Desalination: The demand for seawater desalination is expected to double every 10 years for the next several decades as freshwater resources are not able to match demand [55]. NPPs could act as a clean heat and energy source for desalination systems. Furthermore, an NPP that is co-located with a desalination plant could produce potable water with waste heat and continue to produce electricity. In this way an NPP integrated with a desalination system could vary water production without affecting the operation of the plant to add operational flexibility [56]. This type of desalination system could act as an energy storage proxy for an NPP.

- Hydrogen Production: Approximately 50 million tons of hydrogen are consumed annually worldwide. Furthermore, the characteristics of NPPs and hydrogen production systems align well to give NPPs an economic advantage over conventional energy sources for hydrogen production. NPPs can provide the required heat and electricity without producing carbon emissions. Hydrogen production can act as an energy storage proxy for an NPP and decouple the production of energy from electricity consumption. Stored hydrogen can either be used to fuel combustion based generator or sold for other industrial purposes [57]. Hydrogen production was also considered as an energy storage technology in this report.

- Industrial Process Heat Applications: NPPs have been recognized as a convenient source of heat for industrial processes since the beginning of nuclear power. However, less than $1 \%$ of all heat produced by NPPs worldwide is directed towards non-electric applications. In an increasingly volatile electricity market, NPPs could use industrial process heat applications as a proxy for energy storage by directing heat away from electricity generation during off-peak periods. Specifically, high temperature process heat from NPPs could be used in the chemical and petrochemical industries for processes including steam reforming of natural gas, extraction of heavy oils, and coal gasification [56]. Although these applications, particularly methanation and the synthetic production of natural gas, could also be considered as energy storage technologies, they were not included in this report.

- District Heating: In climate zones with relatively long and cold winters, NPPs can act as clean sources of energy for district heating. District heating is the practice of using heat from a large thermal power plant for heating residential and commercial buildings in addition to generating electricity. When NPPs are used to provide this service, an intermediate heat transfer loop is used to avoid transferring radioactivity [56]. NPPs could use a simple energy storage device such as a hot water tank to store heat during off-peak periods that could then be used for district heating while the NPP is generating electricity during peak demand periods. In this way, district heating could act as an energy storage proxy for an NPP.

- Transmission Expansion: The primary motivation for integrating energy storage with nuclear power is to respond to the high penetration of VRES. However, alternative mechanisms exist to reduce the market variability caused by these resources. As electricity markets consolidate and the geographic diversity of renewable energy sources increases, the average variability of the resources will decrease. Therefore, transmission expansion can have the same effect as integrating energy storage with conventional generation resources. Faster economic dispatch intervals in electricity markets can also be used to disperse variability among a larger fleet of generating units [58].

\subsection{Nuclear Power Cycle}

The many different energy storage technologies considered in this report store energy in a variety of different forms. The primary forms of energy stored by the technologies in this report are thermal and electrical energy. Although mechanical and chemical energy storage technologies are also considered, the energy stored by these technologies is generally converted from electrical energy first. In addition to the energy storage technologies considered in this report, many energy storage proxies that are compatible with nuclear power also use various forms of energy. Therefore, it is important to understand how energy is generated in the nuclear power cycle. 
In a nuclear power reactor, energy is produced in the form of heat by splitting atoms of certain elements, typically enriched uranium. These nuclear reactions occur in fuel rods, which are held in fuel assemblies in the reactor's core. The heat released through the continuous fission of atoms within the fuel rods of a nuclear reactor is then transferred to cool water to produce steam. This steam is used to drive a turbine and generate electricity. If water is used as the medium for harnessing the heat produced by the nuclear reactor, then a simple Rankine cycle is used to facilitate the generation of electricity. A simple representation of the nuclear power cycle is displayed below in Figure 10. In this diagram, the gross thermal energy, gross electrical energy, and net electrical energy produced by the nuclear reactor have been separated. The net electrical energy supplied to the grid by a nuclear plant is less than the gross electrical energy produced by the reactor because some of that energy is used to operate the power plant.

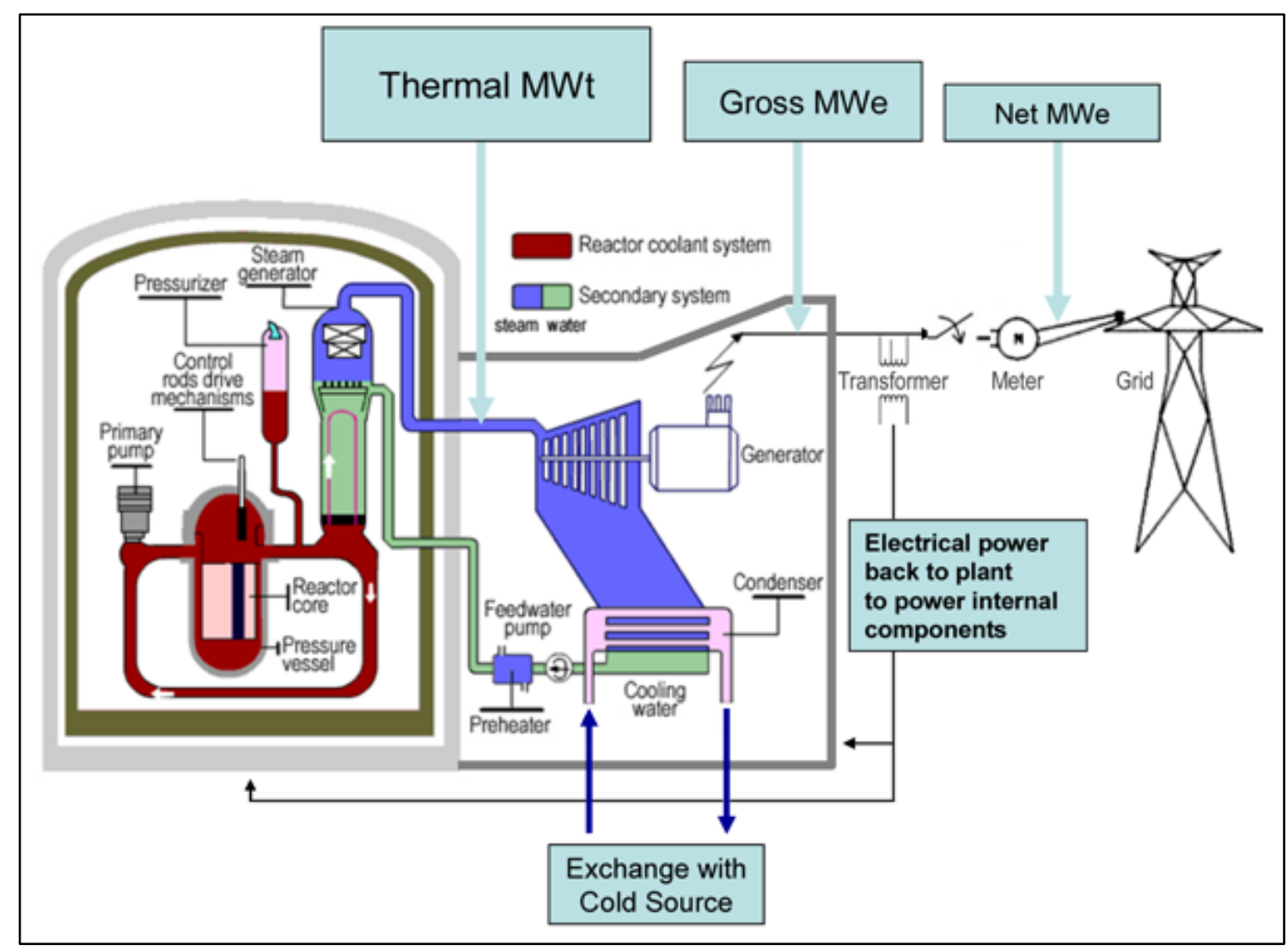

Figure 10. Basic diagram representing the nuclear power cycle [59].

All of the NPPs in the U.S. use one of two nuclear reactor designs to facilitate the generation of heat and electricity, pressurized water reactors (PWRs) and boiling water reactors (BWRs). Pressurized water reactors are the most common type of reactor in the U.S. PWRs are distinguished by having two cooling loops with a heat exchanger connecting the primary and secondary cooling circuits. Cold water in the primary circuit comes into direct contact with the hot fuel rods in the reactor core to capture the energy emitted by the nuclear reactions happening there. This water is highly pressurized to keep it from boiling as heat is absorbed. Heat is then transferred from the primary circuit to the secondary circuit where steam is generated. This steam is then used to drive a turbine and generate electricity. A PWR typically has 150250 fuel assemblies with 80-100 metric tons of uranium, while a BWR could have up to 750 assemblies, holding up to 140 metric tons of uranium [59]. A PWR is illustrated below in Figure 11. 


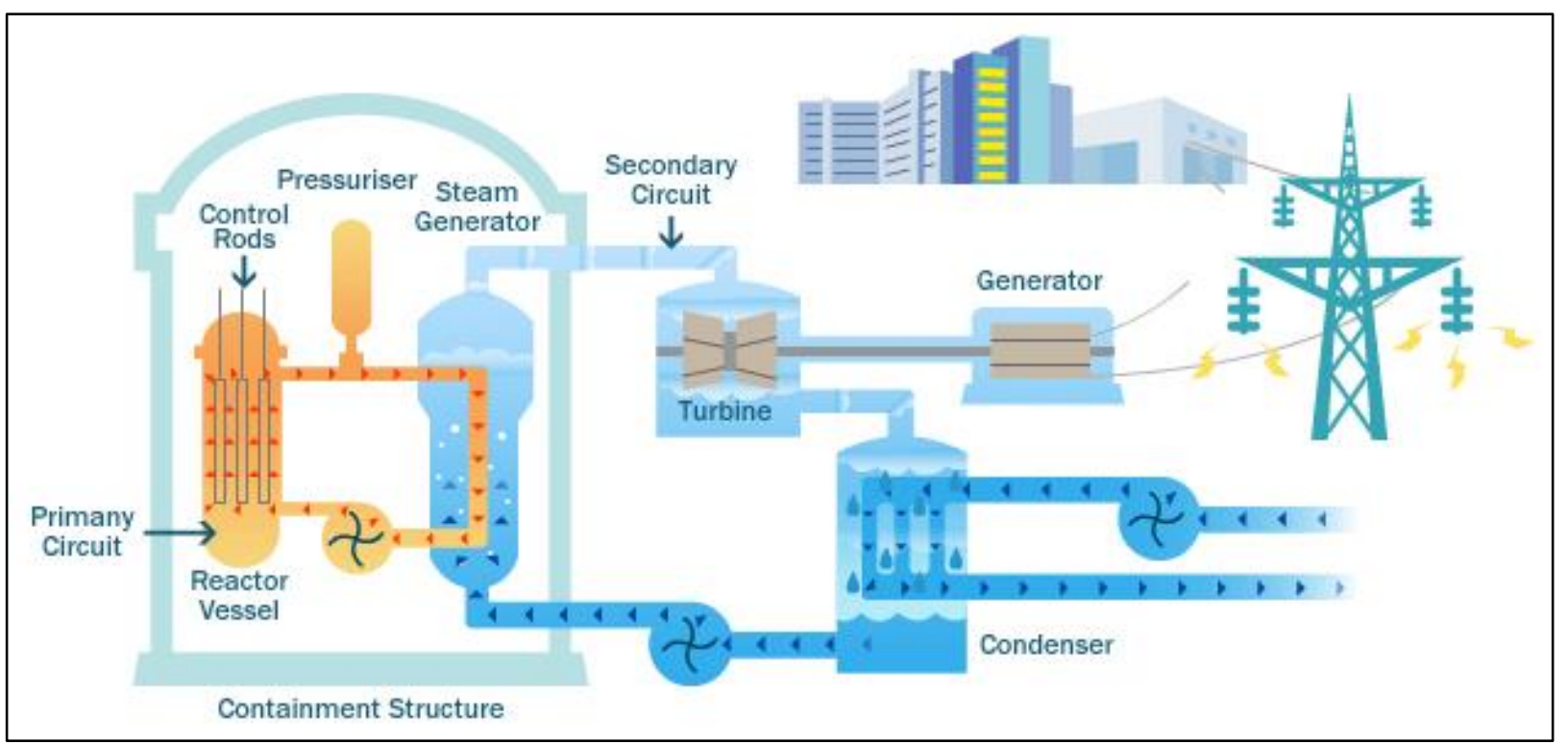

Figure 11. Diagram of a pressurized water reactor [60].

The alternative to the PWR is the BWR. In contrast to the PWR, there is only one cooling loop in a BWR. Cool water in this circuit flows through the core of the nuclear reactor and is transformed into steam as heat is released from the fuel rods. This steam is then used to drive a turbine and generate electricity. The water in a BWR is maintained at approximately 75 times atmospheric pressure to raise its boiling temperature to approximately $285^{\circ} \mathrm{C}$, which allows the temperature of the steam generated by the BWR to be greater than it would be otherwise. The turbine in a BWR must be shielded to prevent deterioration caused by direct interaction with the irradiated steam. Additionally, increased maintenance is required for a BWR because the components of the reactor are continuously exposed to radiation. The additional maintenance costs for a BWR often outweigh the expenses saved with the simpler design, leading to the more prominent use of PWRs [59]. An illustration of a BWR is displayed in Figure 12 below.

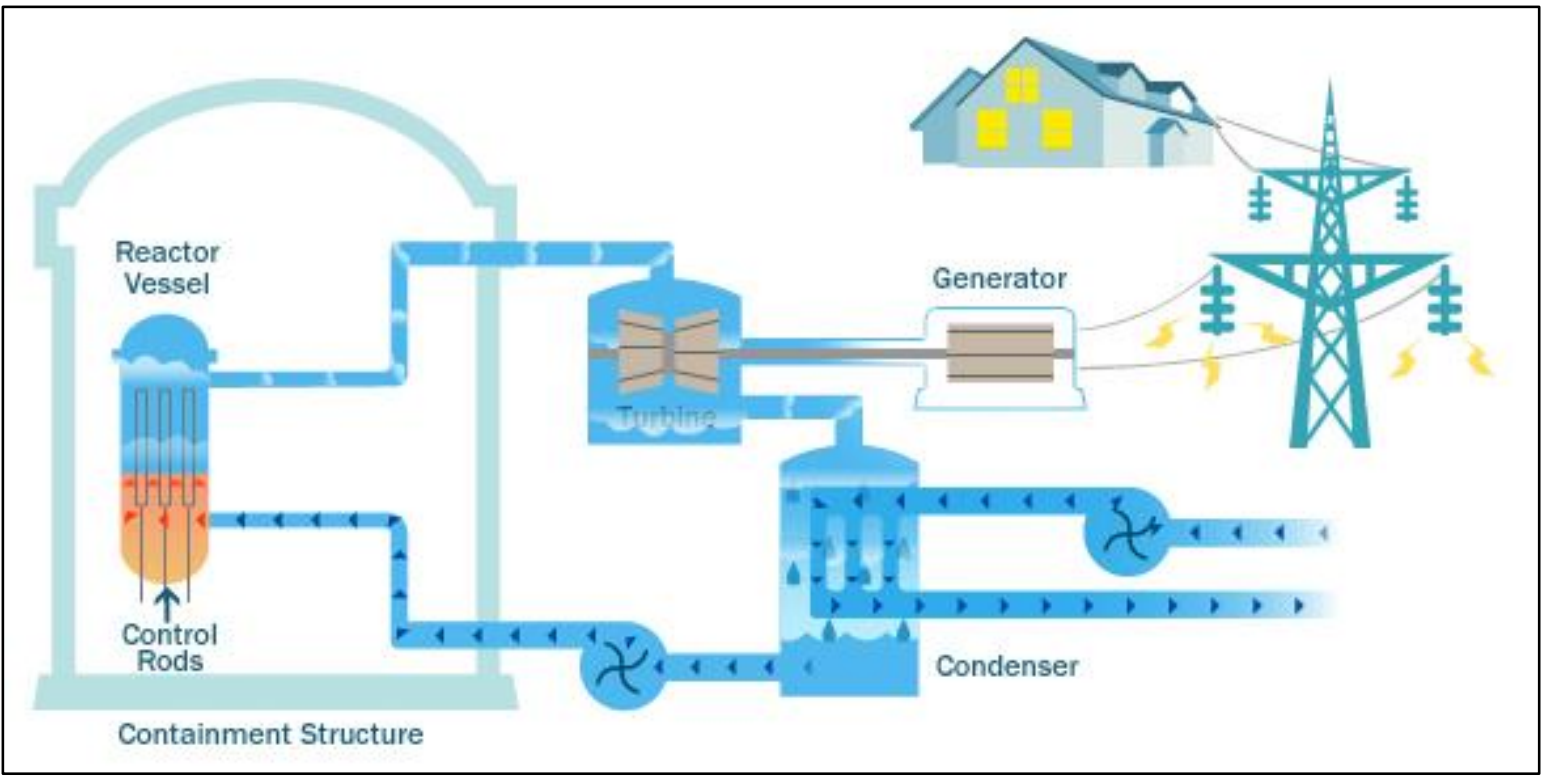

Figure 12. Diagram of a boiling water reactor [60]. 


\subsection{Technology Maturity}

Another parameter to consider when determining whether an energy storage technology is currently viable is the maturity of each technology. Energy storage technologies that have not yet been demonstrated in large-scale installations could be more difficult and costly to integrate with an NPP. An immature technology provides little immediate benefit to NPPs that are facing challenges in electricity markets today. Therefore, the maturity of an energy storage technology must be considered alongside the technology's compatibility with nuclear power as well as the policy and market trends in the power plant's individual region.

\subsection{In this report, a standardized method for assessing maturity was} technology. In 2008, the DOE adopted the Technology Readiness also been used by the Department of Defense and was developed by Administration in the 1980s. The TRA method assigns a Technology technology as an indicator of the technology's maturity. The TRL 1 indicating that only the basic principles of the technology have been that the technology has already been integrated successfully in a realthe TRA method is to ensure that a technology has been investment decisions are made. The TRL scores used by the DOE are

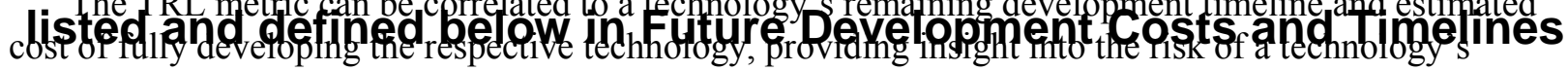
particular stage of development. For example, building a pilot-scale demonstration project for a TRL 3 technology requires significantly higher capital investments and is a much riskier endeavor than performing laboratory-scale experiments. Thus, a curve similar to the correlation displayed in Figure 13 can be postulated for the relationship between the TRL, cost requirements, development risk, and remaining development timeline.

Although the technology maturities displayed in Figure 13 do not perfectly match the TRLs assigned in this report, the general trend associating technology maturity, cost requirements, and technology risk is the same. One of the contradictions between the report and this chart is hydrogen energy storage, which is shown to be less mature than supercapacitors and SMES systems in Figure 13, but was assessed as entering the demonstration and deployment phase in this report. However, the TRLs assigned in this report correspond closely to the estimated technology maturities displayed in Figure 13 for the most part. For instance, in both places PSH facilities are recognized as the most mature technology and thermochemicals are shown to be the least mature. The technologies considered in this report that are not included in Figure 13 can be placed on the curve by estimating their position relative to other technologies with similar TRLs. As a result, this curve can be used to understand how an energy storage technology's future development costs and timeline correlate to the technology's maturity.

Table 2. These TRL scores can be used to determine the maturity of each technology examined in this report and estimate the future development timeline for each technology as well as the remaining development costs for the technology to reach maturation. The DOE has also developed a tool for calculating the TRL of a technology in their Technology Readiness Assessment Guide [61]. This TRL calculator consists of a simple questionnaire to provide an objective process for assigning a TRL score to a technology. This tool was used to assign the technologies in this report with appropriate TRL scores. 


\subsection{Future Development Costs and Timelines}

The TRL metric can be correlated to a technology's remaining development timeline and estimated cost of fully developing the respective technology, providing insight into the risk of a technology's particular stage of development. For example, building a pilot-scale demonstration project for a TRL 3 technology requires significantly higher capital investments and is a much riskier endeavor than performing laboratory-scale experiments. Thus, a curve similar to the correlation displayed in Figure 13 can be postulated for the relationship between the TRL, cost requirements, development risk, and remaining development timeline.

Although the technology maturities displayed in Figure 13 do not perfectly match the TRLs assigned in this report, the general trend associating technology maturity, cost requirements, and technology risk is the same. One of the contradictions between the report and this chart is hydrogen energy storage, which is shown to be less mature than supercapacitors and SMES systems in Figure 13, but was assessed as entering the demonstration and deployment phase in this report. However, the TRLs assigned in this report correspond closely to the estimated technology maturities displayed in Figure 13 for the most part. For instance, in both places PSH facilities are recognized as the most mature technology and thermochemicals are shown to be the least mature. The technologies considered in this report that are not included in Figure 13 can be placed on the curve by estimating their position relative to other technologies with similar TRLs. As a result, this curve can be used to understand how an energy storage technology's future development costs and timeline correlate to the technology's maturity.

Table 2. DOE technology readiness level scale [61].

\begin{tabular}{|c|c|c|c|}
\hline $\begin{array}{l}\text { Relative Level of } \\
\text { Technology } \\
\text { Deployment }\end{array}$ & $\begin{array}{l}\text { Technology } \\
\text { Readiness } \\
\text { Level }\end{array}$ & TRL Definition & Description \\
\hline System Operations & TRL 9 & $\begin{array}{l}\text { Actual system operated } \\
\text { over the full range of } \\
\text { operating conditions }\end{array}$ & $\begin{array}{l}\text { Actual operation of the technology in } \\
\text { its final form, under the full range of } \\
\text { operating conditions. }\end{array}$ \\
\hline \multirow{2}{*}{$\begin{array}{c}\text { System } \\
\text { Commissioning }\end{array}$} & TRL 8 & $\begin{array}{l}\text { Actual system completed } \\
\text { and qualified through } \\
\text { test and demonstration }\end{array}$ & $\begin{array}{l}\text { Technology has been proven to work in } \\
\text { its final form and under expected } \\
\text { conditions. In almost all cases, this } \\
\text { TRL represents the end of true system } \\
\text { development. }\end{array}$ \\
\hline & TRL 7 & $\begin{array}{l}\text { Full-scale similar } \\
\text { (prototypical) system } \\
\text { demonstrated in a } \\
\text { relevant environment }\end{array}$ & $\begin{array}{l}\text { Prototype full-scale system. Represents } \\
\text { a major step up from TRL } 6 \text {, requiring } \\
\text { demonstration of an actual system } \\
\text { prototype in a relevant environment. }\end{array}$ \\
\hline $\begin{array}{c}\text { Technology } \\
\text { Demonstration }\end{array}$ & TRL 6 & $\begin{array}{l}\text { Engineering/pilot-scale, } \\
\text { similar (prototypical) } \\
\text { system validation in a } \\
\text { relevant environment }\end{array}$ & $\begin{array}{l}\text { Representative engineering scale model } \\
\text { or prototype system, which is well } \\
\text { beyond the lab scale tested for TRL 5, } \\
\text { is tested in a relevant environment. } \\
\text { Represents a major step up in a } \\
\text { technology's demonstrated readiness. }\end{array}$ \\
\hline \multirow{2}{*}{$\begin{array}{c}\text { Technology } \\
\text { Development }\end{array}$} & TRL 5 & $\begin{array}{l}\text { Laboratory scale, similar } \\
\text { system validation in } \\
\text { relevant environment }\end{array}$ & $\begin{array}{l}\text { The basic technological components are } \\
\text { integrated so that the system } \\
\text { configuration is similar to (matches) the } \\
\text { final application in almost all respects. }\end{array}$ \\
\hline & TRL 4 & $\begin{array}{l}\text { Component and/or } \\
\text { system validation in } \\
\text { laboratory environment }\end{array}$ & $\begin{array}{l}\text { Basic technological components are } \\
\text { integrated to establish that the pieces } \\
\text { will work together. This is relatively } \\
\text { "low fidelity" compared with the }\end{array}$ \\
\hline
\end{tabular}




\begin{tabular}{|c|l|l|l|}
\hline $\begin{array}{c}\text { Research to Prove } \\
\text { Feasibility }\end{array}$ & TRL 3 & $\begin{array}{l}\text { Analytical and } \\
\text { experimental critical } \\
\text { function and/or } \\
\text { characteristic proof of } \\
\text { concept }\end{array}$ & $\begin{array}{l}\text { Active research and development is } \\
\text { initiated. This includes analytical } \\
\text { studies and laboratory sale studies to } \\
\text { physically validate the analytical } \\
\text { predictions of separate elements of the } \\
\text { technology. }\end{array}$ \\
\hline $\begin{array}{c}\text { Basic Technology } \\
\text { Research/Research } \\
\text { to Prove Feasibility }\end{array}$ & TRL 2 & $\begin{array}{l}\text { Technology concept } \\
\text { and/or application } \\
\text { formulated }\end{array}$ & $\begin{array}{l}\text { Invention begins. Once basic principles } \\
\text { are observed, practical applications can } \\
\text { be invented. Applications are } \\
\text { speculative, and there may be no proof } \\
\text { or detailed analysis to support the } \\
\text { assumptions. }\end{array}$ \\
\hline $\begin{array}{c}\text { Basic Technology } \\
\text { Research }\end{array}$ & TRL 1 & $\begin{array}{l}\text { Basic principles } \\
\text { observed and reported } \\
\text { Scientific research begins to be } \\
\text { translated into applied research and } \\
\text { development (R\&D). }\end{array}$ \\
\hline
\end{tabular}

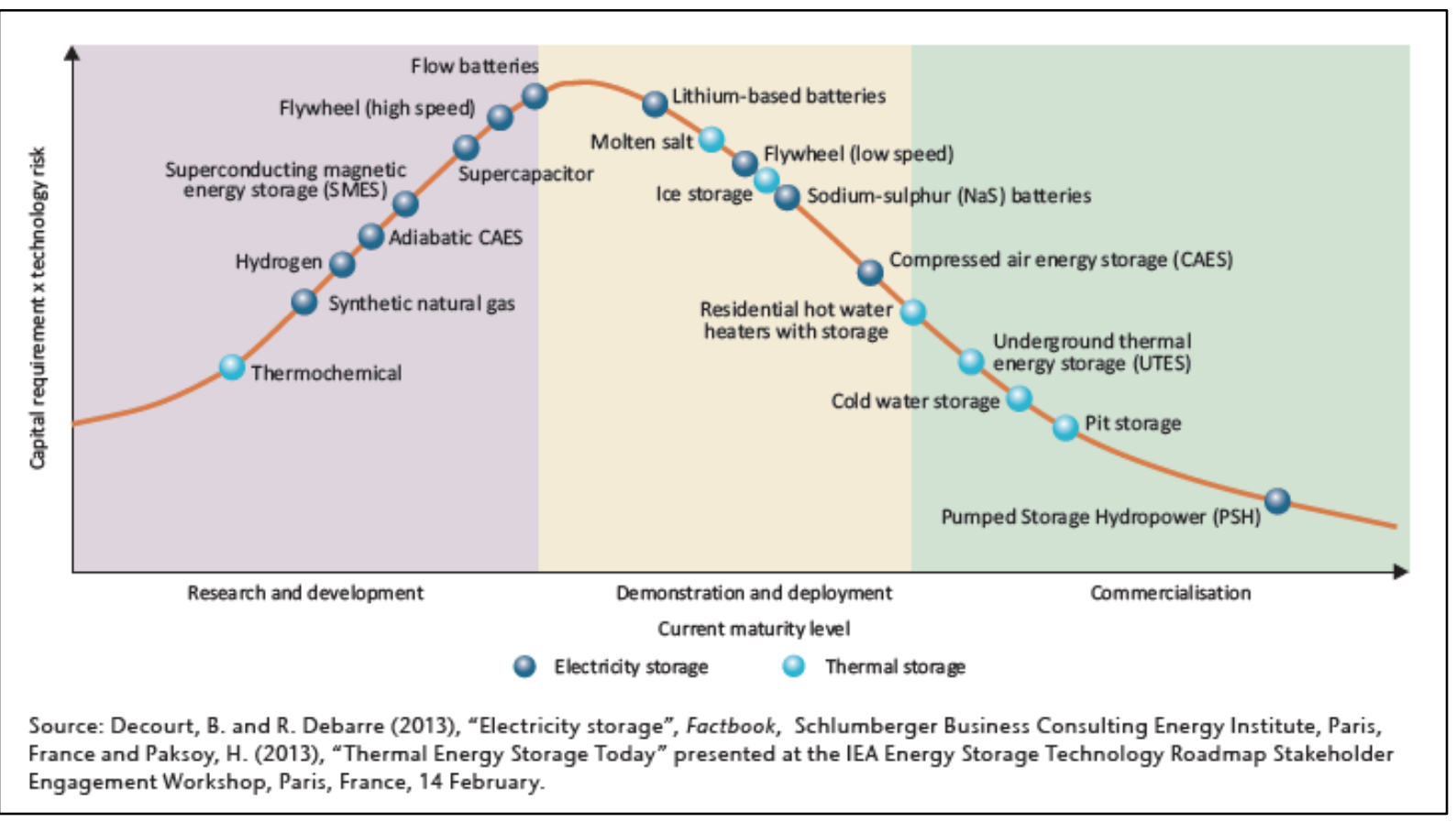

Figure 13. Correlation between maturity level, development costs, and technology risk [20]. 


\section{INVENTORY OF OPTIONS}

There are a multitude of energy storage technologies that have been considered for use with the electric grid in the past several decades. However, very few energy storage technologies have been integrated directly with power plants. In this report, several energy storage technologies, including molten salts, will be considered for their compatibility with nuclear power and their ability to compensate for the increased volatility in electricity markets introduced by VRES providing NPPs with additional operational flexibility.

\subsection{Mechanical Energy Storage}

Mechanical energy storage technologies store energy by converting electricity into either kinetic or potential energy. The most common form of mechanical energy storage is $\mathrm{PSH}$, which is the most prevalent form of energy storage in the world. In fact, the Wall Street Journal reports that pumped storage hydropower facilities are growing in popularity once again to help smooth out electricity generation from variable renewable energy sources, with FERC currently considering proposals for 18,000 MW of additional capacity [62]. PSH facilities store energy by using electric power to transport water to a higher elevation, effectively converting electrical energy to potential energy. CAES facilities also store energy in the form of potential energy. In contrast, the last mechanical energy storage technology considered in this report, flywheels, stores energy in the form of kinetic energy.

\subsubsection{Pumped Storage Hydropower}

\subsubsection{Technology Overview}

Pumped storage hydropower is by far the most developed energy storage technology in the world today. In fact, the International Energy Agency (IEA) estimates that PSH installations account for 99\% of the energy storage capacity worldwide [20]. In the U.S., the pumped storage hydropower fleet consists of $42 \mathrm{PSH}$ plants accounting for $21.6 \mathrm{GW}$ of capacity, or $97 \%$ of the total utility-scale electricity storage in the U.S. at the end of 2015 [63]. The construction of new PSH facilities in the U.S. stalled in the mid1980's due to environmental opposition and the changing needs of the grid, triggered by the transition to restructured electricity markets [21]. However, models built by the DOE have shown that there is potential for $35 \mathrm{GW}$ of additional PSH facilities to be installed by 2050, essentially doubling the current capacity in the U.S. In this modeling scenario, technology advancements lower capital and operating costs, market trends lead to increased revenues and lower financing costs, and several environmental externalities are considered. Thus, this projected growth is dependent on a set of complex variables that are difficult to predict. Regardless, if the deployment of PSH facilities in the U.S. were to grow at the rates projected by the DOE, nearly $\$ 209$ billion could be saved from avoided greenhouse gas (GHG) emissions [63]. Pumped storage hydropower plants store energy by pumping water from a lower reservoir to a higher reservoir using electricity generated during off-peak periods. During peak demand periods, the water is allowed to flow back down to the lower reservoir, generating electricity in the same way a conventional hydropower plant would. This process is displayed in the diagram of a PSH facility shown in Figure 14. Although the energy delivered to and exported from a PSH installation is electrical energy, the energy is converted to mechanical energy and stored in the gravitational potential energy of the water when it is at a higher elevation. PSH facilities actually offer developers better ramp rates than natural gas power plants for increasing the flexibility of the grid. However, the environmental impacts of PSH facilities are significant and the requisite geographic conditions must be available in order to construct a viable PSH plant. Additionally, the investment costs for PSH plants can be prohibitive if a significant man-made reservoir must be constructed [21]. 


\section{Cross section of a PHES plant}

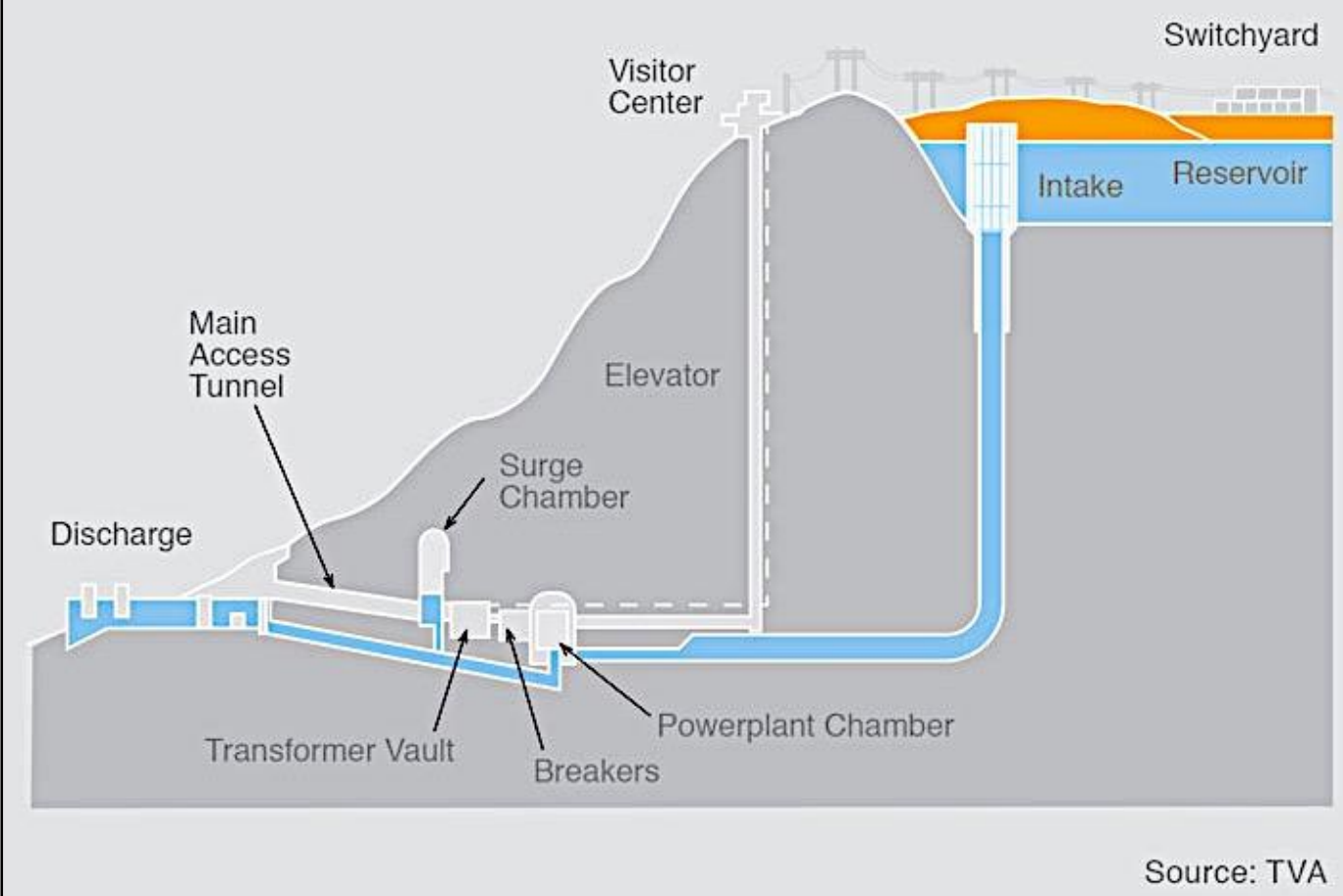

Figure 14. Representative diagram of a PSH facility [64].

\subsubsection{Performance Parameters}

Pumped storage hydropower plants are unique from other energy storage technologies in many ways. PSH installations are much larger than any other energy storage technology besides CAES. As a result, the discharge time for PSH installations is on the order of tens of hours, which is much longer than most other energy storage technologies. The performance parameters for a typical PSH plant are listed in Table 3 at the end of this section.

\subsubsection{Environmental Impact}

The construction of PSH plants impacts the environment in many different ways. Typically, building a PSH plant requires the placement of a large dam and reservoir along a major river system. As a result, the ecosystem of the river is drastically affected. The natural migration of fish populations is disrupted and the creation of a reservoir often displaces native human and wildlife populations in addition to increasing the amount of evaporation from the river. Furthermore, PSH facilities produce GHG emissions during operation due to the decaying vegetation in the reservoir that would not otherwise decompose. Finally, the retirement of PSH facilities is difficult to manage and can cause additional damage to the environment. A potential developer must carefully consider how they will attempt to mitigate these impacts when siting a new PSH project [65]. The environmental impacts of PSH facilities are summarized in Table 4 at the end of this section. 


\subsubsection{Geographic Requirements}

Previously, a major river system and topological features that provided a sufficient elevation change were prerequisites for the construction of a PSH plant. However, developers have begun to consider building "closed-loop" PSH plants that do not need a river to serve as the source of water for the system. Instead, an artificial reservoir is built and filled with water. The reservoir is then refilled during regular operation to replace any water that has evaporated. This new system design enables PSH plants to relocate away from aquatic ecosystems and addresses many of the environmental issues associated with pumped storage hydropower. However, geography is still an important consideration, since a suitable elevation change is necessary for a PSH project. This design also enables developers to build PSH plants closer to where energy storage is needed as long as the necessary geographical features are available [65].

\subsubsection{Policy and Market Conditions}

Although pumped storage hydropower is by far the most established energy storage technology in the world today, developers still face some significant policy and market barriers. Due to the environmental impacts associated with PSH projects, all non-federal PSH developers must obtain FERC licensing before they can begin construction under Section 10(a) of the U.S. Federal Power Act, which could take 3-5 years to complete. Furthermore, although the restructuring of electricity markets has made energy storage technologies more profitable in many ways, there are few long-term revenue streams currently available to bulk energy storage technologies like pumped storage hydropower. Instead, services are sold on realtime or day-ahead markets that provide none of the stability that investors seek before funding a PSH plant. However, there are also market opportunities available to bulk energy storage technologies like PSH. PSH plants can replace conventional reserve generation capacity as the primary response to the increasing penetration of variable generating resources. The existing fleet of load following natural gas plants that currently provides this capacity is inefficient and offsets the environmental benefits offered by the introduction of renewable energy sources. Since a large amount of excess generation capacity is needed to match the demand for electricity throughout the day with conventional resources, PSH plants could increase the efficiency of the grid by reducing the amount of power plants that are operating without contributing any electricity to the grid. Furthermore, not only can PSH plants cleanly and efficiently maximize the value of renewable energy, but they can also gain additional revenue by selling reserve capacity in ancillary service markets. New opportunities for PSH facilities to monetize services that they have provided to the grid since before electricity markets were restructured has increased the value of this technology [65].

\subsubsection{Compatible Applications}

Originally, pumped storage hydropower plants were installed to provide energy arbitrage capabilities to utilities. However, PSH plants are also capable of providing other services in restructured electricity markets. Specifically, the large energy capacity of pumped storage hydropower plants enables them to effectively offer seasonal energy management and critical backup reserves. The services compatible with pumped storage hydropower are listed in Table 5 [19]. The compatibility of these services with PSH plants was determined by comparing certain technical characteristics such as energy and power capacity, discharge time, durability, and response time to the requirements for providing a particular service to the grid. As shown in Table 5, applications were determined to either be compatible, somewhat compatible, or incompatible with PSH plants.

\subsubsection{Technology Maturity}

Pumped storage hydropower plants are already prevalent in the U.S. and are used widely for energy storage applications. According to the DOE, a technology that is operating with a TRL of 9 should have been tested over its full range of operating conditions. Furthermore, the technology should be currently 
operating in its final form. Due to the long history of using PSH for energy storage in the U.S., a TRL score of 9 was confidently given to pumped storage hydropower, as seen in Table 3.

\subsubsection{Future Development}

The primary application of pumped storage hydropower plants in the U.S. is energy arbitrage. However, with the development of variable speed pumping, pumped storage hydropower plants have the potential to become more flexible and provide additional services to the grid. For example, variable speed pumping could enhance the ability of PSH plants to provide load following and frequency regulation services to assist with the integration of variable renewable energy sources [19]. Additionally, efforts to mitigate the geographic impact of PSH plants have encouraged the development of underground PSH installations. However, these systems are still in the initial planning stages [21].

\subsubsection{Compressed Air Energy Storage}

\subsubsection{Technology Overview}

CAES facilities have been commercially deployed, but CAES systems are not nearly as widespread as PSH plants. Only two full-scale CAES systems are in operation in the world today: one in Germany and one in the U.S. state of Alabama [21]. Furthermore, like PSH plants, specific geographic formations are typically required for CAES installations. A CAES system stores energy by using off-peak electricity to compress air and store it in a reservoir. Although large, steel, above-ground containers can be built to operate as a reservoir for this compressed air, naturally occurring salt caverns provide a cost-effective means for storing large quantities of air. The compressed air is heated, expanded, and released to a combustor in a gas turbine during peak demand periods when electricity is needed. A diagram of a CAES facility is shown below in Figure 15. Although CAES plants offer quick ramp rates like PSH facilities, the efficiency of the energy storage and conversion process is relatively low compared to other energy storage technologies. Likewise, CAES plants are slower to respond to disruptions in the grid than quickresponse technologies like flywheels or batteries, which will also be examined in this report [19].

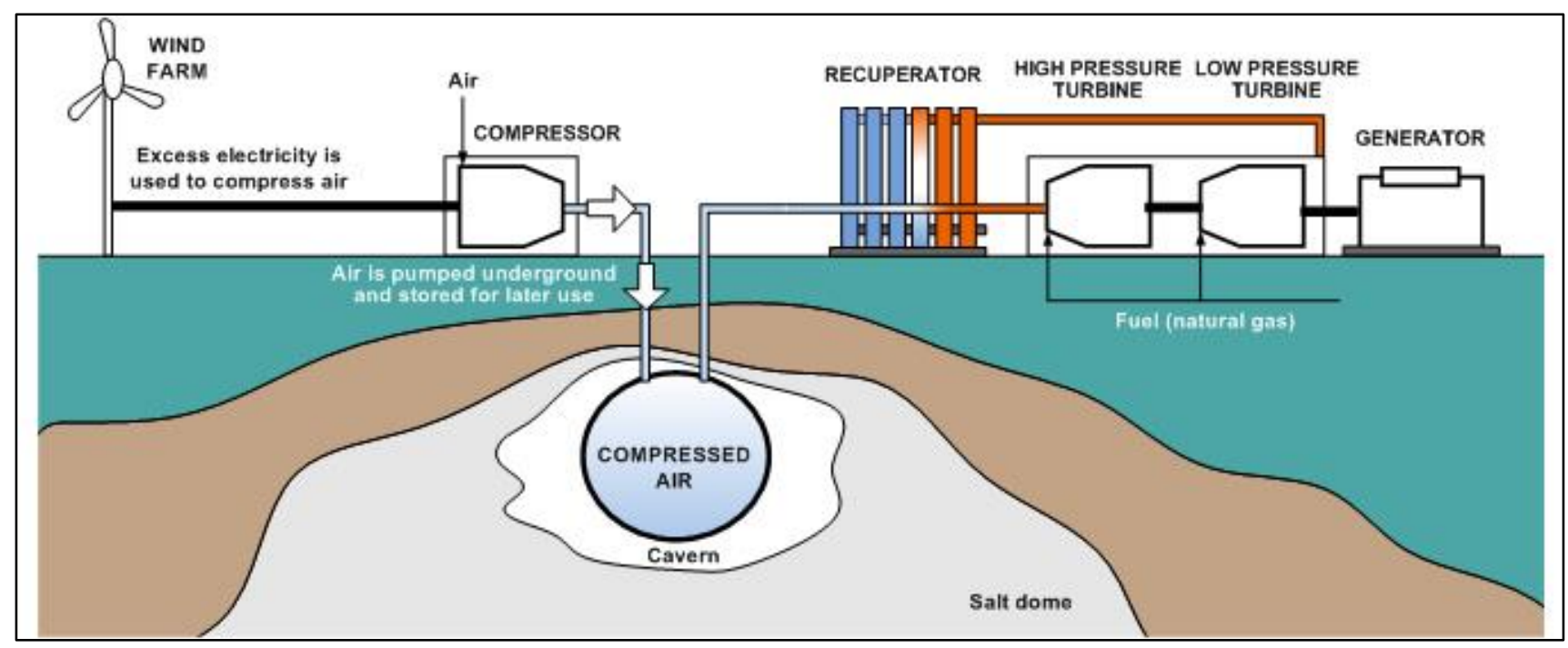

Figure 15. Representative diagram of a CAES facility [66]. 


\subsubsection{Performance Parameters}

Like PSH plants, discharge times for underground CAES installations are generally on the order of tens of hours. However, above-ground installations are typically much smaller, with discharge times on the order of 2-6 hours. In addition, although there are only two CAES installations in the world, these systems have been demonstrated as cost-effective and reliable. This technology has been used successfully to assist with the integration of variable generation from wind power. The performance parameters for a typical CAES system are listed in Table 3 at the end of this section.

\subsubsection{Environmental Impact}

Although CAES plants are similar in size to pumped storage hydropower plants, they are located underground and do not have nearly as significant of an effect on the surface environment. However, natural gas is often needed to expand the compressed air, and as a result, some emissions are produced during the operation of CAES systems [22]. In California, the Pacific Gas and Electric Company is planning a CAES plant with funding from the DOE. The DOE conducted a thorough environmental assessment before beginning the project. In this environmental assessment, the DOE concluded that any significant adverse environmental impacts from the project did not outweigh the environmental benefits provided by the potential CAES plant. The DOE considered air emissions produced during construction, potential for induced seismicity, the impact on native animal populations, and many other factors when performing this assessment [67]. The environmental impacts of CAES facilities are summarized in Table 4 at the end of this section.

\subsubsection{Geographic Requirements}

Although underground formations are not required for CAES facilities, plants with underground storage are capable of storing much more energy than plants with above-ground tanks to contain the compressed air. Furthermore, a large energy and power storage capacity is often necessary for the project to be economically feasible. Potential sites for CAES are plentiful in the U.S., with nearly three-quarters of the country possessing the necessary geography. A map of suitable geography throughout the U.S. is displayed below in Figure 16. Possible CAES sites include evacuated salt caverns, aquifers, and depleted natural gas fields. However, it is still difficult to site these plants since the air storage integrity of the geologic formation must be verified before construction can begin. Ideally, the geologic formation will be close to a power plant (e.g., wind farm) that is able to provide renewable energy for storage. Additionally, since natural gas is often used in the expansion cycle of CAES plants, it is also favorable for a CAES plant to be co-located with a source of natural gas [22]. 


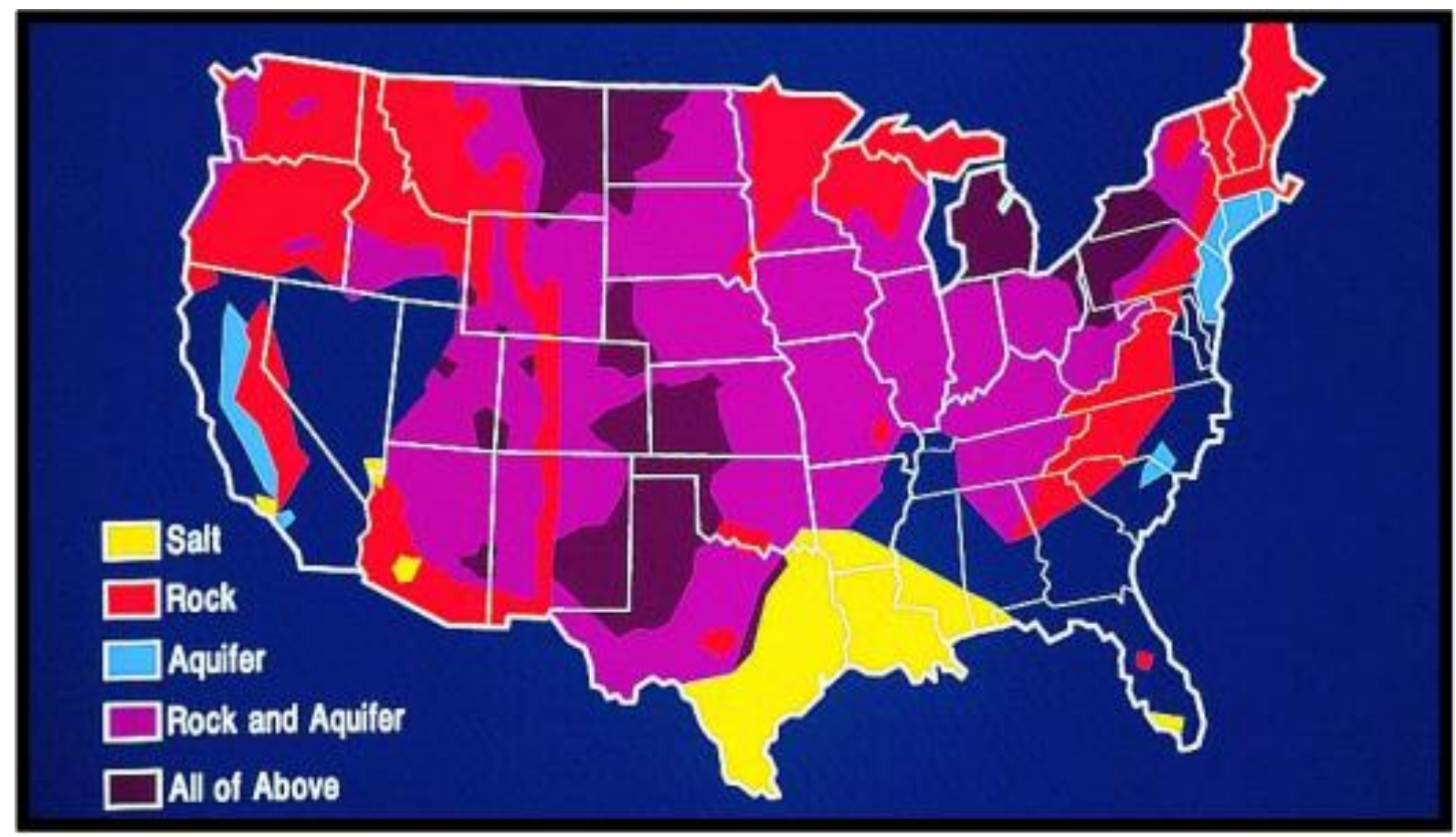

Figure 16. Potentially suitable geologic formations for underground CAES from the Electric Power Research Institute (EPRI) [68].

\subsubsection{Policy and Market Conditions}

CAES plants are most often used for energy arbitrage, the process of storing off-peak electricity to sell during peak demand periods. However, bulk energy storage systems like pumped storage hydropower and CAES can also be used for load following, or stabilizing conventional electricity generation by supplying the grid with energy stored during periods of low demand to minimize ramping in response to fluctuations in the supply of electricity caused by VRES. According to a market estimation performed by the Boston Consulting Group, stabilizing conventional generation, or load following, holds the greatest market potential for CAES due to the increasing penetration of VRES. PSH and CAES plants are well positioned to operate in this market since these technologies have already been proven as economically feasible. Thus, the Boston Consulting Group projects that CAES systems will act as an interim solution to increased market variability until other more efficient and cleaner energy storage technologies become cost-effective [69]. Many of the policy conditions for PSH systems apply to CAES systems, since both systems are technologies for large-scale energy storage and require specific geographic conditions. Furthermore, the DOE has also demonstrated a vested interest in developing CAES systems in the U.S. by contributing almost $\$ 50$ million in funding through the American Recovery and Reinvestment Act of 2009 (ARRA) for a 300 MW CAES facility that is currently being built in California [70].

\subsubsection{Compatible Applications}

Due to the relatively quick response times of CAES systems, research has shown that they work well to mitigate the variability of wind power. For example, the McIntosh CAES installation in Alabama is capable of switching from full generation to full compression in 5 minutes and can switch back to full generation in 15 minutes. CAES systems have also been demonstrated for use with NPPs, since the installation in Huntorf, Germany was originally constructed for use with an NPP [22]. The applications compatible with CAES are listed in Table 5. These compatible applications were determined using the same method that was used to match applications with PSH facilities. 


\subsubsection{Technology Maturity}

Although full-scale installations of CAES systems are rare with only 400 MW of installed capacity worldwide, this technology have been demonstrated as effective across a full range of operating conditions. Furthermore, this energy storage technology has already been proven as compatible with integration alongside an operating NPP [22]. Therefore, CAES was assigned a TRL of 9, as shown in Table 3. This TRL was assigned with first-generation CAES systems in mind.

\subsubsection{Future Development}

Due to the success of first-generation CAES designs, second-generation CAES systems are currently under development. These systems promise lower installation costs, higher efficiencies, and faster construction times than the existing first-generation systems. In one second-generation design, CAES is coupled with a natural gas combustion turbine that is used to generate heat during the expansion process. In this design, two-thirds of the electricity is generated by the expansion turbine and one-third of the electricity is generated by the combustion turbine. However, second-generation designs are still in the demonstration phase of development [21]. Adiabatic CAES systems are also being developed that do not use natural gas for the expansion process, consequently producing no $\mathrm{CO}_{2}$ during operation. Instead, these systems store the thermal energy that is removed from the air during the compression process to be used again during the expansion process. This design is also still in the demonstration phase [70].

\subsubsection{Flywheels}

\subsubsection{Technology Overview}

Flywheels store energy kinetically with a spinning rotor. Controls and a power conversion system are used to convert $\mathrm{AC}$ power delivered by the grid or an electricity generating unit into the rotational energy of the rotor. The energy is later released by applying resistance to the spinning rotor. Flywheels have very low energy capacities compared to PSH and CAES systems, but can deliver much more power per mass. In modern flywheel systems, the spinning rotor is contained in a thick, steel vessel that protects the rotor and the motor-generator used to convert electrical energy into mechanical energy and vice versa. This containment vessel also protects surrounding workers from injury in the event of a catastrophic failure. The rotor is typically surrounded by a vacuum to minimize the frictional loss of energy as the rotor spins [20] [21]. A flywheel energy storage system is represented in the diagram shown below in Figure 17. Flywheels offer many benefits to developers, since they are a durable, modular, and quick-responding technology. Furthermore, flywheel energy storage systems are highly efficient and their scalability to grid-scale applications has been proven [19]. 


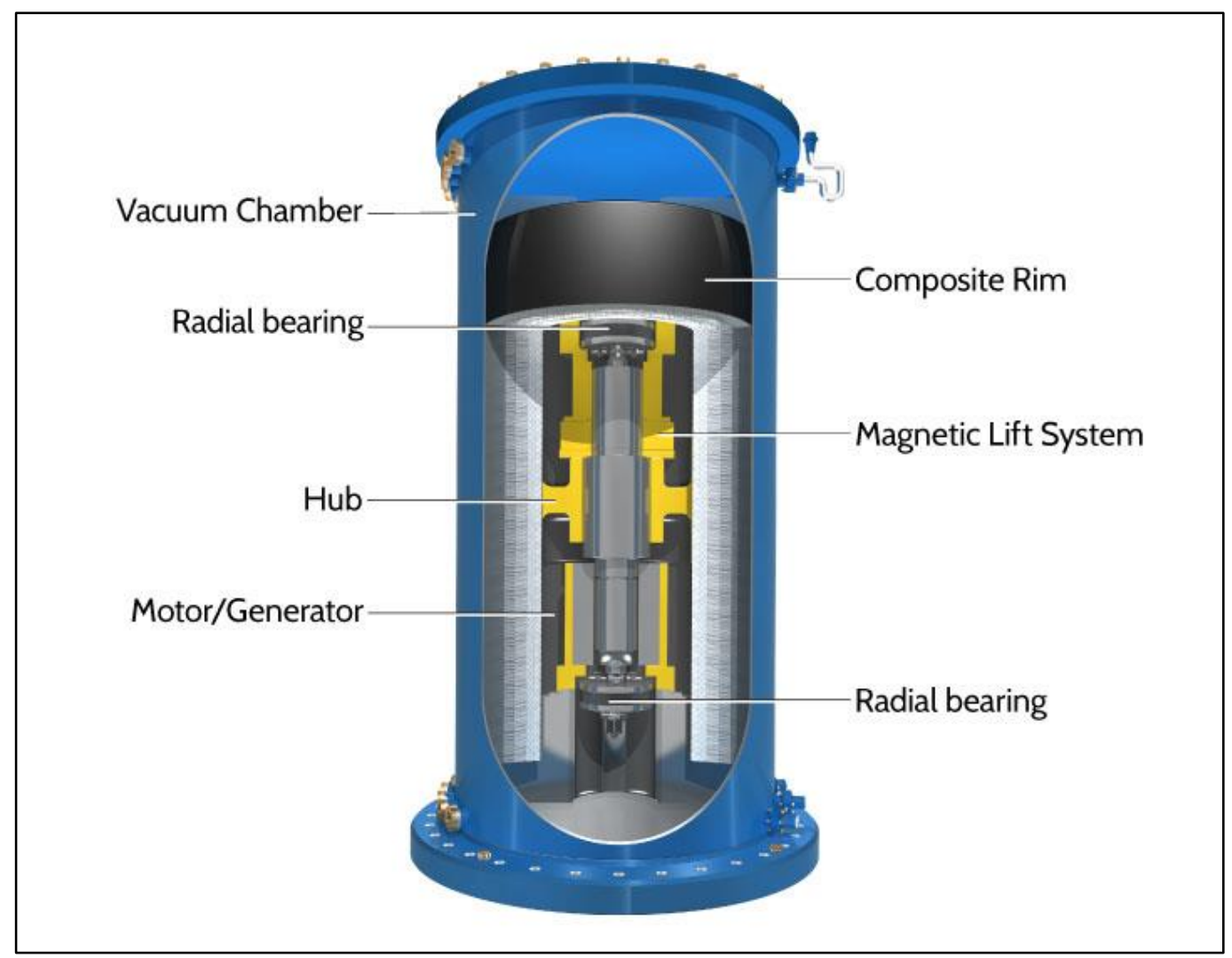

Figure 17. Representative diagram of a flywheel energy storage system [71].

\subsubsection{Performance Parameters}

Although the energy stored in a flywheel system degrades over time due to frictional losses, the power output of a flywheel energy storage system remains relatively constant. Also, flywheels have very high charging and discharging rates. These performance characteristics position flywheels as excellent options for providing frequency regulation services to the grid. Additionally, flywheels have demonstrated excellent cycle life and power density characteristics compared to other energy storage technologies [72]. The performance parameters for a typical flywheel installation are listed in Table 3 at the end of this section.

\subsubsection{Environmental Impact}

In contrast to the other mechanical energy storage technologies considered in this report, the environmental impacts of flywheel systems are minimal. No flywheel systems use hazardous materials in their construction and the technology does not produce any emissions. Also, the systems are sufficiently small so that they have little to no effect on the surrounding ecosystem. Furthermore, in the interest of safety, the spinning rotors are contained within large, steel chamber to protect the surrounding environment from damage [21]. However, as with any energy storage technology, some electricity is wasted in the storage process due to inefficiencies, which could lead to an increase in power plant emissions [49]. The environmental impacts of flywheels are summarized in Table 4 at the end of this section. 
Table 3. Performance parameters for mechanical energy storage systems.

\begin{tabular}{|c|c|c|c|c|c|}
\hline $\begin{array}{c}\text { Storage } \\
\text { Technology }\end{array}$ & $\begin{array}{c}\text { Energy } \\
\text { Capacity } \\
(M W h)\end{array}$ & $\begin{array}{c}\text { Power Capacity } \\
(M W)\end{array}$ & $\begin{array}{c}\text { Energy } \\
\text { Capacity Cost } \\
(\$ / \mathrm{kWh})\end{array}$ & $\begin{array}{c}\text { Power Capacity } \\
\text { Cost }(\$ / k W)\end{array}$ & $\begin{array}{c}\text { Discharge } \\
\text { Time }\end{array}$ \\
\hline$P S H$ & $500-8000[72]$ & $100-5000[22]$ & $5-100[72]$ & $2000-4000[72]$ & $6-10[72]$ \\
\hline$C A E S$ & $\begin{array}{c}580 \text { and } 2860 \\
{[72]}\end{array}$ & 110 and 290 [72] & $2-120[22]$ & $\begin{array}{c}500-1500[20] \\
{[72]}\end{array}$ & $8-20$ [72] \\
\hline Flywheels & $\begin{array}{c}0.0005-0.025 \\
\text { per unit, } 5 \text { total } \\
{[21][73]}\end{array}$ & $\begin{array}{l}0.1-1.65 \text { per unit, } \\
20 \text { total [21] [73] }\end{array}$ & $\begin{array}{c}1000-5000 \\
{[72]}\end{array}$ & $250-350[72]$ & $\begin{array}{c}0-0.25 \mathrm{hr} \\
{[22]}\end{array}$ \\
\hline $\begin{array}{c}\text { Storage } \\
\text { Technology }\end{array}$ & Response Time & $\begin{array}{c}\text { Storage } \\
\text { Degradation } \\
\text { Rate (\%/day) }\end{array}$ & $\begin{array}{c}\text { Energy } \\
\text { Density } \\
\left(\mathrm{kWh} / \mathrm{m}^{3}\right)\end{array}$ & $\begin{array}{l}\text { Power Density } \\
\quad\left(k W / m^{3}\right)\end{array}$ & $\begin{array}{c}\text { Specific } \\
\text { Energy } \\
(W h / k g) \\
\end{array}$ \\
\hline$P S H$ & Minutes [22] & Very small [72] & $0.5-1.5[72]$ & $0.5-1.5[72]$ & $0.5-1.5[72]$ \\
\hline CAES & $\begin{array}{c}\text { Seconds- } \\
\text { minutes [22] }\end{array}$ & Small [72] & $2-6[72]$ & $0.5-2[72]$ & $30-60[72]$ \\
\hline Flywheels & Seconds [22] & $20 \%$ per hr [72] & $20-80[72]$ & $1000-2000[72]$ & $10-30[72]$ \\
\hline $\begin{array}{c}\text { Storage } \\
\text { Technology }\end{array}$ & $\begin{array}{c}\text { Specific Power } \\
(\mathrm{W} / \mathrm{kg})\end{array}$ & $\begin{array}{c}\text { Round-Trip } \\
\text { Efficiency }\end{array}$ & $\begin{array}{l}\text { Cycle Life } \\
\text { (cycles) }\end{array}$ & $\begin{array}{c}\text { Technology } \\
\text { Lifetime (years) }\end{array}$ & $\begin{array}{l}\text { O\&M Costs } \\
(\$ / \mathrm{kW} / \text { year })\end{array}$ \\
\hline$P S H$ & -- & $76-85 \%[21]$ & $\begin{array}{c}10,000- \\
30,000[22]\end{array}$ & $50-60[21]$ & $\sim 3[72]$ \\
\hline$C A E S$ & -- & $\sim 70 \%[72]$ & $\begin{array}{c}8,000-12,000 \\
{[22]} \\
\end{array}$ & $20-40[22]$ & $19-25[72]$ \\
\hline Flywheels & $400-1500[72]$ & $90-95 \%[22]$ & $\begin{array}{c}20,000- \\
100,000[21] \\
{[22]}\end{array}$ & $15-20[21][22]$ & $\sim 20[72]$ \\
\hline $\begin{array}{c}\text { Storage } \\
\text { Technology }\end{array}$ & \multicolumn{5}{|c|}{ Technology Readiness Level } \\
\hline PSH & \multicolumn{3}{|c|}{$9[21]$} & \multicolumn{2}{|l|}{--} \\
\hline CAES & \multicolumn{3}{|c|}{9 [21] } & \multicolumn{2}{|l|}{--} \\
\hline Flywheels & \multicolumn{3}{|c|}{$7[21]$} & -- & \\
\hline
\end{tabular}

Table 4. Environmental impacts of mechanical energy storage systems.

\begin{tabular}{|c|c|c|c|}
\hline Environmental Impact & PSH & CAES & Flywheels \\
\hline Land and Water Impact & Very significant & $\begin{array}{l}\text { Somewhat } \\
\text { significant }\end{array}$ & Insignificant \\
\hline $\begin{array}{c}\text { Emissions Produced During } \\
\text { Operation }\end{array}$ & $\begin{array}{l}\text { Yes, but not very } \\
\text { significant }\end{array}$ & Yes & None \\
\hline Hazardous Materials & None & None & None \\
\hline Hazardous Fumes & None & None & None \\
\hline Short-Term Safety Concerns & Some & Some & Some \\
\hline Resource Depletion & Insignificant & Insignificant & Insignificant \\
\hline Geographic Requirements & Yes & Yes & None \\
\hline
\end{tabular}




\subsubsection{Geographic Requirements}

Modern flywheel systems have a power density five to ten times larger than battery systems that provide similar benefits to the grid. Furthermore, although the energy density for flywheels is low, the total energy storage capacity of a flywheel-based energy storage facility can be increased by adding more flywheel system modules [21].

\subsubsection{Policy and Market Conditions}

The demonstration of the suitability of flywheel systems to provide frequency regulation services has significantly increased the market interest surrounding this technology. Demonstration-scale trials have revealed that $1 \mathrm{MW}$ of flywheel storage can provide 20 to $30 \mathrm{MW}$ of regulation service, which is two to three times more than a conventional generator [21]. Furthermore, the California Energy Commission estimates that flywheels could account for 50 to $60 \mathrm{MW}$ of the total regulation market in the CAISO over the next 10 years [33]. Regulatory policy has also had a major impact on the profitability of flywheel systems. FERC orders 890 and 719 require ISOs to allow energy storage technologies to sell ancillary services in electricity markets. Soon after these orders were passed, FERC order 755 was issued, which recognized flywheels and other energy storage technologies as "fast" responding resources, deserving of additional remuneration based on the quality of their service. This concept was expanded on in FERC order 784, which opened up ancillary service markets even more to energy storage technologies. Thus, these regulations have enabled flywheel systems to competitively sell frequency regulation services in restructured electricity markets and generate more revenue than conventional generating resources are able to bring in [20].

\subsubsection{Compatible Applications}

Flywheels have generally been installed for the purpose of providing power quality and uninterruptible power supply services to consumers. An uninterruptible power supply system provides services similar to the spinning reserves offered by traditional electricity generating units. Likewise, power quality services are similar to voltage support ancillary services. The difference between these services and the ancillary services provided by power plants is that uninterruptible power supply and power quality are services provided on the consumer side of the grid. Therefore, in this report, these services will be considered to be sufficiently similar to spinning reserves and voltage support when determining the applications compatible with flywheel systems, since energy storage technologies are only being considered for integration on the generation side of the grid [21]. Furthermore, flywheels have also been considered as well-suited to provide frequency regulation services to electricity markets. In fact, Spindle Grid Regulation has installed a 20 MW flywheel-based frequency regulation facility in Stephentown, NY to sell frequency regulation services to the New York ISO [22]. The applications compatible with flywheels are listed in Table 5.

\subsubsection{Technology Maturity}

Flywheel systems have been widely used by utilities to provide voltage support and back-up power supply to the grid. Furthermore, the restructuring of electricity markets and the formation of ancillary service markets has opened up new opportunities for flywheel energy storage installations. Therefore, flywheels are now being considered for use with the integration of variable renewable energy sources. Developers claim that flywheels can mitigate the effects of cloud cover on solar power and the variability of wind power [22]. In recent years, full-scale demonstration projects for flywheel energy storage systems have been installed to provide frequency regulation services [21]. Therefore, a TRL score of 7 was assigned, as shown in Table 3. 
Table 5. Compatible applications for mechanical energy storage systems.

\begin{tabular}{|c|c|c|c|}
\hline Service & $\boldsymbol{P S H}$ & $\boldsymbol{C A E S}$ & Flywheels \\
\hline Energy Arbitrage & Compatible & Compatible & Incompatible \\
\hline Frequency Regulation & $\begin{array}{c}\text { Somewhat } \\
\text { compatible }\end{array}$ & $\begin{array}{c}\text { Somewhat } \\
\text { compatible }\end{array}$ & Compatible \\
\hline Load Following & Compatible & Compatible & $\begin{array}{c}\text { Somewhat } \\
\text { Compatible }\end{array}$ \\
\hline Voltage Support & Incompatible & Incompatible & Compatible \\
\hline Spinning Reserves & $\begin{array}{l}\text { Somewhat } \\
\text { compatible }\end{array}$ & $\begin{array}{c}\text { Somewhat } \\
\text { compatible }\end{array}$ & Compatible \\
\hline Non-Spinning \& Supp. & Compatible & Compatible & Incompatible \\
\hline Reserves & Compatible & Compatible & Incompatible \\
\hline Black Start & Compatible & Compatible & Compatible \\
\hline VSR Integration & Compatible & Compatible & Incompatible \\
\hline Seasonal Storage & Incompatible & Incompatible & Incompatible \\
\hline
\end{tabular}

\subsubsection{Future Development}

Further development of flywheel systems for frequency regulation is under way, which could provide an avenue for integration with nuclear power. Also, flywheels are being considered for integration with other energy storage technologies. Due to the characteristics of flywheels, they are able to provide fast ramping, but have a low energy capacity. Therefore, flywheel systems could be integrated with another technology such as pumped storage hydropower to minimize the weaknesses of both technologies. In some cases, wind turbines have been used as flywheels to remove some of the variability of electricity generation from wind power [22]. Finally, freewheels are currently in development that are capable of storing larger quantities of energy, although system studies have just begun on these advanced technologies [21].

\subsection{Electrical Energy Storage}

The two electrical energy storage technologies considered in this report, supercapacitors and superconducting magnetic energy storage systems, store energy in an electrical field and a magnetic field respectively. Electrical energy storage technologies are distinguished as having exceptional power characteristics, but poor energy storage capacities. Thus, these technologies have typically been used in transmission systems.

\subsubsection{Supercapacitors}

\subsubsection{Technology Overview}

Capacitors store energy by collecting positive and negative charge on two conductive plates opposite one another and separated by a dielectric material. An electric field forms between the two plates that can be used to quickly store and release electricity. Supercapacitors, which are also called electric doublelayer capacitors, usually have an energy density hundreds of times greater than that of a conventional capacitor. Supercapacitors store energy between two high surface area electrodes separated by an ionpermeable membrane. An electrolyte solution is used to carry charge between the two electrodes. Supercapacitors are able to package a much larger amount of conductive surface area into the same amount of space as a conventional capacitor, significantly increasing the energy density of the technology [22] [70]. Compared to electrochemical batteries, supercapacitors could be characterized as having high power density and low energy density [19]. A diagram of an electric double layer supercapacitor is displayed below in Figure 18. 


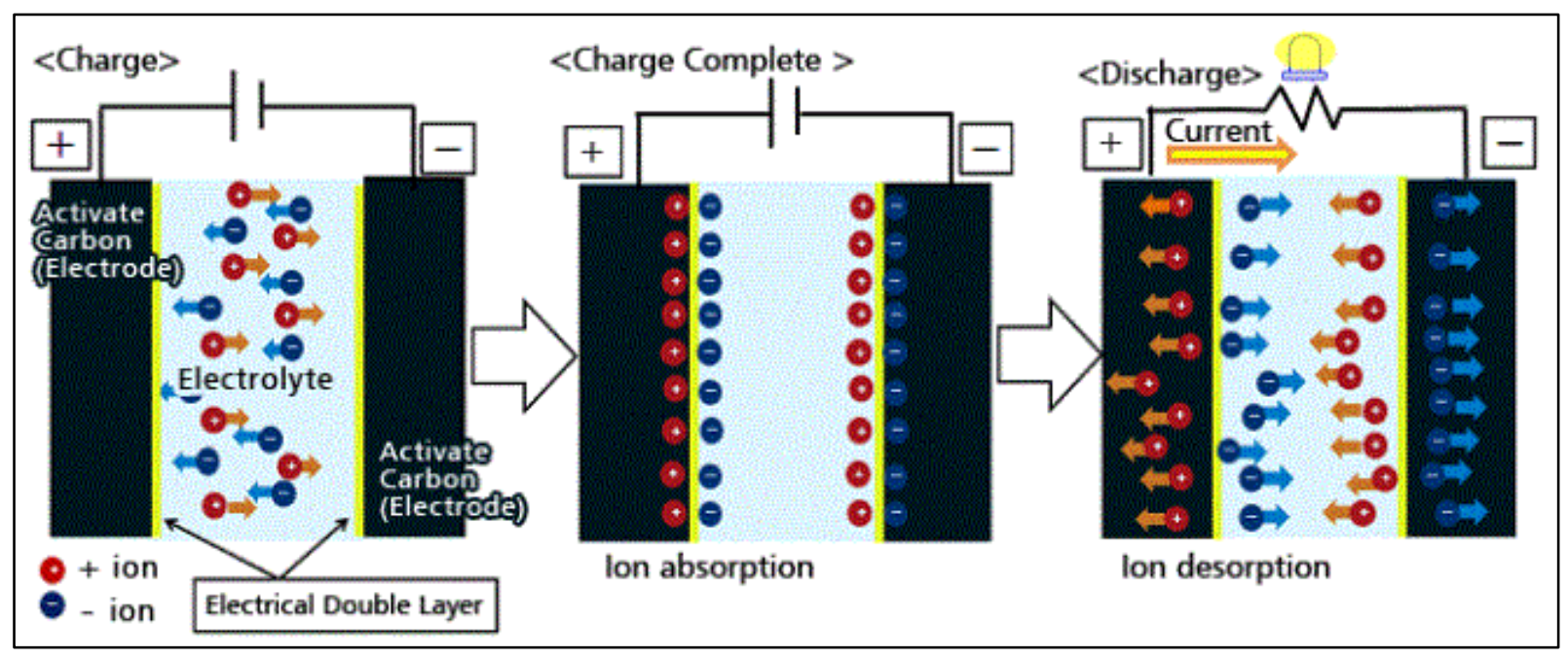

Figure 18. Charging and discharging process for a supercapacitor [74].

\subsubsection{Performance Parameters}

The primary advantage of supercapacitors is how quickly the technology can be charged and discharged. Supercapacitors can be charged much more quickly than batteries and can also be cycled many more times, as shown in Table 6 . However, supercapacitors have a relatively low energy density compared to batteries and other electricity energy storage technologies. Therefore, while batteries may be best suited for energy storage applications, supercapacitors should be used for high power applications [22]. The performance parameters for a typical supercapacitor system are listed in Table 6.

\subsubsection{Environmental Impact}

Supercapacitors have a much less negative impact on the environment than batteries and other energy storage technologies that use more hazardous materials with more limited global reserves. Many electrical energy storage technologies use materials that are limited in quantity and difficult to extract. This can lead to increased costs as materials necessary to construction become rarer. However, the materials used in supercapacitors are available in large quantities around the world. Also, if the materials currently used to build supercapacitors become scarce, there are several substitute materials that could be used instead [22]. The environmental impacts of supercapacitors are summarized in Table 7. The geographical requirements of this technology are also addressed in this table.

\subsubsection{Policy and Market Conditions}

As with other energy storage technologies, electricity markets are redefining supercapacitors so that the technology can profit from the services it provides. In 2009, the New York ISO began to allow limited energy storage resources to sell regulation services. Limited energy storage resources are defined as energy storage technologies that primarily provide the benefit of fast response times as opposed to largescale energy storage capacity, like supercapacitors. However, before supercapacitors can take advantage of the regulatory changes and market opportunities that are developing, the costs of manufacturing these technologies must fall significantly. As economies of scale develop for battery and capacitor technologies due to the increasing popularity of electric vehicles, supercapacitors may become more economically feasible for grid-scale applications [70]. 
Table 6. Performance parameters for electrical energy storage systems.

\begin{tabular}{|c|c|c|c|c|c|}
\hline $\begin{array}{c}\text { Storage } \\
\text { Technology }\end{array}$ & $\begin{array}{c}\text { Energy } \\
\text { Capacity } \\
(M W h)\end{array}$ & $\begin{array}{c}\text { Power Capacity } \\
(M W)\end{array}$ & $\begin{array}{c}\text { Energy } \\
\text { Capacity } \\
\text { Cost } \\
(\$ / k W h) \\
\end{array}$ & $\begin{array}{c}\text { Power } \\
\text { Capacity Cost } \\
(\$ / k W)\end{array}$ & $\begin{array}{c}\text { Discharge } \\
\text { Time }\end{array}$ \\
\hline Supercapacitors & 0.0005 [72] & $0-0.3[22]$ & $10,000[77]$ & $130-515$ [20] & $\begin{array}{c}\text { Milliseconds- } \\
1 \mathrm{hr} \text { [72] }\end{array}$ \\
\hline SMES & $\begin{array}{c}0.001-0.015 \\
{[72]}\end{array}$ & $0.1-10[72]$ & $\begin{array}{c}1,000-10,000 \\
{[22][72]}\end{array}$ & $200-300[72]$ & $\begin{array}{l}\text { Milliseconds- } \\
\text { seconds [72] }\end{array}$ \\
\hline $\begin{array}{c}\text { Storage } \\
\text { Technology }\end{array}$ & Response Time & $\begin{array}{c}\text { Storage } \\
\text { Degradation } \\
\text { Rate }(\% / d a y) \\
\end{array}$ & $\begin{array}{c}\text { Energy } \\
\text { Density } \\
\left(\mathrm{kWh} / \mathrm{m}^{3}\right) \\
\end{array}$ & $\begin{array}{c}\text { Power } \\
\text { Density } \\
\left(\mathrm{kW} / \mathrm{m}^{3}\right) \\
\end{array}$ & $\begin{array}{c}\text { Specific } \\
\text { Energy } \\
(W h / k g) \\
\end{array}$ \\
\hline Supercapacitors & $\begin{array}{l}\text { Milliseconds, } \\
<1 / 4 \text { cycle [22] }\end{array}$ & $20-40 \%$ [72] & $0.01-1[78]$ & $\begin{array}{c}200-10,000 \\
{[79]}\end{array}$ & $2.5-15[72]$ \\
\hline SMES & $\begin{array}{l}\text { Milliseconds, } \\
<1 / 4 \text { cycle [22] }\end{array}$ & $10-15 \%$ [72] & $0.2-2.5[72]$ & $\begin{array}{c}1000-4000 \\
{[72]}\end{array}$ & $0.5-5[72]$ \\
\hline $\begin{array}{c}\text { Storage } \\
\text { Technology }\end{array}$ & $\begin{array}{c}\text { Specific Power } \\
(\mathrm{W} / \mathrm{kg})\end{array}$ & $\begin{array}{c}\text { Round-Trip } \\
\text { Efficiency }\end{array}$ & $\begin{array}{c}\text { Cycle Life } \\
\text { (cycles) }\end{array}$ & $\begin{array}{c}\text { Technology } \\
\text { Lifetime } \\
\text { (years) }\end{array}$ & $\begin{array}{l}\text { O\&M Costs } \\
\text { (\$/kW/year) }\end{array}$ \\
\hline Supercapacitors & $500-5000[72]$ & $90-95 \%$ [22] & $\begin{array}{c}100,000+ \\
{[22]}\end{array}$ & $10-30$ [72] & $\sim 6$ [72] \\
\hline SMES & $500-2000$ [72] & $95-98 \%$ [22] & $\begin{array}{l}100,000+ \\
{[22][72]}\end{array}$ & $\begin{array}{c}20-30[22] \\
{[72]}\end{array}$ & 18.5 [72] \\
\hline $\begin{array}{c}\text { Storage } \\
\text { Technology }\end{array}$ & \multicolumn{5}{|c|}{ Technology Readiness Level } \\
\hline Supercapacitors & \multicolumn{3}{|c|}{$5[20]$} & \multicolumn{2}{|l|}{--} \\
\hline SMES & \multicolumn{3}{|c|}{$5[20]$} & -- & \\
\hline
\end{tabular}

Table 7. Environmental impacts for electrical energy storage systems.

\begin{tabular}{|c|c|c|}
\hline Environmental Impact & Supercapacitors & SMES \\
\hline Land and Water Impact & Insignificant & Insignificant \\
\hline Emissions Produced During Operation & None & None \\
\hline Hazardous Materials & None & None \\
\hline Hazardous Fumes & None & None \\
\hline Short-Term Safety Concerns & Minimal & Several \\
\hline Resource Depletion & Somewhat significant & Somewhat significant \\
\hline Geographic Requirements & None & None \\
\hline
\end{tabular}

\subsubsection{Compatible Applications}

The quick-response characteristics of supercapacitors make this technology especially well-suited to providing frequency regulation services. Furthermore, conventional capacitors are regularly used in transmission systems to provide reliability services and voltage support, and supercapacitors can be used in the same applications. Supercapacitors are also capable of supplying short-term reserves, although other technologies with higher energy densities can be better suited for this application [22]. The applications compatible with supercapacitors are listed in Table 8. 
Table 8. Compatible applications for electrical energy storage systems.

\begin{tabular}{|c|c|c|}
\hline Service & Supercapacitors & SMES \\
\hline Energy Arbitrage & Incompatible & Incompatible \\
\hline Frequency Regulation & Compatible & Compatible \\
\hline Load Following & Compatible & Compatible \\
\hline Voltage Support & Compatible & Compatible \\
\hline Spinning Reserves & Somewhat compatible & Somewhat compatible \\
\hline Non-Spinning \& Supp. Reserves & Incompatible & Incompatible \\
\hline Black Start & Incompatible & Incompatible \\
\hline VSR Integration & Compatible & Incompatible \\
\hline Seasonal Storage & Incompatible & Incompatible \\
\hline Process Heat Applications & Incompatible & Incompatible \\
\hline
\end{tabular}

\subsubsection{Technology Maturity}

Higher energy density supercapacitors are still being developed and have not yet been installed in any high-voltage applications [22]. However, conventional capacitors are used widely as transmission assets. The first supercapacitor was developed in 1971, and the technology has progressed rapidly since then as new materials and nano-manufacturing techniques have been developed. Furthermore, supercapacitors have been used for regenerative braking in electric vehicles and trains as well as for load leveling for utilities [70]. Therefore, a TRL of 5 was estimated for supercapacitors since similar systems have been demonstrated in relevant operational environments, but no grid-scale projects have been completed, as shown in Table 6.

\subsubsection{Future Development}

Supercapacitors have many marketable applications, but their low energy density severely limits the potential uses for this technology. Therefore, hybrid electrical energy storage systems are being developed that combine the benefits of batteries and supercapacitors to develop a technology with a relatively large storage capacity as well as quick charge and discharge rates [72]. As the scientific community's understanding of nanomaterials grows, engineers might be able to further increase the energy and power density of supercapacitors [70].

\subsubsection{Superconducting Magnetic Energy Storage}

\subsubsection{Technology Overview}

SMES systems store energy in a magnetic field. This magnetic field is generated by a DC current travelling through a superconducting coil. In a normal wire, as electrical current passes through the wire, some energy is lost as heat due to electrical resistance. However, in a SMES system, this wire is made from a superconducting material that has been cryogenically cooled below its critical temperature. As a result, electrical current can pass through the wire with almost no resistance, allowing energy to be stored in a SMES system for a longer period of time. Common superconducting materials include mercury, vanadium, and niobium-titanium. The energy stored in a SMES system is discharged by connecting an AC power convertor to the conductive coil [72]. SMES systems are an extremely efficient storage technology, but they have very low energy densities and are still far from being economically viable [19]. A SMES system is represented in the diagram displayed in Figure 19. 


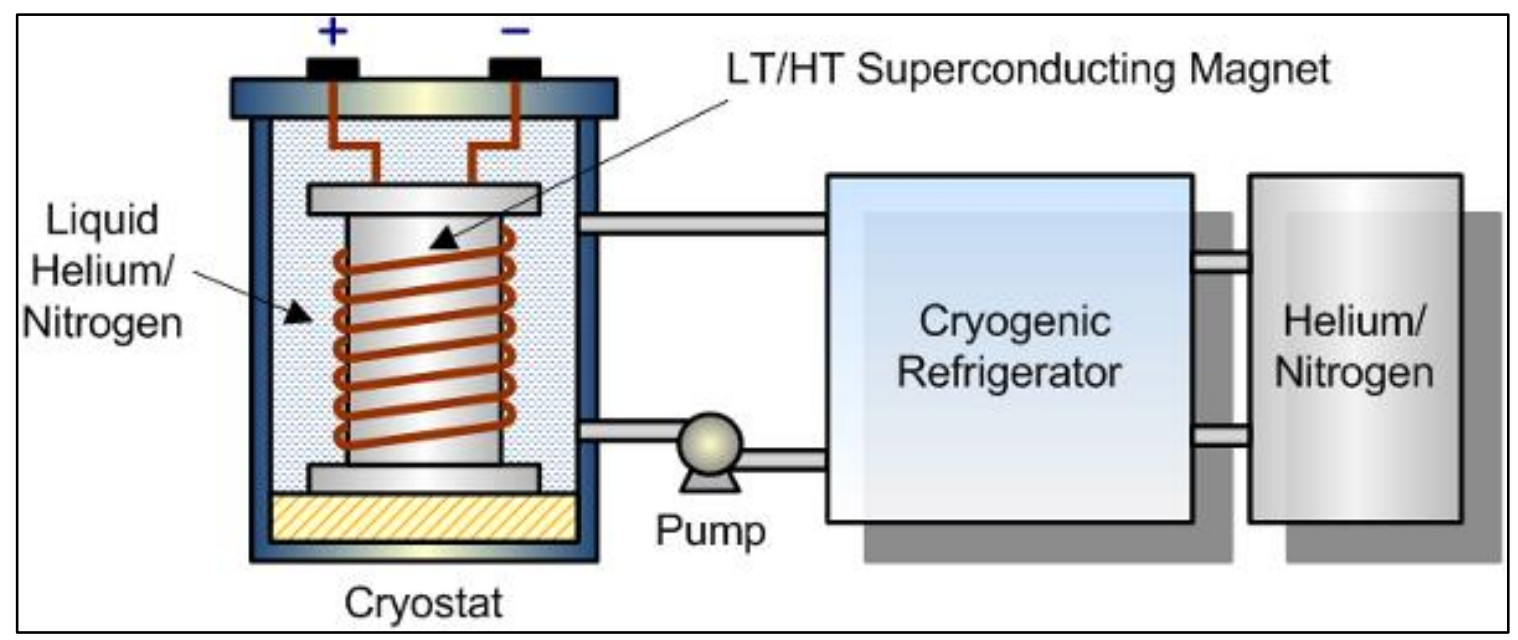

Figure 19. Representative diagram of a SMES system [75].

\subsubsection{Performance Parameters}

SMES systems have technical characteristics similar to those of flywheels and supercapacitors. These systems have relatively high power densities and fast response times, positioning them well in electricity markets to provide regulation services. Additionally, SMES systems have higher cycle efficiencies and lifetimes than several other electrical energy storage technologies. However, these systems are prohibitively expensive and can only supply energy for a short amount of time [72]. The performance parameters of a typical SMES system are listed in Table 6.

\subsubsection{Environmental Impact}

The most significant environmental impact from SMES systems comes as a result of the strong magnetic fields they produce. This magnetic field can adversely affect the health of both humans and animals in the immediate vicinity of the SMES system [76]. Like supercapacitors, although many of the materials used to build SMES systems are rare and can be difficult to extract, there are many other superconducting materials that can be used in place of these materials. Therefore, material scarcity is not a major concern for the production of SMES systems, since another material could be used as soon as the costs of extraction exceed a certain threshold [22]. The environmental impacts of SMES systems are summarized in Table 7. The geographical requirements for SMES systems are also addressed in Table 7.

\subsubsection{Policy and Market Conditions}

The market potential for superconducting magnetic energy storage systems is much the same as the market potential for flywheels and supercapacitors. The quick-response characteristics of SMES systems position the technology well to provide regulation services to electricity markets. Micro-SMES systems have been installed in the U.S. to provide voltage support and uninterruptible power supply services to utilities. However, there are no grid-scale developments currently. Although SMES systems are a clean and efficient energy storage method, flywheels and supercapacitors are less expensive than SMES systems and provide many of the same benefits. As a result, these technologies are better suited than SMES systems for facilitating the integration of renewable energy sources [22]. The recent FERC regulations pertaining to ancillary services also affect SMES systems and their marketability in restructured energy markets by opening ancillary service markets to fast responding energy storage systems that are able to provide frequency regulation [20]. 


\subsubsection{Compatible Applications}

SMES systems are able to supply the grid with many of the same services as flywheels and supercapacitors. Therefore, SMES systems are best suited for power applications, such as voltage support, frequency regulation, and fast, short-term reserves. In addition, SMES systems are often used as transmission assets in the same way that supercapacitors are often used. However, SMES systems provide little to no additional capabilities that flywheels or supercapacitors cannot provide to assist with responding to the increasing penetration of VRES on the grid [22]. The compatible services that SMES systems can provide are listed in Table 8 .

\subsubsection{Technology Maturity}

In 2011, Brookhaven National Laboratory, SuperPower Inc., and the Texas center for superconductivity at the University of Houston began a project with the intention of developing a grid-scale SMES system [72]. However, only micro-SMES systems in the range of 1-10 MW are currently commercially available [22]. Therefore, a TRL of 5 was given to superconducting magnetic energy storage since a pilot-scale project is currently in development, as shown in Table 6.

\subsubsection{Future Development}

The SMES systems commercially available today must be maintained at a temperature of approximately $5^{\circ} \mathrm{K}\left(-268.15^{\circ} \mathrm{C}\right)$, which requires complex cryogenic technology. However, high temperature superconducting coils are being developed that work at approximately $70^{\circ} \mathrm{K}\left(-203.15^{\circ} \mathrm{C}\right)$ [72]. Reducing the amount of cooling needed by the superconducting coils could significantly reduce the costs of the associated refrigeration systems. Thus, the majority of the research and development concerning SMES systems is focused on reducing costs in this way and making SMES systems more economically feasible.

\subsection{Electrochemical Energy Storage}

Although electrochemical energy storage technologies are often considered as a type of electrical energy storage, in this report electrochemical energy storage technologies are considered separately. Furthermore, electrochemical energy storage is divided into conventional batteries and flow batteries in this report to provide more resolution in the categorization of these technologies. Electrochemical batteries are composed of an anode, cathode, and electrolyte. Batteries operate by harnessing electrochemical reactions at the electrode terminals that exchange electronic between chemical species. By connecting the electrodes with an external circuit, the electrons are able to flow directly between the terminals while the positively and negatively charged cations and anions flow through the electrolyte. A load, such as a light bulb, can be placed in the external circuit, allowing useful work to be produced from the electrical current.

\subsubsection{Conventional Batteries}

Two types of batteries are considered in this report, conventional batteries and flow batteries. The difference between these two types of batteries is that conventional batteries store charge in solid electrode systems, while flow batteries rely on storing charge in at least one liquid. The conventional batteries considered in this report include lithium-ion, sodium-sulfur, lead-acid, and nickel-cadmium batteries. 


\subsubsection{Lithium-Ion}

\subsubsection{Technology Overview}

In recent years, lithium-ion batteries have been used as the energy storage technology of choice for consumer products, electric vehicles, personal electronics, and many other applications in which the weight of the energy storage technology needs to be minimized. Furthermore, in the past couple of years, lithium-ion batteries have dominated the market for stationary grid-scale energy storage applications [21]. In a lithium-ion battery cell, energy is stored by causing positively charged lithium ions to travel through a liquid electrolyte as electrons are transferred through an external circuit. When the battery is discharging, the reverse process occurs and electrons are transferred to the opposite electrode. Lithium has a high galvanic potential, giving lithium-ion batteries favorable technical characteristics. However, lithium is also highly reactive when exposed to oxygen or water and must be packaged carefully. Additionally, the lifetime and costs for this technology are not as favorable as other energy storage technologies, although lithium-ion batteries offer superior energy density and specific energy characteristics compared to other commercially available electrochemical energy storage technologies. Thus, lithium-ion batteries are still the storage technology of choice for many mobile devices [70]. A typical lithium-ion battery is diagrammed in Figure 20.

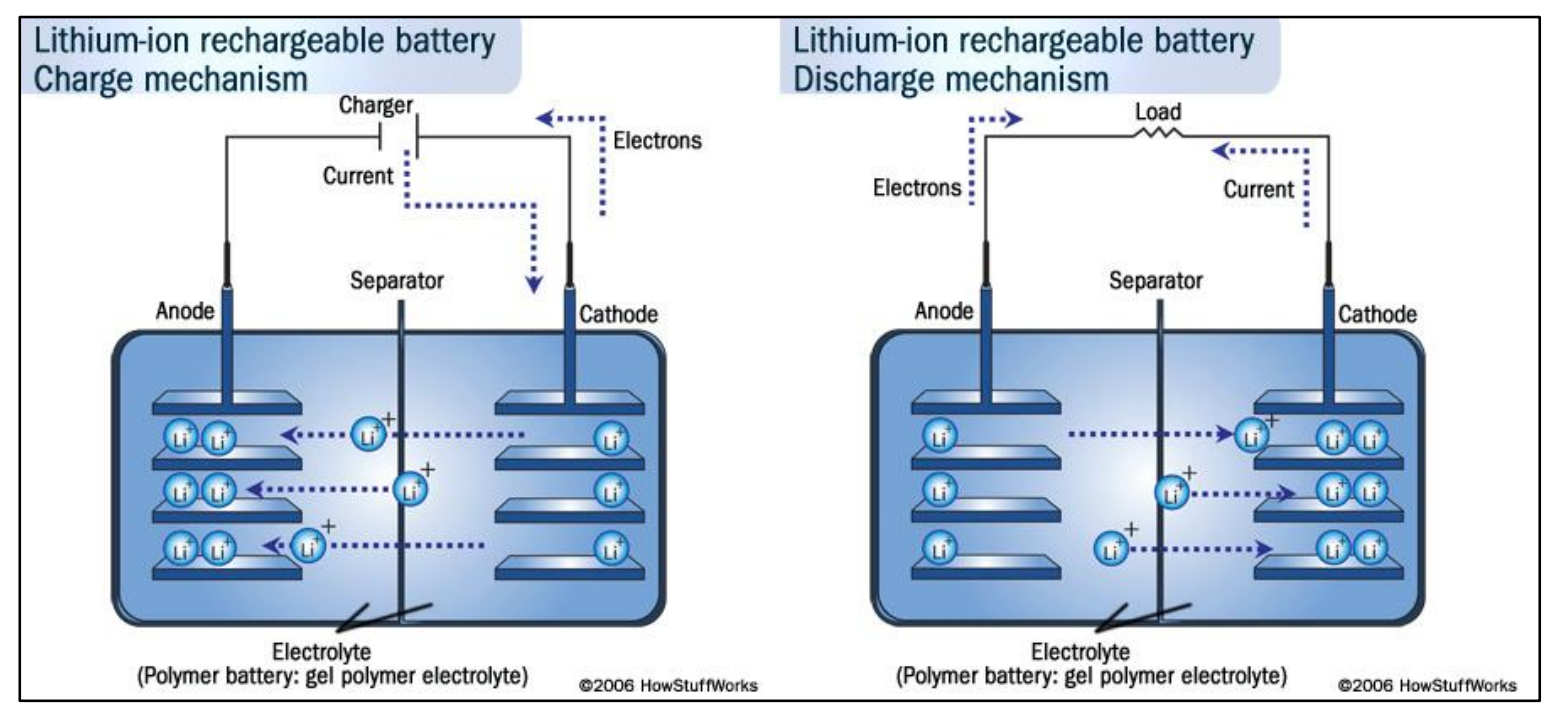

Figure 20. Representative diagram of a lithium-ion battery [80].

\subsubsection{Performance Parameters}

The most attractive quality for lithium-ion batteries is their superior power and energy densities compared to other commercially available electrochemical batteries. Furthermore, these batteries operate with a very high cycle efficiency and cycle life given a certain depth of discharge. However, the lifetimes of lithium-ion batteries are often shortened by deep discharging (anything over 80\% depth-of-discharge). Lithium-ion batteries also typically have quick response times, which make them well-suited for many portable electronics applications as well as grid-scale regulation services. The performance parameters for typical lithium-ion batteries are listed in Table 9. 
Table 9. Performance parameters for conventional battery systems.

\begin{tabular}{|c|c|c|c|c|c|}
\hline $\begin{array}{c}\text { Storage } \\
\text { Technology }\end{array}$ & $\begin{array}{c}\text { Energy } \\
\text { Capacity } \\
(M W h)\end{array}$ & $\begin{array}{c}\text { Power Capacity } \\
(M W)\end{array}$ & $\begin{array}{c}\text { Energy } \\
\text { Capacity Cost } \\
(\$ / \mathrm{kWh})\end{array}$ & $\begin{array}{c}\text { Power } \\
\text { Capacity Cost } \\
(\$ / k W)\end{array}$ & $\begin{array}{l}\text { Discharge } \\
\text { Time }\end{array}$ \\
\hline Lithium-ion & $0.25-25[73]$ & $0.005-50[21]$ & $600-2500[72]$ & $\begin{array}{c}1200-4000 \\
{[72]}\end{array}$ & $\begin{array}{c}\text { Minutes-hours } \\
{[72]}\end{array}$ \\
\hline$N a S$ & $\sim 300[73]$ & $\sim 50[73]$ & $300-500[72]$ & $\begin{array}{c}1000-3000 \\
{[72]}\end{array}$ & $\begin{array}{c}\text { Seconds-hours } \\
{[72]}\end{array}$ \\
\hline Lead-Acid & $0.001-40[72]$ & $\sim 0-20[22][72]$ & $200-400[72]$ & $\begin{array}{c}300-600[22] \\
{[72]} \\
\end{array}$ & $\begin{array}{c}\text { Seconds-hours } \\
{[72]}\end{array}$ \\
\hline $\mathrm{NiCd}$ & $\sim 6.75[72]$ & $\sim 0-40$ [22] [72] & $800-1500$ [72] & $500-1500[72]$ & $\begin{array}{c}\text { Seconds-hours } \\
{[72]}\end{array}$ \\
\hline $\begin{array}{c}\text { Storage } \\
\text { Technology }\end{array}$ & Response Time & $\begin{array}{c}\text { Storage } \\
\text { Degradation } \\
\text { Rate }(\% / \text { day) }\end{array}$ & $\begin{array}{c}\text { Energy } \\
\text { Density } \\
\left(\mathrm{kWh} / \mathrm{m}^{3}\right)\end{array}$ & $\begin{array}{l}\text { Power Density } \\
\quad\left(k W / m^{3}\right)\end{array}$ & $\begin{array}{c}\text { Specific } \\
\text { Energy } \\
\text { (Wh/kg) }\end{array}$ \\
\hline Lithium-ion & $\begin{array}{l}\text { Milliseconds, } \\
<1 / 4 \text { cycle [72] }\end{array}$ & $0.1-0.3 \%[72]$ & $200-500[72]$ & $30-300[78]$ & $75-200[72]$ \\
\hline$N a S$ & $\begin{array}{l}\text { Milliseconds, } \\
<1 / 4 \text { cycle [22] }\end{array}$ & Almost zero [72] & $150-250[72]$ & $140-180[72]$ & $150-240[72]$ \\
\hline Lead-Acid & $\begin{array}{l}\text { Milliseconds, } \\
<1 / 4 \text { cycle [22] }\end{array}$ & $0.1-0.3 \%[72]$ & $50-80[72]$ & $10-400[72]$ & $30-50[72]$ \\
\hline $\mathrm{NiCd}$ & $\begin{array}{l}\text { Milliseconds, } \\
<1 / 4 \text { cycle [22] }\end{array}$ & $0.2-0.6 \%[72]$ & $60-150[72]$ & $80-600[72]$ & $50-75[72]$ \\
\hline $\begin{array}{c}\text { Storage } \\
\text { Technology }\end{array}$ & $\begin{array}{c}\text { Specific Power } \\
(\mathrm{W} / \mathrm{kg})\end{array}$ & $\begin{array}{l}\text { Round-trip } \\
\text { Efficiency }\end{array}$ & $\begin{array}{c}\text { Cycle Life } \\
\text { (cycles) }\end{array}$ & $\begin{array}{c}\text { Technology } \\
\text { Lifetime } \\
\text { (years) }\end{array}$ & $\begin{array}{l}\text { O\&M Costs } \\
\text { (\$/kW/year) }\end{array}$ \\
\hline Lithium-ion & $750-1250$ [92] & $75-90 \%$ [72] & $\begin{array}{c}\sim 3000 \text { at } 80 \% \\
\text { depth-of- } \\
\text { discharge }[72]\end{array}$ & $5-15$ [22] [72] & 10 [93] \\
\hline $\mathrm{NaS}$ & $150-230[72]$ & $\begin{array}{c}75-90 \%[22] \\
{[72]}\end{array}$ & $\begin{array}{c}2500-4500[22] \\
{[72]}\end{array}$ & $10-15$ [22] [72] & 80 [72] \\
\hline Lead-Acid & $75-300[72]$ & $70-80 \%$ [72] & $\begin{array}{c}500-1000[22] \\
{[72]}\end{array}$ & $5-15[22][72]$ & $50[72]$ \\
\hline $\mathrm{NiCd}$ & $150-300[72]$ & $60-70 \%[72]$ & $\begin{array}{c}2000-2500[22] \\
{[72]}\end{array}$ & $10-20$ [22] [72] & 20 [72] \\
\hline $\begin{array}{c}\text { Storage } \\
\text { Technology }\end{array}$ & \multicolumn{5}{|c|}{ Technology Readiness Level } \\
\hline Lithium-ion & \multicolumn{3}{|c|}{$7[21]$} & \multicolumn{2}{|l|}{--} \\
\hline$N a S$ & \multicolumn{3}{|c|}{$8[21]$} & \multicolumn{2}{|l|}{--} \\
\hline Lead-Acid & \multicolumn{3}{|c|}{$9[73]$} & \multicolumn{2}{|l|}{--} \\
\hline $\mathrm{NiCd}$ & \multicolumn{3}{|c|}{7 [72] } & \multicolumn{2}{|l|}{--} \\
\hline
\end{tabular}

\subsubsection{Environmental Impact}

Since lithium-ion batteries are considered to be the primary contender for use in electric vehicles, further development of this technology could lead to a significant reduction in greenhouse gas emissions through the use of efficient electric vehicles. Although $\mathrm{CO}_{2}$ emissions are still produced during the manufacturing process for lithium-ion batteries, only $70 \mathrm{~kg}$ of $\mathrm{CO}_{2}$ are produced per $\mathrm{KWh}$ of storage capacity. Therefore, after about 120 charges, fewer emissions will have been produced when compared to a conventional fossil fuel vehicle. However, there are other environmental issues that must also be 
considered with lithium-ion batteries. For instance, the electrolyte most often used in the construction of lithium-ion batteries, a $\mathrm{LiFP}_{6}$ organic carbonate solution, is a highly flammable and highly toxic substance [70]. Additionally, as the demand for lithium-ion batteries rises, the environmental impacts associated with mining lithium will also become more significant. Lithium is found in the brine of salt flats and reserves of this valuable material are highly concentrated in a few South American countries, specifically Bolivia and Chile. The extraction process for lithium carbonate can have a severe impact on the surrounding water supply and the chemicals used to process the raw materials into lithium can lead to localized soil, water, and air pollution. The impoverished and arid communities in which lithium is being mined struggle to cope with these byproducts of lithium extraction and several conflicts have already arisen as a result [81]. Integrating lithium-ion battery energy storage with 800 million vehicles worldwide would correspond to a $30 \%$ reduction in the world's lithium reserves, which could in turn increase costs. However, at current production rates for lithium-ion batteries, there are still 150 years of remaining viable lithium reserves [22]. The environmental impacts of lithium-ion batteries are summarized alongside other conventional battery systems in Table 11.

Table 10. Environmental impacts of conventional battery systems.

\begin{tabular}{|c|c|c|c|c|}
\hline Environmental Impact & Lithium-ion & NaS & Lead-Acid & NiCd \\
\hline Land and Water Impact & Insignificant & Insignificant & Insignificant & Insignificant \\
\hline $\begin{array}{c}\text { Emissions Produced During } \\
\text { Operation }\end{array}$ & None & None & None & None \\
\hline Hazardous Materials & Yes & Yes, recyclable & $\begin{array}{c}\text { Yes, } \\
\text { recyclable }\end{array}$ & Yes \\
\hline Hazardous Fumes & None & None & Yes & None \\
\hline Short-Term Safety Concerns & Several & Some & Several & None \\
\hline Resource Depletion & $\begin{array}{c}\text { Somewhat } \\
\text { significant }\end{array}$ & $\begin{array}{c}\text { Somewhat } \\
\text { significant }\end{array}$ & $\begin{array}{c}\text { Very } \\
\text { significant }\end{array}$ & $\begin{array}{c}\text { Very } \\
\text { significant }\end{array}$ \\
\hline Geographic Requirements & None & None & None & None \\
\hline
\end{tabular}

\subsubsection{Policy and Market Conditions}

In the pasts several years, lithium-ion batteries have identified and claimed a sizeable market opportunity by producing batteries for portable electronics. The demand for these batteries has grown since they were first commercialized by Sony in 1991 [22]. Furthermore, lithium-ion batteries have been identified as ideal for integration with hybrid and full electric vehicles, which could represent an even larger future market opportunity. Finally, lithium-ion batteries have been investigated for use with utilityscale applications and a trial project was recently deployed in the United Kingdom to assess the economic viability of battery energy storage as a part of the U.K.'s Carbon Plan. The companies involved with this project claim that the facility could save up to $\$ 9$ million by avoiding the necessary traditional system upgrades and the ability to assist with the integration of renewable energy sources [72]. In the U.S., a demonstration project in Southern California was recently deployed that received over \$6 million in funding from the California Energy Commission's Public Interest Energy Research (PIER) program. Additionally, the Sacramento Municipal Utilities District (SMUD) received funding from the federal government through the ARRA for the installation of several lithium-ion battery systems to assist with integrating renewable energy and improve system reliability [70]. In fact, many policies and regulations have been passed concerning lithium-ion batteries recently due to their compatibility with electric vehicles and residential solar panel installations. First, there are not only numerous safety standards and protocols that apply to the construction of lithium-ion batteries, but also many electrical, building and fire codes relating to the installation of these energy storage systems [82]. ARRA has also contributed significant financial support to the development of a supply chain for lithium-ion batteries that are 
equipped for use with electric vehicles. In fact, the DOE has offered almost $\$ 25$ billion in low-interest loans to these battery companies and approximately $\$ 2.4$ billion of funding to battery manufacturers. Finally, the ARRA has funded significant research and development into electric vehicles, which could lead to economies of scale forming around the production of lithium-ion batteries [83].

\subsubsection{Compatible Applications}

Lithium-ion batteries have superior power and energy density characteristics, making this technology flexible and useful in many lucrative applications. Grid-scale systems are currently under development to provide frequency regulation, reserves, and other grid stabilization services [22]. However, lithium-ion batteries are best suited for applications that require less than 4 hours of storage. As with most electrochemical energy storage technologies, the system size required to store energy for longer periods of time makes large-scale energy storage applications more difficult. This technology can also be used by an electricity consumer to provide support for several of the energy management strategies described in this report [21]. A few of the compatible applications for lithium-ion batteries are listed in Table 12.

Table 11. Environmental impacts of conventional battery systems.

\begin{tabular}{|c|c|c|c|c|}
\hline Environmental Impact & Lithium-ion & NaS & Lead-Acid & NiCd \\
\hline $\begin{array}{c}\text { Land and Water Impact } \\
\text { Operation }\end{array}$ & Insignificant & Insignificant & Insignificant & Insignificant \\
\hline Hazardous Materials & None & None & None & None \\
\hline Hazardous Fumes & None & Yes, recyclable & $\begin{array}{c}\text { Yes, } \\
\text { recyclable }\end{array}$ & Yes \\
\hline Short-Term Safety Concerns & Several & Some & Yes & None \\
\hline Resource Depletion & $\begin{array}{c}\text { Somewhat } \\
\text { significant }\end{array}$ & $\begin{array}{c}\text { Somewhat } \\
\text { significant }\end{array}$ & $\begin{array}{c}\text { Very } \\
\text { significant }\end{array}$ & $\begin{array}{c}\text { Very } \\
\text { significant }\end{array}$ \\
\hline Geographic Requirements & None & None & None & None \\
\hline
\end{tabular}

\subsubsection{Technology Maturity}

Lithium-ion batteries are already prevalent in the consumer sector, but have experienced minimal adoption for grid-scale applications. However, a few companies have installed systems for use in utilityscale energy markets. In the New York ISO, the U.S. company, AES Energy Storage, has installed systems for both frequency regulation and variable supply resource integration [72]. However, these systems are largely still under development. According to the DOE/EPRI Electricity Storage Handbook, full-scale systems have been demonstrated under a range of operating conditions, which would correspond to a TRL of 7, as shown in Table 9. As economies of scale develop to facilitate the production of lithium-ion batteries for use in electric vehicles, it is expected that their development status will quickly progress to commercialization for grid-scale services [21].

\subsubsection{Future Development}

Research and development efforts concerning lithium-ion battery systems are currently focused on developing more advanced materials for use in the battery's components. Researchers are seeking to increase the power capabilities and specific energy of the battery by integrating nanomaterials into electrode and electrolyte designs [72]. Furthermore, researchers are exploring alternative threedimensional architectures to make the technology even more compact. Researchers are also attempting to minimize safety concerns by developing a safer and more reliable electrolyte solution. In addition to these design innovations, developers have begun to consider how battery systems no longer operating at the 
rated performance standards for use in an electric vehicle can be re-used for other applications, thereby prolonging the lifetime of the battery and reducing the cost to the consumer [70].

\subsubsection{Sodium-Sulfur}

\subsubsection{Technology Overview}

Proponents of sodium-sulfur $(\mathrm{NaS})$ battery systems claim that this technology is the most economically feasible battery storage option available, though in many ways $\mathrm{NaS}$ battery systems are similar to other battery systems. This technology's defining characteristic is its long discharge period, which exceeds 6 hours. NaS batteries require careful maintenance due to their extreme operating conditions. In a NaS battery, molten sodium and sulfur act as the battery's two electrodes, with betaalumina acting as the solid electrolyte. Sodium ions layered in aluminum oxide carry charge across the electrolyte. Therefore, the operating temperature of the battery must be kept between 300 and $350^{\circ} \mathrm{C}$. Furthermore, the sodium must be prevented from coming into contact with water and combusting. The high operating temperatures coupled with the high reactivity of the component elements used in $\mathrm{NaS}$ batteries have led to strict safety measures concerning this energy storage technology [21]. Despite the safety challenges, $\mathrm{NaS}$ batteries offer superior energy densities and show promise for use in applications that require short and powerful bursts of energy [72]. A NaS battery is diagrammed below in Figure 21.

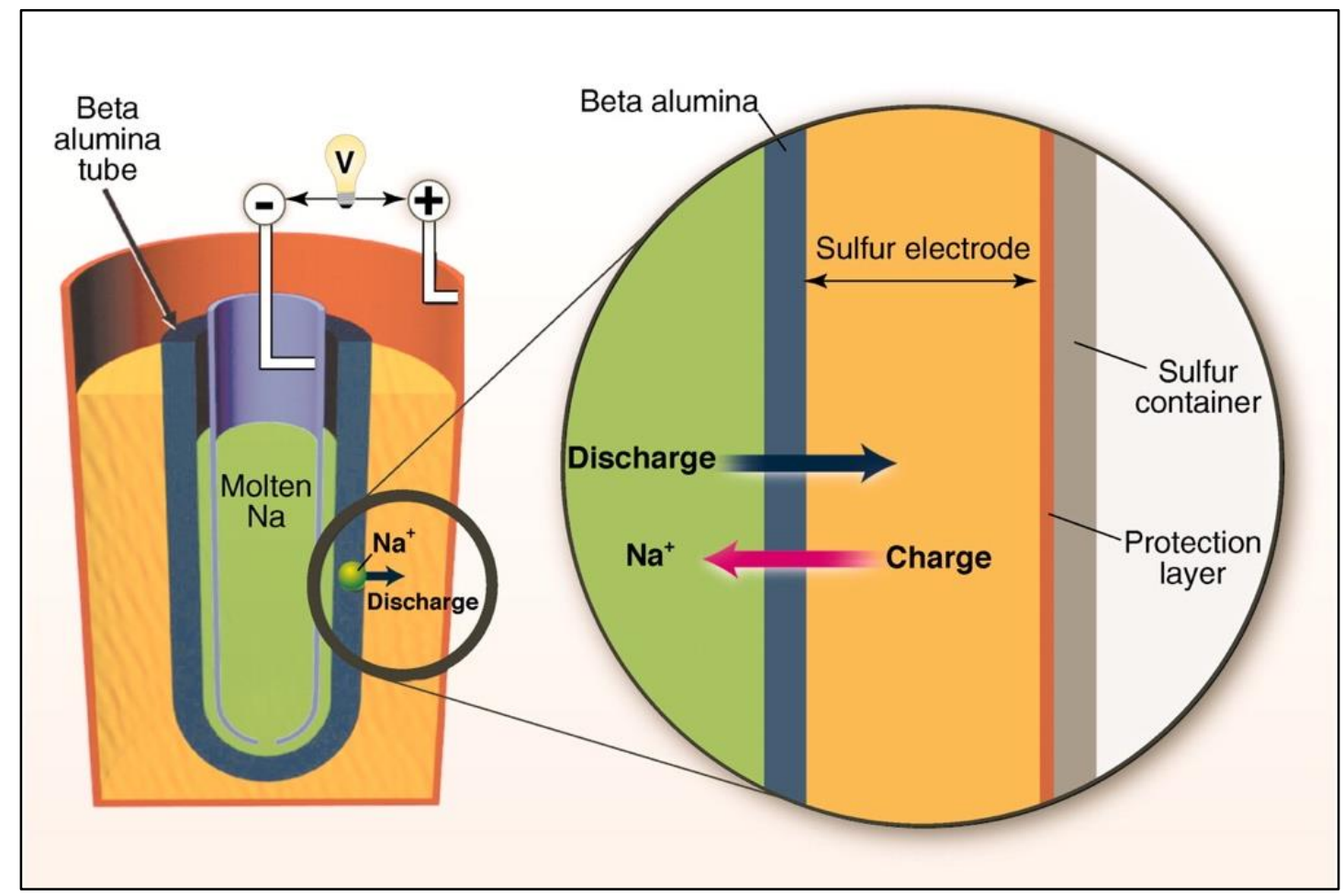

Figure 21. Representative diagram of a sodium-sulfur battery [84].

\subsubsection{Performance Parameters}

In addition to the relatively high energy densities of $\mathrm{NaS}$ battery systems, this storage technology boasts a long storage duration, higher rated energy storage capacities than other batteries, high pulse power capacity, as well as a high cycle life and efficiency. A high pulse power capacity indicates that a technology is capable of providing quick bursts of high power, which is advantageous for many grid-scale applications. Thus, these batteries are well-suited for variable renewable energy source integration as well as other marketable applications. However, the materials used in these batteries and the safety concerns 
with the high operating temperatures can drive up operating and maintenance costs [70] [72]. The performance parameters for a typical NaS battery system are listed in Table 9.

\subsubsection{Environmental Impact}

Compared to other battery storage technologies, $\mathrm{NaS}$ batteries have a relatively small impact on the environment. Since the batteries must be tightly sealed to prevent the enclosed sodium from reacting, these batteries produce no emissions or hazardous fumes during operation. Furthermore, $99 \%$ of the technology's total weight can be recycled and only sodium must be handled as a hazardous material. Although sodium is a limited resource with dwindling reserves, at current consumption rates the worldwide supply of sodium will last another 150 years, leaving enough time for the costs of $\mathrm{NaS}$ batteries to fall sufficiently to encourage widespread commercialization. Thus, the depletion of rare-earth metal reserves to build $\mathrm{NaS}$ batteries is not a significant concern [22]. The environmental impacts of NaS batteries are summarized in Table 11.

\subsubsection{Policy and Market Conditions}

$\mathrm{NaS}$ batteries have emerged as a particularly attractive option for mitigating the variability of renewable energy sources due to their long cycle lives, high power density, and high efficiency. As a result, installations of these battery systems have grown significantly over the past decade. Furthermore, due to their long storage duration, NaS batteries are gaining popularity as a smaller and less expensive option to provide load following services and might soon become more economical than PSH and CAES facilities. Regarding policy, the Southern California Edison Company recently announced a planned NaS battery storage system to increase system reliability and meet the CPUC's policy goals established in SB 17 and Smart Grid OIR, which are intended to facilitate the integration of smart grid technologies such as energy storage [70]. Additionally, the DOE has collaborated on projects in Korea concerning NaS battery development and the Advanced Research Projects Agency - Energy office has funded several NaS battery projects as a part of its open solicitations in 2009 and 2012 [19]. However, NaS battery deployment faces regulatory barriers as well. Ownership regulations in several ISOs across the U.S. have obstructed NaS and other battery storage system owners from monetizing all of the benefits provided by the energy storage system. Specifically, market services such as energy arbitrage and ancillary services, which have been deregulated, and grid services such as transmission upgrade deferral and reliability enhancement, which are still regulated, cannot both be offered by the same NaS battery installation. This separation is caused by FERC regulations that relegate transmission and generation assets to distinct markets and do not allow the two to mix. This regulatory barrier has led to delayed or failed NaS battery storage projects in both Texas and California electricity markets [85].

\subsubsection{Compatible Applications}

$\mathrm{NaS}$ battery systems are particularly well-suited for several energy storage applications. First, since this technology has a long storage duration compared to other batteries, NaS batteries can offer load following services. NaS batteries have approximately 7 hours of storage at rated capacity, enabling the technology to follow large-scale magnitude swings in electricity demand throughout the day. Also, since $\mathrm{NaS}$ batteries have a favorable energy to power density ratio, they can offer reserves to fill gaps in supply when the actual generation from variable generating resources does not match the forecasted amount [22]. Although this technology provides some of the most favorable characteristics for variable renewable energy source integration, current installations primarily operate as support for utilities by supplying peak shifting and voltage support services. A few of the applications compatible with NaS batteries are listed in Table 12 . 


\subsubsection{Technology Maturity}

NaS battery installations world-wide have grown exponentially in recent years [22]. The DOE Global Energy Storage Database has catalogued $34 \mathrm{NaS}$ battery installations worldwide with a total capacity of nearly 200 MW [26]. NGK Insulators Inc. in Japan has installed a 34 MW and 245 MWh energy storage system in northern Japan for use with a large wind farm using $\mathrm{NaS}$ batteries. This is the largest energy storage system in the world besides PSH and CAES plants [22]. The rapid growth of this technology is largely in response to the growth of variable renewable energy resources, particularly wind power. NaS batteries offer a cost-effective energy management solution to variable electricity generating units. General Electric has recently entered the market for NaS batteries, seeking a reserve power supply for data centers, hospitals, and wireless communication towers. In addition, innovation will continue to flourish as the increased competition in electricity markets encourages improved performance parameters, reduced costs, and continued widespread commercialization of NaS battery systems [72]. Thus, this technology was given a TRL of 8 since it is in the process of establishing itself in electricity markets, as shown in Table 9.

\subsubsection{Future Development}

$\mathrm{NaS}$ batteries are currently limited by their high annual operating costs and complex thermal management systems. A majority of the research and development on this technology focuses on eliminating the temperature constraints that affect NaS batteries [72]. Thus, sodium-nickel-chloride batteries that offer similar technical characteristics, but can operate at temperatures between -40 and $70^{\circ} \mathrm{C}$ have recently been developed [22]. Researchers have also postulated that optimizing the battery's shape could improve the efficiency of the battery, as well as reduce costs and lower the required operating temperature [70]. If these challenges can be overcome, NaS battery systems could be the most economical and technically viable energy storage technology for responding to the increased variability in electricity markets introduced by renewable energy sources [22].

\subsubsection{Lead-Acid}

\subsubsection{Technology Overview}

Lead-acid batteries are the oldest form of rechargeable battery storage available. This storage technology was first developed in the mid-1800s and has been widely used to power engine starters in consumer vehicles since its invention. In a lead-acid battery, the cathode is made of lead-dioxide and the anode is made of metallic lead. The two electrodes are separated by an electrolyte of sulfuric acid. As the battery charges, the sulfuric acid reacts with the lead in the anode and cathode to produce lead sulfate. A reverse process occurs when the battery is discharging. The production and decomposition of this chemical produces short and powerful bursts of energy, enough to start a car, boat, or plane. However, the gradual crystallization and build-up of lead sulfate in the battery's core severely reduces the cycle life of these batteries. Therefore, they are not an ideal technology for several energy management services [21] [22] [70] [72]. Furthermore, due to their low energy density, this technology has a larger footprint than other batteries [19]. A typical lead-acid battery is diagrammed below in Figure 22. 


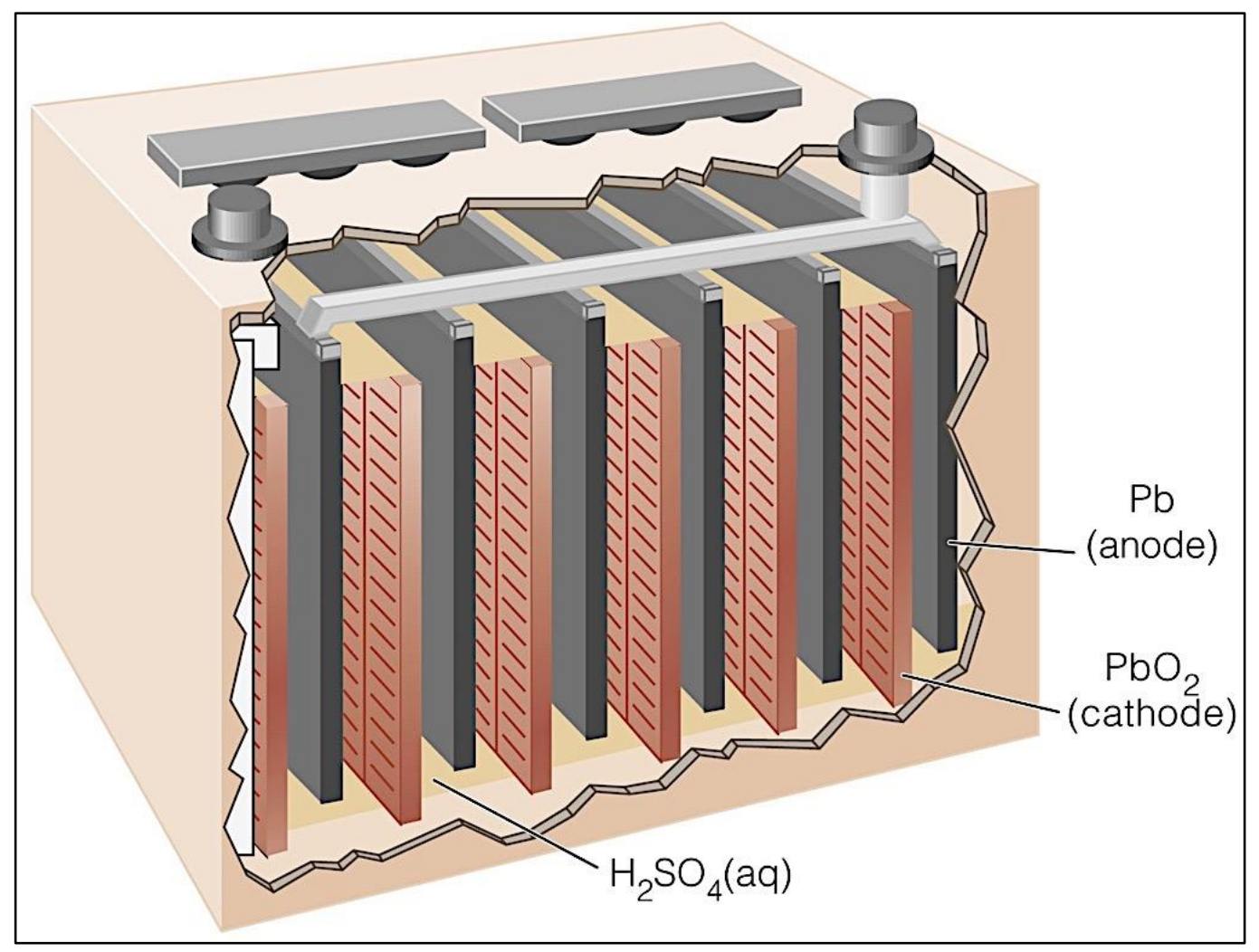

Figure 22. Representative diagram of a lead-acid battery [86].

\subsubsection{Performance Parameters}

An advantage to being the most commercially mature rechargeable battery technology in the world is that lead-acid batteries can be produced at a relatively low cost. Additionally, these batteries are highly reliable and efficient and possess strong surge capabilities. This would indicate that the technology is capable of supplying quick bursts of power when necessary. However, the characteristics of the battery's construction cause the technology to have a relatively low cycle life compared with other battery technologies. Lead-acid batteries also require thermal management systems due to their poor performance at lower temperatures. The performance parameters for a typical lead-acid battery system are displayed in Table 9 [22] [72].

\subsubsection{Environmental Impact}

Unlike some of the other battery technologies considered in this report, the emissions from lead-acid batteries do have an impact on the environment. These batteries can produce explosive gas and acid fumes during operation. However, this is a less significant problem in maintenance free valve-regulated lead-acid batteries, though these devices are not quite as effective for large-scale grid storage as conventional lead-acid batteries [70]. Lead-acid batteries must also be carefully disposed of due to the strict environmental regulations concerning the handling of lead. As a result, lead-acid batteries are one of the most recycled products in the world for use in the production of new batteries [21]. Lead-acid batteries might also face resource supply shortages in the coming years, since there are projected to be only 20 remaining years of lead reserves available in the world. While this does not mean that lead resources throughout the world will be completely depleted by that time, it does imply that mining lead will become prohibitively expensive [22]. The environmental impacts of lead-acid batteries are summarized in Table 11. 


\subsubsection{Policy and Market Conditions}

As a well-established energy storage technology, lead-acid batteries have seen periods of widespread commercialization for consumer products. However, newer battery technologies are typically better suited to take advantage of new market opportunities, such as providing grid-scale reliability services. Thus, utility-scale lead-acid battery storage system installations around the world are few in number, although lead-acid batteries are used in $75 \%$ of new solar PV installations in China. Advanced lead-acid battery systems could reclaim some of the market share from newer battery technologies, since these systems have fast response times similar to flywheels and supercapacitors and could be competitive in ancillary service markets [22] [72]. Since conventional lead-acid batteries are on their way out to make way for new battery technologies and advanced lead-acid batteries, recent policy measures pertaining to lead-acid batteries have primarily discussed the appropriate disposal process for these batteries. The Lead-Acid Battery Recycling Act was passed in California in April of 2016 to facilitate the recycling of the lead in these batteries for use in future battery production. This initiative will also help to address the problem of diminishing reserves. This bill also imposed a recycling fee of \$15-20 on every lead-acid battery sold in the state of California, which is to be contributed to the Lead-Acid Battery Cleanup Fund. Similar recycling laws have been passed in New York and many other states [87].

\subsubsection{Compatible Applications}

Although the poor cycle lives associated with lead-acid batteries limit the energy management services that can be provided by this battery technology, lead-acid batteries are still well-suited to providing spinning reserves and other back-up power supply applications. Despite their shortcomings, these technologies have been one of the leading energy storage options for these applications over the years due to their technical maturity and proven effectiveness. However, the development of new battery technologies with better cycling characteristics and lower operating and maintenance costs has led to other batteries being considered by developers [22]. Thus, although lead-acid batteries can also effectively provide frequency regulation, variable supply resource integration, and other valuable gridscale services, other battery technologies are more widely used for these applications [70]. A few of the compatible applications for lead-acid batteries are listed in Table 12.

\subsubsection{Technology Maturity}

Lead-acid batteries are the most mature rechargeable battery technology available. Additionally, many advanced lead-acid battery systems are in development to tackle the challenges currently facing lead-acid batteries. Lead-acid batteries have also been widely used in hybrid and electric vehicles worldwide, although many producers are moving towards lithium-ion batteries due to their superior energy density. Given the long history of this technology, lead-acid batteries were assigned a TRL of 9, as shown in Table 9 [22]. However, advanced lead-acid batteries are still only demonstration-scale.

\subsubsection{Future Development}

In recent years, engineers have refocused their attention on lead-acid batteries, seeking ways to extend the cycle life of the battery and reduce operating costs. Two types of lead-acid battery are currently in development, lead-acid carbon technologies and advanced lead-acid battery technologies. First, researchers have found that adding carbon to a conventional lead-acid battery seems to affect the growth rate of lead sulfate in the battery's core, which could improve the technology's cycling characteristics and increase the lifetime of the battery [70]. This improvement could help lead-acid batteries reclaim some of the market share available to storage technologies for VRES integration. Laboratory-scale prototypes of lead-acid carbon technologies are currently being developed. Other advanced lead-acid battery technologies development projects often focus on optimizing the material components of the battery to maximize performance. Some of these technologies are touted to have supercapacitor-like response times. Many of these technologies are currently in field trials [72]. 


\subsubsection{Nickel-Cadmium}

\subsubsection{Technology Overview}

Nickel-cadmium (NiCd) batteries are direct competitors with lead-acid batteries since these batteries offer similar technical characteristics, but with superior cycling abilities and energy density. In a NiCd battery, nickel oxide hydroxide is used to make the cathode and the anode is made out of metallic cadmium. An aqueous alkali solution is used as the electrolyte between the two electrodes. NiCd batteries are currently widely used for portable electronics applications, similar to lead-acid and lithium-ion batteries. However, despite the superior cycling characteristics and energy density, NiCd batteries are not necessarily an ideal solution. The batteries are constructed from highly toxic materials and suffer from the "memory effect," which requires that the battery be fully recharged after even a partial discharge [22] [70] [72]. The design of a typical NiCd battery is displayed below in Figure 23.

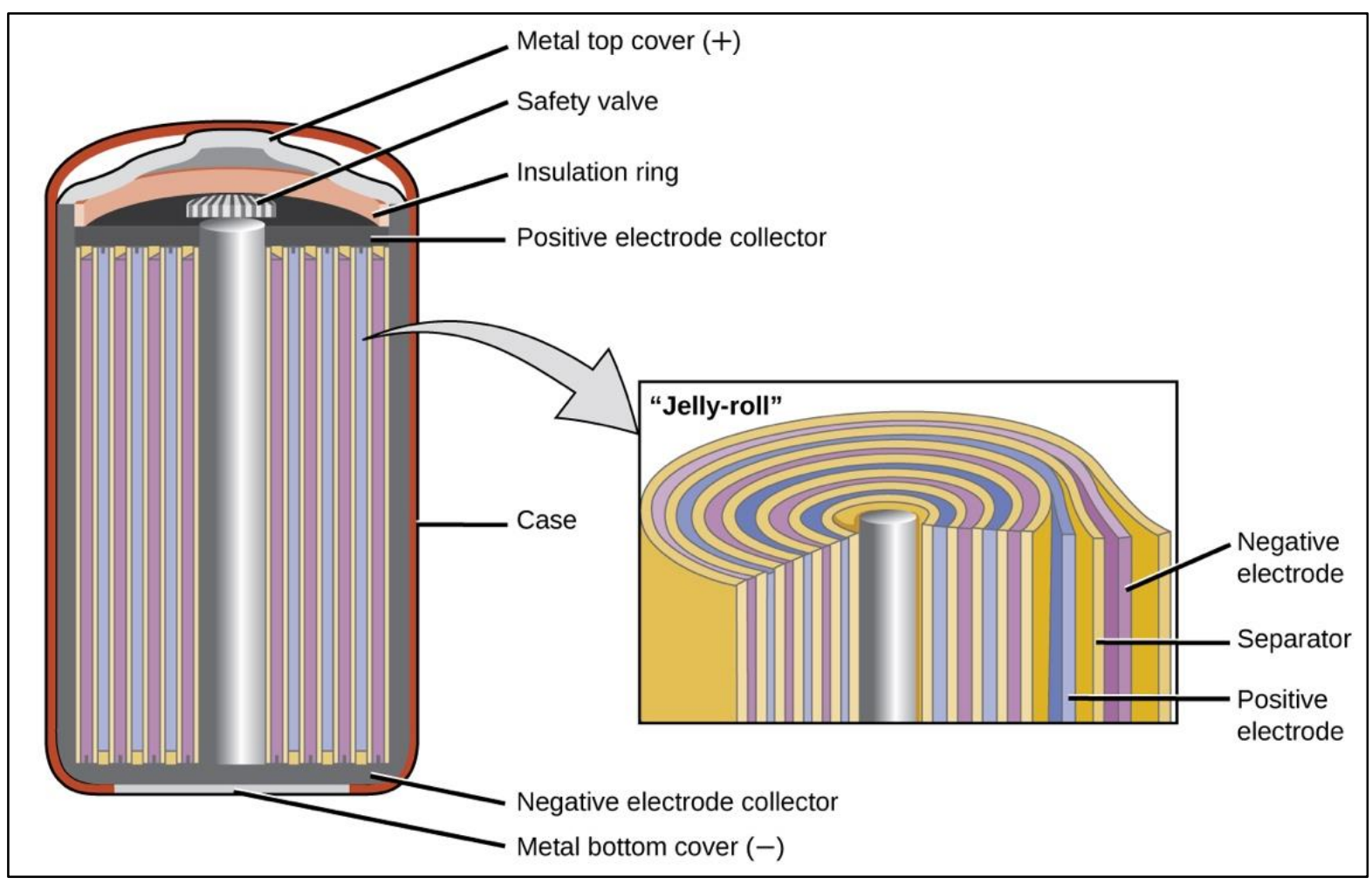

Figure 23. Representative diagram of a nickel-cadmium battery [88].

\subsubsection{Performance Parameters}

Compared to lead-acid batteries, NiCd batteries not only have higher energy densities and a longer cycle life, they also require less maintenance. Furthermore, this technology does not require a thermal management system to maintain a specific operating temperature. However, the "memory effect" mentioned earlier does severely impact the battery's performance. If the battery is not completely recharged immediately after discharging, the maximum capacity of the battery system will begin to decrease rapidly. The performance parameters for a typical NiCd battery are listed in Table 9 [22] [72]. 


\subsubsection{Environmental Impact}

One of the primary limitations facing NiCd batteries are the numerous environmental hazards associated with the materials used to construct the batteries. Cadmium and nickel are both toxic heavy metals that must be carefully handled and controlled. In 2008, the European Union effectively banned $\mathrm{NiCd}$ batteries with a legislative directive regulating the materials used in batteries and accumulators [22]. In fact, the concentration of these regulated metals in NiCd batteries is so high that used batteries are considered to be a secondary source for the metals. Cadmium is classified as a carcinogenic substance for humans, while nickel can induce lung and gastrointestinal cancer. Thus, the disposal of these materials must be carefully managed to limit the contamination to soil and water, which could result in dangerous health hazards for humans and the surrounding ecosystem [89]. Although nickel is a material commonly found in the earth's crust, less than 50 years of nickel reserves remain at current extraction rates. Furthermore, cadmium is being depleted at rates similar to lithium, which has resulted in several cadmium recycling programs [90]. The environmental impacts of NiCd batteries are summarized in Table 11 .

\subsubsection{Policy and Market Conditions}

Lead-acid batteries are beginning to lose market share to alternate technologies such as $\mathrm{NiCd}$ batteries. Many of the market opportunities for NiCd batteries are some of the former uses for lead-acid batteries, such as generator starting applications. However, environmental controls seem to have mitigated many of the advantages of NiCd batteries and have seriously deflated the growth of this technology. In fact, the European Union passed the Restriction of Hazardous Substances Directive in 2003 and effectively banned NiCd batteries for use in many applications. [22] In the U.S., the Universal Waste Rule (UWR), which was passed by the EPA in 1995, governs NiCd materials in a similar manner. The UWR was passed in parallel with several state regulations regulating the disposal of consumer NiCd batteries in an effort to redirect the waste materials towards recycling facilities. However, the UWR does not limit the production of NiCd batteries to the level the directive from the EU does, it simply encourages the recycling of these batteries. In 1996, the Battery Management Act was passed to solidify the UWR and coalesce the many disparate state regulations into a cohesive waste disposal policy. This policy measure established uniform labeling requirements and required easy removal of NiCd batteries from consumer products. Additionally, Congress implemented universal adoption of the UWR since some states had not yet conformed to the EPA directive [91].

\subsubsection{Compatible Applications}

Although NiCd batteries are primarily used in portable electronics, there are some grid-scale installations and compatible grid-scale services that this technology can provide. NiCd batteries can effectively provide black start capabilities and spinning reserves. However, this technology is not wellsuited for assisting with the integration of variable renewable energy sources due to the "memory effect." In fact, only one successful utility-scale storage application for NiCd batteries has been demonstrated on the market, a plant in Golden Valley, Alaska that was commissioned to offer spinning reserves and grid stabilization services [22] [72]. A few of the applications compatible with NiCd batteries are listed in Table 12 .

\subsubsection{Technology Maturity}

$\mathrm{NiCd}$ batteries are prevalent in the portable electronics market, but their application in utility-scale installations has been delayed. In fact, sales of NiCd battery systems has been in a continuous decline since 1995. This could be due to environmental concerns or the high cost of $\mathrm{NiCd}$ batteries coupled with the few profitable applications of the technology. A TRL of 7 was assigned, as shown in Table 9, because although full-scale NiCd battery systems have been installed, the limited success of these projects has prevented any further installations from receiving funding [72]. 
Table 12. Compatible applications for conventional battery systems.

\begin{tabular}{|c|c|c|c|c|}
\hline Service & Lithium-ion & NaS & Lead-Acid & NiCd \\
\hline Energy Arbitrage & $\begin{array}{c}\text { Somewhat } \\
\text { compatible }\end{array}$ & Compatible & Compatible & $\begin{array}{c}\text { Somewhat } \\
\text { compatible }\end{array}$ \\
\hline Frequency Regulation & Compatible & Compatible & Compatible & Incompatible \\
\hline Load Following & $\begin{array}{c}\text { Somewhat } \\
\text { compatible }\end{array}$ & Compatible & $\begin{array}{c}\text { Somewhat } \\
\text { compatible }\end{array}$ & Incompatible \\
\hline Voltage Support & Compatible & Compatible & Compatible & Incompatible \\
\hline $\begin{array}{c}\text { Spinning Reserves } \\
\text { Non-Spinning \& Supp. } \\
\text { Reserves }\end{array}$ & $\begin{array}{c}\text { Somewhat } \\
\text { compatible }\end{array}$ & Compatible & Compatible & Compatible \\
\hline $\begin{array}{c}\text { Incompatible } \\
\text { Black Start }\end{array}$ & $\begin{array}{c}\text { Somewhat } \\
\text { compatible }\end{array}$ & Compatible & $\begin{array}{c}\text { Somewhat } \\
\text { compatible }\end{array}$ & Incompatible \\
\hline VSR Integration & Compatible & Compatible & Compatible & Incompatible \\
\hline $\begin{array}{c}\text { Seasonal Storage } \\
\text { Process Heat } \\
\text { Applications }\end{array}$ & Incompatible & Incompatible & Incompatible & Incompatible \\
\hline
\end{tabular}

\subsubsection{Future Development}

An alternative technology to the NiCd battery with similar characteristics but fewer environmental concerns and a reduced "memory effect" is currently in development, the nickel-metal-hydride (NiMH) battery. NiMH batteries have similar chemistry to NiCd batteries, but include a hydrogen-containing alloy instead of cadmium in the battery's anode, which results in an energy storage capacity two to three times greater. However, although the energy density of NiMH batteries is $25-30 \%$ better than NiCd batteries, NiMH batteries still fall far behind lithium-ion batteries [70]. Furthermore, they suffer from severe selfdischarge rates of approximately 5-20\% per day. As a result, nickel-based batteries are not projected to play a significant role in the integration of variable renewable energy sources in electricity markets. NiMH batteries are mainly used in hybrid and electric vehicles for energy storage [72].

\subsubsection{Flow Batteries}

Flow batteries offer many distinct advantages over conventional battery systems, and have seen increased support as an energy storage technology in recent years. Flow batteries store energy in the electrolyte of the battery, rather than the electrodes, which allows a flow battery to be quickly recharged by simply replacing the electrolyte fluids in the battery system. Two types of flow batteries are considered in this report, redox flow batteries and hybrid flow batteries. The zinc-bromine flow battery is a hybrid flow battery, indicating that the battery uses one fuel cell electrode and one battery electrode. In contrast, the vanadium redox battery is a redox flow battery, so both of the battery's electrode are analogous to the electrodes of a fuel cell. Flow batteries are modular, meaning that the storage capacity of a flow battery can be increased by simply attaching another cell to the battery system. Additionally, since the electrolytes in a flow battery system can be stored apart from the battery itself in sealed tanks, the storage duration for this technology is very high. However, flow batteries can also be more complex and expensive than conventional batteries [72]. 


\subsubsection{Zinc-Bromine Flow Battery}

\subsubsection{Technology Overview}

Zinc-bromine $(\mathrm{ZnBr})$ flow batteries can be categorized as hybrid flow batteries, which means that some of the energy is stored in the electrolyte and some of the energy is stored on the anode by plating it with zinc metal during charging. In a $\mathrm{ZnBr}$ battery, two aqueous electrolytes act as the electrodes of the battery and store charge. The electrolyte solutions contain the reactive components, zinc and bromine, and as these solutions flow through the battery's cells, reversible electrochemical reactions occur and energy is either charged to the battery or discharged. When the battery is charging, elemental zinc attaches to the carbon-plastic electrodes connecting each cell in the battery to form the anode and bromine forms at the cathode. Carbon-plastic is used for the electrodes because of the highly corrosive nature of bromine. Additionally, a selective membrane is included in the battery's design to separate the electrolytes while still allowing ion transfer to maintain charge neutrality [21] [70] [72]. Flow batteries have many advantages including long lifetimes, modularity, and almost no energy loss throughout the technology's storage duration. However, the design for these battery systems can be very complex, which can lead to increased costs and difficulties in development [19] [22]. ZnBr flow batteries also feature lower efficiencies and stricter operating conditions than most other battery storage technologies [72]. A typical $\mathrm{ZnBr}$ flow battery is diagrammed in Figure 24.

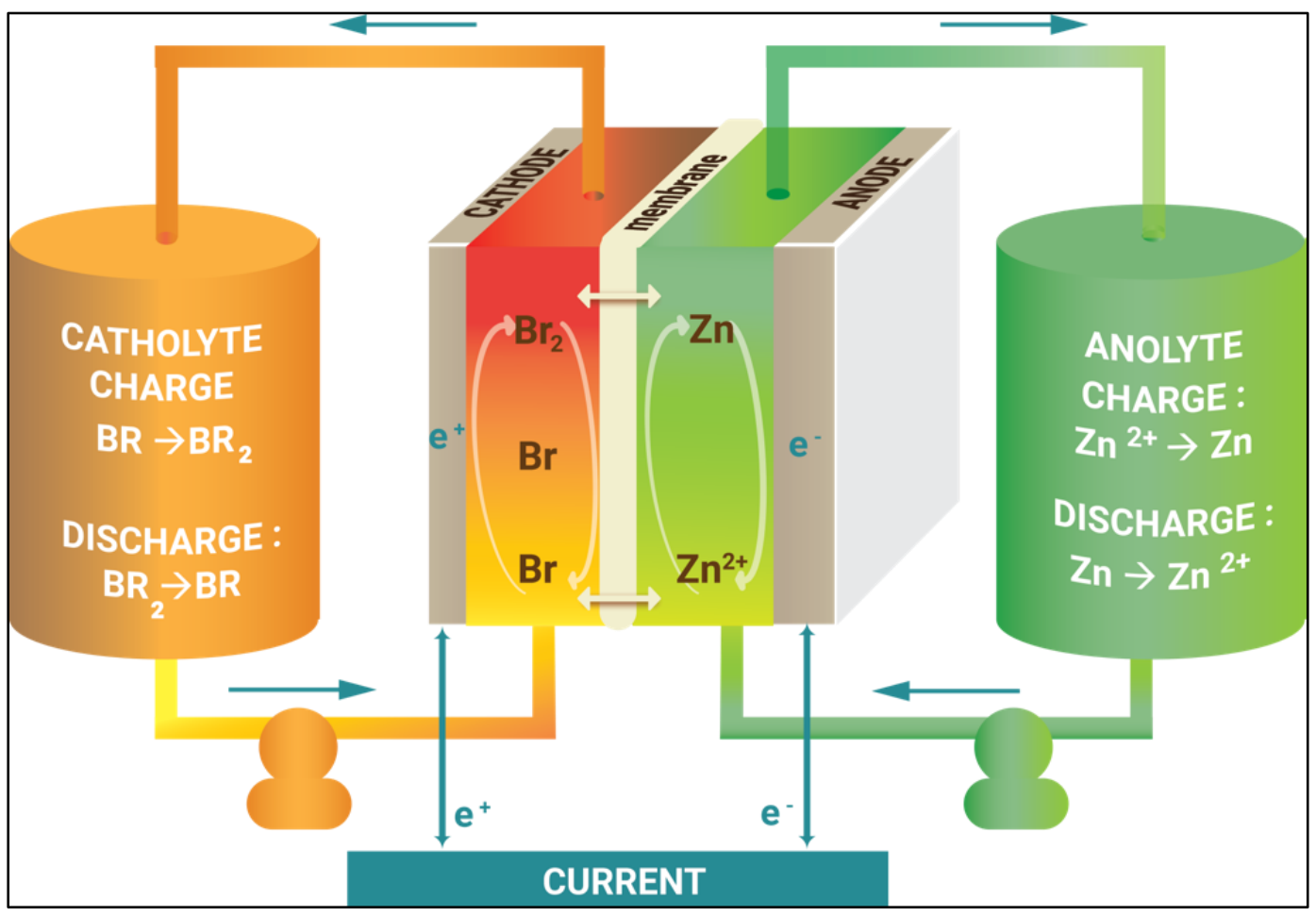

Figure 24. Representative diagram of a zinc-bromine flow battery [94].

\subsubsection{Performance Parameters}

The unique characteristics of flow batteries make them well-suited for grid-scale energy management in many ways. Flow batteries are not impacted by parameters that can be severely restricting for conventional batteries, such as the power capacity, depth-of-discharge, and self-discharge rate for the battery. Additionally, the response times for flow batteries can be sub-millisecond, enabling flow batteries to provide fast ancillary services for the integration of variable renewable energy sources. Studies have 
shown that flow batteries also offer the lowest cost of energy when providing these services. However, $\mathrm{ZnBr}$ batteries also have low round-trip efficiencies and can be susceptible to corrosion due to the use of bromine in the battery's electrolyte [22] [72]. The performance parameters for a typical $\mathrm{ZnBr}$ flow battery are listed in Table 13.

Table 13. Performance parameters for flow battery systems.

\begin{tabular}{|c|c|c|c|c|c|}
\hline $\begin{array}{c}\text { Storage } \\
\text { Technology }\end{array}$ & $\begin{array}{l}\text { Energy } \\
\text { Capacity } \\
(M W h)\end{array}$ & $\begin{array}{c}\text { Power Capacity } \\
(M W)\end{array}$ & $\begin{array}{c}\text { Energy } \\
\text { Capacity } \\
\text { Cost }(\$ / k W h)\end{array}$ & $\begin{array}{c}\text { Power } \\
\text { Capacity Cost } \\
(\$ / k W)\end{array}$ & $\begin{array}{c}\text { Discharge } \\
\text { Time }\end{array}$ \\
\hline $\mathrm{ZnBr}$ & $\sim 250[73]$ & $\sim 50$ [73] & $\begin{array}{c}150-1000 \\
{[72]}\end{array}$ & $700-2500[72]$ & $\begin{array}{l}\text { Seconds- } \\
\sim 10 \mathrm{hr}[72]\end{array}$ \\
\hline$V R B$ & $\sim 250[73]$ & $\sim 50[73]$ & $\begin{array}{c}150-1000 \\
{[72]}\end{array}$ & $600-1500[72]$ & $\begin{array}{c}\text { Seconds- } \\
24+\mathrm{hr} \text { [72] }\end{array}$ \\
\hline $\begin{array}{c}\text { Storage } \\
\text { Technology }\end{array}$ & Response Time & $\begin{array}{c}\text { Storage } \\
\text { Degradation Rate } \\
\text { (\%/day) }\end{array}$ & $\begin{array}{c}\text { Energy } \\
\text { Density } \\
\left(\mathrm{kWh} / \mathrm{m}^{3}\right)\end{array}$ & $\begin{array}{c}\text { Power Density } \\
\quad\left(\mathrm{kW} / \mathrm{m}^{3}\right)\end{array}$ & $\begin{array}{l}\text { Specific } \\
\text { Energy } \\
\text { (Wh/kg) }\end{array}$ \\
\hline $\mathrm{ZnBr}$ & $\begin{array}{l}\text { Milliseconds, } \\
<1 / 4 \text { cycle [22] }\end{array}$ & $\begin{array}{c}\text { Small, almost zero } \\
\text { when electrolyte } \\
\text { stored separately } \\
{[72]}\end{array}$ & $30-60[72]$ & $<25[72]$ & $30-50[72]$ \\
\hline$V R B$ & $\begin{array}{l}\text { Milliseconds, } \\
<1 / 4 \text { cycle }[22]\end{array}$ & $\begin{array}{c}\text { Small, almost zero } \\
\text { when electrolyte } \\
\text { stored separately } \\
{[72]}\end{array}$ & $25-35[72]$ & $<2[72]$ & $10-30[72]$ \\
\hline $\begin{array}{c}\text { Storage } \\
\text { Technology }\end{array}$ & $\begin{array}{c}\text { Specific Power } \\
(W / k g)\end{array}$ & $\begin{array}{l}\text { Round-trip } \\
\text { Efficiency }\end{array}$ & $\begin{array}{l}\text { Cycle Life } \\
\text { (cycles) }\end{array}$ & $\begin{array}{c}\text { Technology } \\
\text { Lifetime } \\
\text { (years) }\end{array}$ & $\begin{array}{l}\text { O\&M Costs } \\
\text { (\$/kW/year) }\end{array}$ \\
\hline $\mathrm{ZnBr}$ & $\sim 100[72]$ & $65-75 \%[72]$ & $\begin{array}{c}2000+[22] \\
{[72]}\end{array}$ & $5-10[22][72]$ & -- \\
\hline$V R B$ & $\sim 166[72]$ & $65-75 \%[72]$ & $\begin{array}{c}12,000+[22] \\
{[72]}\end{array}$ & $5-10[22][72]$ & $70[72]$ \\
\hline $\begin{array}{c}\text { Storage } \\
\text { Technology }\end{array}$ & \multicolumn{5}{|c|}{ Technology Readiness Level } \\
\hline $\mathrm{ZnBr}$ & \multicolumn{3}{|c|}{$6[21]$} & \multicolumn{2}{|l|}{--} \\
\hline$V R B$ & \multicolumn{2}{|r|}{$7[21]$} & & -- & \\
\hline
\end{tabular}

\subsubsection{Environmental Impact}

One potential environmental concern associated with $\mathrm{ZnBr}$ battery systems arises from the use of bromine in the battery's composition. This chemical tends to attack any material it comes into contact with and has been known to cause damaged seals, collector corrosion, and warped electrodes. Furthermore, bromine is an environmental contaminant and must be recycled or properly disposed of after use. Zinc is also considered a restricted, transition-metal contaminant in some countries. However, $\mathrm{ZnBr}$ battery systems pose little threat to the environment during operation [21]. In addition, zinc reserves are scarce and are only expected to last another 35-45 years at current rates of consumption [22]. Thus, the rate of resource depletion caused by the production of $\mathrm{ZnBr}$ flow batteries contributes to the environmental impact of this energy storage technology. The environmental impacts of $\mathrm{ZnBr}$ batteries are summarized in Table 14 along with vanadium redox batteries. 
Table 14. Environmental impacts of flow battery systems.

\begin{tabular}{|c|c|c|}
\hline Environmental Impact & $\mathbf{Z n B r}$ & $\boldsymbol{V R \boldsymbol { B }}$ \\
\hline Land and Water Impact & Insignificant & Insignificant \\
\hline Emissions Produced During Operation & None & None \\
\hline Hazardous Materials & Yes, recyclable & Yes, recyclable \\
\hline Hazardous Fumes & None & None \\
\hline Short-Term Safety Concerns & Minimal & None \\
\hline Resource Depletion & Very significant & Somewhat significant \\
\hline Geographic Requirements & None & None \\
\hline
\end{tabular}

\subsubsection{Policy and Market Conditions}

Studies have shown that flow battery systems deliver the lowest cost per unit of stored energy when responding to low levels of wind penetration on the grid compared to other energy storage technologies. Therefore, the changing grid and evolving electricity markets in the U.S. present a considerable market opportunity for $\mathrm{ZnBr}$ flow batteries. In the U.S., electric utilities have begun conducting demonstration trials for this technology to test its ability to assist with system reliability. For example, the SMUD has planned to build a $1 \mathrm{MW}$ demonstration facility [72]. $\mathrm{ZnBr}$ flow batteries have also been the recipients of substantial policy support. The California Energy Commission's PIER program has funded a $25 \mathrm{MW}$ and $75 \mathrm{MWh} \mathrm{ZnBr}$ battery storage facility to provide grid-scale ancillary services and assist with the integration of renewable energy sources. The SMUD also received funding through the ARRA for the installation of two $\mathrm{ZnBr}$ flow battery systems in their jurisdiction [70]. In fact, the Lawrence Berkeley National Laboratory recently began a research project focusing on the development of flow batteries for grid-scale energy storage, demonstrating the DOE's interest in the commercialization of this technology [72]. However, $\mathrm{ZnBr}$ flow batteries are likely to face many regulatory barriers when they reach more widespread commercialization. In Australia, where the development of $\mathrm{ZnBr}$ batteries has been well funded, concerns regarding the connection of unproven storage technologies to the grid and the proliferation of bromine chemicals have acted as barriers to the further deployment of this technology [95]. Concerns surrounding $\mathrm{ZnBr}$ batteries in the U.S. could likely have a similar effect.

\subsubsection{Compatible Applications}

Due to their almost negligible self-discharge rate, $\mathrm{ZnBr}$ batteries are capable of seasonal storage on a scale similar to CAES and PSH plants. Flow batteries are also well-suited for providing the grid stabilization services necessary for the integration of variable renewable energy sources. $\mathrm{ZnBr}$ batteries can also effectively provide energy arbitrage with a profitable price of 41-45 cents per kilowatt-hour according to a study that compared a number of other storage technologies with flow batteries and found flow batteries to be the least costly form of energy storage [22]. Several compatible applications for $\mathrm{ZnBr}$ flow battery systems are listed in Table 15 .

\subsubsection{Technology Maturity}

While $\mathrm{ZnBr}$ flow batteries have been proven as compatible with small-scale applications and medium-scale applications over the past couple of decades, large-scale systems are still being tested. Several field demonstration installations have been commissioned in the last few years, including a $1 \mathrm{MW}$ installation for multiple energy management applications that was built in Sacramento as a field trial for the technology [72]. Field experience is not expansive enough for widespread commercialization yet though. Therefore, the technology was given a TRL of 6 , as shown in Table 13. 
Table 15. Compatible applications for flow battery systems.

\begin{tabular}{|c|c|c|}
\hline Service & $\boldsymbol{Z n B r}$ & $\boldsymbol{V R B}$ \\
\hline Energy Arbitrage & Somewhat compatible & Somewhat compatible \\
\hline Frequency Regulation & Compatible & Compatible \\
\hline Load Following & Compatible & Compatible \\
\hline Voltage Support & Compatible & Compatible \\
\hline Spinning Reserves & Compatible & Compatible \\
\hline Non-Spinning \& Supp. Reserves & Compatible & Compatible \\
\hline Black Start & Compatible & Compatible \\
\hline VSR Integration & Compatible & Compatible \\
\hline Seasonal Storage & Somewhat compatible & Somewhat compatible \\
\hline Process Heat Applications & Incompatible & Incompatible \\
\hline
\end{tabular}

\subsubsection{Future Development}

$\mathrm{ZnBr}$ batteries themselves are under development, so there are few advanced versions of the technology. However, despite limited experience with the technology, vendors are observing long lifetimes and cycle lives in the demonstration phase. Extensive research and development are being devoted to this technology since it has the necessary technical characteristics to be a reliable and effective grid stabilization solution. Lawrence Berkeley National Laboratory recently began a study concerning flow batteries called "flow batteries for grid-scale energy storage" focusing on discovering more about this new technology and other flow battery systems [21] [72].

\subsubsection{Vanadium Redox}

\subsubsection{Technology Overview}

In contrast to $\mathrm{ZnBr}$ flow batteries, vanadium redox batteries (VRBs) only store energy within the electrolyte of the battery. VRBs are the most mature type of flow battery available today. They were first developed in the 1980s and now constitute over $20 \mathrm{MWh}$ of installed storage capacity worldwide. VRBs are primarily used for small and medium scale applications, but their utility in responding to variable generation from renewable energy resources has already been demonstrated. VRBs store energy with vanadium redox couples that are kept in two separate electrolyte tanks. As the electrolyte flows through the battery during charging, vanadium ions accept electrons at the anode and deposit electrons at the cathode. The reactions run in the reverse direction when the battery is discharging. As with $\mathrm{ZnBr}$ flow batteries, a proton exchange membrane must be used to allow charge to flow while the electrolyte solutions are kept separate. A significant advantage of VRB systems is that the two electrolyte solutions are chemically identical, which makes the operation of the battery much simpler and less expensive [21] [22] [70] [72]. However, VRBs still face some technical challenges, including low electrolyte stability and solubility which can lead to decreased energy densities. Additionally, the operating costs for VRBs are still too high for the technology to be particularly profitable [72]. A typical VRB system is diagrammed below in Figure 25. 


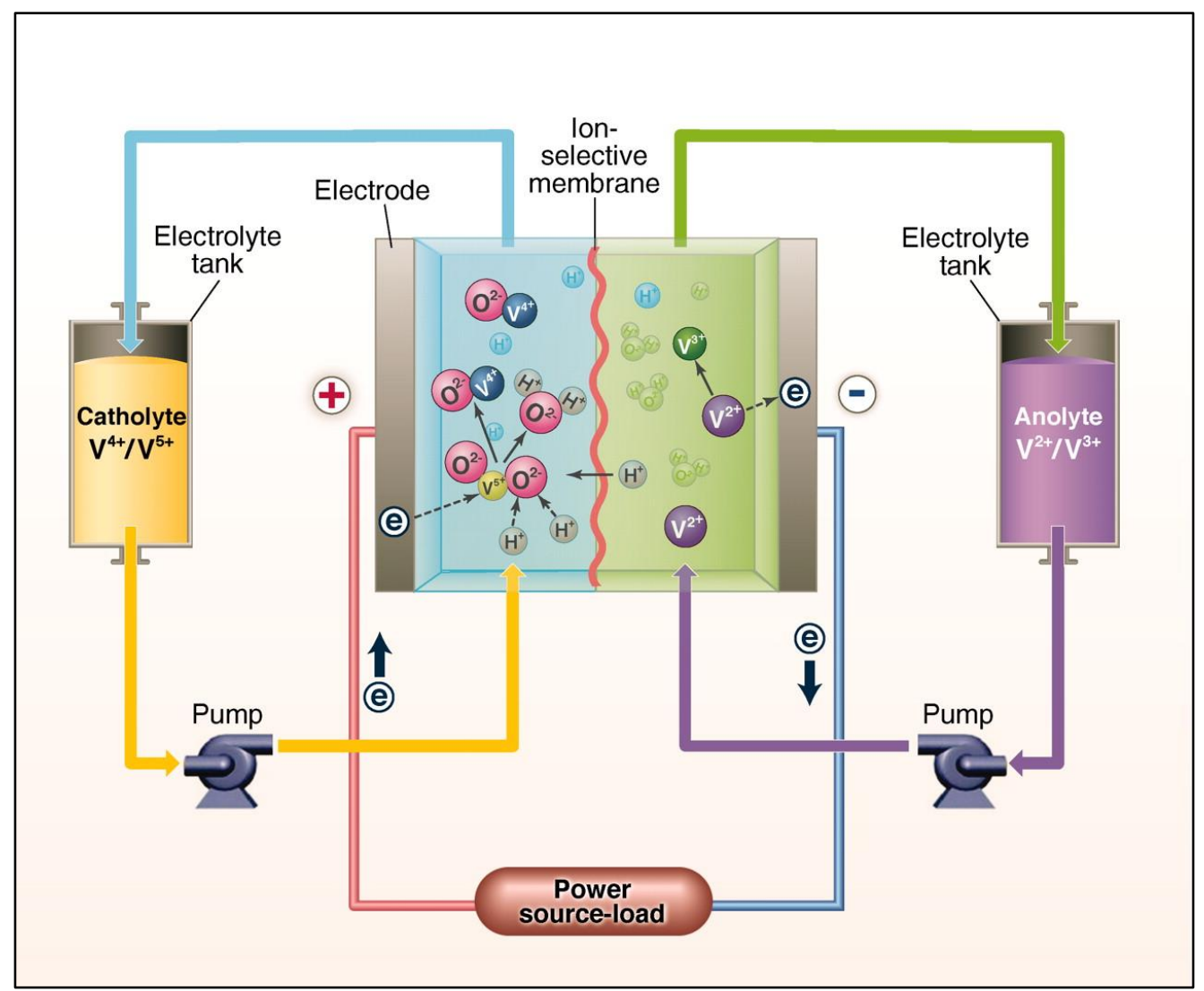

Figure 25. Representative diagram of a vanadium-redox flow battery [84].

\subsubsection{Performance Parameters}

VRB systems can have relatively high efficiencies and cycle lives with proper maintenance. However, the energy density of VRB systems is comparatively lower than other battery storage systems. VRB systems are modular, like most other flow battery systems, so the energy storage capacity of a VRB system can be upgraded for a relatively low incremental cost. However, the operating and maintenance costs for a VRB system are too high at present to encourage widespread commercialization [22] [72]. Lastly, the self-discharge rate for VRB systems is negligible, as with $\mathrm{ZnBr}$ battery systems and other flow batteries. The performance parameters for a typical VRB system are listed in Table 13.

\subsubsection{Environmental Impact}

VRBs are actually considered to be one of the energy storage systems with the least impactful effect on the environment. Although vanadium cannot be replaced with an alternative material in a VRB's system architecture, reserves for vanadium could last another 150 years at current consumption and production rates [22]. Additionally, vanadium is non-toxic and can be extracted through alternative means, such as through the combustion of oil to release trace vanadium deposits. Therefore, the mining impacts from the production of VRBs are insignificant [96]. When disposing of a VRB system, the membrane that was used to separate the two electrolytes should be handled carefully since it may be highly acidic or alkaline. The used electrolyte should also be recycled if possible and the vanadium should be separated from the liquid if the electrolyte cannot be recycled. Research is still being conducted to determine the environmental impact of disposing of the used vanadium [21]. The environmental impacts of VRBs are summarized in Table 14. 


\subsubsection{Policy and Market Conditions}

There are over $20 \mathrm{MWh}$ of VRB systems installed worldwide. The minimal environmental impact and high modularity of this technology have drawn attention to VRB systems as an attractive option for mitigating the variability of renewable energy sources [22]. However, some barriers to widespread commercialization still exist, such as the high operating costs and low energy density for this technology [72]. Like $\mathrm{ZnBr}$ flow battery systems, VRB systems have received a sizable amount of funding from the Australian Department of Resource and Energy to drive the commercialization of this technology. In contrast, most of the funding for this technology in the U.S. has come from private entities, who are generally more risk-averse. As a result, few VRB energy storage systems have been installed in the U.S. The first VRB energy storage facility in this country was built in Castle Valley, Utah by Utah Power in November of 2004 to provide load levelling services for the utility. Since then, a couple more kW-scale facilities have been commissioned or announced, but not many [26] [97]. VRB systems are also currently facing several policy-related barriers. In most energy markets, VRBs are competing directly with more well-established energy storage technologies that have received greater attention from the government. Additionally, VRB systems are rarely rewarded for their part in reducing GHG emissions, which increases the perceived relative costs of VRB technologies. These barriers, along with the lack of standardized reliability estimates and the uncertainty surrounding maintenance costs for VRB systems, have led to an increased perception of risk and have limited the commercialization of this energy storage technology as a result. Market-based policy instruments such as subsidies and tax incentives for energy storage might be required to accelerate the development of VRBs and promote the adoption of this technology in order for this energy storage technology to succeed [97].

\subsubsection{Compatible Applications}

VRBs are a versatile technology capable of providing multiple services to the grid. Presently, VRB installations are used for energy management strategies such as peak shifting, variable supply resource integration, spinning reserves and other back-up power applications, voltage support, and black start for remote area power systems. Multiple systems have been built worldwide specifically to manage fluctuations in the supply of wind and solar power [22]. VRBs are also able to supply continuous power for up to an entire day, acting like a generating power plant. Small-scale trials are currently in process to test the viability of VRBs for energy arbitrage with renewable energy generating units and the scalability of the technology for large-scale energy arbitrage [72]. Thus, a few of the compatible applications for VRB systems are listed in Table 15.

\subsubsection{Technology Maturity}

Compared to the other type of flow battery considered in this report, $\mathrm{ZnBr}$ flow batteries, VRBs have achieved broader commercial adoption. Based on their successful demonstration in the marketplace and vetted technological performance, VRBs can be considered the most mature flow battery design available to developers. VRB systems have been installed for multiple applications worldwide. A few of the largest VRB installations include a $0.25 \mathrm{MW}$ and $0.2 \mathrm{MWh}$ storage facility operated by VRB power systems and a 4 MW and 6 MWh unit in Japan operated by Sumitomo Electric Industries [22]. Although there are examples of successful commercial ventures involving VRB systems, VRBs continue to be tested in the field for a wide range of applications [21]. Therefore, a TRL of 7 was assigned, as shown in Table 13.

\subsubsection{Future Development}

VRBs are the most mature flow battery storage technology available, but this technology still faces several challenges that must be overcome before the technology will see widespread commercialization in the U.S. Operating costs are still relatively high for VRBs compared to most of the other energy storage technologies considered in this report, only NaS batteries have higher O\&M costs, and these must be reduced to enhance the profitability of the technology. Furthermore, the electrolyte used in VRB systems 
is relatively unstable and insoluble, which leads to an unattractive energy density for the storage technology. However, the performance characteristics of VRB storage systems position the technology as a potential solution to the variability caused by the high penetration of renewable energy sources and this market opportunity should continue to drive the innovation and development of VRBs [72].

\subsection{Chemical Energy Storage}

Storing energy in hydrogen bonds was the only technology categorized within chemical energy storage for the purpose of this report. However, some of the other technologies considered within this report use chemical bonds and reaction to store energy, such as thermochemicals and electrochemical batteries. Fossil fuels were also briefly discussed in this section to provide perspective on the energy storage capabilities of the technologies considered in this report.

\subsubsection{Hydrogen Energy Storage}

\subsubsection{Technology Overview}

The production of hydrogen for energy storage is different than many of the other technologies considered in this report. Producing hydrogen for alternative applications is even considered as an energy storage proxy in an earlier section. However, hydrogen has also been considered as a storage mechanism for many grid-scale energy management applications. First, rather than simply charging an energy storage device directly, hydrogen must be produced from some alternative resource. Hydrogen is often produced through the electrolysis of water using electricity produced by a nearby power plant or other electricity generating unit. An electrolyzer introduces an electric current to the water to produce hydrogen and oxygen [22] [72]. Two primary electrolysis technologies are currently available on the market, alkaline electrolysis and proton exchange membrane electrolysis, and both operate at relatively low temperatures $\left(<100^{\circ} \mathrm{C}\right)$. However, high temperature hydrogen production methods $\left(700-900^{\circ} \mathrm{C}\right)$ are being researched and could be more compatible with NPPs [98]. After the hydrogen is produced, it must be stored or used for another application. Possible post-production uses include power-to-power, when hydrogen is stored in an underground cavern or pressurized tank to be converted to electricity later using either a fuel cell or a hydrogen fueled gas turbine. Other post-production uses include power-to-gas, when hydrogen is either blended with natural gas or used to create synthetic methane, power-to-fuel, when the hydrogen is used as a fuel for the transportation sector, and finally power-to-feedstock, when produced hydrogen is used for chemical and refining industries [23]. Although hydrogen production is a versatile energy storage method, offering clean and efficient electricity generation as well as scalability and a compact design, many challenges still face this technology. The primary limitations of hydrogen energy storage systems are the durability of the system components, high investment costs, and possible geographic requirements concerning the hydrogen storage vessel [22] [72]. A diagram of the process of producing hydrogen for energy storage is displayed below in Figure 26. 


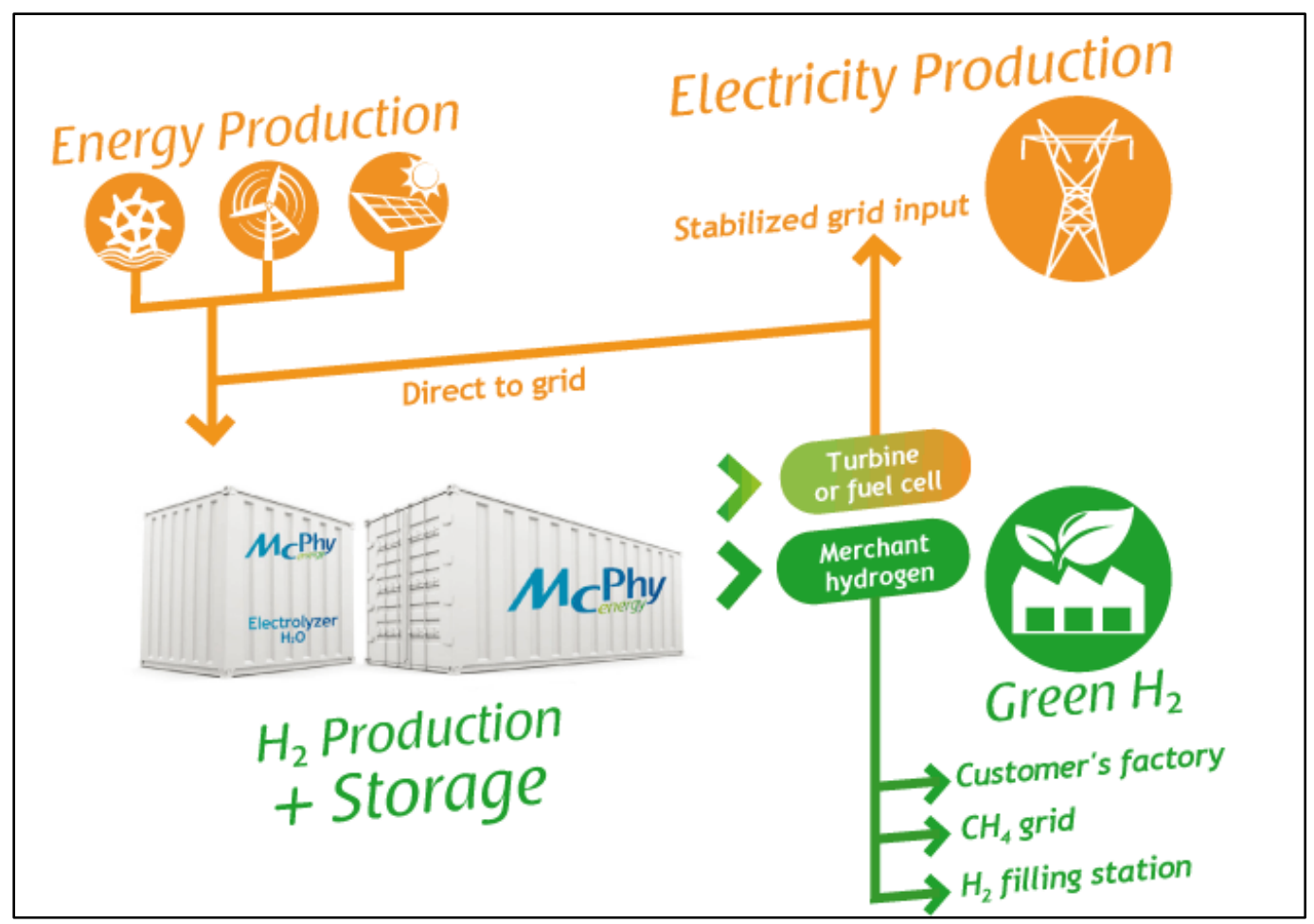

Figure 26. Production and uses for a hydrogen energy storage system [99].

\subsubsection{Performance Parameters}

Electricity generation with fuel cells is much quieter, cleaner, and more efficient than fossil fuel combustion [72]. However, due to the numerous conversions necessary to use hydrogen for energy storage, the production of hydrogen as a whole is only 20-30\% efficient [23]. Since the storage conversion efficiencies for hydrogen production systems are so low and the capital costs for this energy storage technology are much higher than other options, hydrogen production systems are generally considered to be a non-optimal solution for addressing the increasing penetration of VRES. Furthermore, producing electricity with hydrogen fuel cell and electrolyzer system is approximately four and a half times more expensive than natural gas electricity generation, which presents fossil fuel combustion as a much more economically attractive solution. However, coupling a hydrogen production process with a hydrogen combustion turbine could be a more economically attractive model. The capital costs for the hydrogen production systems considered in this report take into account the fuel cell, electrolyzer, and reservoir needed to use hydrogen production for large-scale energy storage. Due to high costs, hydrogen production is not typically considered to be well-suited for the daily management of fluctuations in electricity markets caused by variable electricity generation from renewable energy sources. However, hydrogen fuel cell costs are expected to drop significantly in the next decade [22]. Hydrogen production systems can also be easily expanded for grid-scale applications. In addition, hydrogen energy storage systems are compact and can be easily integrated into a power plant's generation cycle [72]. One major disadvantage of hydrogen storage systems is the fact that although hydrogen is the most abundant element on earth, it is usually bonded to other elements such as water or hydrocarbons, so it costs more energy to produce than other energy storage media such as compressed air [70]. The performance parameters for a typical hydrogen storage system with an electrolyzer and fuel cell are listed in Table 16. 
Table 16. Performance parameters for chemical energy storage systems.

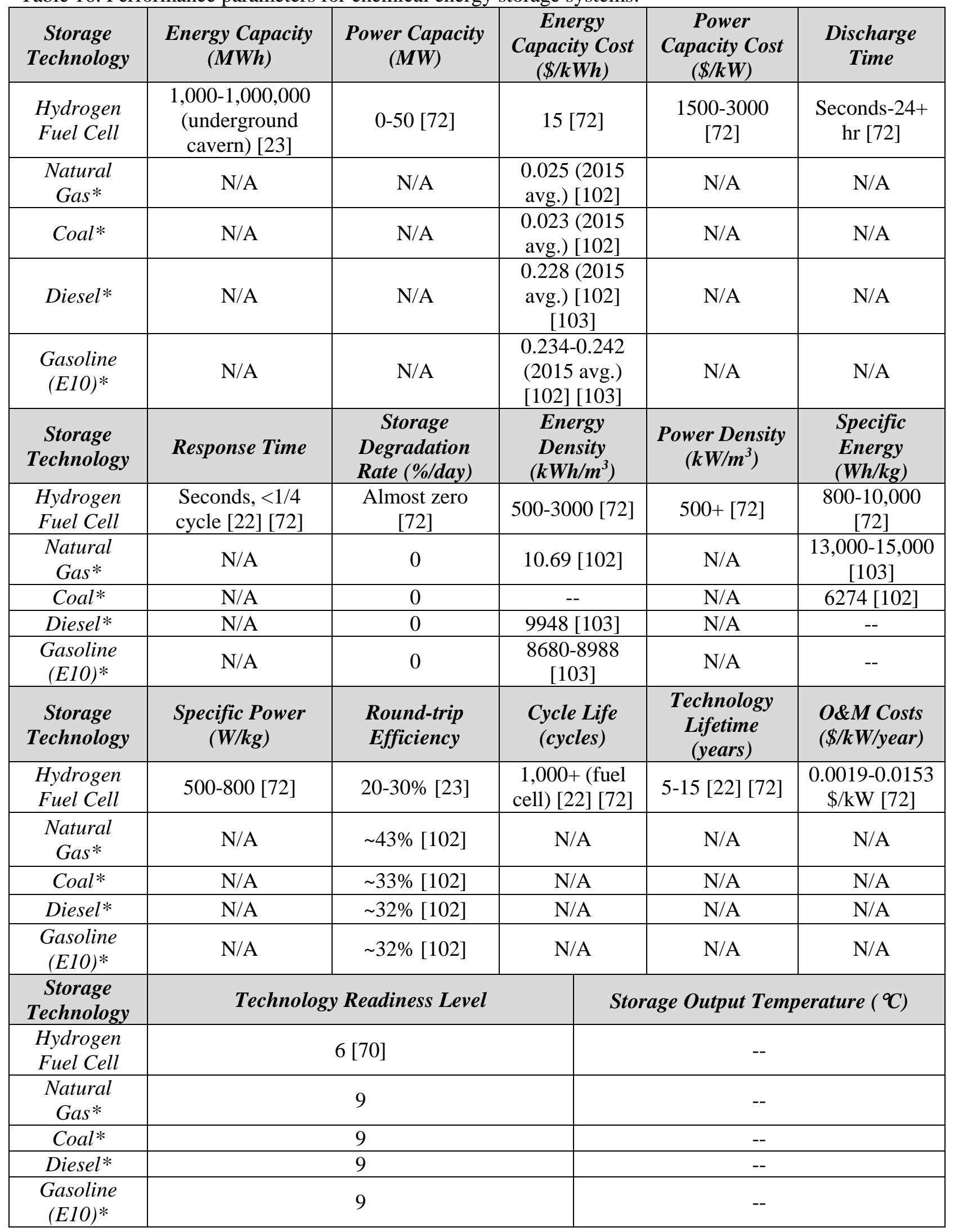




\subsubsection{Environmental Impact}

Above all, the development of hydrogen energy storage systems could reduce the emissions of power generation as compared to the emissions produced from the combustion of fossil fuels. The integration of hydrogen fuel cells in the transportation sector and the use of hydrogen energy storage to minimize generation from peaking power plants can reduce $\mathrm{CO}_{2}$ emissions, since the only byproduct of hydrogen combustion is water. However, the lifecycle carbon emissions from a hydrogen fuel cell are dependent on the primary energy source and the process used to produce the hydrogen. The amount of water used in hydrogen production could also have a considerable environmental impact. Although, when the hydrogen is recombined with oxygen in a fuel cell to produce electricity, water is produced and can be returned to the original source. [23] The disposal of exhausted fuel cells is another component of hydrogen production for energy storage that must be carefully controlled to minimize environmental impact, since toxic metals such as palladium are used for the electrodes and catalysts. Recently, there has been significant research and development into the recycling and reprocessing of palladium to reduce this environmental impact [72]. Overall, since nuclear energy will be examined as the primary energy source for hydrogen energy storage in this report, the emissions and environmental impact of hydrogen production should be minimal. The environmental impacts associated with hydrogen production are summarized in Table 17.

Table 17. Environmental impacts of chemical energy storage systems [102].

\begin{tabular}{|c|c|c|c|c|c|}
\hline Environmental Impact & Hydrogen & $\begin{array}{c}\text { Natural } \\
\text { Gas* }\end{array}$ & Coal $^{*}$ & Diesel* & $\begin{array}{c}\text { Gasoline } \\
(\text { E10 }) *\end{array}$ \\
\hline Land and Water Impact & Significant & N/A & N/A & N/A & N/A \\
\hline $\begin{array}{c}\text { Emissions Produced During } \\
\text { Operation (million metric tons } \\
\text { of } \mathrm{CO}_{2} \text { in 2015) }\end{array}$ & None & 1,480 & 1,486 & \multicolumn{2}{|c|}{ 1,123 (combined) } \\
\hline Hazardous Materials & Yes & N/A & N/A & N/A & N/A \\
\hline Hazardous Fumes & None & N/A & N/A & N/A & N/A \\
\hline Short-Term Safety Concerns & Some & N/A & N/A & N/A & N/A \\
\hline Resource Depletion & Insignificant & $\begin{array}{c}\text { Very } \\
\text { significant }\end{array}$ & $\begin{array}{c}\text { Very } \\
\text { significant }\end{array}$ & $\begin{array}{c}\text { Very } \\
\text { significant }\end{array}$ & $\begin{array}{c}\text { Very } \\
\text { significant }\end{array}$ \\
\hline Geographic Requirements & Yes & N/A & N/A & N/A & N/A \\
\hline
\end{tabular}

\subsubsection{Geographic Requirements}

The hydrogen produced using the electricity from a power plant or electricity generating unit for energy storage must be stored in some physical space. Medium-scale systems can store the produced hydrogen in pressurized steel or composite vessels, which have been developed for other industrial applications [72]. However, the large-scale energy storage systems that are the most useful for providing grid-scale services and responding to the high penetration of renewable energy sources often use geographic features as the storage vessel. Understanding the potential for storage in geological features near the primary energy source is an important area of research and development for hydrogen production. Possible natural storage vessels include evacuated salt caverns, depleted oil and gas reservoirs, and aquifer formations. Thus, identifying a potential storage space that is nearby and is also compatible with existing infrastructure can be essential to reducing the investment cost for hydrogen energy storage systems [23].

\subsubsection{Policy and Market Conditions}

Many large-scale hydrogen energy storage installations have either been launched, planned, or announced in recent years. In particular, several projects have been announced in Germany to manage the 
high penetration of renewable energy electricity generation in the country. The German national government has passed extensive policy measures to assist with the integration of energy storage technologies, including exemptions from grid access charges and approvals for participation in energy markets. Furthermore, the Australian government has approved research funding for the development of hydrogen-enabled storage systems for solar power [72]. Similar policies might be needed in the U.S. to motivate the development of this technology. One major potential policy initiative for hydrogen energy storage should be motivating private capital to fund hydrogen technologies. In the U.S., the California Fuel Cell Partnership and $\mathrm{H}_{2}$ USA initiative with the U.S. Department of Energy represent existing partnerships between public and private entities to promote the development of hydrogen energy storage technologies and transmission infrastructure. Additionally, long-range emissions reduction goals and increasing carbon prices related to emissions regulations could lead to the development of hydrogen technologies if research and development funding continues. Further policy measures suggested by the IEA for hydrogen energy storage integration include the exemption of electrolyzers from renewable surcharges and grid usage fees and the proliferation of certificates rewarding the clean production of natural gas through methanation [23]. At the present, hydrogen energy storage is not well-suited for daily energy management applications such as mitigating the impact of VRES due to its high cost and the lack of favorable policies. However, seasonal energy storage might be a potential market opportunity for hydrogen energy storage technologies. Since electricity generation from renewable energy sources is highly seasonal and few energy storage technologies possess the large energy storage capacity and low self-discharge rates of hydrogen energy storage systems, long-term storage could become economically attractive as the penetration of VRES increases. One study suggests that if wind penetration increased by $18 \%$ in Southern California, hydrogen energy storage used in this way could become profitable. Hydrogen energy storage could also see additional market opportunities if hydrogen fuel cells are widely adopted as a means of energy storage for the transportation sector [22].

\subsubsection{Compatible Applications}

The grid-scale applications for hydrogen energy storage are limited, although future development should provide new opportunities for hydrogen technologies. Although hydrogen energy storage systems struggle to provide services to assist with integrating VRES due to their high capital costs and low storage conversion efficiencies, they are capable of providing seasonal energy storage [22]. Hydrogen energy storage technologies are technically compatible with daily energy arbitrage, but the levelized cost of electricity must be approximately $\$ 90$ per MWh for this service to be economically feasible, which would require significant drops in capital costs and increased efficiencies. With ongoing research and development, hydrogen energy storage could provide these services in the future [23]. The compatible applications for hydrogen energy storage systems are listed in Table 19.

Table 18. Compatible applications for chemical energy storage systems [19] [22].

\begin{tabular}{|c|c|}
\hline Service & Hydrogen \\
\hline Energy Arbitrage & Somewhat compatible \\
\hline Frequency Regulation & Incompatible \\
\hline Load Following & Somewhat compatible \\
\hline Voltage Support & Incompatible \\
\hline Spinning Reserves & Somewhat compatible \\
\hline Non-Spinning \& Supp. Reserves & Compatible \\
\hline Black Start & Somewhat compatible \\
\hline VSR Integration & Incompatible \\
\hline Seasonal Storage & Compatible \\
\hline Process Heat Applications & Incompatible \\
\hline
\end{tabular}


*Note that the fossil fuels included in Table 16 and Table 17 are included only as a point of comparison for a few technology characteristics, namely energy density, specific energy, emissions produced during operation, etc.

\subsubsection{Technology Maturity}

Hydrogen fuel cell technologies are in the development and demonstration stage. However, stationary energy storage applications involving the production of hydrogen are a relatively mature process. Largescale deployments of stationary hydrogen energy storage technologies for use with the grid still face several challenges though, including cost and durability issues [70]. The first utility-scale hydrogen energy storage installation was built in Norway to assist with the integration of variable electricity generation from wind power. The plant has the capacity to store enough hydrogen to power 10 houses for 2-3 days. The facility stores the energy produced by a $600 \mathrm{~kW}$ wind turbine and generates power with a $48 \mathrm{~kW}$ electrolyzer and a $10 \mathrm{~kW}$ fuel cell [22]. Hydrogen energy storage systems have been the subject of extensive research and development in recent years. As technological advances continue to be made, the cost of this technology will likely continue to fall, which might incentivize additional commercialization. Although the systems needed for wide scale commercialization of hydrogen storage are still under development, some components of the system are more mature than others and already deployed in the marketplace. Compressors and pressurized vessels for hydrogen storage are commercially mature, while electrolyzers and fuel cells are still in the process of achieving widespread commercialization [70]. In this report, hydrogen energy storage systems were assigned a TRL of 6, as shown in Table 16, since these systems are still in the demonstration stage of development.

\subsubsection{Future Development}

Cost reduction and reliability improvement are the most immediate needs for research and development for hydrogen energy storage technologies. Investment costs for these systems must be significantly reduced before hydrogen energy storage can be a feasible solution to the fluctuations seen in energy markets today [72]. In particular, the costs of the electrolyzers used in hydrogen energy storage systems need to be reduced. A research avenue relevant to integrating energy storage with NPPs is the development of high-temperature electrolysis methods. Specifically, solid oxide electrode cell electrolysis systems that operate at temperatures ranging from $700-900^{\circ} \mathrm{C}$ and could utilize high temperature steam produced in a nuclear power cycle are being considered. Solid oxide electrode cell electrolysis systems have been shown to operate with efficiencies comparable to conventional proton exchange membrane electrolysis systems and with even better performance characteristics when operating at high hydrogen production rates [98]. The operational flexibility of electrolysis systems could also be enhanced to enable hydrogen energy storage systems that are able to provide additional ancillary services, which would improve the marketability of the technology. Improving the efficiency of fuel cells and reducing the cost of manufacturing the devices could make fuel cell systems more economically appealing as well. A more effective utilization of waste heat could help with this effort and could also help to reduce costs. Largescale manufacturing processes should also be developed for electrolyzer technologies to further reduce costs [23].

\subsubsection{Conventional Fossil Fuels}

\subsubsection{Technology Overview}

Fossil fuels are not generally considered to be a viable energy storage technology, although it is possible to extend the hydrogen production process to create methane. However, other than synthetic methanation, energy cannot be continually charged and discharged to and from fossil fuels. Although

fossil fuels can rarely be used as a storage technology that can be cycled, it is still important to record the technical characteristics of fossil fuels as a point of comparison to other energy storage technologies [100]. 


\subsubsection{Performance Parameters}

The superior energy density of fossil fuels, particularly gasoline and diesel, has positioned these fuels as the preferred choice for providing an onboard supply of energy for light duty road vehicles. The energy density, cost, and material properties, such as whether or not something is liquid at standard temperature and pressure, are especially important when considering fuels for the transportation sector. Not only does additional weight reduce a vehicle's fuel efficiency, but fuels that require large storage containers to provide adequate range can also reduce the amount of space available for passengers. Furthermore, the price of many alternative storage technologies, such as batteries and fuel cells, has limited widespread deployment [101]. However, in recent years, some auto manufacturers such as Tesla have made strides to reduce the cost of electric vehicles. The high energy content of fossil fuels and the favorable material properties that simplify production and transportation of the fuel also explains why they are used so widely for electricity generation. Typical performance parameters for natural gas, coal, diesel, and gasoline are listed in Table 16.

\subsubsection{Environmental Impact}

The environmental impacts associated with fossil fuels are some of the motivating factors behind the push for energy storage integration on the grid. As renewable energy sources introduce volatility to electricity markets, the grid has been forced to rely on expensive peaking power plants that can quickly turn on when there are periods of high demand or when forecasted renewable energy is unavailable. By adding energy storage, the emissions from these peaking power plants could be eliminated as supply is more precisely matched with demand. The total emissions from the four fossil fuels considered in this report are listed in Table 17. Fossil fuels also produce and emit several other harmful pollutants that must be carefully monitored and controlled.

\subsubsection{Geographic Requirements}

The geographic requirements for large fossil fuel storage facilities are similar to CAES installations. For example, the U.S. Strategic Petroleum Reserve occupies several salt caverns along the Gulf Coast, constituting over 700 million barrels of storage. Additionally, in Cushing, Oklahoma, the aboveground tanks used to store petroleum before it is sold and transported to a power plant or refinery offer another 80-90 million barrels of storage. Natural gas can also be stored in pressurized salt caverns, using the same methods for storing compressed air in these caverns. Coal is generally stored in aboveground piles rather than in a specially designed underground storage space or aboveground tanks [100].

\subsubsection{Policy and Market Conditions}

Fossil fuels have been subsidized more than any other energy source or energy storage technology, even after accounting for subsidies and policy support for renewable energy sources in recent decades. Furthermore, if the defense spending focused on securing the supply of fossil fuels to the U.S. is considered, the government's financial support for fossil fuels is even greater. However, recent policy initiatives have also hurt fossil fuels. For example, the recently proposed Clean Power Plan encourages additional development of renewable energy sources and will likely result in a shift from coal to natural gas power plants in an effort to reduce carbon emissions in the U.S. to $32 \%$ lower than 2005 levels by 2030. Market opportunities for some fossil fuel power plants have expanded with the introduction of renewable energy though. Recent technological advances and the development of hydraulic fracturing coupled with the added variability in electricity markets has created a unique opportunity for natural gas power plants. In contrast, coal power plants are quickly losing economic viability and the push towards electric vehicles might eventually narrow the petroleum demand for transportation fuel [100]. 


\subsubsection{Compatible Applications}

Fossil fuels are included in this report so that the energy densities and costs of other energy storage technologies can be put in the proper perspective. Many of the applications considered in this report are not applicable to fossil fuels as an energy storage technology. The primary benefit offered through energy storage with fossil fuels is the ability to separate the production of fuels from the generation of electricity. Thus, power plants do not have to immediately burn fossil fuels as soon as they arrive at the power plant if it is not economically favorable.

\subsubsection{Technology Maturity}

All of the fossil fuels considered in this report have been used to provide energy and generate electricity for decades. Furthermore, the means for storing fossil fuels has been well understood for years. Therefore, fossil fuels can safely be assessed with a TRL of 9, as shown in Table 16.

\subsubsection{Future Development}

Advanced methods for extracting the energy from fossil fuels are being developed and, in some cases, the means for creating these fuels from other energy sources are being studied. Due to the harmful pollutants and carbon emissions produced when these fuels are burned and the diminishing reserves, other methods for producing energy and storing energy are being pursued.

\subsection{Thermal Energy Storage}

Thermal energy storage technologies are capable of storing the heat produced by nuclear fission at an NPP or the heat produced from combustion at another large thermal power plant. The heat is typically stored in a particular storage medium within a large, insulated storage reservoir. Alternatively, a thermal energy storage technology can also hold a medium at a state that represents the absence of heat (e.g., a low temperature), sometimes with the help of a refrigeration system. In this report, two types of thermal energy storage technologies were considered, sensible heat and latent heat storage technologies. Latent heat storage technologies incorporate a phase change with the storage medium, whereas sensible heat storage technologies often try to prevent the storage medium from changing phase. Thermal energy storage technologies can require fewer energy conversions between storing the energy and discharging it back to the grid, so thermal energy storage technologies can potentially be more efficient than some electrical energy storage technologies. However, additional generation capacity is often required to efficiently operate a thermal energy storage technology, since the heat must be converted to electricity while the power plant is still operating [72].

\subsubsection{Sensible Thermal Energy Storage}

Sensible thermal energy storage technologies employ many different storage mediums to transport and hold the thermal energy produced by the power plant. In particular, water and rocks are effective and inexpensive storage mediums. Additionally, concrete is also often used for thermal energy storage for the same reasons. Since several of the materials used for energy storage with these technologies are commonly found in nature, the environmental impact of sensible thermal energy storage technologies is often minimal. However, the energy density of these storage mediums is typically not as high as some of the electrical and electrochemical energy storage technologies considered in this report [72].

\subsubsection{Underground Thermal Energy Storage}

\subsubsection{Technology Overview}

Underground thermal energy storage (UTES) systems store energy by pumping heat into an underground storage space. There are three typical underground locations in which thermal energy is 
stored: boreholes, aquifers, and caverns or pits. Typically, the storage medium used for this method of thermal energy storage is water. Boreholes are man-made vertical heat exchangers that work to transfer heat between the energy carrier and the ground layers. However, aquifers and underground caverns or pits are natural storage spaces for thermal energy. In aquifers, thermal energy is transferred to the aquifer by injecting or extracting hot or cold water from the aquifer itself. Finally, thermal energy stored in underground caverns or pits is stored in a large underground reservoir. Although, this last form of underground thermal energy storage is technically feasible, installations have been limited due to high investment costs. Additionally, although UTES systems are a convenient form of bulk thermal energy storage, their success is largely dependent on surrounding geographic conditions and a local need for district heating. UTES systems are also incapable of contributing to high temperature applications since water cannot be stored above its boiling temperature [20] [24]. An example of an aquifer thermal energy storage system is represented below in Figure 27. In this figure, the green clouds represent cooled air streams resulting from air that has passed over the heat exchanger connected to the underground aquifer. The blue arrows in the figure show how the cool air moves through the building and eventually exits the building as hot air, due to the heat absorbed throughout the cooling process.

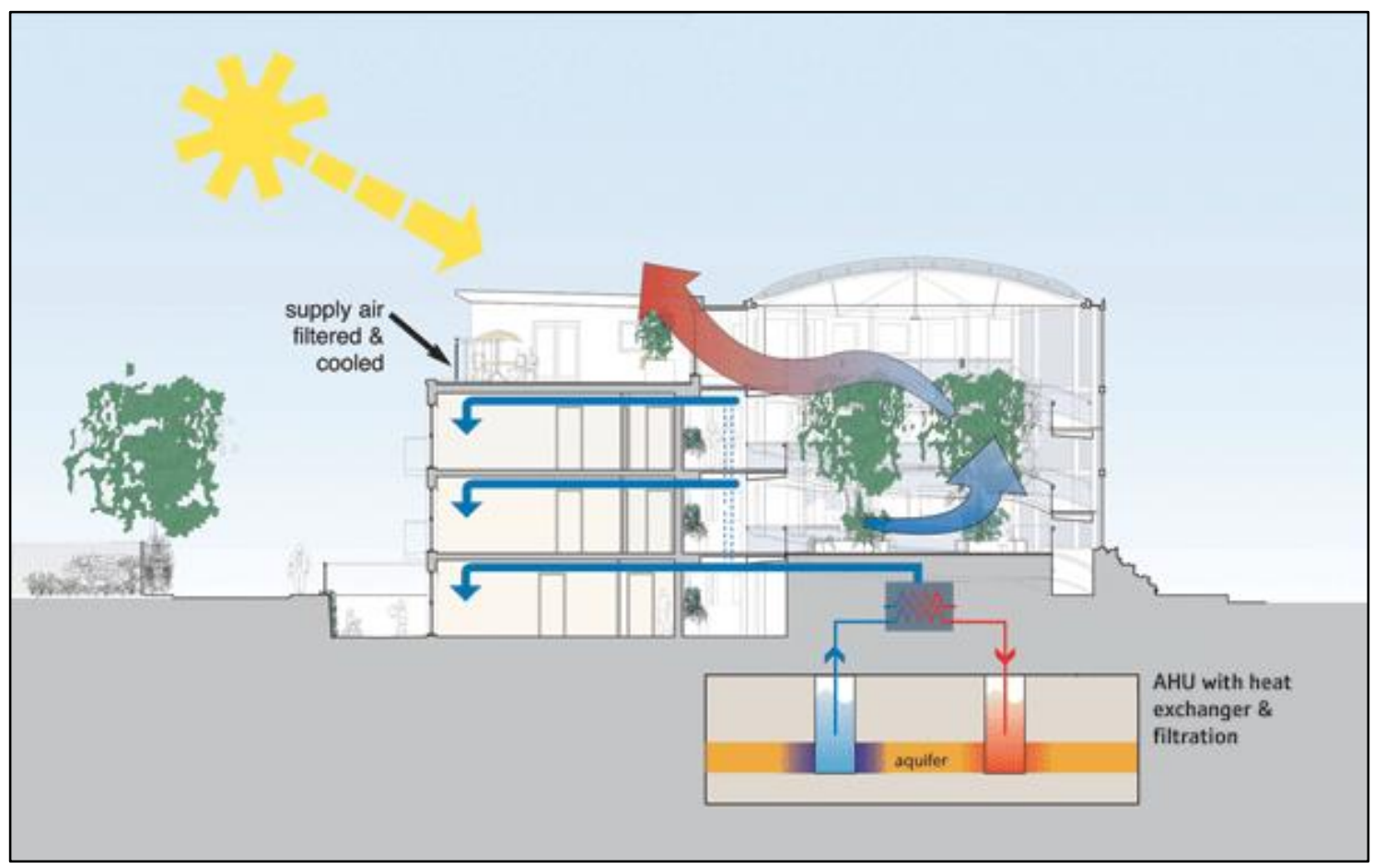

Figure 27. Representative diagram of an aquifer TES system for building heating and cooling [104].

\subsubsection{Performance Parameters}

Underground thermal energy storage systems are ideally suited for seasonal storage. Therefore, the energy capacity and self-discharge rates for these storage systems must be optimized when developing a UTES facility. The prohibitive investment costs for this technology also tend to motivate the use of UTES systems for seasonal energy storage rather than daily energy management. The technical characteristics of UTES systems are similar to aboveground sensible thermal energy storage systems such as hot and cold water tanks, since the storage medium for both of these technologies is water. However, the size of most UTES systems makes them better suited for long-term energy storage [24]. The performance parameters for a typical UTES system are displayed in Table 19. 
Table 19. Performance parameters for sensible thermal energy storage systems.

\begin{tabular}{|c|c|c|c|c|c|}
\hline $\begin{array}{c}\text { Storage } \\
\text { Technology }\end{array}$ & $\begin{array}{c}\text { Energy } \\
\text { Capacity } \\
(M W h)\end{array}$ & $\begin{array}{c}\text { Power Capacity } \\
(M W)\end{array}$ & $\begin{array}{c}\text { Energy } \\
\text { Capacity Cost } \\
(\$ / k W h)\end{array}$ & $\begin{array}{c}\text { Power } \\
\text { Capacity Cost } \\
(\$ / k W)\end{array}$ & $\begin{array}{c}\text { Discharge } \\
\text { Time }\end{array}$ \\
\hline UTES & $\sim 3900[114]$ & -- & $\sim 0.055[114]$ & $3400-4500[20]$ & -- \\
\hline $\begin{array}{c}\text { Hot and Cold } \\
\text { Water (storage } \\
\text { tanks) }\end{array}$ & $10-2000[20]$ & $\begin{array}{c}--[24][110] \\
{[114]}\end{array}$ & $0.1-10[24]$ & $300-600[20]$ & $\begin{array}{c}\text { Minutes-hours } \\
{[106]}\end{array}$ \\
\hline $\begin{array}{c}\text { Solid Media } \\
\text { (concrete) }\end{array}$ & $>1100[110]$ & -- & $\sim 40[110]$ & $500-3000[20]$ & $\sim 1$ day [110] \\
\hline $\begin{array}{c}\text { Storage } \\
\text { Technology }\end{array}$ & $\begin{array}{c}\text { Response } \\
\text { Time }\end{array}$ & $\begin{array}{c}\text { Storage } \\
\text { Degradation } \\
\text { Rate }(\% / \text { day) }\end{array}$ & $\begin{array}{c}\text { Energy } \\
\text { Density } \\
\left(k W h / m^{3}\right) \\
\end{array}$ & $\begin{array}{l}\text { Power Density } \\
\quad\left(\mathrm{kW} / \mathrm{m}^{3}\right)\end{array}$ & $\begin{array}{c}\text { Specific } \\
\text { Energy } \\
(W h / k g)\end{array}$ \\
\hline UTES & -- & Almost zero [24] & $20-30[106]$ & -- & -- \\
\hline $\begin{array}{c}\text { Hot and Cold } \\
\text { Water (storage } \\
\text { tanks) }\end{array}$ & $\begin{array}{c}\text { Seconds- } \\
\text { hours [106] }\end{array}$ & Almost zero [24] & $20-30[106]$ & -- & -- \\
\hline $\begin{array}{c}\text { Solid Media } \\
\text { (concrete) }\end{array}$ & -- & -- & $\sim 22[110]$ & -- & $\sim 5[115]$ \\
\hline $\begin{array}{c}\text { Storage } \\
\text { Technology }\end{array}$ & $\begin{array}{c}\text { Specific } \\
\text { Power } \\
(\mathrm{W} / \mathrm{kg})\end{array}$ & $\begin{array}{c}\text { Round-Trip } \\
\text { Efficiency }\end{array}$ & $\begin{array}{l}\text { Cycle Life } \\
\text { (cycles) }\end{array}$ & $\begin{array}{c}\text { Technology } \\
\text { Lifetime } \\
\text { (years) }\end{array}$ & $\begin{array}{l}\text { O\&M Costs } \\
(\$ / k W / \text { year })\end{array}$ \\
\hline UTES & -- & $50-90 \%[20]$ & -- & -- & -- \\
\hline $\begin{array}{c}\text { Hot and Cold } \\
\text { Water (storage } \\
\text { tanks) }\end{array}$ & -- & $50-90 \%[20]$ & -- & $10-30+[106]$ & -- \\
\hline $\begin{array}{c}\text { Solid Media } \\
\text { (concrete) }\end{array}$ & -- & $50-90 \%[20]$ & -- & $>2[110]$ & -- \\
\hline $\begin{array}{c}\text { Storage } \\
\text { Technology }\end{array}$ & \multicolumn{3}{|c|}{ Technology Readiness Level } & \multicolumn{2}{|c|}{ Storage Output Temperature $\left({ }^{\circ} \mathrm{C}\right)$} \\
\hline UTES & \multicolumn{3}{|c|}{$8[20]$} & \multicolumn{2}{|c|}{$<250[20]$} \\
\hline $\begin{array}{c}\text { Hot and Cold } \\
\text { Water (storage } \\
\text { tanks) }\end{array}$ & \multicolumn{3}{|c|}{$7[20]$} & \multicolumn{2}{|c|}{$95-98$ or $120-130$ (pressurized) [20] } \\
\hline $\begin{array}{c}\text { Solid Media } \\
\text { (concrete) }\end{array}$ & \multicolumn{3}{|c|}{$6[110]$} & \multicolumn{2}{|c|}{$350[110]$} \\
\hline
\end{tabular}

\subsubsection{Environmental Impact}

Although UTES systems are not as common in the U.S., several UTES systems have been installed in European countries where district heating is more popular. Large UTES systems for heating and cooling capacity exist in the Netherlands, Sweden, German, and Canada. Furthermore, pit storage is used for district heating networks in Denmark [20]. Therefore, the environmental impact of these systems has been extensively studied. The most significant impact from this technology is water usage. In the Netherlands, installed aquifer TES systems use approximately 350 million $\mathrm{m}^{3}$ of ground water per year, which is a significant portion of the 1500 million $\mathrm{m}^{3}$ of groundwater that was extracted in total in the country in 2007. Although this water is subsequently returned to the aquifer, the flow pattern and quality of the groundwater can be affected by the thermal energy storage process. Other countries might experience 
different hydrological impacts due to installed aquifer TES systems, but the situation in the Netherlands is presented as a reference case. Groundwater flow patterns can also be affected by poorly constructed borehole TES systems that fail to adequately separate different aquifer layers. Aquifer and borehole TES systems can also have adverse thermal, chemical, and microbiological effects on groundwater when they are installed [105]. The environmental impacts of underground thermal energy storage systems are summarized in Table 20.

Table 20. Environmental impacts of sensible thermal energy storage systems.

\begin{tabular}{|c|c|c|c|}
\hline Environmental Impact & UTES & $\begin{array}{c}\text { Hot and Cold Water } \\
\text { (storage tanks) }\end{array}$ & Solid Media (concrete) \\
\hline Land and Water Impact & Significant & Insignificant & Insignificant \\
\hline Emissions Produced During Operation & None & None & None \\
\hline Hazardous Materials & None & None & None \\
\hline Hazardous Fumes & None & None & None \\
\hline Short-Term Safety Concerns & None & None & None \\
\hline Resource Depletion & Insignificant & Insignificant & Insignificant \\
\hline Geographic Requirements & Yes & None & None \\
\hline
\end{tabular}

\subsubsection{Geographic Requirements}

The geographic requirements for UTES systems are similar to the requirements for PSH and CAES systems. The type of storage space that is selected for a particular UTES system depends on the local geological conditions, especially for aquifer and cavern or pit thermal energy storage systems. The geological requirements for UTES systems also contribute significantly to the high investment costs for this technology [24].

\subsubsection{Policy and Market Conditions}

Market opportunities for UTES systems are plentiful in Europe where district heating is more common due to the colder climate. However, this technology has not seen the same widespread commercialization in the U.S. The regulatory barriers that UTES systems currently face primarily revolve around their groundwater usage. As a result, the siting and permitting process for UTES systems can be extremely long and cumbersome [20]. The U.S. can learn much from the successes and failures of policy ventures in European nations relating to UTES systems so that these systems can be efficiently implemented when the economic conditions are more favorable. In general, studies have shown that nationwide guidelines can help ensure uniform quality assurance and control standards are used for the installation of UTES systems [105].

\subsubsection{Compatible Applications}

Underground thermal energy storage is almost exclusively used for seasonal thermal energy storage and district heating applications. Due to the manner in which thermal energy is stored either in aquifers and underground reservoirs or the ground itself, the dispatchability of this technology is limited. The applications compatible with UTES systems are marked in Table 21. Note that combined heat and power and waste heat utilization have been added as potential compatible applications for the technologies in this section. 
Table 21. Applications compatible with sensible thermal energy storage systems.

\begin{tabular}{|c|c|c|c|}
\hline Service & UTES & $\begin{array}{c}\text { Hot and Cold Water } \\
\text { (storage tanks) }\end{array}$ & Solid Media (concrete) \\
\hline Energy Arbitrage & Incompatible & Compatible & Compatible \\
\hline Frequency Regulation & Incompatible & Incompatible & Incompatible \\
\hline Load Following & Incompatible & Incompatible & Incompatible \\
\hline Voltage Support & Incompatible & Incompatible & Incompatible \\
\hline Spinning Reserves & Incompatible & Incompatible & Incompatible \\
\hline Non-Spinning \& Supp. Reserves & Incompatible & Compatible & Compatible \\
\hline Black Start & Incompatible & Incompatible & Incompatible \\
\hline VSR Integration & Incompatible & Compatible & Compatible \\
\hline Seasonal Storage & Compatible & Compatible & Incompatible \\
\hline Process Heat Applications & Compatible & Compatible & Compatible \\
\hline
\end{tabular}

\subsubsection{Technology Maturity}

Underground thermal energy storage systems are a well-established and commercially mature method for seasonally shifting thermal energy. However, this technology has not seen widespread acceptance in the U.S. due to climate and policy differences as compared to Europe. Furthermore, this technology is not able to efficiently assist with the integration of variable generating renewable energy sources. Therefore, this technology cannot claim the same market opportunities as many of the other energy storage technologies considered in this report. As a result, a TRL of 8 was given, as shown in Table 19.

\subsubsection{Future Development}

In Europe, the number of aquifer TES installations has grown from about 100 to around 1,000 in the past decade. The number of borehole TES installations has grown at an even faster rate [105]. However, a considerable amount of research and development concerning UTES systems is still needed to make these systems more thermally and economically efficient. The reliability of UTES systems at medium temperatures must also improve before UTES systems will see worldwide acceptance. Although, one inherent limitation of UTES systems is that some of these inefficiencies are due to theoretical constraints. As developers continue to explore geothermal energy production opportunities in an effort to further develop renewable energy sources, an increased understanding of UTES systems could be achieved as a byproduct. Understanding the operational characteristics of storing thermal energy in geologic formations is an essential piece to increasing the effectiveness of this storage technology [20].

\subsubsection{Hot and Cold Water Storage}

\subsubsection{Technology Overview}

Hot and cold water storage tanks are probably the most prominent form of thermal energy storage. These energy storage systems are used primarily to shift the energy demand for the heating and cooling of residential and commercial buildings to off-peak periods to reduce costs. There are many different versions of this simple technology. For example, domestic water heaters can be used as a distributed form of thermal energy storage. In fact, in France, the thermal energy storage capacity available in domestic electric water heaters is responsible for reducing the country's peak energy demand in the winter by about $5 \%$. By allowing the utilities to gain control over individual water heaters throughout the country, the peak energy demand can be reduced and costs are returned to the consumer [20]. Additionally, steam accumulators are another form of hot water energy storage in which steam produced by a power plant is stored directly as a pressurized saturated liquid [106]. In a typical thermal energy storage system using hot or cold water, the device chills or transfers heat to the water, which is then stored in an insulated tank. The water is generally held at temperatures either right above the freezing temperature of water or right 
below the boiling temperature. However, pressurized storage tanks can hold water at even higher temperatures. Even still, the storage output temperature of this technology is severely limited [20] [70]. A diagram of a system of utility-scale hot and cold water storage tanks is included in Figure 28.

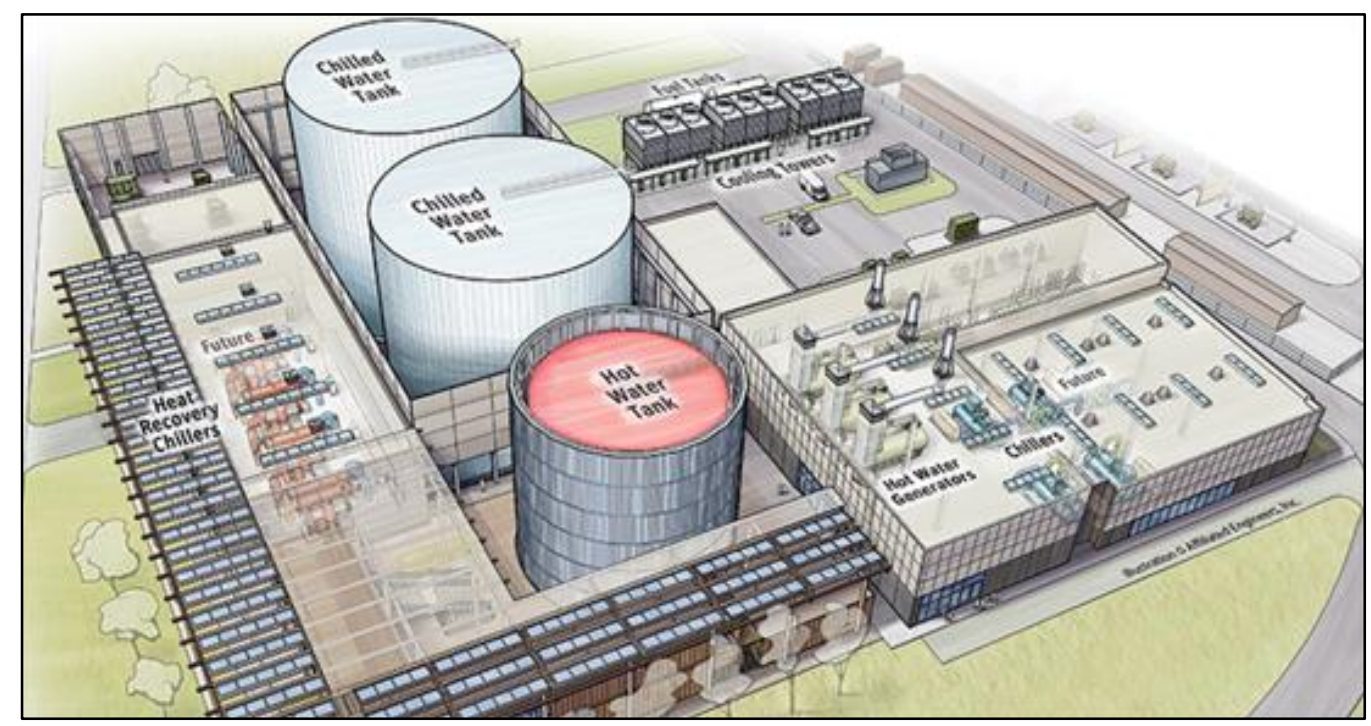

Figure 28. Representative diagram of hot and cold water energy storage tanks [107].

\subsubsection{Performance Parameters}

The performance parameters of hot and cold water storage systems are dependent on the size of the tanks used as well as the design and nature of the system. For example, steam accumulator systems are designed for very fast discharge rates and response times, since steam can quickly be generated from the available superheated water [106]. Furthermore, the storage output temperature for hot and cold water storage systems is dependent on the freezing and boiling temperatures of water. Therefore, water storage tanks are severely limited in their range of possible output temperatures. Although pressurized water storage tanks can be used to achieve higher storage temperature and energy densities, the associated investment costs are higher as well. The performance parameters for a typical hot or cold water storage tank are listed in Table 19.

\subsubsection{Environmental Impact}

Since the medium for energy storage in this technology is water, the environmental impact of hot and cold water storage systems is minimal. The tanks can be relatively large, especially the ones used for seasonal energy storage, ranging in size from 100 to 50,000 cubic meters of storage space [20]. However, the land impact of this storage technology is also negligible when compared to underground thermal energy storage systems. The environmental impacts of hot and cold water storage systems are summarized in Table 20. The geographic requirements for this technology are also addressed in this table. Note that this table focuses primarily on the environmental impacts of hot and cold water storage tanks.

\subsubsection{Policy and Market Conditions}

The process of heating or chilling water during periods of low demand to meet building cooling or heating loads when electricity is more expensive is a mature energy storage method. However, the building in which the energy storage system is installed must have a maximum load that is much higher than the average load in order for this technology to be economically viable [70]. Furthermore, the use of residential water heaters as a form of distributed energy storage in France has been demonstrated to 
reduce the country's peak energy demand in the winter as well as save money for electricity consumers that are able to avoid expensive demand charges [20]. On the other hand, steam accumulators have not experienced the same level of success in reaching commercialization. Although steam accumulators offer a unique benefit by providing power plants with short-term, fast responding thermal energy storage, unlike water storage tanks and residential water heaters, the components of a steam accumulator system are also expensive and detract from the potential profitability of the device [106]. Hot and cold water storage systems have also been adapted by electric utilities in the U.S. as a measure for enhancing system reliability, since one of the primary applications of hot and cold water storage is district heating. For example, Austin Energy (Austin, TX) operates three chilled water systems in the city of Austin to decrease the peak demand and reduce electricity charges for Austin Energy's customers. In addition, the District Cooling program reduces investment costs for commercial customers that would otherwise need to install their own chillers and cooling tower. The District Cooling program also helps support Austin Energy's Resource, Generation, and Climate Protection plan meant to incentivize the development of energy storage resources in the city [108]. Yet, hot and cold water storage systems still face regulatory barriers that must be overcome. In particular, the lack of time-of-use pricing in the majority of electricity markets in the U.S. has limited the economic benefit that energy storage could potentially provide [109].

\subsubsection{Compatible Applications}

As with the performance parameters of this technology, the applications compatible with hot and cold water energy storage depend on the size and the nature of the system. Steam accumulators are ideally suited for providing firming capacity for renewables and fast response services such as spinning reserves [106]. Firming capacity is defined as the ability to smooth out generation from variable generating resources by providing power when there are sudden outages in the supply. Conversely, large scale hot water storage tanks are well-suited for seasonal energy storage and residential water heaters can be used effectively for energy arbitrage and load following [20]. Therefore, although hot and cold water energy storage is compatible with many applications, not every form of the technology is compatible with every application. The applications compatible with hot and cold water energy storage tanks are listed in Table 21.

\subsubsection{Technology Maturity}

Thermal energy storage in the form of hot and cold water tanks used to shift the energy demand for heating and cooling buildings to off-peak periods is a mature technology that has been around for decades [70]. However, there has been little to no integration of this technology with power plants. The deployment of this technology beyond the HVAC space has been limited to the integration of steam accumulators with a 50 MW NPP in the Berlin island grid [106]. Therefore, hot and cold water storage tanks as an energy storage technology have only seen demonstration-scale deployment. This technology was given a TRL of 7 since it is mature, but has not yet been fully integrated with power plants, as shown in Table 19.

\subsubsection{Future Development}

Due to the many forms and applications of hot and cold water thermal energy storage systems, there are many opportunities for further research and development. Much of the research and development for hot water storage tanks is focused on developing better insulation, specifically evacuated super insulation is being developed with a thermal loss rate of $0.01 \mathrm{~W} / \mathrm{mK}$ at $90^{\circ} \mathrm{C}$ [24]. For steam accumulators, advanced storage techniques are being considered, such as the storage of steam in the existing heat exchanger to reduce investment costs [106]. Finally, efforts to quantify the amount of distributed thermal energy storage that is available in the form of electric water heaters in the U.S. is key to developing hot water energy storage as a method for reducing peak demand [20]. 


\subsubsection{Solid Media Storage}

\subsubsection{Technology Overview}

Water has a very high heat capacity and as a result, water has a high energy storage density. However, as a form of sensible thermal energy storage, water also has limitations. Since the boiling and freezing temperatures for water are relatively close compared to other materials, such as concrete, water can only be heated to a certain temperature without causing it to boil, and it can only be cooled so much before it begins to freeze. Freezing or boiling water can have drawbacks because water is often transported as a liquid through pipes and stored in tanks, or in the case of UTES, underground caverns and aquifers. Thus, solid media energy storage systems offer a form of sensible thermal energy storage for high-temperature applications. Common solid materials used for thermal energy storage include concrete, bricks, and rocks. These materials are inexpensive, environmentally friendly, and easy to handle and manipulate. However, the energy density of solid materials is generally much lower than liquid storage media [20] [24]. Energy is usually transferred to a solid storage medium by first transferring the thermal energy to some heat transfer fluid that runs alongside the solid storage medium as in a conventional heat exchanger [110]. However, the solid storage medium could also be electrically heated, as with firebrick thermal energy storage systems [111]. An example of a module from a concrete thermal energy storage system is displayed below in Figure 29.

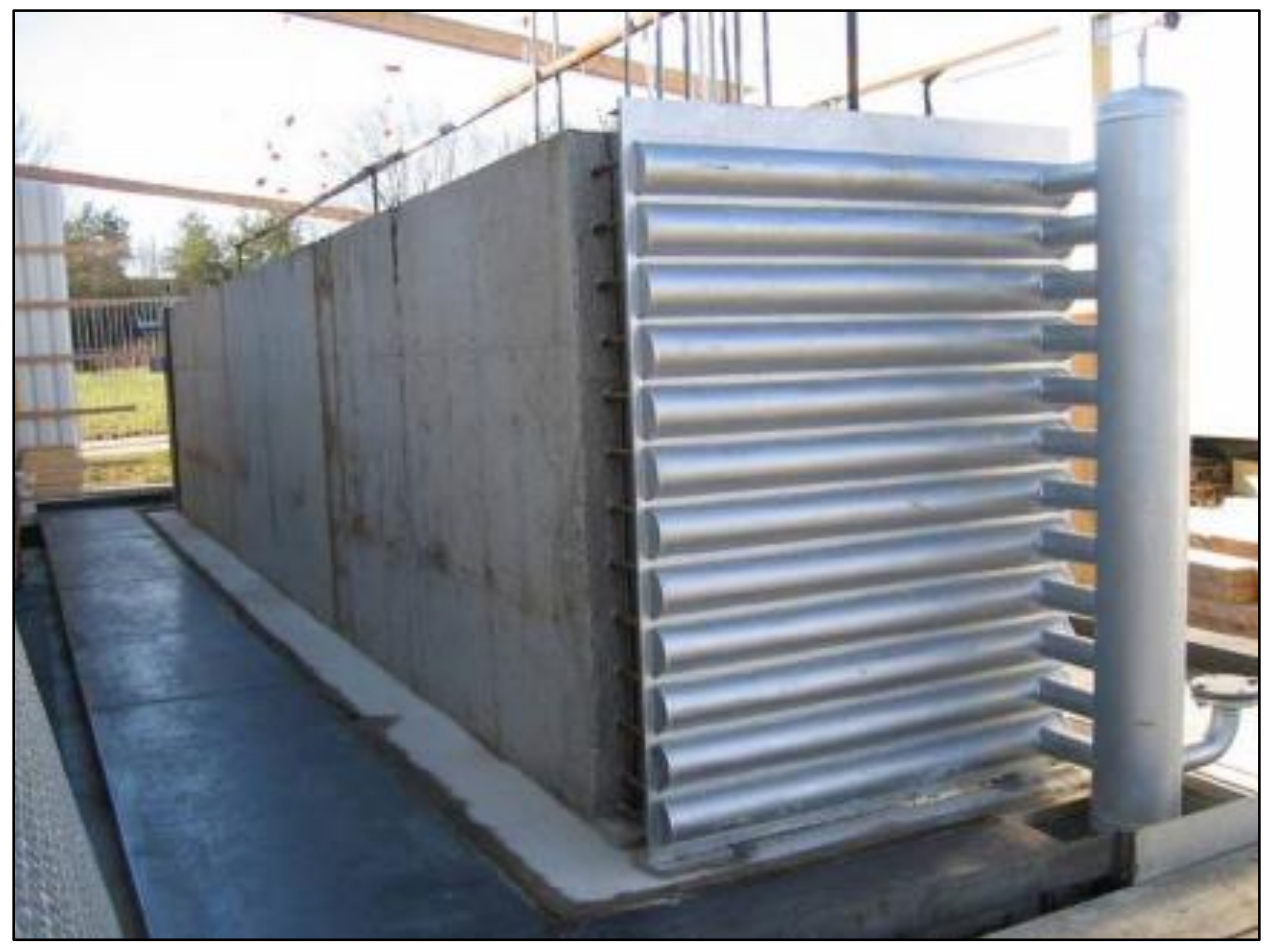

Figure 29. Example of a concrete thermal energy storage module [110].

\subsubsection{Performance Parameters}

The key advantage to solid storage media over liquids is that solids can be heated to higher temperatures without causing a change in phase. Additionally, solid storage media are more widely available and relatively inexpensive compared to other sensible thermal energy storage systems and phase change materials. Other sensible heat storage systems may require complex system designs to avoid phase changes or address the limitations of a particular material, but the system design for solid media storage systems can be as simple as a standard heat exchanger. The performance parameters for a concrete 
thermal energy storage system are listed in Table 19. Concrete was chosen because it has received the most attention for research and development of the potential materials [110].

\subsubsection{Environmental Impact}

The three types of solid media for thermal energy storage considered in this report are concrete, firebricks, and geothermal energy storage systems. Neither concrete nor firebricks are made from environmentally critical materials, and water or air is typically used as the heat transfer fluid for storing energy in these systems. Therefore, the environmental impact of these two systems is minimal. However, the effect that storing energy in artificially created geothermal heat reserves has on the surrounding geology is uncertain. As the geothermal energy storage system is repeatedly charged and discharged, mechanical stresses can be applied to the rocks and the nature of the geology could be permanently affected. Further research and development into the environmental impact of geothermal heat storage systems is required, since the long-term impacts are unknown [112]. The environmental impacts of solid media storage systems are summarized in Table 20. However, the information in this table focuses on concrete thermal energy storage systems. The geographic requirements for this technology are also addressed in this table.

\subsubsection{Policy and Market Conditions}

Solid media thermal energy storage systems operate in a similar manner to hot and cold water storage tanks in many ways. However, solid media storage systems are able to claim market opportunities inaccessible to hot and cold water storage systems due to their much higher storage output temperatures. Therefore, solid media storage systems are more ideally suited for integration with NPPs, which are known to output heat at very high temperatures [20] [24]. Currently, solid media storage systems are being investigated for use with concentrating solar power (CSP) plants. Studies have shown that in the summer, an energy storage facility operating with concrete as the storage medium could enable a CSP plant to operate almost the entire night using energy stored during the day, which would greatly increase the profitability of the CSP plant [110]. Due to the simplicity of solid media storage systems and the minimal environmental impact of this technology, there are few regulatory barriers impeding commercialization. Although, there are likely to be regulations restricting geothermal energy storage systems similar to regulations regarding hydraulic fracturing for shale gas [112]. The DOE has expressed interest in funding the development of solid media storage systems as a part of the SunShot Initiative. This funding has been given to the University of Arkansas to develop a novel concrete material capable of withstanding temperatures of $500^{\circ} \mathrm{C}$ or more for use with CSP plants [113].

\subsubsection{Compatible Applications}

Solid media storage facilities have been considered for use with solar thermal power plants, due to their ability to store high-temperature heat. Solid media storage systems provide solar thermal power plants with the ability to generate continuous power throughout the day and be dispatchable when necessary. The operation of a full-scale solid media storage facility was simulated for integration with a solar thermal power plant, using weather patterns for the year 2005 in Guadix, Spain. It was estimated that the thermal energy provided by the facility would contribute approximately $30 \%$ of the 3,500 full load hours of electricity generation supplied to the grid by the solar thermal power plant in a year [110]. Some of the applications compatible with solid media storage are listed in Table 21. Once again, only concrete thermal energy storage was considered when selecting compatible applications. Seasonal storage is compatible with geothermal energy storage systems, although concrete and firebrick energy storage systems are not optimized to provide this service [112]. 


\subsubsection{Technology Maturity}

Of the solid media considered in this report for thermal energy storage, concrete is the closest to commercialization. Although firebricks and geothermal rocks have been considered theoretically, and their technical feasibility and economic viability has been determined, the development of these technologies has been limited to analytical studies. However, a concrete storage module has been built and used for extensive experimental testing in Stuttgart, Germany to physically validate the viability of concrete as a thermal energy storage medium [110]. While firebricks and geothermal energy storage have only progressed to a TRL of 2 or 3, concrete has progressed to a TRL of 6 , since an engineering-scale project has been built in Germany. The TRL for solid media is listed in Table 19.

\subsubsection{Future Development}

Each solid storage material considered in this section has different areas of need for research and development. Physical validation of the conceptual systems that have been developed for firebricks and geothermal energy storage systems is needed before these technologies can progress any further towards commercialization. Alternatively, for concrete energy storage systems, a more efficient design for the heat transfer process responsible for storing the thermal energy generated by a power plant in the solid storage medium could significantly reduce system costs. Additionally, better storage control strategies could increase the available storage capacity and discharge times for solid media storage facilities [110]. For firebrick energy storage systems, work is still needed to identify materials with the optimal combination of energy density and charge-rate capabilities [111]. Finally, geothermal energy storage systems require further research concerning the long-term effects this technology has on the mechanical integrity of the rocks [112].

\subsubsection{Latent Thermal Energy Storage}

When a material changes phase, all of the energy transferred to that material is directed towards facilitating the phase change instead of increasing the temperature of the material. The phase change process often requires a significant amount of heat transfer per unit mass of material. As a result, latent thermal energy storage technologies can often store more energy per unit mass and they are able to discharge energy at a constant temperature. These unique characteristics of latent thermal energy storage technologies makes them a particularly good fit for integration with industrial process heat applications. There are a wide range of different latent thermal energy storage designs. However, sophisticated system design is often required to ameliorate the weaknesses of the chosen latent thermal energy storage medium. Latent thermal energy storage technologies are also often more expensive than sensible thermal energy storage technologies [24]. The latent thermal energy storage technologies considered in this report are thermochemicals, molten salts, liquid air, and phase change materials.

\subsubsection{Thermochemicals}

\subsubsection{Technology Overview}

Thermochemical storage (TCS) systems have emerged as a potential energy storage solution recently due to the technology's superior energy density and absence of any energy leakage throughout the technology's storage duration. TCS systems store energy in endothermic chemical reactions and the energy can be retrieved at any time by facilitating the reverse, exothermic reaction. Therefore, the storage output temperature is dependent on the properties of the thermochemical that was used as the storage medium [20]. Typically, thermochemical energy storage refers to two main processes, thermochemical reactions and sorption processes. Thermal adsorption reactions can be used to store heat or cold in the bonding of a substance to another solid or liquid. A common sorption process used in TCS systems is the adsorption of water vapor to silica gel or zeolites. During charging, the water is desorbed from the inner surface of the adsorbent and is adsorbed again when the stored energy is discharged from the system [24]. 
Alternatively, heat can be stored by directing thermal energy to an endothermic chemical reaction. In this reaction, a thermochemical absorbs the energy and splits into separate substances, which can be stored until the energy is needed again. The reverse reaction occurs when the two substances are recombined and thermal energy is released through this exothermic reaction. The latent heat of the reaction for the selected thermochemical is equal to the storage capacity of the system [116]. Although the energy densities of thermochemicals are greatly superior to other energy storage technologies, thermochemicals are currently economically infeasible [19]. An example of a thermochemical energy storage system using solar energy to power the principal chemical reaction is diagrammed below in Figure 30.

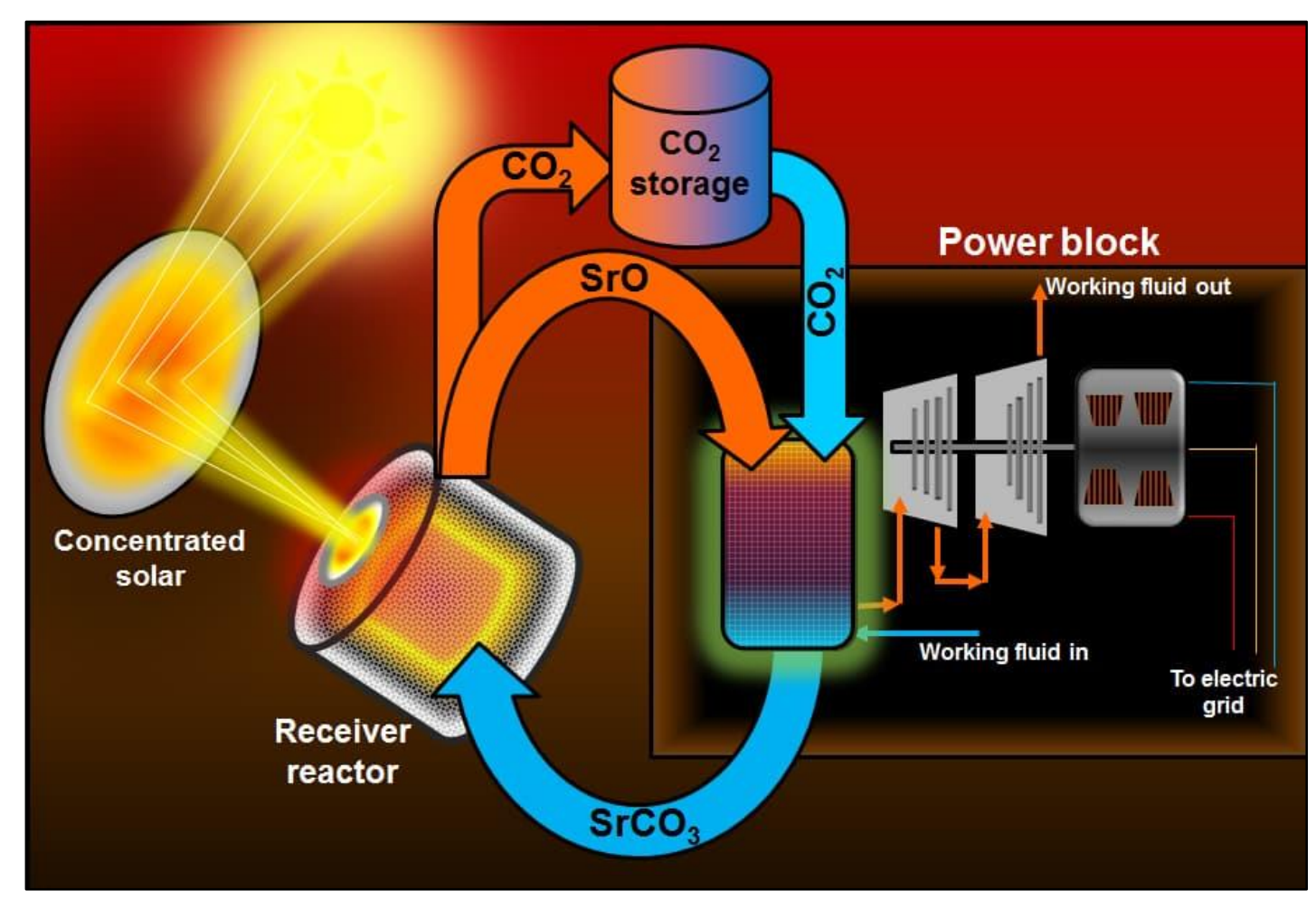

Figure 30. Representative diagram of a thermochemical energy storage system [117].

\subsubsection{Performance Parameters}

The most attractive characteristic of TCS systems is their superior energy density. A large amount of thermal energy might be required to split a certain thermochemical, but the only storage space required afterwards is related to the volume of the two substances resulting from the endothermic reaction. Therefore, TCS systems offer many unique services that other technologies cannot provide, such as the ability to transport large amounts of thermal energy from place to place. Additionally, since a chemically stable state is reached in both the adsorption and thermochemical reaction processes, minimal energy is lost throughout the storage duration compared to other thermal storage systems [24] [116]. However, the technical characteristics for TCS systems are wide ranging since many different chemicals can be used. The performance parameters for a typical TCS system are listed in Table 22. 
Table 22. Performance parameters for latent thermal energy storage systems.

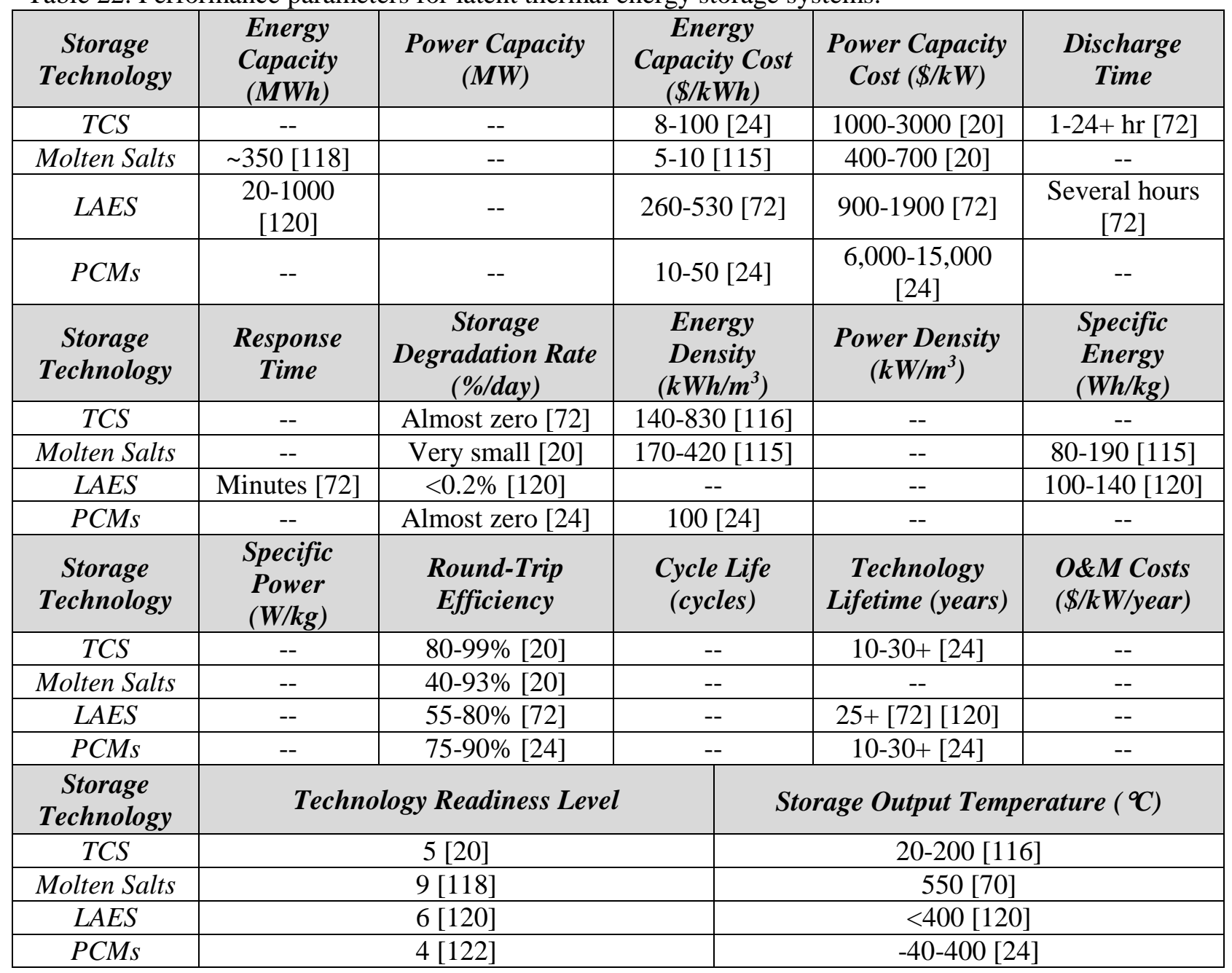

\subsubsection{Environmental Impact}

Thermochemical energy storage is an energy storage method that could directly impact the adverse environmental effects associated with peaking natural gas power plants. TCS systems can make integrating renewable energy sources into the grid more efficient by disconnecting the supply and demand of electricity. Specifically, TCS systems are capable of storing thermal energy in a compact space, which can be critical to maximizing the efficiency of the grid since the growing population in the U.S. has led to limited space and environmental concerns have led to project siting issues for larger energy storage technologies. TCS systems can also help to decouple the supply and demand of electricity spatially by transporting large amounts of thermal energy from renewable energy sources to a location where it can be more effectively used to match demand. However, as these distances increase, the emissions produced during transportation become an issue as well. Additionally, some thermochemical materials can degrade significantly with cycling, or can be toxic or corrosive and difficult to handle. Therefore, the environmental impact of the thermochemical material chosen for a particular energy storage application should be considered in addition to its technical characteristics [24] [116]. The environmental impacts of thermochemical storage systems are summarized in Table 23 with other latent thermal energy storage systems. The geographic requirements of this technology are also addressed in this table. 
Table 23. Environmental impacts of latent thermal energy storage systems.

\begin{tabular}{|c|c|c|c|c|}
\hline Environmental Impact & TCS & Molten Salts & LAES & PCMs \\
\hline Land and Water Impact & Insignificant & Insignificant & Insignificant & Insignificant \\
\hline Emissions Produced During Operation & None & None & Yes & None \\
\hline Hazardous Materials & Yes & Yes & None & Yes \\
\hline Hazardous Fumes & None & Yes & None & None \\
\hline Short-Term Safety Concerns & None & Minimal & None & None \\
\hline Resource Depletion & Insignificant & Insignificant & Insignificant & Insignificant \\
\hline Geographic Requirements & None & None & None & None \\
\hline
\end{tabular}

\subsubsection{Policy and Market Conditions}

One of the most important market niches that TCS systems have the potential to fill is the transportation of stored energy. As transmission systems reach capacity in electricity markets all over the U.S., TCS systems offer an alternative method for transporting energy to consumers. Since the selfdischarge rate for this technology is negligible, the energy can be transported relatively efficiently. An ongoing demonstration project has shown that a sorption process can be performed at $150^{\circ} \mathrm{C}$, the chemicals transported over 7 kilometers, and the stored energy discharged at $180^{\circ} \mathrm{C}$. The long storage duration of this technology also enables TCS systems to offer seasonal energy storage services similar to PSH and CAES systems [24]. In addition, a few DOE programs are funding further development of TCS systems. The Renewable Power program within the Energy Efficiency and Renewable Energy office is investigating TCS systems for concentrating solar power in an effort to meet SunShot targets. Furthermore, the NSF initiative funding renewable energy storage (RESTOR) awarded four grants to energy storage projects in 2010, including a project examining thermochemical options for solar fuel production [19].

\subsubsection{Compatible Applications}

Although transmission deferral is a valuable service provided by thermochemical energy storage, due to the ability to easily transport thermochemicals over large distances, this service does not expressly benefit nuclear power and was not considered in this report. However, the ability of TCS systems to provide long-term seasonal energy storage as well as daily energy arbitrage makes this technology particularly interesting due to its relatively wide range of compatible applications. The compact nature of TCS systems also make them well-suited for capturing waste heat from a power plant or other industrial process and storing this energy [24] [116]. The applications compatible with TCS systems are listed in Table 24 at the end of this section.

\subsubsection{Technology Maturity}

Of all the energy storage technologies considered in this report, TCS systems are probably the furthest from commercialization. A few demonstration projects have been commissioned, including a facility in Germany and a couple of mobile storage units, but many of the aspects of TCS systems are still under development [20] [24]. Furthermore, identifying the ideal chemicals for use with grid-scale energy storage applications is still a work in progress [116]. Therefore, this technology was assessed with a TRL of 5 , since the technology is in development and a similar system has been demonstrated for an alternate use. The TRL for TCS systems is listed in Table 22. 
Table 24. Compatible applications for latent thermal energy storage systems.

\begin{tabular}{|c|c|c|c|c|}
\hline Service & TCS & Molten Salts & LAES & PCMs \\
\hline Energy Arbitrage & Compatible & Compatible & Compatible & Compatible \\
\hline Frequency Regulation & Incompatible & Incompatible & Incompatible & Incompatible \\
\hline Load Following & Incompatible & $\begin{array}{c}\text { Somewhat } \\
\text { compatible }\end{array}$ & Compatible & Incompatible \\
\hline Voltage Support & Incompatible & Incompatible & Incompatible & Incompatible \\
\hline Spinning Reserves & Incompatible & Compatible & Compatible & Incompatible \\
\hline $\begin{array}{c}\text { Non-Spinning \& Supp. } \\
\text { Reserves }\end{array}$ & $\begin{array}{c}\text { Somewhat } \\
\text { compatible }\end{array}$ & Compatible & Compatible & $\begin{array}{c}\text { Somewhat } \\
\text { compatible }\end{array}$ \\
\hline Black Start & Incompatible & Incompatible & Compatible & Incompatible \\
\hline VSR Integration & Compatible & Compatible & Compatible & Compatible \\
\hline $\begin{array}{c}\text { Seasonal Storage } \\
\text { Process Heat } \\
\text { Applications }\end{array}$ & Compatible & Incompatible & Compatible & Compatible \\
\hline
\end{tabular}

\subsubsection{Future Development}

The future research and development directions for thermochemical energy storage technologies can be divided into three groups: low-temperature, medium-temperature, and high-temperature applications. Due to its high energy density compared to other energy storage technologies, TCS systems are currently at the forefront of research and development into energy storage technologies. TCS systems are capable of storing 5-20 times more energy than sensible thermal energy storage technologies can store in the same amount of space. Although this exceptional energy density positions TCS systems as an attractive option for all energy storage applications, it is unclear how thermochemical systems would be able to store low temperature heat. Therefore, identifying a role for TCS systems that can store low temperature heat is a growing area of research. Medium temperature applications are more compatible with current TCS systems and demonstration projects have been completed in Germany and other countries, although the control systems are still in need of major development. Finally, TCS systems are most attractive for high temperature applications, due to their high energy density, high cycle lives, and low self-discharge rates. Additionally, TCS systems are more cost-effective than many other storage technologies that are compatible with high temperature applications. TCS systems will still have to overcome a few technical challenges before they will see widespread implementation though. Emphasis on research into material stability and thermochemical containment vessels is crucial, along with more effective control systems, to successfully deploy this storage technology. TCS systems show great promise as a compact and costeffective storage medium [20].

\subsubsection{Molten Salts}

\subsubsection{Technology Overview}

Molten salts are a phase change material that is commonly used for thermal energy storage. Molten salts are solid at room temperature and atmospheric pressure, but change to a liquid when thermal energy is transferred to the storage medium. However, in most molten salt energy storage systems, the molten salt is maintained as a liquid throughout the energy storage process. Molten salts are typically made up of $60 \%$ sodium nitrate and $40 \%$ potassium nitrate, and the salts melt at approximately $220^{\circ} \mathrm{C} \mathrm{[70].} \mathrm{Molten}$ salts are often used with CSP plants to store thermal energy to be used later for electricity generation [20]. In CSP plants, excess heat that is not used for electricity generation is diverted to the molten salt, which is then stored in an insulated tank. After sunset, this thermal energy can be used to produce steam and continue to generate electricity when the sun is no longer providing energy to the CSP plant. Additionally, this thermal energy storage capacity can be used to smooth electricity production 
throughout the day and mitigate the variability associated with most other solar power technologies [118]. In fact, the integration of thermal energy storage capacity can increase the capacity factor of a CSP plant from $25 \%$ to nearly $70 \%$ [70]. A molten salt thermal energy storage system is diagrammed below in Figure 31 for a CSP plant.

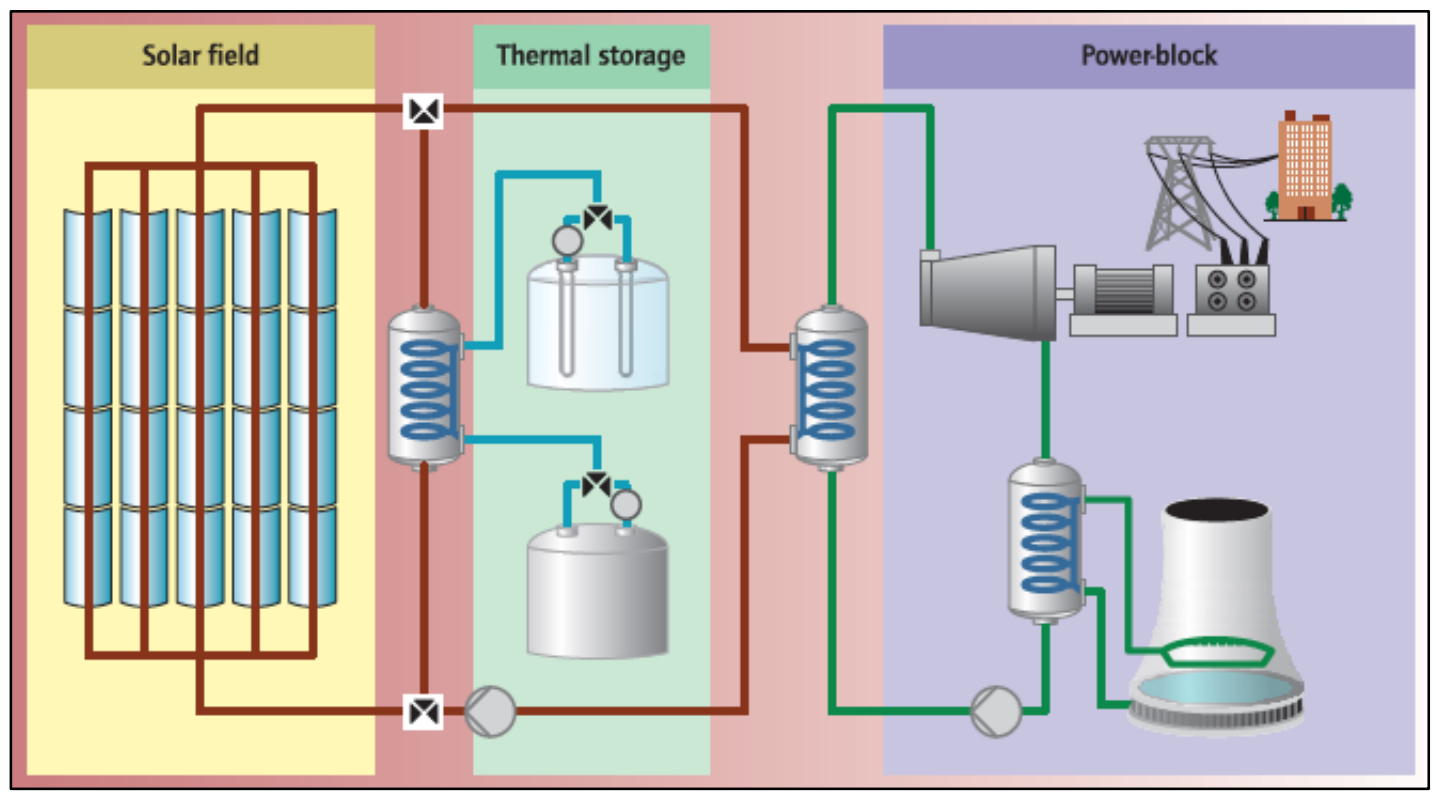

Figure 31. Representative diagram of a molten salt TES system for a CSP plant [118].

\subsubsection{Performance Parameters}

Ideally, molten salt thermal energy storage systems would enable a power plant to generate electricity during peak demand periods and provide the grid with key ancillary services. Furthermore, the thermal energy storage system should grant an electricity generating unit independence from conventional peaking power plants by providing firming capacity to the power system. However, these capabilities require enough storage capacity to produce power for several hours [70]. Molten salt energy storage systems of this size have been demonstrated in Spain, where molten salts can provide the heat to generate electricity for more than 7 hours. Additionally, another plant in Spain is under construction that could store enough thermal energy to produce power for 16 hours at full capacity [118]. Molten salt energy storage systems are also a relatively low-cost and efficient storage medium [70]. Performance parameters for a typical molten salt energy storage system are listed in Table 22 at the end of this section.

\subsubsection{Environmental Impact}

Using molten salts for thermal energy storage can reduce a power plant's reliance on a conventional peaking power plants and in that way, molten salt energy storage systems reduce the total amount of $\mathrm{CO}_{2}$ emissions produced. However, the environmental impacts associated with molten salt leaks and the disposal of molten salts when a plant is decommissioned are still significant. A study examining the lifecycle environmental impacts of molten salts determined that the largest impacts come from the emissions produced during the transportation of materials and the possibility of toxic compounds being produced if the used material is landfilled. However, these environmental impacts can be easily mitigated by exploring alternative methods for transporting and recycling materials. Thus, the environmental impact of molten salts energy storage systems is relatively low [119]. Furthermore, since molten salts are typically stored in large, insulated tanks, the land impact for these storage systems is also minimal [118]. The 
environmental impacts of molten salts are summarized in Table 23. The geographic requirements for this technology are also addressed in this table.

\subsubsection{Policy and Market Conditions}

Molten salts are already a commercially viable energy storage medium since this material is already being used with CSP plants. Therefore, there is already a significant opportunity for the development of molten salt energy storage systems. Molten salt energy storage systems enhance the capability of CSP plants by removing the variability usually associated with solar power and enabling CSP plants to operate like conventional base-load power suppliers. Furthermore, federal programs like the Renewable Energy Grant Program and Federal Loan Guarantee Program that encourage investment in innovative CSP technologies could also drive the development of molten salt energy storage systems [118].

\subsubsection{Compatible Applications}

The most obvious application of molten salt energy storage systems is variable supply resource integration since molten salts are most often used with concentrating solar power plants. However, molten salts can also serve as a storage medium and bring flexibility and dispatchability to other primary energy sources as well. Molten salts enable CSP plants to perform energy arbitrage by storing excess heat produced during the day so that the plant can generate electricity at night. Molten salts can also provide other ancillary services to improve the profitability of the storage system, such as spinning reserves [70]. A few of the compatible applications for molten salt energy storage systems are listed in Table 24 at the end of this section.

\subsubsection{Technology Maturity}

Since molten salt energy storage systems are already being used with CSP plants, they are a relatively mature storage technology. Therefore, this technology was given a TRL of 9, as shown in Table 22 . However, although the molten salt energy storage systems have been implemented on a large scale they have not been integrated with an NPP at the time of this report. The TRL score could be considered to be lower than 9 if focused exclusively on nuclear or other applications that molten salt energy storage systems have not yet been applied to.

\subsubsection{Future Development}

Molten salts are an excellent storage medium because they can reach high temperatures without boiling, are an efficient and low-cost storage medium, are compatible with modern high-pressure and high-temperature steam turbines, and are non-flammable and non-toxic [70]. However, many methods for improving the efficiency and storage capacity of molten salts have been considered and are currently in development. These methods include the addition of nanoparticles to increase the heat capacity of molten salts and using thermocline separation to separate hot and cold molten salts in a single storage tank. Thermocline separation has proven to be difficult though, leading to an increased risk of leakage from the molten salt energy storage system [118]. In the future, these storage systems could potentially be integrated with other primary energy sources to increase the flexibility of the grid as a whole.

\subsubsection{Liquid Air}

\subsubsection{Technology Overview}

Liquid air energy storage (LAES) technologies are gaining traction as an efficient and cost-effective energy storage method due to their large scale and long duration as well as their compatibility with existing infrastructure. LAES systems store energy using a method very similar to CAES systems. However, instead of storing compressed air in a large cavern, the volume of the gas is reduced further by refrigerating the air and liquefying it. The liquid air is then stored in an insulated, low-pressure tank above 
ground, eliminating the geographic requirements associated with CAES systems. Since the air is liquefied, LAES was categorized as a latent thermal energy storage system for the purposes of this report. In LAES systems, natural gas is typically burned to drive the expansion process. However, the advanced adiabatic and isothermal compression methods that are being developed for CAES systems are applicable to LAES systems as well. Furthermore, utilizing waste heat or cold from other processes, such as LNG terminals or landfill gas engines could further improve the efficiency of this technology and eliminate the need for an external energy source [120]. The simple three-step process for storing energy with liquid air is displayed below in Figure 32.

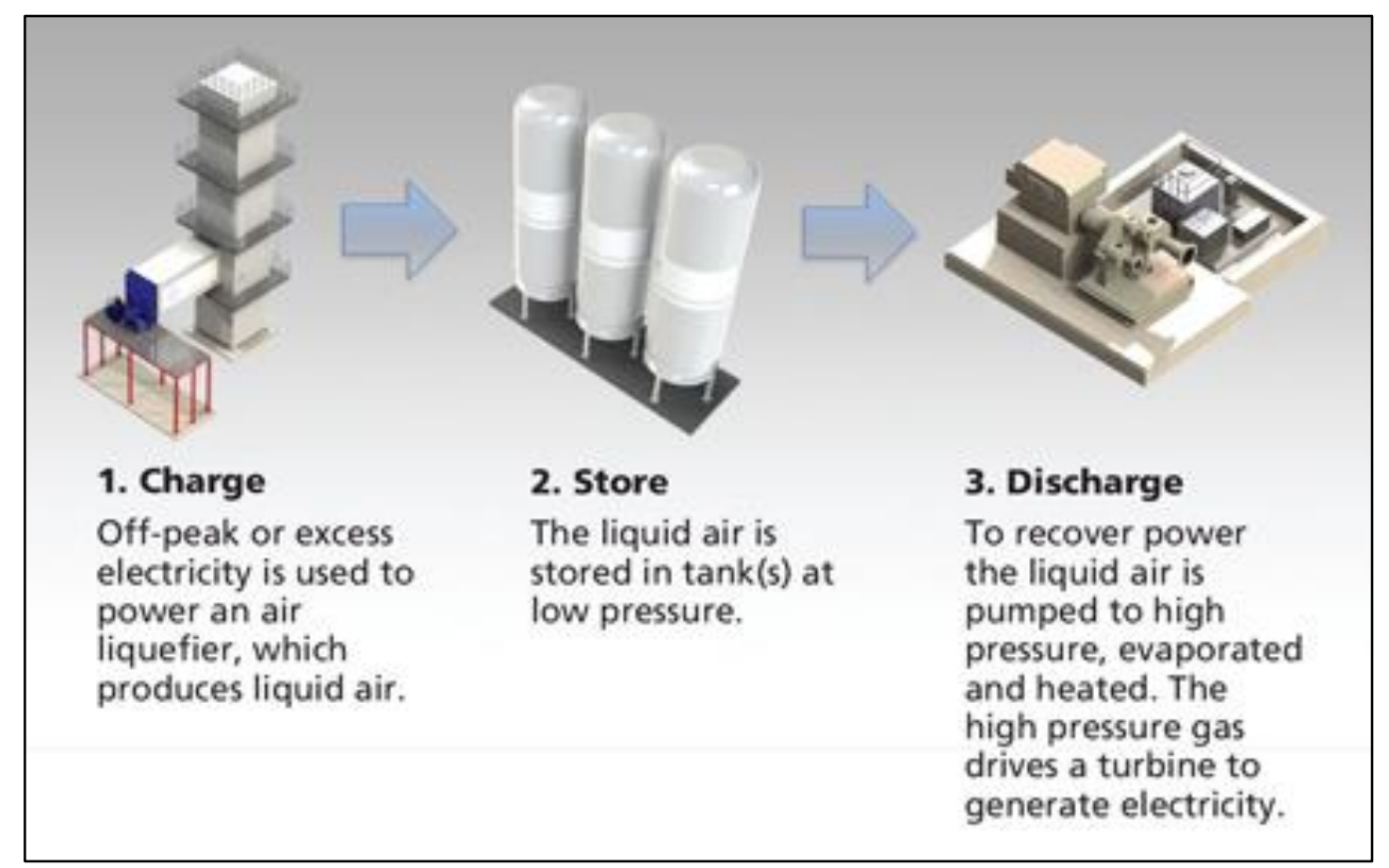

Figure 32. Representative diagram of the liquid air energy storage process [121].

\subsubsection{Performance Parameters}

LAES systems are particularly attractive as a method of thermal energy storage due to their high expansion ratio from liquid to gaseous air and the high power density of liquid air compared to compressed air [72]. Similar to CAES and PSH systems, LAES systems operate more effectively at a larger scale, where the economics, self-discharge rate, and efficiency all improve. Therefore, the technical characteristics of this technology are best suited for long duration storage applications [120]. The performance parameters for a typical LAES system are listed in Table 22.

\subsubsection{Environmental Impact}

As with most other energy storage technologies, using energy storage to address system balancing issues introduced by VRES not only provides power during peak demand periods when renewable energy sources are not producing, but also increases the overall load factor of the system. As a result, fewer expensive, high-emitting gas turbine plants are needed to provide the grid with additional flexibility. Energy storage can also slightly lower the efficiency of the system due to efficiency losses as energy is stored and released from the storage technology. A major environmental concern for LAES systems is the need for an additional natural gas turbine to provide heat during the expansion process, negating some of the environmental benefits of storing energy. If some of the thermal energy removed from the air during 
compression were stored, this heat could then be used again during the expansion process. LAES systems are not constructed with any scarce or hazardous materials. The liquefication phase of LAES systems reduces the volume of the working fluid so that it can be stored in above ground tanks rather than in underground caverns, so the land impact for LAES systems is also minimal [120]. The environmental impacts of liquid air energy storage systems are summarized in Table 23. The geographic requirements of this technology are also addressed in this table.

\subsubsection{Policy and Market Conditions}

The market opportunities for LAES systems should be similar to the opportunities for CAES and PSH systems, since this technology offers many of the same services. However, the ability to site these systems without having to consider geographic requirements could reduce the lead times for LAES projects and increase the marketability of the technology compared to CAES and PSH systems. LAES technology is relatively new, with only a single pilot-scale project completed in the United Kingdom. In 2011, this installation was commissioned by Highview Power Storage to provide energy storage for Scottish and Southern Energy's 80 MW biomass power plant in London. This project was partially funded by the United Kingdom's Department of Energy and Climate Change grant, indicating a willingness from government bodies to pass initiatives incentivizing private investment in this technology. As LAES technology develops, similar policy measures could be passed in the U.S. and other countries that are considering this technology to encourage development [120].

\subsubsection{Compatible Applications}

The applications for liquid air energy storage systems are similar to the applications for a CAES system. The LAES system could aptly be described as a thermo-mechanical system, since the energy is stored thermally, but withdrawn mechanically to produce electricity. LAES systems are better matched with electrical applications than thermal applications, such as district heating. Thus, by observing the applications for CAES systems and the technical characteristics of LAES systems, several applications compatible with LAES could be identified [120]. These applications are listed in Table 24 at the end of this section.

\subsubsection{Technology Maturity}

A single fully integrated LAES storage plant has been commissioned at the demonstration scale. Based on the success of this project, Highview Power Storage is beginning to pursue additional large scale commercial plants in the United Kingdom as well as abroad. One factor that could accelerate the development of this technology is the existence of mature components used by the natural gas and electricity industries that can be converted for use in a LAES system. Therefore, LAES technology was assigned a TRL of 6 since a pilot-scale project has been built, but the technology is also still undergoing further development. The TRL for LAES systems is listed in Table 22 [120].

\subsubsection{Future Development}

One of the biggest hurdles for LAES systems to overcome is gaining independence from external energy sources, such as natural gas turbines. These limitations increase the carbon emissions associated with the operation of this storage technology and reduce the number of services the technology can provide. Therefore, advanced adiabatic compression and isothermal compression methods that are being developed for CAES systems are also being considered for LAES systems. In fact, Highview Power Storage's LAES installation stores excess heat withdrawn from the air during the compression stage in either hot water or oil for use in the expansion cycle. This process mimics an advanced adiabatic compressor for a CAES system. These developments could improve the cost-effectiveness and efficiency of LAES systems [120]. 


\subsubsection{Phase Change Materials}

\subsubsection{Technology Overview}

Although sensible thermal energy storage can be effective and is relatively inexpensive, latent thermal energy storage technologies offer superior energy densities and target-oriented discharge temperatures. Molten salts and liquid air are both specific types of phase change materials (PCMs) that have developed into independent technologies due to their maturity compared to other PCMs. In theory, any PCM can be used for thermal energy storage, but a few have been proven for their effectiveness. With PCMs, as thermal energy is transferred to or away from the chosen storage medium, the material changes phase. Since all of the thermal energy transferred to the material is directed to changing the material's phase, PCMs absorb and release heat isothermally throughout the phase change process. Depending on the material used, PCM thermal energy storage systems can be used for either daily energy arbitrage or seasonal energy storage. However, although these materials can store 5-14 times more thermal energy per unit volume than sensible energy storage technologies, a phase change material must have very specific properties to be an effective storage medium. For example, to be used as latent heat storage medium, PCMs should have a phase-transition temperature that aligns well with the desired operating temperature, a high latent heat of fusion, and high thermal conductivity. These materials can also be expensive and rare, which could slow the technology's progression toward maturity [24] [122]. An ice thermal energy storage system is presented below in Figure 33. Ice, along with liquid air and molten salts, is considered to be a phase change material since energy is stored in the form of latent heat.

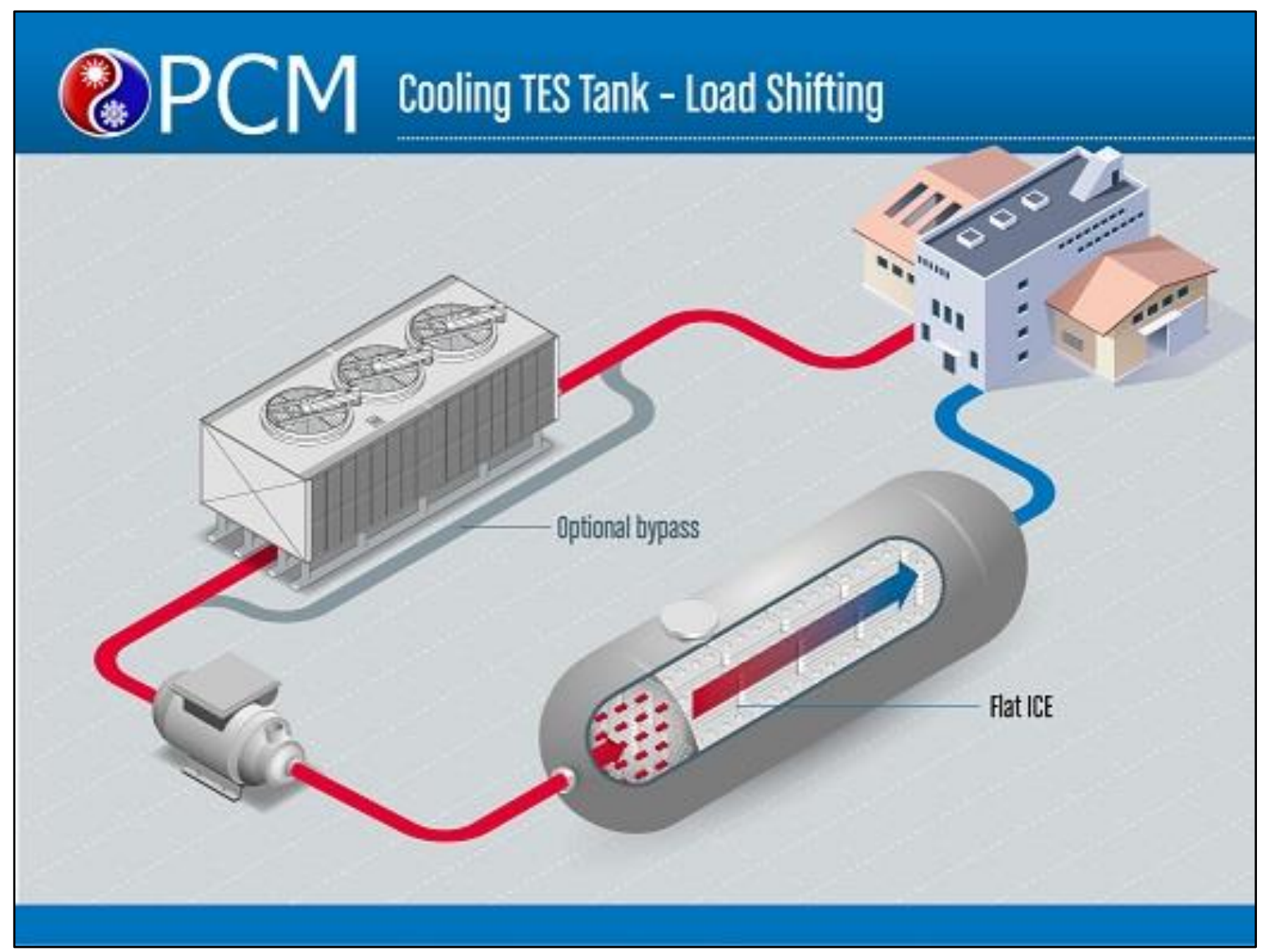

Figure 33. Representative diagram of an ice thermal energy storage system [123]. 


\subsubsection{Performance Parameters}

Melting processes can offer energy densities on the order of $100 \mathrm{kWh} / \mathrm{m}^{3}$, which is the energy density of melting ice. This energy density is much higher than the typical $25 \mathrm{kWh} / \mathrm{m}^{3}$ for sensible thermal energy storage systems [24]. However, the performance parameters of PCMs can vary widely depending on the chemical properties of the material used in the storage system. For example, the storage output temperature of a PCM thermal energy storage system can be matched to a particular application by selecting the appropriate phase change material, although it is rare that a single PCM will qualify as an adequate storage media on its own. Instead, the weaknesses of the chosen material should be accounted for with the design of the storage system in an effort to mitigate the shortcomings of the PCM [122]. Commonly used PCMs include paraffin wax (an organic compound), ice for HVAC systems, and salt hydrates [24]. The performance parameters applicable to most phase change materials are listed in Table 22 at the end of this section.

\subsubsection{Environmental Impact}

As with other energy storage technologies, PCM thermal energy storage systems can benefit the environment by increasing the efficiency of the grid. The use of PCM thermal energy storage systems can also contribute to energy and cost savings for individual power plants. Therefore, the majority of the environmental effects stemming from the use of PCMs are positive. For example, no significant emissions are produced while PCMs are being charged or discharged [122]. However, the disposal process for PCMs must be carefully considered, since paraffins and petroleum-based PCMs are known to be toxic to plants and wildlife. The environmental impact of the disposal process is also long-term, since these materials could take years, or even decades to fully decompose in a landfill. Over the course of a 28-day biodegradability analysis, petroleum-based products were found to decompose from their original form to natural compounds by $0-45 \%$, while paraffin wax was found to degrade by $21-55 \%$. This indicates that these materials will take a minimum of 3 years to fully decompose, with a longer degradation period likely, and could require additional remediation to mitigate their environmental impact. Salt hydrates do decompose naturally, dissociating into their respective ions. However, these materials can be corrosive to their surrounding environment and can also be dangerous for native plants and animals. As can be seen, the environmental impact of PCMs typically comes late in the technology's life cycle, but should still be seriously considered in the event that materials are not disposed of properly [124]. The environmental impacts of phase change materials are summarized in Table 23.

\subsubsection{Policy and Market Conditions}

There are forms of PCM storage systems that are applicable to NPPs. Ice storage tanks are used by a number of electric utilities in the U.S. to provide district cooling and time shift energy demands. For instance, Austin Energy employs two chiller plants currently and is planning a third that creates ice at night when electricity is more available and inexpensive. During peak demand periods throughout the day, the ice is melted and the cold water is used to meet cooling demands for electricity customers connected to the cooling loop. Many other marketable applications for phase change materials exist that are beyond the scope of this report and are not useful for increasing the flexibility of NPPs [108]. Like all other new energy storage technologies, PCMs still face many potential regulatory barriers to full-scale deployment. Primarily, building regulations have not adapted at the same rate as energy storage technologies and as a result, there are many inconsistencies between what the regulations allow and the capabilities of PCMs. Thus, the conflict between building codes and the technical characteristics of PCMs has hindered the progress of this energy storage technology [125].

\subsubsection{Compatible Applications}

The potential applications for PCMs are numerous, ranging from daily to seasonal energy storage, since the chemical properties of phase change materials are so diverse. Additionally, PCMs can be used 
for unique residential cooling applications in addition to providing services to the grid. For example, the incorporation of micro-encapsulated paraffin wax into building walls can provide the building with passive cooling by solidifying overnight and then slowly absorbing heat throughout the day [122]. There are a number of other residential and commercial building applications for PCMs, such as solar water heaters and under-floor heating systems. However, for the purposes of this report, the grid services that PCMs can provide will be the primary focus. Off-peak electricity from a generating power plant can be used to melt a PCM and store energy in the form of latent heat. Only pilot systems of this technology have been developed, and this concept is most often used to store off-peak thermal energy for a building [124]. A few of the applications compatible with PCMs are listed in Table 24.

\subsubsection{Technology Maturity}

Phase change materials hold great promise as a prospective energy storage technology, but there are still significant needs for research and development before a large scale PCM thermal energy storage system can be developed. Studies have been conducted and pilot-scale systems have been developed featuring various PCMs, such as salt hydrates and paraffin wax, demonstrating the viability of the technology and the advantages associated with the superior energy density of PCMs. However, this technology is still far from commercialization [122]. Therefore, this technology was assessed with a TRL of 4, since the technology is in development, but no grid-scale demonstration projects have been proposed. The TRL for PCM energy storage systems is listed in Table 22.

\subsubsection{Future Development}

Research and development still plays a primary role in the development of PCM thermal energy storage systems. Industrial applications are driving research on PCMs that are capable of discharging heats at temperatures on the order of $150^{\circ} \mathrm{C}$ [24]. In addition, the development of phase change materials that are ideally suited for thermal energy storage and can operate effectively without assistance from the storage system's design is another pursuit of researchers studying PCMs. The enhanced equipment currently required to obtain the desired characteristics from a PCM thermal energy storage system often costs much more than the storage material itself [122]. Thus, technical advances, policy measures, and investment incentives will likely be necessary to make phase change materials economically feasible [24]. 


\section{DECISION TOOL DEVELOPMENT (Methods and Analytical Approach)}

Each of the energy storage technologies considered in this report has advantages and disadvantages that can make a technology well-suited for a particular application or incompatible with the desired application altogether. Many other factors can also affect a technology's suitability for integration with a power plant, such as the respective power plant's location, the surrounding geography, policies currently in place, recent trends in regional electricity markets, and profitability of the grid-scale services provided by the technology. Identifying the advantages and disadvantages of a comprehensive selection of available energy storage technologies is an important step that should be completed before the compatibility of specific energy storage technologies with NPPs can be considered. Thus, a decision tool was developed to distill the information presented in this report into a few specific technology recommendations based on the unique requirements of a power plant developer. This tool can help developers identify how the advantages and disadvantages of available energy storage technologies could impact the success of integrating energy storage in their specific context.

\subsection{Summary of Technology Inventory}

Many technology characteristics were detailed in this report and are used by the decision tool to compare and contrast the inventoried energy storage technologies and recommend technology solutions that are well-suited to a developer's intended application. These characteristics include the environmental impacts, performance metrics, and policy and market conditions for several energy storage technologies. Understanding where certain technologies excel and other technologies struggle in these various areas is critical to the operation of the decision tool. A few of the performance parameters for the energy storage technologies catalogued in this report are compared and contrasted in the following section to summarize the energy storage technology options and performance metrics that were considered.

\subsubsection{Comparison of Performance Parameters}

Two of the most important performance parameters observed in this report were the energy density and specific energies of energy storage technologies. These parameters define how much energy can be stored by a technology in a limited amount of space or with specific weight requirements, which can be especially critical for vehicles and other mobile applications. The energy capacity cost, or the cost of energy storage, is another essential performance parameter that was examined. Furthermore, these parameters were also considered for traditional fossil fuels to provide some perspective on the performance of the energy storage technologies in this report. The energy densities and energy capacity costs of the applicable energy storage technologies and fossil fuels are displayed below in Figure 34 . The chart in Figure 34 displays which technologies are able to provide the greatest amount of energy storage in the least amount of space and for the least cost. Since energy storage technologies and fossil fuels are being directly compared in this chart, it should be noted that while the energy density of an energy storage technology accounts for the entire technology's volume, the energy density of a fossil fuel only considers the fuel itself. Hydrogen can be considered as both a fuel and an energy storage technology. As a result, this energy storage medium is displayed twice in Figure 34. Hydrogen fuel cell refers to the energy storage technology considered in this report and Hydrogen (chemical) refers to the chemical energy density of hydrogen [126]. According to Figure 34, gasoline and diesel fuel both offer high energy densities for a relatively low price and are located in the lower right portion of this chart. Meanwhile, natural gas is less dense and is located closer to the left edge of the graph. However, the data for the fossil fuels featured in Figure 34 does not account for the weight or costs of the accompanying hardware, which enhances their position on the chart relative to the other energy storage technologies. This chart also reveals that molten salts, hydrogen fuel cells, and thermochemicals are storage technologies with high energy densities and relatively low energy capacity costs. In addition, although the energy densities of 
UTES and hot and cold water storage tanks are lower than some of the other technologies, this chart shows that these technologies are also much less expensive.

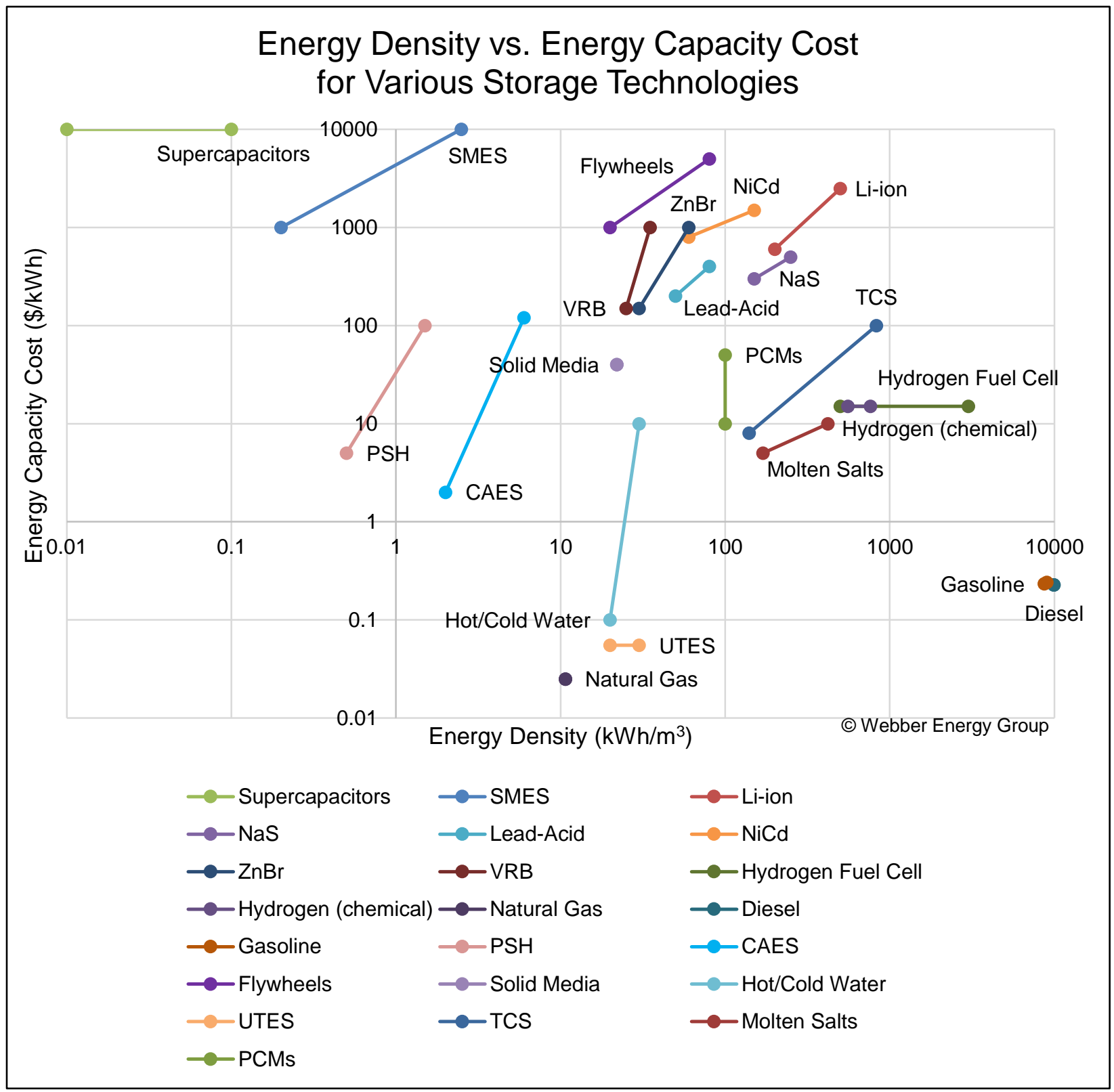

Figure 34. Comparing energy density and cost of storage for various technologies [22] [24] [72] [78] [102] [103] [106] [110] [114] [115] [116] [126].

For some technologies the specific energy, or the total amount of energy that can be stored by a technology divided by the technology's weight, is even more important than the technology's energy density. The specific energies and energy capacity costs for the applicable storage technologies are displayed below in Figure 35. As with Figure 34, it should be noted that the energy storage technologies considered in this report are not completely analogous to fossil fuels as an energy storage medium. Therefore, the specific energy of a hydrogen fuel cell energy storage system and the specific energy of compressed hydrogen have different values. This is important because as an energy storage technology, 
hydrogen fuel cells do not have a greater specific energy than coal and natural gas, but compressed hydrogen on its own does have a higher specific energy than these fossil fuels [103]. Figure 35 reveals that the two fossil fuels that were included in this comparison, coal and natural gas, provide superior specific energy characteristics at low costs, although this data does not factor in the weight or costs of any accompanying hardware. Many of the other storage technologies in this chart are clustered together, demonstrating that these technologies have very similar costs and storage characteristics. Additionally, this chart shows that hydrogen fuel cells can be a very effective form of energy storage, since they provide a higher specific energy at a lower cost than any of the other storage technologies in the chart. This chart also shows that PSH and CAES energy storage systems have lower capacity costs than any of the other storage technologies featured in Figure 35.

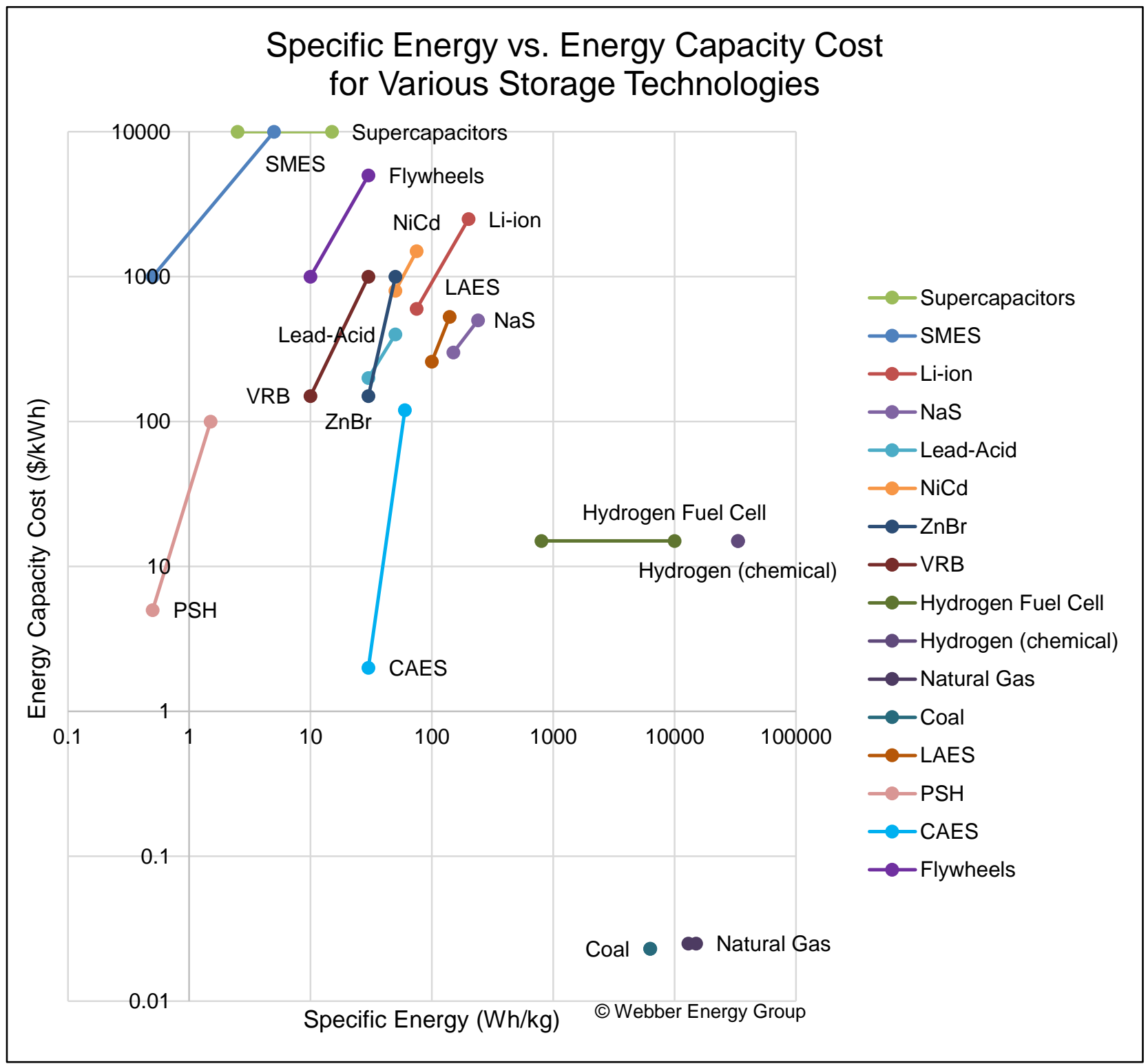

Figure 35. Comparing specific energy and cost of storage for various technologies [22] [24] [72] [102] [103] [110] [114] [115] [120]. 
The amount of energy that a technology can store is not the only parameter useful for assessing the effectiveness of a storage technology, especially since many of the services storage technologies provide to the grid require specific power characteristics. Therefore, the power density and specific power characteristics of the energy storage technologies in this report are also important. The power density and power capacity costs for a few applicable energy storage technologies are displayed below in Figure 36. This chart shows which technologies are capable of providing the greatest amount of power in the least amount of space and for the lowest cost. According to this chart, supercapacitors, SMES systems, and flywheels provide the best combination of power density and capacity cost metrics. Conventional batteries and hydrogen fuel cells have the next highest power densities, although these technologies are also more expensive.

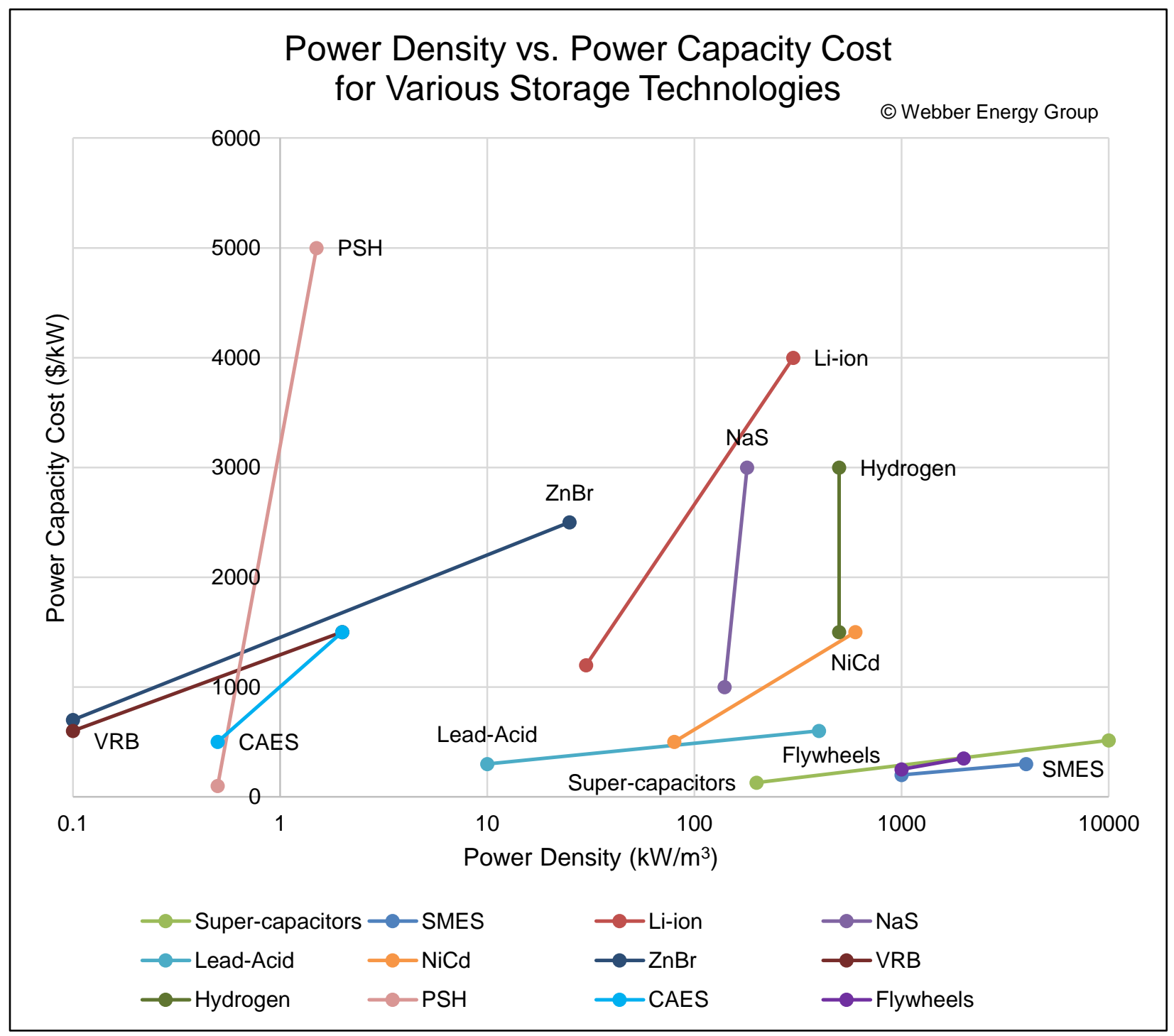

Figure 36. Comparing power density and cost of power for various technologies [20] [72] [78] [79].

For many power plants, space is not a significant concern. However, a power plant could still have specific weight limitations related to the transportation or mobility of the energy storage technology. The specific power and capacity costs for several technologies are compared below in Figure 37. In this chart, 
supercapacitors, SMES systems, and flywheels stand out as the technologies with the greatest specific power and the lowest capacity costs once again. Correspondingly, these technologies are often used for grid-scale power applications. The specific power characteristics of the other storage technologies in Figure 37 all appear to be very similar, with lead-acid, NiCd, and VRB battery systems providing the best combination of high specific power and low costs among this group. Hydrogen fuel cells and lithium-ion batteries have better specific power characteristics than these technologies, but they are also significantly more expensive.

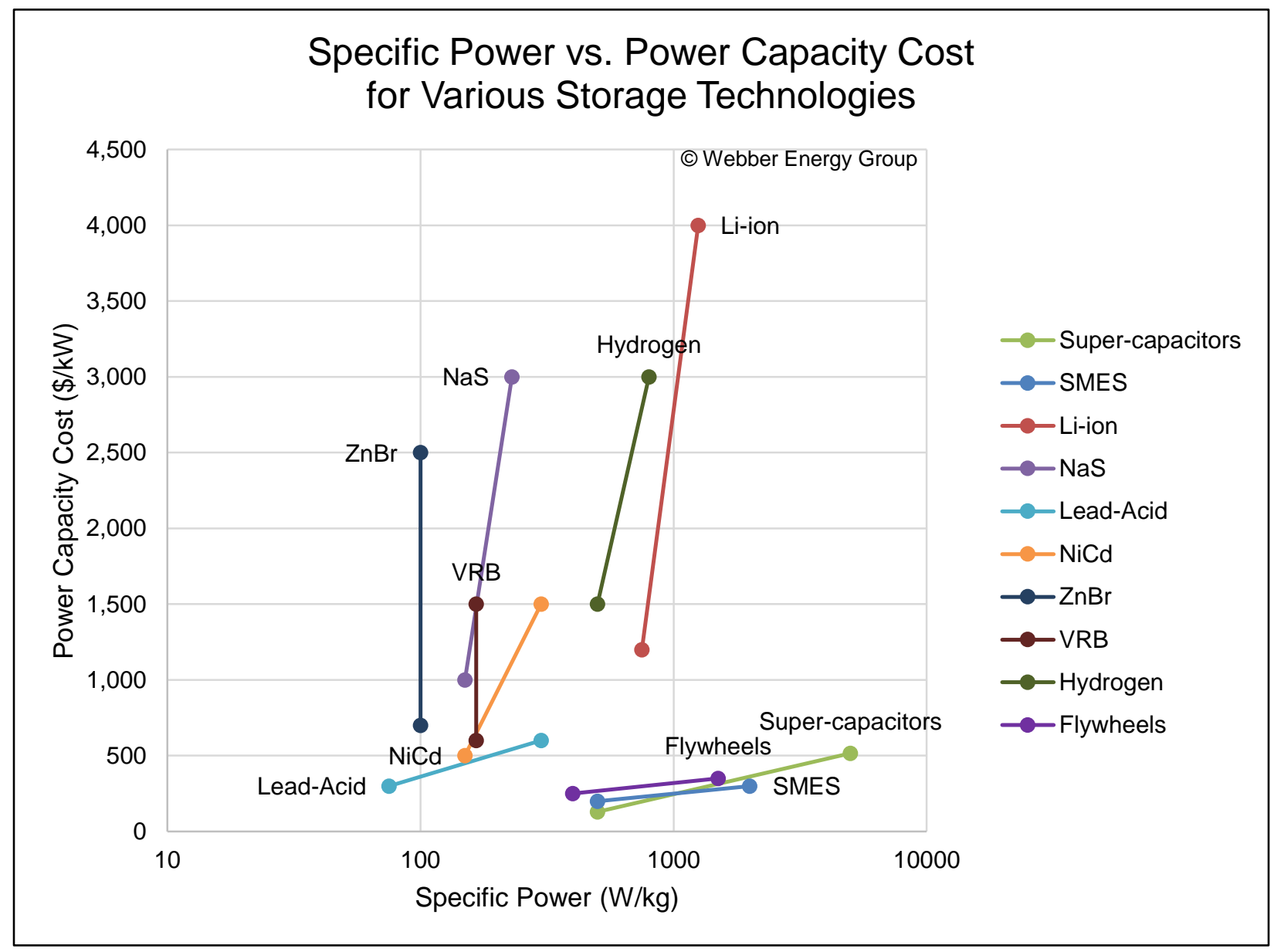

Figure 37. Comparing specific power and cost of power for various technologies [20] [72] [92].

The power characteristics of thermal energy storage technologies are not as readily available as their energy storage capabilities, since these characteristics are largely dependent on external hardware that can have widely differing specifications. However, the power capacity costs for these technologies can still provide an interesting point of comparison. The power capacity costs for each of the thermal energy storage technologies considered in this report are displayed below in Figure 38. This chart reveals that phase change materials are the most expensive form of thermal energy storage when it comes to power capacity. Conversely, hot and cold water storage and molten salts appear to be the least expensive. PCM and TCS energy storage systems are typically much more complex than sensible thermal energy storage systems, which contributes to their higher costs. Since it is difficult to identify a specific thermochemical or phase change material that provides all of the desired storage and power characteristics desired by a developer, significant investment into the accompanying equipment is needed to enhance the heat and 
mass transfer characteristics of these materials. Furthermore, while thermochemicals and phase change materials themselves are not particularly expensive, a complete energy storage system includes a container, heat exchanger, and several other components that increases the investment costs for these technologies [24].

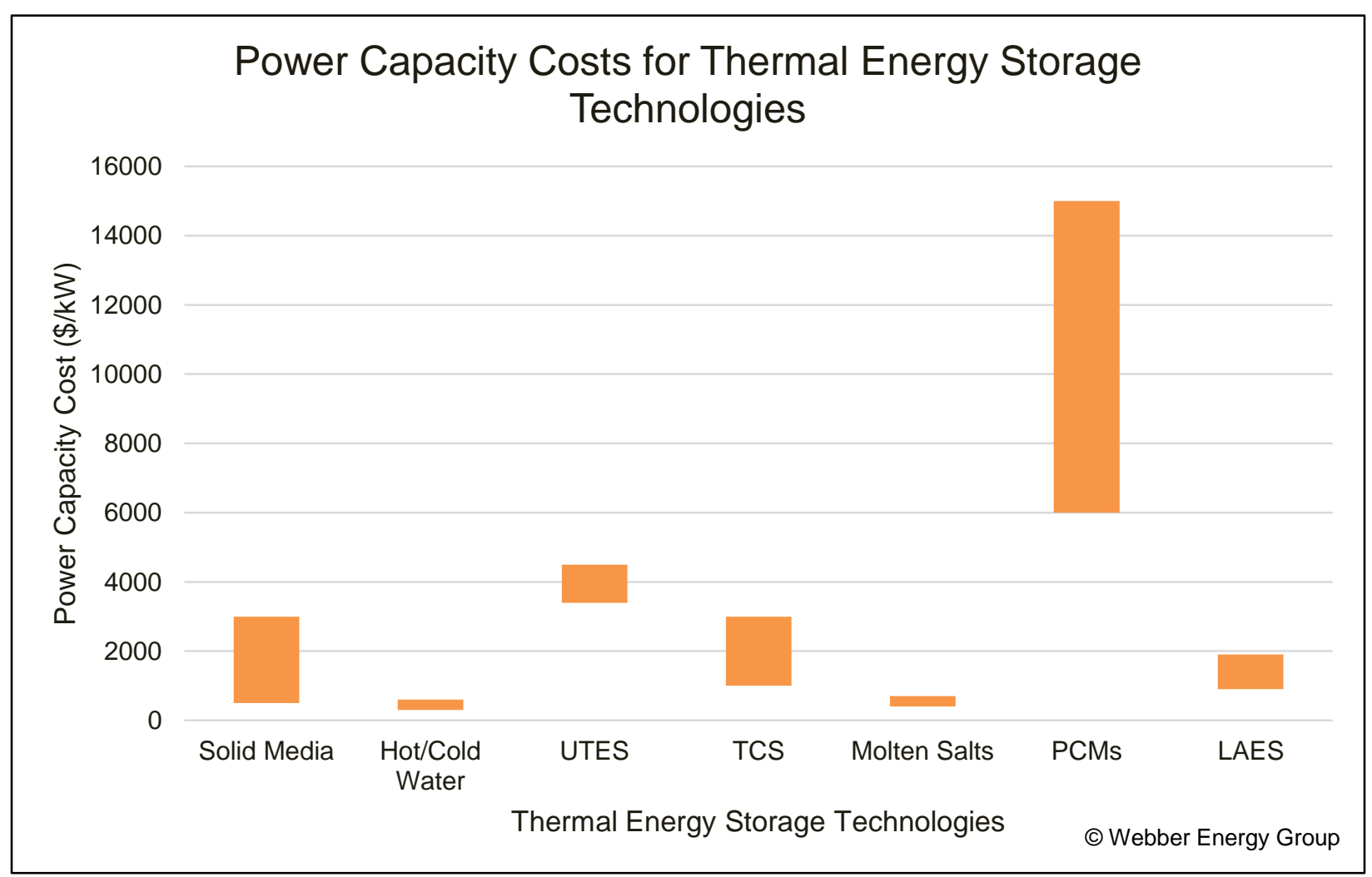

Figure 38. Comparing the cost of power for thermal energy storage technologies [20] [24] [72].

\subsection{Quantifying Technology Characteristics}

The first step in developing the decision tool was quantifying each of the measures that are used to assess and compare the technologies considered in this report. Unless each of the characteristics examined in the Inventory of Options is sufficiently quantified, the characteristics cannot be used to objectively compare the technologies. For some characteristics, such as the performance parameters, this is a relatively simple process, but for other characteristics it can be difficult to immediately discern how the trait can be represented with a numerical value. A method for quantifying and comparing the characteristics of different energy storage technologies is discussed in this section.

\subsubsection{Performance Parameters}

Since many of the performance parameters that are used to compare technologies in this report are already represented numerically, there is no need to quantify these characteristics, although each individual parameter used in this report must have standard units. However, there are still some parameters that must be appropriately quantified to make the development of the decision tool possible. These parameters are displayed below in Table 25. The accompanying quantifications for each tabulated value are also listed in Table 25. Since the time scales that were used to characterize the technologies in this report were often larger than the time scales represented below, these larger time scales (e.g., 
seconds-minutes) should also be appropriately quantified. Fitting evaluations were assessed for these time scales by selecting the median value of the lower and upper ranges of the time scale. For example, seconds to minutes was evaluated as 30 seconds to 30 minutes. At one point, the time scale for a technology's discharge time was referenced as several hours. This value was interpreted to be a smaller range than hours, so this value was quantified as a range half as large as the range for hours and centered on the median of that range. Additionally, in some instances, a time range was defined as either $a-b+,>a$, or $<a$. In each case, the range was extended by $50 \%$ of the value $a$ or $b$ that was associated with one of these qualifiers. These ranges are estimated in Table 25 as well. The "temporal performance metrics" referred to in Table 25 are the response time, storage duration, and discharge time.

Table 25. Quantification of relevant performance parameters.

\begin{tabular}{|c|c|c|}
\hline Parameter & Tabulated Value & Quantified Value \\
\hline \multirow{5}{*}{ Temporal Performance Metrics } & Milliseconds & $1 \times 10^{-6}-1 \times 10^{-4} \mathrm{hr}$ \\
\cline { 2 - 3 } & Seconds & $1 \times 10^{-4}-0.01 \mathrm{hr}$ \\
\cline { 2 - 3 } & Minutes & $0.01-1 \mathrm{hr}$ \\
\cline { 2 - 3 } & Hours & $1-24 \mathrm{hr}$ \\
\cline { 2 - 3 } & Days & $24-168 \mathrm{hr}$ \\
\cline { 2 - 3 } & Weeks & $168-730 \mathrm{hr}$ \\
\cline { 2 - 3 } & Months & $730-8760 \mathrm{hr}$ \\
\cline { 2 - 3 } & Years & $8760+\mathrm{hr}$ \\
\cline { 2 - 3 } & Some range $a-b+$ & $a-1.5 \times b$ \\
\cline { 2 - 3 } & $>$ some value $a$ & $a-1.5 \times a$ \\
\cline { 2 - 3 } & < some value $a$ & $0.5 \times a-a$ \\
\hline \multirow{4}{*}{ Storage Degradation Rate (\%/day) } & Almost zero & $0-0.1 \%$ \\
\cline { 2 - 3 } & Very small & $0.1-1 \%$ \\
\cline { 2 - 3 } & Small & $1-5 \%$ \\
\hline \multirow{4}{*}{ Storage Output Temperature } & < some temp. $T$ & $(T-100)-T$ \\
\cline { 2 - 3 } & $>$ some temp. $T$ & $T-(T+100)$ \\
\hline
\end{tabular}

\subsubsection{Environmental Impact}

\subsubsection{The environmental impacts of each group of storage technologies are} end of each subsection of Section 4. However, many of the descriptive environmental impacts of these technologies need to be quantified compare and contrast the relevant storage methods. Since a the level of impact for each environmental factor, the quantification of simple. The accompanying impact factors for each of the environmental characteristics are listed below in Policy and Market Conditions

In the Inventory of Options, many relevant policies and market trends were discussed in relation to the energy storage technologies considered in this report. In addition to these localized policies and market trends, national and regional policies as well as large-scale market trends can also impact the success of energy storage technologies. These policy and market conditions should be considered when evaluating the favorability of the regulatory environments and markets that these energy storage technologies could be operating in.

Table 26. 


\subsubsection{Policy and Market Conditions}

In the Inventory of Options, many relevant policies and market trends were discussed in relation to the energy storage technologies considered in this report. In addition to these localized policies and market trends, national and regional policies as well as large-scale market trends can also impact the success of energy storage technologies. These policy and market conditions should be considered when evaluating the favorability of the regulatory environments and markets that these energy storage technologies could be operating in.

Table 26. Quantification of relevant environmental impacts.

\begin{tabular}{|c|c|c|}
\hline Environmental Impact & Tabulated Term & Impact Factor \\
\hline \multirow{5}{*}{ Land and Water Impact } & Very significant & 4 \\
\hline & Significant & 3 \\
\hline & Somewhat significant & 2 \\
\hline & Not very significant & 1 \\
\hline & Insignificant & 0 \\
\hline \multirow{3}{*}{ Emissions Produced During Operation } & Yes & 2 \\
\hline & Yes, but not very significant & 1 \\
\hline & None & 0 \\
\hline \multirow{3}{*}{ Hazardous Materials } & Yes & 2 \\
\hline & Yes, recyclable & 1 \\
\hline & None & 0 \\
\hline \multirow{2}{*}{ Hazardous Fumes } & Yes & 1 \\
\hline & None & 0 \\
\hline \multirow{4}{*}{ Short-Term Safety Concerns } & Several & 3 \\
\hline & Some & 2 \\
\hline & Minimal & 1 \\
\hline & None & 0 \\
\hline \multirow{3}{*}{ Resource Depletion } & Very significant & 2 \\
\hline & Somewhat significant & 1 \\
\hline & Insignificant & 0 \\
\hline \multirow{2}{*}{ Geographic Requirements } & Yes & 1 \\
\hline & None & 0 \\
\hline
\end{tabular}

\subsubsection{National Policies and Market Trends}

5.2.4.2 FERC, or the Federal Energy Regulatory Commission, is the regulatory body majority of the policies affecting energy storage technologies. FERC has sale of electricity, and as a result regulates most wholesale electricity markets the exception of the ERCOT grid in Texas which does not sell electricity across regulations and federal laws listed in State Policies

It is important to understand how federal regulations affect the energy storage technologies in this report and identify what steps could be taken to cultivate a more favorable regulatory environment. However, these policies apply uniformly to energy storage installations in different regional electricity markets across the U.S., and as a result, the federal policies and market regulations affecting an energy storage technology cannot help a developer identify a location for installing energy storage. The numerous state policies impacting the success of energy storage technologies within their jurisdiction must also be examined. The policies displayed in Table 28 represent the most significant state policies that affect the commercialization of energy storage technologies. 
Table 27 all affect the energy storage technologies considered in this report in some way. Although FERC has clearly made an effort to diminish the effect of the regulatory barriers facing energy storage technologies, many roadblocks still exist. ISOs and RTOs have been slow to adopt FERC Order 755, which enables fast-responding energy storage technologies to sell ancillary services at higher rates. The New England ISO only recently implemented the practices required by this legislation [25]. One of the most significant obstructions facing energy storage technologies is FERC's restrictions on how technologies can provide the grid with multiple benefits. Under current regulations, energy storage technologies are typically limited to operating either as a generation or transmission asset, but not both. Thus, there is still much progress to be made to help energy storage technologies operate on a level playing field with conventional generating resources.

\subsubsection{State Policies}

It is important to understand how federal regulations affect the energy storage technologies in this report and identify what steps could be taken to cultivate a more favorable regulatory environment. However, these policies apply uniformly to energy storage installations in different regional electricity markets across the U.S., and as a result, the federal policies and market regulations affecting an energy storage technology cannot help a developer identify a location for installing energy storage. The numerous state policies impacting the success of energy storage technologies within their jurisdiction must also be examined. The policies displayed in Table 28 represent the most significant state policies that affect the commercialization of energy storage technologies.

Table 27. Federal regulations affecting energy storage technologies.

\begin{tabular}{|c|c|c|}
\hline Regulation & Description & Impact \\
\hline FERC Order 719 & $\begin{array}{l}\text { Requires ISOs and RTOs to allow } \\
\text { demand response resources to participate } \\
\text { in energy and ancillary service markets. } \\
\text { Also requires shorter intervals for price } \\
\text { calculations, which better accounts for } \\
\text { variability and favors energy storage [25]. }\end{array}$ & $\begin{array}{l}\text { This order is favorable for energy } \\
\text { storage technologies that primarily } \\
\text { act as demand response resources. }\end{array}$ \\
\hline FERC Order 745 & $\begin{array}{l}\text { Requires that electricity markets pay } \\
\text { demand response resources the market } \\
\text { price for energy [25]. }\end{array}$ & $\begin{array}{l}\text { This order had the same effect as } \\
\text { FERC Order } 719 .\end{array}$ \\
\hline FERC Order 755 & $\begin{array}{l}\text { The "Pay for Performance" order ensures } \\
\text { that technologies providing regulation } \\
\text { services are compensated according to the } \\
\text { accuracy and speed of their response [25]. }\end{array}$ & $\begin{array}{l}\text { This order enables fast responding } \\
\text { energy storage technologies to } \\
\text { receive more revenue for regulation } \\
\text { than conventional generators. }\end{array}$ \\
\hline FERC Order 784 & $\begin{array}{l}\text { Expanded on the pay-for-performance } \\
\text { order, FERC Order } 755 \text {, by opening up } \\
\text { ancillary services more broadly to energy } \\
\text { storage participation [20]. }\end{array}$ & $\begin{array}{l}\text { This order further enhanced the } \\
\text { profitability of energy storage and } \\
\text { made the valuation of energy storage } \\
\text { more transparent. }\end{array}$ \\
\hline FERC Order 890 & $\begin{array}{l}\text { Further opened up established energy } \\
\text { markets to non-generating resources such } \\
\text { as demand response and energy storage } \\
{[20] .}\end{array}$ & $\begin{array}{l}\text { Continued to create more markets for } \\
\text { energy storage technologies to sell } \\
\text { services. }\end{array}$ \\
\hline FERC Order 1000 & $\begin{array}{l}\text { This order requires public utility } \\
\text { transmission providers to cooperate at a } \\
\text { regional level. Neighboring regions must } \\
\text { also coordinate to investigate all possible } \\
\text { solutions to meet their requirements } \\
\text { [127]. }\end{array}$ & $\begin{array}{l}\text { Regionally planned transmission and } \\
\text { a clearer cost allocation process } \\
\text { would open the market more to } \\
\text { renewable energy developers, which } \\
\text { could in turn drive the development } \\
\text { of other emerging technologies. }\end{array}$ \\
\hline
\end{tabular}




\begin{tabular}{|c|l|l|}
\hline $\begin{array}{c}\text { STORAGE Act of } \\
2013\end{array}$ & $\begin{array}{l}\text { The Storage Technology for Renewable } \\
\text { and Green Energy (STORAGE) Act of } \\
\text { 2013 proposed a 30\% ITC for businesses } \\
\text { installing in-house energy storage } \\
\text { systems and a 20\% ITC for grid- } \\
\text { connected installations [127]. This bill } \\
\text { was not enacted. }\end{array}$ & $\begin{array}{l}\text { This policy would further enhance } \\
\text { the economic viability of energy } \\
\text { storage and encourage investors to } \\
\text { pursue energy storage opportunities. }\end{array}$ \\
\hline $\begin{array}{c}\text { H.R. 5350, Energy } \\
\text { Resilience and }\end{array}$ & $\begin{array}{l}\text { both businesses and individuals interested } \\
\text { in either producing or installing energy } \\
\text { storage technologies [30]. This bill is } \\
\text { currently before the House Ways and } \\
\text { Means Committee. }\end{array}$ & $\begin{array}{l}\text { If passed, this federal policy would } \\
\text { greatly enhance the economic } \\
\text { feasibility of many energy storage } \\
\text { technologies. }\end{array}$ \\
\hline
\end{tabular}

Table 28. State policies and initiatives affecting energy storage technologies.

\begin{tabular}{|c|c|c|}
\hline State & Policy or Initiative & Description \\
\hline \multirow[b]{2}{*}{ California } & CPUC SGIP Rules & $\begin{array}{l}\text { The CPUC's Self-Generation Incentive Program provides financial incentives } \\
\text { for consumer storage projects [21] [127]. The SGIP was conceived in } 2001 .\end{array}$ \\
\hline & AB 2514 & $\begin{array}{l}\text { Assembly Bill } 2514 \text { passed by the California state legislature tasked the } \\
\text { CPUC with exploring energy storage initiatives. In response, the CPUC } \\
\text { established a procurement target of } 1.325 \mathrm{GW} \text { of storage by } 2020 \text { for all } \\
\text { investor owned utilities [25]. This bill was passed in } 2010 .\end{array}$ \\
\hline \multirow{2}{*}{ Colorado } & $\begin{array}{l}\text { Innovative Clean } \\
\text { Technology } \\
\text { Program }\end{array}$ & $\begin{array}{l}\text { This program was founded by Colorado to provide funding for energy storage } \\
\text { research and development [25]. This program was founded in } 2009 \text {. }\end{array}$ \\
\hline & $\begin{array}{l}\text { Section } 123 \\
\text { Resources }\end{array}$ & $\begin{array}{l}\text { This initiative established by state law provides funding for emerging } \\
\text { technologies without requiring that the technology be economically } \\
\text { competitive [25]. This initiative was established by state law in } 2001 \text {. }\end{array}$ \\
\hline Hawaii & -- & $\begin{array}{l}\text { Hawaii electric companies included energy storage in their } 2013 \text { integrated } \\
\text { resource plan and Maui is considering energy storage as an option for } \\
\text { addressing wind curtailment [127]. }\end{array}$ \\
\hline \multirow[t]{2}{*}{ New Jersey } & $\begin{array}{l}\text { Clean Energy } \\
\text { Program }\end{array}$ & $\begin{array}{l}\text { This program has } \$ 2.5 \text { million of state funding for energy storage projects. } \\
\text { However, they must be connected to a renewable energy source and ideally } \\
\text { would primarily provide resiliency services. Although, the state's Energy } \\
\text { Master Plan concluded that energy storage was not currently economically } \\
\text { viable and recommended against pursuing energy storage as a resiliency } \\
\text { solution [127]. }\end{array}$ \\
\hline & $\begin{array}{l}\text { Critical } \\
\text { Infrastructure } \\
\text { Program }\end{array}$ & $\begin{array}{l}\text { This program has an additional } \$ 500 \text { million for updating existing } \\
\text { infrastructure that could be used to build energy storage installations to defer } \\
\text { upgrading the transmission infrastructure [127]. }\end{array}$ \\
\hline New Mexico & $\begin{array}{l}\text { Energy Storage } \\
\text { Task Force }\end{array}$ & $\begin{array}{l}\text { This task force was formed to investigate investment options in energy } \\
\text { storage for the state [127]. }\end{array}$ \\
\hline \multirow{3}{*}{ New York } & NY BEST & $\begin{array}{l}\text { New York Battery and Energy Storage Technology (BEST) Consortium } \\
\text { provides funding for energy storage development and is supported by the } \\
\text { New York State Energy Research and Development Authority (NYSERDA) } \\
\text { [127]. }\end{array}$ \\
\hline & $\begin{array}{l}\text { Green Bank } \\
\text { Initiative }\end{array}$ & $\begin{array}{l}\text { New York has pledged almost } \$ 1 \text { billion in financing for energy storage and } \\
\text { other "green energy" projects [127]. }\end{array}$ \\
\hline & Energy Highway & $\begin{array}{l}\text { This initiative was proposed by the state for the purpose of incentivizing the } \\
\text { process of updating aging infrastructure [127]. In 2013, the implementation } \\
\text { of this proposal began. }\end{array}$ \\
\hline Oregon & -- & Portland General Electric included energy storage in their 2013 request for \\
\hline
\end{tabular}




\begin{tabular}{|c|c|l|}
\hline State & Policy or Initiative & \multicolumn{1}{c|}{ Description } \\
\hline \multirow{5}{*}{ Texas } & SB 943 & $\begin{array}{l}\text { proposals, opening the door for investment in energy storage installations } \\
\text { [127]. }\end{array}$ \\
\cline { 2 - 4 } & $\begin{array}{l}\text { This bill required energy storage installations to be registered as generation } \\
\text { assets when used to sell energy or ancillary services, limiting the benefits that } \\
\text { energy storage can provide in the state [127]. This bill became law in 2011. }\end{array}$ \\
\hline Washington & 39917 & $\begin{array}{l}\text { TD 39917 required energy storage charging and discharging to be considered } \\
\text { wholesale energy transactions. This change improved the economics of } \\
\text { energy storage and eliminated several market distortions in the location and } \\
\text { operation of resources [25]. This initiative was issued in 2012. }\end{array}$ \\
\hline Other States & -- & $\begin{array}{l}\text { Washington Utilities and Transportation Commission requested that utilities } \\
\text { in the state include energy storage when considering resource options for } \\
\text { their next integrated resource plan [127]. }\end{array}$ \\
\hline & - & $\begin{array}{l}\text { Connecticut, Maryland, and Maine are also evaluating energy storage and } \\
\text { micro-grid development as options to improve grid resiliency and enable } \\
\text { smart grid technologies [127]. }\end{array}$ \\
\hline
\end{tabular}

\subsubsection{Regional Market Trends and Regulations}

In addition to the state policies affecting energy storage technologies installed in that area, the regulations enacted by the regional electricity markets in which a particular storage technology is operating can also influence the success of that technology. When determining the favorability of regional policy conditions, these regulations should also be considered. Several of the pertinent market regulations currently affecting energy storage are listed below in Table 29. Although there might not be specific regulations addressing energy storage technologies in every electricity market in the U.S., how an ISO or non-ISO regional market defines energy storage can also provide insight into the favorability of regional policy conditions. Several relevant market trends are also listed in Table 29.

Table 29. Market trends and regulations affecting energy storage technologies.

\begin{tabular}{|c|c|l|}
\hline $\begin{array}{c}\text { Regional } \\
\text { Market }\end{array}$ & Regulation or Trend & \multicolumn{1}{c|}{ Description } \\
\hline \multirow{5}{*}{ CAISO } & $\begin{array}{c}\text { Modified Rules to } \\
\text { Allow Non-Generation } \\
\text { Resources }\end{array}$ & $\begin{array}{l}\text { Removed restrictions on which resources could provide ancillary } \\
\text { services. Also reduced minimum capacity and continuous energy } \\
\text { requirements. This rule change allowed energy storage } \\
\text { technologies to provide regulation services [21]. }\end{array}$ \\
\cline { 2 - 4 } & $\begin{array}{c}\text { Flexible Capacity } \\
\text { Procurement for } \\
\text { Variable Supply } \\
\text { Resource Integration }\end{array}$ & $\begin{array}{l}\text { The CAISO is currently considering various options for } \\
\text { addressing the steep ramping requirements introduced by wind } \\
\text { and solar resources coming online due to California's heavy } \\
\text { renewable portfolio standard mandate. There is potential for } \\
\text { energy storage technologies to provide this capacity [21]. }\end{array}$ \\
\hline \multirow{4}{*}{ ERCOT } & $\begin{array}{c}\text { Emerging Technologies } \\
\text { Workflow Group }\end{array}$ & $\begin{array}{l}\text { This group has identified possible revisions to ERCOT rules that } \\
\text { would make it easier for emerging technologies to enter the } \\
\text { market. This group has also explored the idea of creating a new } \\
\text { asset group for energy storage technologies [25]. }\end{array}$ \\
\cline { 2 - 4 } & $\begin{array}{c}\text { Fast Responding } \\
\text { Regulation Service Pilot }\end{array}$ & $\begin{array}{l}\text { The FRRS pilot program was founded to determine whether } \\
\text { emerging technologies could respond to large frequency events } \\
\text { before conventional resources. This program is meant to identify } \\
\text { ways to improve system reliability without increasing costs, } \\
\text { possibly through the use of energy storage [25]. }\end{array}$ \\
\cline { 2 - 4 } & $\begin{array}{l}\text { Rurrent market rules indicate that energy storage technologies } \\
\text { must register as generating entities and controllable loads, }\end{array}$ \\
\hline
\end{tabular}




\begin{tabular}{|c|c|c|}
\hline & & introducing more requirements for developers [25]. \\
\hline \multirow[b]{2}{*}{ MISO } & $\begin{array}{l}\text { Considering the } \\
\text { Addition of Ramping } \\
\text { Capacity }\end{array}$ & $\begin{array}{l}\text { Like the CAISO, the MISO is considering energy storage } \\
\text { technologies as potential ramping capacity to help with the } \\
\text { integration of variable supply resources [25]. }\end{array}$ \\
\hline & $\begin{array}{l}\text { 2011 MISO } \\
\text { Transmission Expansion } \\
\text { Plan }\end{array}$ & $\begin{array}{l}\text { This plan launched two major energy storage studies that } \\
\text { investigated the value of long-term energy storage. However, this } \\
\text { study found that energy storage is not currently economically } \\
\text { viable [25]. }\end{array}$ \\
\hline \multirow[b]{2}{*}{$\begin{array}{l}\text { Non-ISO } \\
\text { Regions }\end{array}$} & Lack of Price Signaling & $\begin{array}{l}\text { Due to the nature of regulated markets, there is little price } \\
\text { signaling to developers to indicate the potential profitability of } \\
\text { energy storage [25]. }\end{array}$ \\
\hline & $\begin{array}{l}\text { More Conducive to } \\
\text { Benefits-Stacking }\end{array}$ & $\begin{array}{l}\text { Since utilities in non-ISO regions are vertically integrated, they } \\
\text { are free to utilize their assets in any way they see fit and gather } \\
\text { revenue accordingly. Therefore, the separation of transmission } \\
\text { and generation assets is not an issue [25]. }\end{array}$ \\
\hline
\end{tabular}

Although these regulations and market trends are helpful for determining the favorability of regional market conditions, they can change as quickly as state policies. Therefore, they are not the best indicator for how well suited a market is to energy storage. Since the primary purpose of exploring the potential for energy storage in this paper is to address the market variability introduced by renewable energy resources, assessing the variability of the regional electricity markets considered in this report might be a more accurate and enduring estimate of a market's suitability to energy storage integration. The variability of a market is related to the percentage of renewable energy resources supplying electricity to the grid in that region, so this quantity was used to estimate the favorability of regional market conditions. The regions used to determine these percentages correspond to the census division regions rather than the regional electricity markets discussed in this report, but the resource mixes in these regions should closely resemble the resource mixes in their constituent electricity markets. These regions are displayed below in Figure 39. Although the electricity generation data for wind and solar resources are only given for the regions specified in Table 30, the decision tool will have access to this information for every individual state in the U.S. 


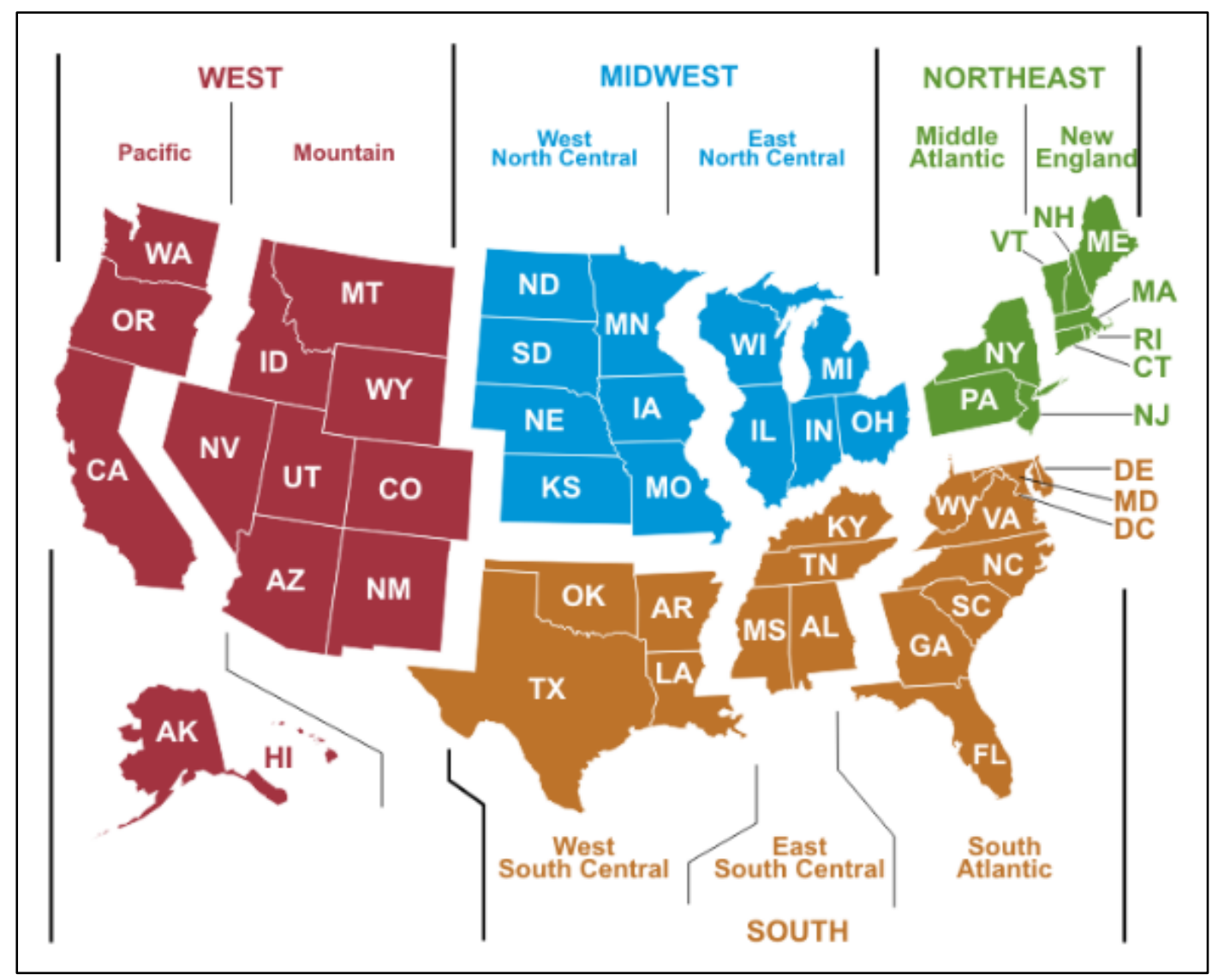

Figure 39. Regions used to determine market variability [128].

Since the percentage of electricity generated from VRES in each region is the parameter of interest, only this quantity was recorded instead of the complete resource mix for each region. Additionally, since not all renewable energy resources contribute to the market volatility in a given region, only the electricity generation from wind and solar resources in each region were observed. The percentage of electricity generation from wind and solar resources in each region are displayed below in Table 30 [129]. Note that this data is for the net generation of electricity by wind, solar PV, and solar thermal resources in 2015.

Table 30. Variability in certain regions of the U.S.

\begin{tabular}{|c|c|}
\hline Region & $\begin{array}{c}\text { Percentage of Wind and Solar } \\
\text { Electricity Generation by Region }\end{array}$ \\
\hline New England & $3.58 \%$ \\
\hline Middle Atlantic & $2.36 \%$ \\
\hline East North Central & $3.90 \%$ \\
\hline West North Central & $15.77 \%$ \\
\hline South Atlantic & $0.63 \%$ \\
\hline East South Central & $0.06 \%$ \\
\hline West South Central & $8.66 \%$ \\
\hline Mountain & $7.28 \%$ \\
\hline Pacific Contiguous & $12.63 \%$ \\
\hline Pacific Noncontiguous & $9.04 \%$ \\
\hline
\end{tabular}




\subsubsection{Favorability Analysis}

Once specific policies and market trends in each region were identified, the favorability of the policy and market conditions in each region could be determined. However, more than any other technology characteristic considered in this report, these conditions could change quickly over time. Therefore, for the purposes of the decision tool, the policy and market conditions were simplified to notifying the developer using the tool of the existence of favorable policies and regional market variability at their location. When indicating to the developer whether or not favorable policies existed in their respective region, both market regulations and state policies were considered. When identifying favorable market conditions, the decision tool designates that a market has a high penetration of VRES if the concentration of wind and solar resources in the region is greater than the $66^{\text {th }}$ percentile. For example, if wind and solar resources in a particular region generate a higher percentage of that region's electricity than $66 \%$ of the regions analyzed in this report, that region is regarded as having high variability. A regional market with a penetration of VRES less than the $33^{\text {rd }}$ percentile is designated as having low variability, and a regional market in between the $33^{\text {rd }}$ and $66^{\text {th }}$ percentile is assessed as having a medium amount of variability.

\subsubsection{Compatible Applications}

The terms that were used in the Compatible Applications tables in this report to indicate the compatibility between a storage technology and a specific application or grid-scale service should also be appropriately quantified. These terms were quantified with a simple $0-1$ scale, as shown below in Table 31.

Table 31. Quantification for level of compatibility with grid-scale applications.

\begin{tabular}{|c|c|}
\hline Tabulated Term & Compatibility Factor \\
\hline Compatible & 1 \\
\hline Somewhat compatible & 0.5 \\
\hline Incompatible & 0 \\
\hline
\end{tabular}

However, every application is not equal and many applications are much more profitable than others. The amount of revenue each of the applications considered in this report is capable of generating should also be considered. The profitability of each application is approximated in Table 32. Although understanding how some applications can provide more revenue than others is helpful, the values displayed in Table 32 are simply estimates and depend greatly on local market conditions. Additionally, since seasonal storage is a service that still has not seen much market exposure and the profitability of process heat applications are highly situational, price estimates for these services were not included. These values were not integrated with the decision tool.

Table 32. Profitability of several grid-scale applications.

\begin{tabular}{|c|c|}
\hline Grid-Scale Application & Revenue Generated (\$/kW) \\
\hline Energy Arbitrage & $400-700[33]$ \\
\hline Frequency Regulation & $785-2010[33]$ \\
\hline Load Following & $600-1000[33]$ \\
\hline Voltage Support & $400-800[33]$ \\
\hline Spinning Reserves & $\sim 258[22]$ \\
\hline Non-Spinning \& Supplemental Reserves & $\sim 72[22]$ \\
\hline Black Start & $5.50[69]$ \\
\hline Variable Supply Resource Integration & $500-1000[33]$ \\
\hline Seasonal Storage & -- \\
\hline Process Heat Applications & -- \\
\hline
\end{tabular}


In addition to understanding the profitability of each individual application, the success of an energy storage technology often depends on how many services the technology can provide. Since the developers using this decision tool will likely have a specific application in mind for the chosen energy storage technology, knowing the additional services that technology can provide is critical. The compatibility of the grid-scale services considered in this report with other marketable services are displayed below in Table 33. In this table, $\square$ represents compatibility, $\square$ indicates that the applications are somewhat compatible, and $\otimes$ indicates that two applications are incompatible [33].

Table 33. Applications compatibility matrix [33].

\begin{tabular}{|c|c|c|c|c|c|c|c|c|c|c|}
\hline Applications & $\begin{array}{c}\text { Energy } \\
\text { Arbitrage }\end{array}$ & $\begin{array}{l}\text { Freq. } \\
\text { Reg. }\end{array}$ & $\begin{array}{c}\text { Load } \\
\text { Following }\end{array}$ & $\begin{array}{l}\text { Volt. } \\
\text { Supp. }\end{array}$ & $\begin{array}{l}\text { Spin. } \\
\text { Res. }\end{array}$ & $\begin{array}{l}\text { Non- } \\
\text { Spin. }\end{array}$ & $\begin{array}{c}\text { Black } \\
\text { Start }\end{array}$ & $\begin{array}{l}\text { VSR } \\
\text { Int. }\end{array}$ & $\begin{array}{c}\text { Seasonal } \\
\text { Storage }\end{array}$ & $\begin{array}{c}\text { Process } \\
\text { Heat }\end{array}$ \\
\hline $\begin{array}{c}\text { Energy } \\
\text { Arbitrage }\end{array}$ & & $\square$ & $\nabla$ & $\nabla$ & $\nabla$ & $\nabla$ & $\nabla$ & $\square$ & 凶 & $\nabla$ \\
\hline Freq. Reg. & $\square$ & & $\square$ & $\varnothing$ & $\square$ & $\square$ & $\square$ & 区 & $\square$ & 区 \\
\hline $\begin{array}{c}\text { Load } \\
\text { Following }\end{array}$ & $\nabla$ & $\square$ & & $\nabla$ & $\nabla$ & $\nabla$ & $\nabla$ & 凶 & 凶 & $\square$ \\
\hline Volt. Supp. & $\nabla$ & $\varnothing$ & $\nabla$ & & $\nabla$ & $\nabla$ & $\nabla$ & 区 & $\nabla$ & 凶 \\
\hline Spin. Res. & $\nabla$ & $\square$ & $\nabla$ & $\nabla$ & & $\nabla$ & $\nabla$ & $\square$ & $\nabla$ & 区 \\
\hline Non-Spin. & $\nabla$ & $\square$ & $\nabla$ & $\nabla$ & $\nabla$ & & $\nabla$ & $\square$ & $\nabla$ & $\square$ \\
\hline Black Start & $\nabla$ & $\square$ & $\nabla$ & $\nabla$ & $\nabla$ & $\nabla$ & & $\square$ & $\nabla$ & $凶$ \\
\hline VSR Int. & $\square$ & 凶 & 区 & 凶 & $\square$ & $\square$ & $\square$ & & 区 & 区 \\
\hline $\begin{array}{c}\text { Seasonal } \\
\text { Storage }\end{array}$ & 凶 & $\square$ & 凶 & $\nabla$ & $\nabla$ & $\nabla$ & $\nabla$ & 凶 & & $\nabla$ \\
\hline Process Heat & $\nabla$ & 区 & $\square$ & 区 & 区 & $\square$ & 区 & 区 & $\nabla$ & \\
\hline
\end{tabular}

\subsection{Scaling Technology Characteristics}

Although quantifying the technology characteristics considered in this report does objectify these metrics for the most part, they are still measured across many different orders of magnitude. Therefore, some characteristics need to be appropriately scaled down so that no characteristic is weighted more than the others. For the purposes of this report, each technology characteristic was scaled down to a number between 0 and 1 by dividing the quantified value by the maximum possible value for that characteristic. Additionally, before a score was presented to the developer for a particular category of technology characteristics, such as the environmental impact, the score for that technology was normalized again to a ten-point scale. For example, to scale the environmental impact factors for the technologies in this report, the impact factor for each technology was divided by the maximum possible impact factor to produce a normalized score between zero and one. These scaled values were then added together to produce an overall environmental impact score that was normalized again to a ten-point scale and integrated with the down-selection tool.

\subsection{Gathering Developer Input}

One of the primary outputs of this study was to develop a tool that allows developers to compare the relative performance of different storage technologies. To properly compare the relative performance of different technologies it is important to understand the unique needs of the developer. The developers using this decision tool will answer a series of questions, which will subsequently yield weighting factors that are used to numerically assess the importance of each technology characteristic. The developer's responses are also used to identify technologies that are incapable of fulfilling their individual requirements. The following questions address several of the technology characteristics examined in this report with the intention of accurately interpreting the desires and requirements of a developer. 


\subsubsection{Performance Parameters}

Although it might be easy to see how a few of the performance parameters discussed in this report could be used to determine the viability of a particular storage technology, these parameters are often only meaningful in the correct context. Therefore, the following questions will provide the necessary insight and information from a developer to determine the importance of the various performance characteristics.

- Questions \#1-2: How much storage capacity is required for your application? How much power is required for your application? The storage and power requirements for a developer's application provide the tool with the necessary information to calculate the total investment cost for the project. This information, along with the developer's space and weight requirements, can be used to determine which technologies are capable of providing the storage and power performance metrics desired by the developer. Furthermore, the storage and power requirements can be compared with the developer's available budget to identify which technologies are economically viable.

- Questions \#3-4: How much space do you have available for an energy storage installation? Do you have any weight limitations? If the energy or power density of a technology is not sufficiently high and the amount of space available to a developer is too low, then certain technologies can be ruled out from consideration by the tool altogether. Similar logic would apply to a technology's specific energy and power specifications and the amount of weight available to a developer.

- Question \#5: What is the available budget for this project? If the costs of a particular energy storage technology exceed a developer's budget, then that technology can be ruled out completely. The costs of an energy storage installation are calculated by multiplying the energy and power capacity needs of the developer by the capacity and power costs (e.g., $\$ / \mathrm{kWh}$ and $\$ / \mathrm{kW}$, respectively) for the technology in question. The larger of these two costs is the amount used for the comparison to present a worst-case scenario.

- Question \#6: What is the proposed timeline for this project? When will the chosen energy storage technology be installed? Many of the energy storage technologies considered in this report are still in development and are not currently ready to be deployed. Thus, if a developer was looking to retrofit an existing plant within the next couple of years, many of the storage technologies in this report might not yet be technically or economically feasible for commercial deployment. However, if the storage technology will not be integrated for several years, more technologies could be viable by the time the project is completed. Therefore, the developer's response to this question corresponds to a weighting factor that is applied to the TRL of a storage technology to reduce the importance of this parameter for longer project timelines. This weighting factor is such that for an average TRL of 5, a project timeline of 5-10 years would weigh the TRL so that the weighted value is 6 . Hence, a technology is expected to progress approximately one TRL every 5-10 years.

- Other performance parameters: Round-trip efficiency, cycle life, technology lifetime, daily selfdischarge rate, response time, storage duration, etc. Many other performance parameters were identified in this paper that are not directly affected by a developer's specific requirements. For example, many of the performance metrics pertaining to the temporal characteristics of a storage technology determined which applications that technology can provide, so these parameters are accounted for elsewhere. Likewise, the cycle life and lifetime for a storage technology factor into that technology's levelized cost. Therefore, no input is needed from the developer regarding these parameters.

\subsubsection{Environmental Impact}

Many of the environmental impacts considered in this report, such as the emissions produced by a technology during operation, a technology's land and water impacts, and the usage of rare-earth materials in an energy storage technology's construction should not be weighted, since these impacts are significant 
regardless of how the storage technology is used. However, other environmental impacts could be magnified by a storage technology's location. The following questions are intended to determine if such a situation exists.

- Question \#7: How close will this technology be located to human habitation or sensitive wildlife regions? The purpose of this question is to determine the importance of certain environmental impacts, specifically the use of hazardous materials in a storage technology, the production of hazardous fumes by the technology, and safety concerns associated with the technology. The developer's response to this question yields a weighting factor that adjusts the importance of these specific environmental impacts so that they can potentially have a decreased effect on the technology's total environmental impact score. If a technology is very far away from people and sensitive wildlife regions, then the environmental impact will be minimized, corresponding to a higher environmental impact score as calculated by the decision tool (a higher score indicates a lower overall impact on the environment). Conversely, if the technology is in close proximity, then the corresponding environmental impact factors will not be reduced.

\subsubsection{Geographic Requirements}

The availability of nearby geographic features conducive to energy storage is critical to the success of many storage technologies in this report. However, completing a full geological survey of the U.S. to assess which regions are most ideally suited for these technologies is outside of the scope of this report. Therefore, the following questions will attempt to obtain the necessary information from the developer.

- Question \#8: Are there any nearby geographic features compatible with energy storage in the immediate vicinity of the project? The developer will be able to select the features that are nearby to the energy storage siting location. If the requisite geographic features are selected by the developer (e.g., a salt cavern, which can be conducive to CAES), then the corresponding energy storage technologies will not be eliminated from consideration.

\subsubsection{Policy and Market Conditions}

In previous sections, policy and market conditions have been identified for distinct regions in the U.S. Therefore, the developer must provide the regional location of their project so that the correct policies and market opportunities can be associated with the energy storage technologies being evaluated. There are many national policies and large-scale economic factors that affect energy storage as well, but these have not been integrated with the tool since they apply to all storage technologies uniformly.

- Question \#9: In what state will the chosen energy storage technology be installed? Many states have specific energy storage goals or regulations that apply only in that state. Therefore, the developer's state must be known in order to identify these regulations. Additionally, the regional market variability can be estimated by calculating the concentration of wind and solar resources generating electricity in that state.

\subsubsection{Compatible Applications}

Identifying the grid-scale services that each energy storage technology can provide is an essential part of determining the economic viability of that technology. The developer using this tool should be able to select the primary application that they intend to use the storage technology for. The following question aims to provide the developer with the opportunity to express this information.

- Question \#10: Which grid-scale service is the most important to your application? This question will give the developer using the decision tool a chance to choose the primary application that they want the energy storage technology to perform. Their response will give the tool the necessary 
information to identify specific technologies that are and are not capable of performing in ways that are compatible with the desired application.

\subsection{Building the Decision Tool}

Once sufficient information about the specific situation for the developer using the tool has been gathered, these requirements can be combined with a technology database to begin distinguishing between energy storage options that are compatible with the developer's needs. Each technology will be compared against the other technologies considered in this report using a number of different characteristics and performance metrics. This section outlines the analytical methods used to quantify the characteristics of the different storage technologies based on the input from the developer.

\subsubsection{Environmental Impact}

\subsubsection{As demonstrated in Policy and Market Conditions}

In the Inventory of Options, many relevant policies and market trends were discussed in relation to the energy storage technologies considered in this report. In addition to these localized policies and market trends, national and regional policies as well as large-scale market trends can also impact the success of energy storage technologies. These policy and market conditions should be considered when evaluating the favorability of the regulatory environments and markets that these energy storage technologies could be operating in.

\subsubsection{Table 26, several individual impact factors constitute a technology's overall environmental impact score. These factors include a technology's land and water impact, emissions produced during operation, use of hazardous materials, production of hazardous fumes, short-term safety concerns, and impact on resource depletion. Each storage technology assigned an impact factor for each of these characteristics as shown in Policy and Market Conditions}

In the Inventory of Options, many relevant policies and market trends were discussed in relation to the energy storage technologies considered in this report. In addition to these localized policies and market trends, national and regional policies as well as large-scale market trends can also impact the success of energy storage technologies. These policy and market conditions should be considered when evaluating the favorability of the regulatory environments and markets that these energy storage technologies could be operating in.

Table 26. These impact factors were then normalized to a number between 0 and 1 . The relevant impact factors were then weighted according to the developer's responses to the questionnaire in Appendix A. Finally, these impact factors were averaged to generate an overall environmental impact score that was normalized to a ten-point scale. This final value is used by the decision tool to compare the various technologies after it is flipped so that a high score indicates a technology with a low environmental impact. This calculation is represented below in Equation 1. The variables $x_{\theta}$ and $y$ represent each individual environmental impact factor and its associated weighting factor, respectively. The variable $N$ represents the normalization factor. The variable $\epsilon$ represents the overall environmental impact score.

Equation 1. Calculation of environmental impact score. 


$$
\epsilon=\left[10-\stackrel{(0,10]}{N}\left(\frac{\Sigma\left[\stackrel{(0,1]}{N}^{2}\left(x_{\theta}\right) \times \stackrel{(0,1]}{N}(y)\right]}{6}\right)\right]
$$

\subsubsection{Technology Maturity}

The maturity of the energy storage technologies in this report was summarized by the TRL. This number was determined using a method standardized by the DOE for assessing the maturity of a technology based on its commercial readiness. For the purposes of this work, the TRL number was used to assess the remaining development time needed for a particular technology to reach full-scale commercialization. The TRL number for each technology was normalized to a ten-point scale and weighted according to the length of a developer's construction timeline. The calculation of the technology maturity score is represented below in Equation 2. The variable $T$ represents a value corresponding to the developer's construction timeline and is used to calculate an appropriate weighting factor. The variable $T R L$ represents the technology readiness level. The variable $N$ represents the normalization factor. The variable $\mu$ represents the overall technology maturity score.

Equation 2. Calculation of technology maturity score.

$$
\mu=\left.[\stackrel{[0,10]}{N}(T \stackrel{[0,9]}{T R})]\left[1+\frac{[1,5]}{T}-1\right]\right|_{\max =10}
$$

\subsubsection{Geographic Availability}

Many of the energy storage technologies considered in this report have specific geographic requirements. Therefore, if the specific geographic feature required by a storage technology is not in the immediate vicinity of the developer's location, then that storage technology should not be considered as a viable option. Using the developer's responses, the decision tool will indicate with a simple value of 1 or 0 whether or not the technology in question is viable based on the technology's geographic requirements. If the decision tool returns a score of 1 , then the storage technology is compatible with the geographic features available to the developer, and if the tool returns a score of 0 , then the storage technology is incompatible and should be removed from consideration. This logical tool is represented by Equation 3, which is displayed below. The variable $\delta$ represents the logical indicator that either has a value of 1 or 0 corresponding to the presence of geographic features compatible with energy storage technologies in the developer's vicinity. The variable $\gamma$ represents the geographic availability logical indicator.

Equation 3. Geographic availability logical indicator.

$$
\gamma=\left.\stackrel{[0,1]}{\delta}\right|_{\text {geo } r e q^{\prime} s}
$$

\subsubsection{Cost Requirements}

The tool assesses cost requirements in a similar manner to geographic requirements. The decision tool returns a simple value of 1 or 0 to indicate whether or not the storage technology in question fulfills the developer's energy storage and power requirements at a cost below the developer's available budget. The cost of a particular energy storage technology is calculated by multiplying the technology's storage and 
power capacity costs by the developer's required storage and power capacity. The largest of these values is then chosen to represent the most that a developer would have to pay for that storage technology. The difference between the cost of the technology and the developer's available budget is also calculated by the decision tool so that the cheapest technologies can still be identified. The analytical method for assessing the cost requirements and cost surplus is displayed below in Equation 4. The variables $C_{E}$ and $C_{P}$ represent the energy and power capacity costs for a particular energy storage technology, respectively. The variables $E_{r e q}$ and $P_{r e q}$ represent the developer's energy and power capacity requirements, respectively. The variable $B$ represents the developer's available budget. The variable $C_{\text {surplus }}$ represents the difference between the developer's available budget and the actual cost of installing the storage technology. The variables $C_{r e q_{E}}$ and $C_{r e q_{P}}$ represent the costs of fulfilling the developer's energy and power capacity requirements with a particular energy storage technology, respectively. The variable $\delta$ represents the logical indicator designating whether or not the storage technology fulfills the developer's cost requirements.

Equation 4. Cost requirements and cost surplus calculations.

$$
C=\left\{\begin{array}{l}
C_{\text {surplus }}=B-\max \left(C_{E} * E_{r e q}, C_{P} * E_{r e q}\right) \\
{[0,1]} \\
\delta=\operatorname{if}\left[\max \left(C_{r e q_{E}}, C_{r e q_{P}}\right)>B, 0,1\right]
\end{array}\right.
$$

\subsubsection{Space and Weight Requirements}

Once again, the decision tool communicates a particular energy storage technology's ability to provide the desired performance within the space and weight available to the developer with a simple logical indicator. If the value is 1 , then the technology fulfills the space or weight requirements of the developer, and if the value is 0 , then the technology fails these requirements. Note that the decision tool has separate indicators for space and weight requirements. The space or weight required by a technology is calculated by multiplying the developer's energy and power capacity requirements by the energy and power density or specific energy and power of each energy storage technology. Then, the maximum amount of space or weight required by each technology is compared to the developer's space and weight requirements to determine each technology's viability. Finally, the amount of additional space and weight is calculated by the tool, along with the additional storage or power capacity that could be installed by the developer for the technologies that satisfy the initial space and weight requirements. This information can be used to compare the performance of different energy storage technologies. The space and weight compatibilities for each energy storage technology are calculated using Equation 5 and Equation 6. In Equation 5, the variables $E_{r e q}$ and $P_{r e q}$ represent the developer's energy and power capacity requirements, respectively. The variables $\rho_{E}$ and $\rho_{P}$ represent the energy and power densities for a particular energy storage technology, respectively. The variable $V_{\text {avail }}$ represents the amount of space available to the developer. The variable $\delta$ represents the logical indicator designating whether or not a particular energy storage technology fulfills the developer's space requirements. The variables $V_{r e q_{E}}$ and $V_{r e q_{P}}$ represent the volume required to fulfill the developer's energy and power capacity requirements with a particular energy storage technology, respectively. The variables $E_{\text {excess }}$ and $P_{\text {excess }}$ represent the difference between the amount of energy or power capacity that can be provided by a particular energy storage technology given the amount of space available to the developer and the developer's energy and power capacity requirements, respectively. In Equation 6, many of the variables are the same. The variables $\sigma_{E}$ and $\sigma_{P}$ represent the specific energy and power characteristics of a particular energy storage technology, respectively. Additionally, the variables $M_{\text {avail }}, M_{r e q_{E}}$, and $M_{r e q_{P}}$ correspond directly to the similar variables $V_{\text {avail }}, V_{r e q_{E}}$, and $V_{r e q_{P}}$ in Equation 5, but refer to the developer's weight requirements instead. 
Equation 5. Space requirements and excess energy storage capacity calculations.

$$
V=\left\{\begin{array}{l}
{[0,1]} \\
\delta=\text { if }\left[\max \left(\frac{E_{r e q}}{\rho_{E}}, \frac{P_{r e q}}{\rho_{P}}\right)>V_{\text {avail }}, 0,1\right] \\
E_{\text {excess }}=\text { if }\left[V_{\text {avail }}>V_{\text {req }},\left(V_{\text {avail }} * \rho_{E}\right)-E_{\text {req }}, 0\right] \\
P_{\text {excess }}=\text { if }\left[V_{\text {avail }}>V_{\text {req }},\left(V_{\text {avail }} * \rho_{P}\right)-P_{r e q}, 0\right]
\end{array}\right.
$$

Equation 6. Weight requirements and excess power capacity calculations.

$$
M=\left\{\begin{array}{l}
{[0,1]} \\
\delta=i f\left[\max \left(\frac{E_{r e q}}{\sigma_{E}}, \frac{P_{r e q}}{\sigma_{P}}\right)>M_{\text {avail }}, 0,1\right] \\
E_{\text {excess }}=\text { if }\left[M_{\text {avail }}>M_{r e q_{E}},\left(M_{\text {avail }} * \sigma_{E}\right)-E_{r e q}, 0\right] \\
P_{\text {excess }}=\text { if }\left[M_{\text {avail }}>M_{r e q_{P}},\left(M_{\text {avail }} * \sigma_{P}\right)-P_{r e q}, 0\right]
\end{array}\right.
$$

\subsubsection{Application Compatibility}

Every developer using this tool will likely be pursuing energy storage for some specific application. Therefore, the compatibility of each energy storage technology with that particular application is critical to the technology's success. Based on the developer's responses to the survey in Appendix A, the decision tool will return a score for each technology of either $0,0.5$, or 1 . A score of 0 indicates that the storage technology is incompatible with the developer's desired application, a score of 0.5 indicates that the technology is somewhat compatible, and a score of 1 indicates that the technology is fully compatible.

\subsubsection{Policy and Market Conditions}

In order to determine the policies and market trends affecting a developer, the developer's location must be ascertained. This information is gained from the developer's responses to the questionnaire in Appendix A. Based on the input from the developer, the relevant policy information for the developer's project site is gathered from Table 28, Table 29, and Table 30. For the policy conditions, a simple logical indicator expresses whether or not there are favorable policy conditions for energy storage in the developer's state. Likewise, to determine a developer's market conditions, the level of regional electricity variability for the developer's state is assessed and output by the decision tool. The decision tool estimates the variability in each regional electricity market to be either high, medium, or low. As described earlier, the variability of a regional electricity market is designated as high if the percentage of electricity generation from wind and solar power in that region exceeds the $66^{\text {th }}$ percentile, medium if this percentage falls between the $33^{\text {rd }}$ and $66^{\text {th }}$ percentiles, and low if it is below the $33^{\text {rd }}$ percentile. 


\section{RESULTS AND ANALYSIS}

This section will provide an overview of how the tool developed for this report can yield actionable feedback for a power plant or energy storage technology developer. This is done by analyzing the results of the comparative tool for three real-world scenarios with a focus on the requirements of an NPP.

\subsection{Scenario 1}

The first scenario that was studied focused on energy arbitrage. Energy arbitrage was selected for the first scenario because the motivation for investigating energy storage is often focused on finding ways to provide power plants with the capability to continue operating with a high capacity factor, while avoiding selling electricity at prices below the plant's marginal cost of producing electricity. Scenario 1 assumed that energy produced during a four-hour period of low demand is stored and then sold during an equally long period of high demand. Thus, for a $1 \mathrm{GW}$ NPP, the storage technology must have $4 \mathrm{GWh}$ of storage capacity and $1 \mathrm{GW}$ of power capacity if the developer plans on simply doubling their output during the period of high demand. This type of energy arbitrage favors electricity storage technologies because these technologies do not require the installation of additional thermal generation capacity (i.e., turbines) to double the plant's power output during the four-hour peak demand period. This scenario is represented below in Figure 40. The dotted line in Figure 40 represents actual wholesale electricity prices for a day in the ERCOT electricity market in 2012. Typically, NPPs will operate as a base-load power supplier, not changing their output to match demand throughout the day. However, an energy storage technology would allow an NPP to follow the power output profile displayed by the solid line in Figure 40.

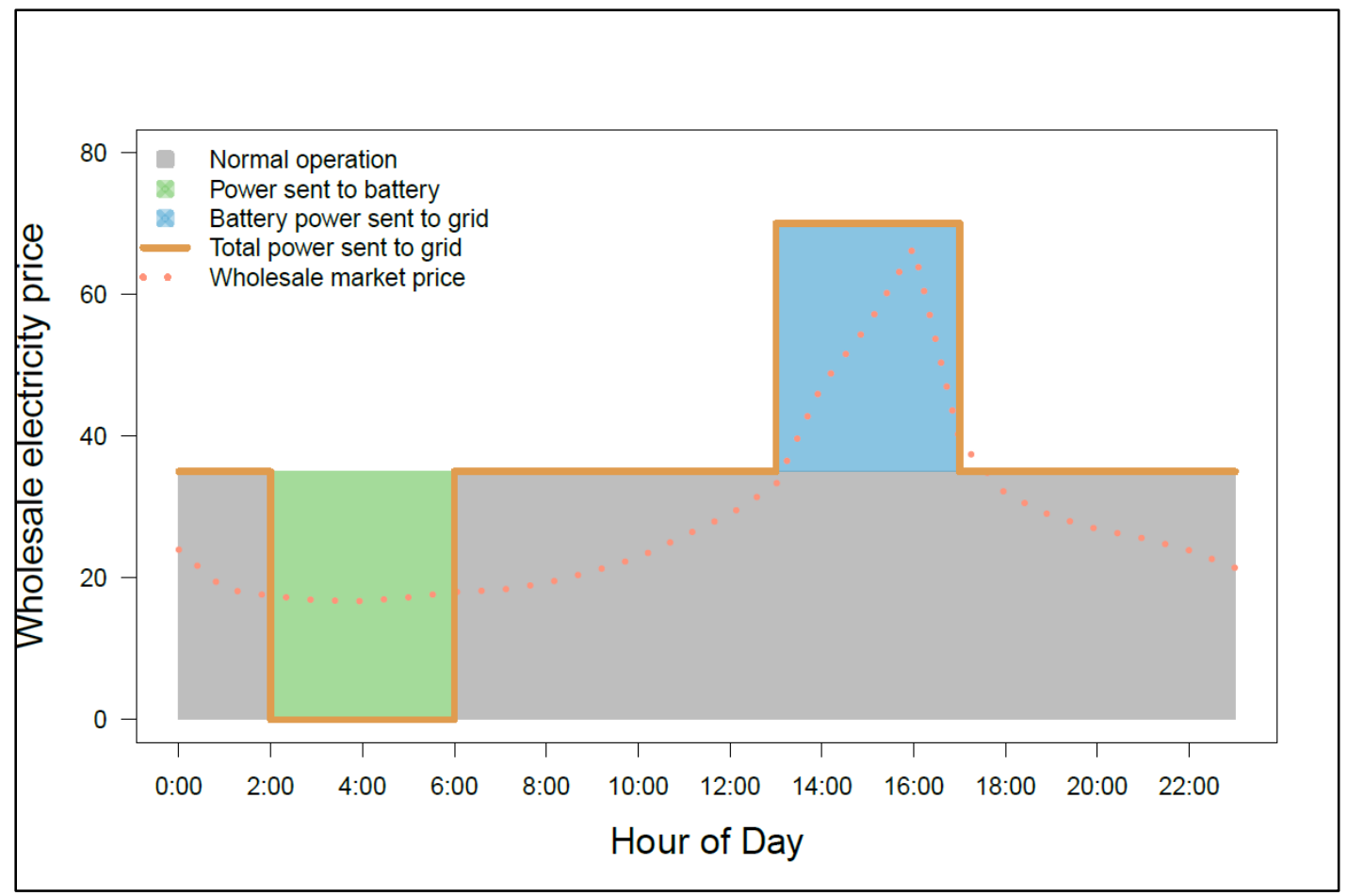

Figure 40. Energy arbitrage to capture peak demand pricing in Scenario 1.

In this scenario, the space and weight limits were set so that no technologies were eliminated from consideration because of this requirement. Similarly, the developer's site was assumed to be nearby many different geographic features so that the technologies with specific geographic requirements were not 
ruled out. Additionally, a budget of $\$ 10$ million was selected because it was sufficiently high to not eliminate all of the energy storage technologies. Weighting factors were also selected for this scenario corresponding to a project timeline of 11-15 years and a technology location that is very close to human habitations and sensitive wildlife regions. Finally, the state of California was selected to implement regional effects because of the many favorable policies concerning energy storage technologies in this state. The full list of specifications and requirements for Scenario 1 is displayed below in Table 34 .

Table 34. Requirements for energy arbitrage to capture peak demand pricing for Scenario 1.

\begin{tabular}{|c|c|}
\hline Developer Inputs & Value \\
\hline Required Energy Storage $(\mathrm{MWh})$ & 4000 \\
\hline Required Power $(\mathrm{MW})$ & 1000 \\
\hline Available Space $\left(\mathrm{m}^{3}\right)$ & Unlimited \\
\hline Available Weight $(\mathrm{kg})$ & Unlimited \\
\hline Budget $(\$)$ & $\$ 10 \mathrm{M}$ \\
\hline Project Timeline & $11-15$ years \\
\hline Technology Proximity & Very Close \\
\hline Geographic Availability & $\begin{array}{c}\text { Elevation Change, Water Source, } \\
\text { Evacuated Salt Cavern }\end{array}$ \\
\hline Desired Application & Energy Arbitrage \\
\hline Location & California \\
\hline
\end{tabular}

Since there are so many different factors at play when identifying compatible energy storage technologies for a developer's individual application, the decision tool does not propose a single technology as the most suitable option to fulfill a developer's needs. Instead, the decision tool takes the developer's requirements and the information catalogued in this report to produce a "stoplight chart" that shows the developer how the relative performance of different technologies compare across the complete range of characteristics of interest. Since almost twenty different technologies were considered by the decision tool for Scenario 1, a few technologies were selected to focus on for the purposes of comparison. The stoplight chart for Scenario 1 is displayed in Figure 41. Cells with favorable values are shown in green. Cells with unfavorable values are shown in red. Only electricity storage technologies are shown because this scenario is geared towards technologies that do not require additional turbines to be installed onsite to deliver stored energy during periods of high demand. The two boxes in the bottom portion of the stoplight chart indicate that the policy and market conditions in California, the developer's selected location, are favorable towards energy storage technologies, as shown by their green color. A red box would indicate that the policy conditions are not obviously favorable and the market has low variability, while a yellow box for the market variability metric would indicate mild variability in the power plant's native electricity market. The tool reveals that pumped storage hydropower, CAES, lithium-ion batteries, and vanadium redox flow batteries can successfully store energy for a period of 4 hours and then discharge that energy for the same length of time given the constraints shown above in Table 34. If a technology's name in the top row is highlighted in red, then the decision tool has determined that the respective technology is incompatible with the developer's requirements. Thus, the tool communicates that flywheels, supercapacitors, and SMES systems have difficulty meeting the developer's requirements in this scenario. The displayed performance metrics for each technology can be used to compare and contrast the technologies and identify well-suited solutions to the developer's requirements. For example, CAES systems have a relatively low environmental impact and are already fully commercialized. The tool reveals that CAES systems are also the least expensive of the selected technologies, as demonstrated by the fact that the cost difference for CAES systems is highlighted in green. In contrast, flywheels, supercapacitors, and SMES systems are too costly to implement with the developer's available budget, as indicated by the red boxes in the row labelled Cost Requirements. The cost differences for these technologies are also highlighted in red, while the cost difference for other technologies that are still 
affordable are highlighted in yellow. A few energy storage technologies in Figure 41 have boxes that are not highlighted at all. These uncolored boxes indicate that there was not enough available data to analyze the characteristic represented by the row containing the empty boxes for those technologies. For instance, information from Lazard's Levelized Cost of Storage (LCOS) report is also included in this chart, but specific cost data was not available for supercapacitors and SMES systems. According to Lazard's data, CAES systems have the lowest LCOS [130]. The tool shows that VRB systems have a lower environmental impact than CAES systems, as indicated by their higher environmental impact score, but they are not capable of supplying energy arbitrage services as effectively and as inexpensively as CAES systems. Thus, although only a selection of the analyzed energy storage technologies is shown in Figure 41, a developer following this decision-making process with the constraints defined in Table 34 would likely identify CAES as a well-suited technology to fulfill their requirements.

\begin{tabular}{|c|c|c|c|c|c|c|c|}
\hline Technology Characteristics & PSH & CAES & Flywheels & $\begin{array}{c}\text { Super- } \\
\text { capacitors }\end{array}$ & SMES & Li-ion & $\begin{array}{c}\text { Vanadium } \\
\text { Redox }\end{array}$ \\
\hline Environmental Impact & 6.39 & 6.39 & 8.89 & 8.61 & 7.50 & 5.83 & 8.33 \\
\hline Technology Maturity & 10.00 & 10.00 & 10.00 & 7.78 & 7.78 & 10.00 & 10.00 \\
\hline Geographic Availability & 1.00 & 1.00 & 1.00 & 1.00 & 1.00 & 1.00 & 1.00 \\
\hline Cost Requirements & 1.00 & 1.00 & 0.00 & 0.00 & 0.00 & 1.00 & 1.00 \\
\hline Cost Difference (S) & $6.00 \mathrm{E}+06$ & $8.50 \mathrm{E}+06$ & $-1.00 \mathrm{E}+07$ & $-3.00 \mathrm{E}+07$ & $-3.00 \mathrm{E}+07$ & $0.00 \mathrm{E}+00$ & $6.00 \mathrm{E}+06$ \\
\hline Space Requirements & 1.00 & 1.00 & 1.00 & 1.00 & 1.00 & 1.00 & 1.00 \\
\hline Weight Requirements & 1.00 & 1.00 & 1.00 & 1.00 & 1.00 & 1.00 & 1.00 \\
\hline Potential Additional Storage Capacity $(\mathrm{kWh})$ & $5.00 \mathrm{E}+11$ & $2.00 \mathrm{E}+12$ & $2.00 \mathrm{E}+13$ & $2.50 \mathrm{E}+09$ & $4.96 \mathrm{E}+08$ & $7.50 \mathrm{E}+10$ & $1.00 \mathrm{E}+10$ \\
\hline Potential Additional Power Capacity $(\mathrm{kW})$ & $5.00 \mathrm{E}+11$ & $5.00 \mathrm{E}+11$ & $1.00 \mathrm{E}+15$ & $5.00 \mathrm{E}+11$ & $5.00 \mathrm{E}+11$ & $7.50 \mathrm{E}+11$ & $1.50 \mathrm{E}+11$ \\
\hline Application Compatibility Factor & 1.00 & 1.00 & 0.00 & 0.00 & 0.00 & 0.50 & 0.50 \\
\hline Levelized Cost of Storage, Lower-End $(S / M W h)$ & 188 & 192 & 276 & NA & NA & 321 & 248 \\
\hline Levelized Cost of Storage, Upper-End $(S / M W h)$ & 274 & 192 & 989 & NA & NA & 658 & 927 \\
\hline Favorable Policy Conditions & YES & & & & & & \\
\hline Market Variability & $\mathrm{IGH}$ & & & & & & \\
\hline
\end{tabular}

Figure 41. Stoplight chart with selected electricity storage technologies for Scenario 1.

\subsection{Scenario 2}

In Scenario 2, energy arbitrage was selected again as the developer's chosen application for the energy storage technology, but the developer's requirements were adapted to be better suited for thermal energy storage technologies. In Scenario 1, energy was stored during a four-hour period of low demand and was sold during an equally long period of high demand to take full advantage of peak demand pricing. However, with a thermal energy storage technology, a power plant would need to essentially double its thermal generation capacity by, for example, installing additional turbines, to have the ability to double its output during peak demand periods. This additional expense could make operating in this manner economically infeasible for thermal energy storage technologies. Therefore, an alternative mode of operation is considered in this scenario. Instead, the energy stored during a four-hour period of low demand is sold throughout the day instead of in a single block. Thus, although additional generation capacity is still required, not nearly as much is needed. This approach to energy arbitrage might not be as profitable as the approach displayed in Figure 40, but it would still enable an NPP to operate at a high capacity factor and avoid selling electricity at prices below the plant's marginal cost of producing electricity. The energy arbitrage technique used in Scenario 2 is represented graphically in Figure 42 below. 


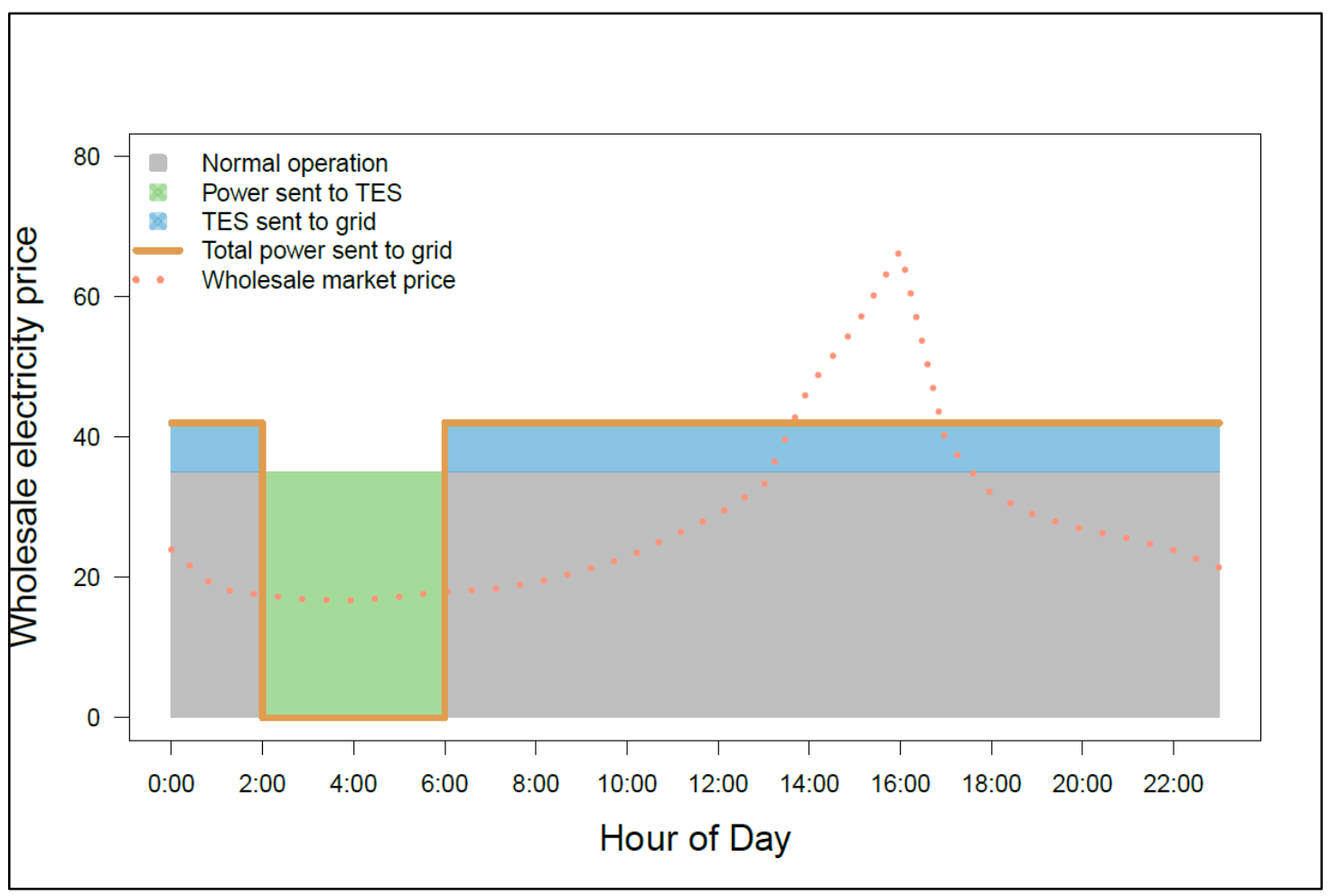

Figure 42. Energy arbitrage to avoid low prices in Scenario 2.

For Scenario 2, many of the constraints from Scenario 1 remained the same. However, since the energy stored during the initial four-hour period of low demand is being discharged over a period of 20 hours in this example, the required power output of the energy storage technology is one-fifth the required power output in the first scenario. Thus, only $200 \mathrm{MW}$ of additional generation capacity is needed, instead of another $1 \mathrm{GW}$. The geographic features available to the developer were also changed to accommodate the various thermal energy storage technologies featured in the report. A different state was also selected for this scenario to demonstrate the range of potential policy and market conditions that could affect a developer depending on their location. The full list of specifications and developer requirements is displayed below in Table 35 .

Table 35. Requirements for energy arbitrage to avoid low prices in Scenario 2.

\begin{tabular}{|c|c|}
\hline Developer Inputs & Value \\
\hline Required Energy Storage $(\mathrm{MWh})$ & 4000 \\
\hline Required Power $(\mathrm{MW})$ & 200 \\
\hline Available Space $\left(\mathrm{m}^{3}\right)$ & Unlimited \\
\hline Available Weight $(\mathrm{kg})$ & Unlimited \\
\hline Budget $(\$)$ & $\$ 10 \mathrm{M}$ \\
\hline Project Timeline & $11-15$ years \\
\hline Technology Proximity & Very Close \\
\hline Geographic Availability & $\begin{array}{c}\text { Elevation Change, Water Source, } \\
\text { Aquifer, Underground Cavern or Pit }\end{array}$ \\
\hline Desired Application & Energy Arbitrage \\
\hline Location & Texas \\
\hline
\end{tabular}


The resulting stoplight chart produced by the constraints listed above in Table 35 is displayed below in Figure 43. However, only selected thermal energy storage technologies and a few electricity storage technologies are presented in this chart, since the described method of energy arbitrage is not feasible for all of the energy storage technologies considered in this report. Once again, the regional policy and market conditions for the developer's chosen location, the state of Texas, are favorable towards energy storage technologies. There are also several technologies that do not fulfill the developer's requirements, which are recorded in Table 35. Underground thermal energy storage systems cannot effectively perform energy arbitrage, due to the manner in which energy is stored using this technology, and CAES and hydrogen production systems do not have the necessary natural storage reservoirs available within the immediate vicinity of the power plant's location. Of the remaining technologies, it appears that several of the thermal energy storage technologies displayed in Figure 43 offer superior energy storage characteristics. For example, the environmental impact scores of hot and cold water storage tanks, solid media storage, and phase change materials are relatively high, which indicates a minimal impact on the environment. Additionally, the costs of each of these technologies are relatively low. In contrast, although the energy capacity cost of pumped storage hydropower systems is low, the environmental impact score of this technology is significantly lower than the thermal energy storage technologies featured in Figure 43. Thus, a sufficient amount of information is available in Figure 43 for a developer using this tool to narrow in on a suitable storage technology under the assumptions of Scenario 2.

\begin{tabular}{|c|c|c|c|c|c|c|c|c|}
\hline Technology Characteristics & PSH & CAES & Hydrogen & UTES & \begin{tabular}{|c|} 
Hot and Cold \\
Water
\end{tabular} & $\begin{array}{c}\text { Solid } \\
\text { Media } \\
\end{array}$ & $\begin{array}{c}\text { Molten } \\
\text { Salts }\end{array}$ & PCMs \\
\hline Environmental Impact & 6.39 & 6.39 & 5.97 & 8.75 & 10.00 & 10.00 & 6.11 & 8.33 \\
\hline Technology Maturity & 10.00 & 10.00 & 9.33 & 10.00 & 10.00 & 9.33 & 10.00 & 6.22 \\
\hline Geographic Availability & 1.00 & 0.00 & 0.00 & 1.00 & 1.00 & 1.00 & 1.00 & 1.00 \\
\hline Cost Requirements & 1.00 & 1.00 & 0.00 & 1.00 & 1.00 & 1.00 & 1.00 & 1.00 \\
\hline Cost Difference (\$) & $9.20 \mathrm{E}+06$ & $9.52 \mathrm{E}+06$ & $-2.00 \mathrm{E}+06$ & $9.10 \mathrm{E}+06$ & $9.88 E+06$ & $9.40 \mathrm{E}+06$ & $9.86 \mathrm{E}+06$ & $7.00 \mathrm{E}+06$ \\
\hline Space Requirements & 1.00 & 1.00 & 1.00 & 1.00 & 1.00 & 1.00 & 1.00 & 1.00 \\
\hline Weight Requirements & 1.00 & 1.00 & 1.00 & 1.00 & 1.00 & 1.00 & 1.00 & 1.00 \\
\hline Potential Additional Storage Capacity $(\mathrm{kWh})$ & $5.00 \mathrm{E}+11$ & $2.00 \mathrm{E}+12$ & $8.00 \mathrm{E}+11$ & $2.00 \mathrm{E}+13$ & $2.00 \mathrm{E}+13$ & $5.00 E+09$ & $8.00 \mathrm{E}+10$ & $1.00 \mathrm{E}+14$ \\
\hline Potential Additional Power Capacity $(\mathrm{kW})$ & $5.00 \mathrm{E}+11$ & $5.00 \mathrm{E}+11$ & $5.00 \mathrm{E}+11$ & $\mathrm{NA}$ & $\mathrm{NA}$ & $\mathrm{NA}$ & $\mathrm{NA}$ & $\mathrm{NA}$ \\
\hline Application Compatibility Factor & 1.00 & 1.00 & 0.50 & 0.00 & 1.00 & 1.00 & 1.00 & 1.00 \\
\hline Levelized Cost of Storage, Lower-End (S/MWh) & 188 & 192 & $\mathrm{NA}$ & $\mathrm{NA}$ & NA & $\mathrm{NA}$ & $\mathrm{NA}$ & $\mathrm{NA}$ \\
\hline Levelized Cost of Storage, Upper-End (S/MWh) & 274 & 192 & NA & NA & NA & NA & NA & NA \\
\hline Favorable Policy Conditions & YES & & & & & & & \\
\hline Market Variability & HIGH & & & & & & & \\
\hline
\end{tabular}

Figure 43. Spotlight chart with selected thermal energy storage technologies for Scenario 2.

\subsection{Scenario 3}

In addition to the two energy arbitrage scenarios previously considered, a third scenario should be considered to demonstrate the full operational range of the decision tool. In this scenario, frequency regulation was chosen as the desired application instead of energy arbitrage. In addition, space limitations were included in the developer's requirements to exhibit the effect this parameter has on the decision tool's output. Furthermore, the project timeline was reduced to show how this weighting factor affects the results. The proximity of the storage technology to workers and sensitive wildlife populations was also adjusted. Finally, the developer's location was changed again to a region in which there are not many favorable policies in place specifically focusing on energy storage technologies. The full list of specifications and developer requirements is displayed below in Table 36. 
Table 36. Requirements for frequency regulation in Scenario 3.

\begin{tabular}{|c|c|}
\hline Developer Inputs & Value \\
\hline Required Energy Storage $(\mathrm{MWh})$ & 4000 \\
\hline Required Power $(\mathrm{MW})$ & 1000 \\
\hline Available Space $\left(\mathrm{m}^{3}\right)$ & $1,000,000$ \\
\hline Available Weight $(\mathrm{kg})$ & Unlimited \\
\hline Budget $(\$)$ & $\$ 10 \mathrm{M}$ \\
\hline Project Timeline & $1-5$ years \\
\hline Technology Proximity & Far Away \\
\hline Geographic Availability & $\begin{array}{c}\text { Elevation Change, Water Source, } \\
\text { Evacuated Salt Cavern }\end{array}$ \\
\hline Desired Application & Frequency Regulation \\
\hline Location & Idaho \\
\hline
\end{tabular}

For Scenario 3, the full catalogue of energy storage technologies investigated in this report is displayed below in Figure 44 and Figure 45. First, the mechanical and electrical energy storage technologies and conventional batteries are displayed in Figure 44. Although all of the geographic requirements for the technologies displayed in Figure 44 are fulfilled, the cost requirements for flywheels, supercapacitors, and SMES systems are greater than the developer's available budget. This is due to the high energy capacity costs for these technologies. Since the energy storage and power requirements for energy arbitrage were maintained for this scenario, which would enable the developer to perform both energy arbitrage and frequency regulation services, these technologies are not able to provide the required 4,000 MWh of storage cost-effectively. In addition, pumped storage hydropower systems and CAES systems do not fulfill the space constraints that were included in this scenario. Finally, NiCd batteries are also eliminated from consideration by the decision tool since they cannot effectively provide frequency regulation, which was the desired application for this scenario. As a result, only lithium-ion, NaS, and lead-acid batteries are compatible with all of the developer's requirements in this group of technologies. According to Lazard's LCOS analysis, lithium-ion batteries have the lowest levelized cost of these technologies [130].

\begin{tabular}{|c|c|c|c|c|c|c|c|c|c|}
\hline Technology Characteristics & PSH & CAES & Flywheels & $\begin{array}{c}\text { Super- } \\
\text { capacitors }\end{array}$ & SMES & Li-ion & $\mathrm{NaS}$ & Lead-Acid & $\mathrm{NiCd}$ \\
\hline Environmental Impact & 7.06 & 7.06 & 9.56 & 9.44 & 9.00 & 8.33 & 8.89 & 7.67 & 8.67 \\
\hline Technology Maturity & 10.00 & 10.00 & 7.78 & 5.56 & 5.56 & 7.78 & 8.89 & 10.00 & 7.78 \\
\hline Geographic Availability & 1.00 & 1.00 & 1.00 & 1.00 & 1.00 & 1.00 & 1.00 & 1.00 & 1.00 \\
\hline Cost Requirements & 1.00 & 1.00 & 0.00 & 0.00 & 0.00 & 1.00 & 1.00 & 1.00 & 1.00 \\
\hline Cost Difference (\$) & $6.00 \mathrm{E}+06$ & $8.50 \mathrm{E}+06$ & $-1.00 E+07$ & $-3.00 \mathrm{E}+07$ & $-3.00 \mathrm{E}+07$ & $0.00 \mathrm{E}+00$ & $7.00 \mathrm{E}+06$ & $8.40 \mathrm{E}+06$ & $4.00 \mathrm{E}+06$ \\
\hline Space Requirements & 0.00 & 0.00 & 1.00 & 0.00 & 0.00 & 1.00 & 1.00 & 1.00 & 1.00 \\
\hline Weight Requirements & 1.00 & 1.00 & 1.00 & 1.00 & 1.00 & 1.00 & 1.00 & 1.00 & 1.00 \\
\hline Potential Additional Storage Capacity $(\mathrm{kWh})$ & $0.00 E+00$ & $0.00 \mathrm{E}+00$ & $1.60 \mathrm{E}+07$ & $0.00 \mathrm{E}+00$ & $0.00 \mathrm{E}+00$ & $1.96 \mathrm{E}+08$ & $1.46 \mathrm{E}+08$ & $4.60 \mathrm{E}+07$ & $5.60 \mathrm{E}+07$ \\
\hline Potential Additional Power Capacity $(\mathrm{kW})$ & $0.00 \mathrm{E}+00$ & $0.00 \mathrm{E}+00$ & $9.99 \mathrm{E}+08$ & $0.00 \mathrm{E}+00$ & $0.00 \mathrm{E}+00$ & $2.90 \mathrm{E}+07$ & $1.39 \mathrm{E}+08$ & $9.00 \mathrm{E}+06$ & $7.90 \mathrm{E}+07$ \\
\hline Application Compatibility Factor & 0.50 & 0.50 & 1.00 & 1.00 & 1.00 & 1.00 & 1.00 & 1.00 & 0.00 \\
\hline Levelized Cost of Storage, Lower-End (S/MWh) & 188 & 192 & 276 & NA & $\mathrm{NA}$ & 321 & 365 & 419 & NA \\
\hline Levelized Cost of Storage, Upper-End $(S / M W h)$ & 274 & 192 & 989 & NA & NA & 658 & 948 & 1247 & NA \\
\hline Favorable Policy Conditions & NO & & & & & & & & \\
\hline Market Variability & $\mathrm{HIGH}$ & & & & & & & & \\
\hline
\end{tabular}

Figure 44. Mechanical, electrical, and electro-chemical energy storage technologies for Scenario 3.

The remaining energy storage technologies, including flow batteries and thermal energy storage technologies, are displayed below in Figure 45. Of these technologies, only the two types of flow batteries, $\mathrm{ZnBr}$ and vanadium redox, are compatible with the desired application for this scenario, 
frequency regulation. It is generally difficult for thermal energy storage technologies to provide frequency regulation unless the storage reservoir is already being discharged, since a steam cycle is generally used to convert the thermal energy into electricity. The characteristics of $\mathrm{ZnBr}$ and VRBs are very similar, but the stoplight chart in Figure 45 shows that VRBs are more mature and have a less severe effect on the environment. However, the LCOS of lithium-ion batteries is lower than the LCOS for VRBs, so lithiumion batteries might be the most well-suited energy storage solution for this particular set of requirements.

\begin{tabular}{|c|c|c|c|c|c|c|c|c|c|c|}
\hline Technology Characteristics & $\begin{array}{c}\text { Zinc- } \\
\text { Bromine } \\
\end{array}$ & $\begin{array}{c}\text { Vanadium } \\
\text { Redox }\end{array}$ & Hydrogen & UTES & $\begin{array}{c}\text { Hot and Cold } \\
\text { Water }\end{array}$ & $\begin{array}{r}\text { Solid } \\
\text { Media } \\
\end{array}$ & TCS & $\begin{array}{c}\text { Molten } \\
\text { Salts }\end{array}$ & LAES & PCMs \\
\hline Environmental Impact & 8.78 & 9.33 & 7.64 & 8.75 & 10.00 & 10.00 & 9.33 & 8.44 & 8.33 & 9.33 \\
\hline Technology Maturity & 6.67 & 7.78 & 6.67 & 8.89 & 7.78 & 6.67 & 5.56 & 10.00 & 6.67 & 4.44 \\
\hline Geographic Availability & 1.00 & 1.00 & 1.00 & 0.00 & 1.00 & 1.00 & 1.00 & 1.00 & 1.00 & 1.00 \\
\hline Cost Requirements & 1.00 & 1.00 & 0.00 & 1.00 & 1.00 & 1.00 & 1.00 & 1.00 & 1.00 & 0.00 \\
\hline Cost Difference (\$) & $6.00 \mathrm{E}+06$ & $6.00 \mathrm{E}+06$ & $-2.00 \mathrm{E}+06$ & $5.50 \mathrm{E}+06$ & $9.40 \mathrm{E}+06$ & $7.00 \mathrm{E}+06$ & $7.00 \mathrm{E}+06$ & $9.30 \mathrm{E}+06$ & $7.88 \mathrm{E}+06$ & $-5.00 \mathrm{E}+06$ \\
\hline Space Requirements & 1.00 & 1.00 & 1.00 & 1.00 & 1.00 & 1.00 & 1.00 & 1.00 & 1.00 & 1.00 \\
\hline Weight Requirements & 1.00 & 1.00 & 1.00 & 1.00 & 1.00 & 1.00 & 1.00 & 1.00 & 1.00 & 1.00 \\
\hline Potential Additional Storage Capacity $(\mathrm{kWh})$ & $2.60 \mathrm{E}+07$ & $2.10 \mathrm{E}+07$ & $4.96 \mathrm{E}+08$ & $1.60 \mathrm{E}+07$ & $1.60 \mathrm{E}+07$ & $1.80 \mathrm{E}+07$ & $1.36 \mathrm{E}+08$ & $1.66 \mathrm{E}+08$ & $1.00 \mathrm{E}+11$ & $9.60 \mathrm{E}+07$ \\
\hline Potential Additional Power Capacity $(\mathrm{kW})$ & $1.15 E+07$ & $0.00 \mathrm{E}+00$ & $4.99 \mathrm{E}+08$ & NA & NA & NA & NA & NA & NA & NA \\
\hline Application Compatibility Factor & 1.00 & 1.00 & 0.00 & 0.00 & 0.00 & 0.00 & 0.00 & 0.00 & 0.00 & 0.00 \\
\hline Levelized Cost of Storage, Lower-End $(\mathrm{S} / \mathrm{MWh})$ & 248 & 248 & NA & $\mathrm{NA}$ & NA & $\mathrm{NA}$ & NA & NA & NA & $\mathrm{NA}$ \\
\hline Levelized Cost of Storage, Upper-End $(S / M W h)$ & 927 & 927 & NA & NA & NA & NA. & NA & NA & NA & NA \\
\hline Favorable Policy Conditions & NO & & & & & & & & & \\
\hline Market Variability & HIGH & & & & & & & & & \\
\hline
\end{tabular}

Figure 45. Flow batteries and thermal energy storage technologies for Scenario 3.

\subsection{Analysis of the Impacts of Energy Storage Integration}

The first two scenarios used to display the operational capabilities of the decision tool highlight some of the value that energy storage could add to an NPP. The increasing presence of electricity generation from renewable energy resources on the grid has caused electricity prices to fall when these resources are generating electricity and demand is low. Part of the reason why electricity prices have fallen is because of the available subsidies for both wind and solar technologies. These subsidies enable renewable energy resources to sell electricity at prices below the marginal cost of producing electricity for an NPP, forcing the NPP to either sell electricity at a loss or ramp down their production. As demonstrated in Figure 40 and Figure 42, energy storage could enable an NPP to continue operating with a constant power output while still appearing flexible to the grid. Furthermore, if the energy stored during these periods of low electricity prices could be sold during peak demand periods, NPPs could increase their profitability in addition to reducing their losses. The quick response characteristics of some of the energy storage technologies considered in this report could also equip an NPP with the fast ramping capabilities that will likely be necessary to respond to the needs of the grid when variable generating resources such as wind and solar are not operating at their forecasted capacity. These services, along with the many other ancillary services that energy storage technologies can perform, could enhance the market competitiveness of NPPs at a time in which these plants are struggling to remain economically viable. Thus, energy storage could help NPPs adapt to a changing grid and maintain economic feasibility. However, as demonstrated by the scenarios considered in this section, a sizeable budget is needed to install a sufficient amount of energy storage to provide these benefits. With thermal energy storage, these investment costs could rise even further if additional generation capacity is required to perform energy arbitrage in the manner illustrated in Figure 40. Additionally, the limited development progress of some of these energy storage technologies could severely limit the options available to a developer interesting in installing an energy storage solution in the immediate future. This work, including the tool for downselecting viable energy storage technologies, could help diminish the confusion surrounding energy storage and remove some of the barriers to investment as developers are able to confidently identify which technologies are most suitable to their applications. 


\section{CONCLUSIONS}

Energy storage technologies have the potential to provide a variety of benefits to power plants and the electric grid. In particular, energy storage technologies might be able to provide unique solutions for increasing the competitive nature of NPPs as changes to the generation mix and demand curves require more flexibility. However, due to the nascent state of many of the energy storage technologies catalogued in this report, many technical, regulatory, and economic barriers still stand in the way of widespread commercial deployment. As a result, developers are often cautious to invest heavily in these technologies since their benefits have not been well defined and their costs remain high. This report seeks to inform the possibility of integrating energy storage by compiling a database of information concerning several key energy storage technologies and by demonstrating a first-cut tool that helps to down-select available energy storage technologies based on the unique needs of a potential developer. Combined, this report and tool could help to clarify the process for integrating energy storage with a power plant and identify some of the barriers obstructing the further development of these technologies.

\subsection{Key Takeaways}

This report includes pertinent information regarding a range of energy storage technologies. Not only does this report catalogue several important energy storage technologies, but it also compiles data regarding their maturity, relevant regulations and market trends, and performance metrics that can be used to compare and contrast the technologies. This information and the decision tool that was built to accompany this report have also helped to identify a few key energy storage technologies that could be well-suited to integration with an NPP. From the scenarios explored, it appears that CAES systems provide a compelling case for expanded use. This conclusion is consistent with some of the literature that has pointed to CAES systems as an effective interim solution since it is much further along in its development than some of the other energy storage technologies considered [69]. However, as economies of scale evolve for technologies such as lithium-ion batteries and vanadium redox flow batteries, these technologies might become attractive options as well.

Several other promising technologies were identified when the capabilities of thermal energy storage were highlighted. Specifically, hot and cold water storage tanks emerged as a particularly inexpensive technology with a minimal environmental impact that could perform many of the services desired by developers. Additionally, alternative forms of water storage, such as steam accumulators, could be used in tandem to provide additional services such as frequency regulation. However, the best technology for a developer's individual situation is still largely dependent on the constraints defined by the developer. The technology conclusions presented within this study are based on only a few example scenarios. Many other storage technologies could also be well-suited for integration with an NPP or any other large thermal power plant.

In addition to providing the information to identify potential compatible technologies for power plant developers, this report also contributed to the construction of a simplified decision tool that can be adapted to a developer's unique situation. Past research has used energy and power capacity costs for comparing energy storage technologies, but the decision tool described in this report considers many other factors. All of the metrics used by the decision tool to compare and contrast technologies are outlined in detail in the report so that developers using the tool can understand why a certain technology is well-matched with their application. As regulations change and technologies are developed further, this tool will need to be updated, but the framework set forth by this report will remain foundational.

Investors and policy-makers across the U.S. have expressed interest in promoting energy storage, as demonstrated by the DOE's grid modernization efforts, the efforts of various state legislatures, and the demonstration projects for many of the technologies mentioned in this report. However, investment in 
energy storage appears to be high-risk since the benefits provided by these technologies are unclear and the costs of installation are high. This tool and report could help to provide some clarity regarding the implementation of energy storage and give developers the tools to evaluate the associated economic tradeoffs.

\subsection{Future Work}

Although the decision tool is capable of providing valuable information as a first-cut assessment, additional refinement of the tool could further increase the value provided to developers. In addition to simply refining the metrics that feed into the tool, increased precision could be obtained by integrating new parameters and extending the operational capabilities of the tool. These new parameters and features comprise the bulk of the future research directions noted below.

\subsubsection{Detailed Market Analysis}

Since the compatibility of energy storage technologies with large thermal power plants, specifically NPPs, has only been considered in theory for this report, the actual market performance of an NPP coupled with an energy storage technology should be examined via unit commitment and dispatch modeling. This modeling would entail the optimization of several different operational parameters. For example, it has been discussed in this report that an energy storage technology cannot offset its installation costs by simply offering energy arbitrage services. However, the manner in which other ancillary services are aggregated with energy arbitrage is constrained by the technical capabilities of the storage technology, as illustrated in Table 33, and regulatory requirements. Thus, optimizing the provision of these services to maximize the amount of additional revenue available to the NPP is a primary objective for future work. Along with determining which services the chosen storage technology can effectively provide, the delivery of these services should also be optimized to coordinate with actual grid activity so that the true monetary value of integrating energy storage with an NPP can be estimated. Lastly, although the main concern of developers using this tool might be the effect energy storage would have on the power plant with which the technology is integrated, a more flexible NPP might also be able to increase the reliability and efficiency of the electric grid as a whole. For instance, there might be less of a need for the natural gas combined cycle plants that are predominantly used to generate electricity during peak demand periods in today's electric grid in the U.S. if NPPs were capable of operating flexibly. Therefore, the system effects of integrating energy storage with NPPs will also be modeled.

\subsubsection{Plant Design Optimization}

The issue of plant design was discussed briefly when two separate scenarios for electricity energy storage and thermal energy storage technologies were analyzed. While an electricity energy storage technology can discharge energy directly to the electrical grid without converting the form of energy, thermal energy storage systems require some sort of mechanism for converting the energy from heat to electricity. The power plant itself has these capabilities, but if an NPP is integrating energy storage so that the plant can continue to operate at a constant power output throughout the day, then additional generation assets would be required to increase the output of the power plant at any point. Thus, a thermal energy storage system might discharge its stored energy slowly throughout the day instead of all at once during the peak demand period to reduce the amount of additional generation capacity needed. However, exactly how slowly the thermal energy storage system would need to discharge the stored energy to adequately reduce the installation costs of supplementary turbines is unclear. The optimization of this problem could be a primary focus of any future work. Furthermore, in addition to this specific issue, the design of the power plant could also be optimized to match the most profitable use profile for an integrated energy storage system as determined with a detailed market analysis. This future research direction could be integrated with the previously discussed unit commitment and dispatch modeling to explore the further development of the decision tool. 


\subsubsection{Investigation of Life-Cycle Impacts}

The environmental impacts of each energy storage technology featured in this report are explored in great detail. However, the only emissions that are considered for each technology are the hazardous fumes produced either during the operation or decommissioning of certain technologies and any greenhouse gases that are emitted during operation. The greenhouse gas emissions that are produced during the construction of these technologies are not considered. As a result, these energy storage technologies appear slightly more environmentally friendly then they actually are, although the decision tool is still able to sufficiently compare the technologies amongst themselves. Thus, the consideration of life-cycle emissions and other life-cycle environmental impacts could be a worthwhile addition to future versions of the decision tool.

\subsubsection{Refinement of Performance Metrics}

All of the performance metrics that are inventoried in this report and comprise the database that informs the decision tool were gathered through an extensive review of the available literature. However, due to the scarcity of significant research concerning energy storage technologies, these parameters could be refined and verified through an extended search. Industrial stakeholders might be made that could in turn provide valuable data to improve the operation of the decision tool. As the other future research directions mentioned in this report are completed and additional capabilities are added to the decision tool, the manner in which the decision tool recommends certain technologies could also be clarified and adapted. This future work will be a continual process as the included energy storage technologies improve, new energy storage technologies are introduced, and regulations and market conditions change. 


\section{ACKNOWLEDGEMENTS}

This report is a product of the efforts of individuals at both The University of Texas at Austin and Idaho National Laboratory. The authors of this report would like to acknowledge the U.S. Department of Energy and, specifically, the Idaho National Laboratory for funding this research. 


\section{REFERENCES}

[1] Lawrence Livermore National Laboratory, "Estimated U.S. Energy Consumption in 2015: 97.5 Quads," 2016 March. [Online]. Available:

https://flowcharts.llnl.gov/content/assets/images/energy/us/Energy_US_2015.png .

[2] World Resource Institute, "U.S. GHG Emissions Flow Chart," 2003. [Online]. Available: https://flowcharts.llnl.gov/content/assets/images/energy/us/Energy_US_2015.png .

[3] L. R. Brown, J. Larsen, M. Roney and E. E. Adams, The Great Transition: Shifting from Fossil Fuels to Solar and Wind Energy, Earth Policy Institute, 2015.

[4] B. Mann, "Unable to Compete on Price, Nuclear Power on the Decline in the U.S.," National Public Radio, 7 April 2016. [Online]. Available:

http://www.npr.org/2016/04/07/473379564/unable-to-compete-on-price-nuclear-power-onthe-decline-in-the-u-s. [Accessed 22 July 2016].

[5] U.S. Nuclear Regulatory Commission, "NRC Maps of Decommissioning Sites," 14 September 2015. [Online]. Available: http://www.nrc.gov/reading-rm/doccollections/maps/decommissioning-sites.html\#power-reactors-status. [Accessed 22 July 2016].

[6] J. R. Lovering, A. Yip and T. Nordhaus, "Historical construction costs of global nuclear power reactors," Energy Policy, vol. 91, pp. 371-382, 2016.

[7] The White House, "Fact Sheet: U.S. Reports its 2025 Emissions Targets to the UNFCCC," 31 March 2015. [Online]. Available: https://www.whitehouse.gov/the-pressoffice/2015/03/31/fact-sheet-us-reports-its-2025-emissions-target-unfccc. [Accessed 22 July 2016].

[8] U.S. Energy Information Administration, "Natural Gas Weekly Update," 21 July 2016. [Online]. Available: http://www.eia.gov/naturalgas/weekly/. [Accessed 22 July 2016].

[9] A. Krupnick, Z. Wang and Y. Wang, "Sector Effects of the Shale Gas Revolution in the United States," Resources for the Future, Washington, DC, 2013.

[10] California ISO, "What the duck curve tells us about managing a green grid," 2016. [Online]. Available: https://www.caiso.com/Documents/FlexibleResourcesHelpRenewables_FastFacts.pdf. [Accessed 22 July 2016].

[11] P. Denholm, J. C. King, C. F. Kutcher and P. P. Wilson, "Decarbonizing the electric sector: Combining renewable and nuclear energy using thermal storage," Energy Policy, vol. 44, pp. 301-311, 2012.

[12] T. Mai, W. Cole, E. Lantz, C. Marcy and B. Sigrin, "Impacts of Federal Tax Extensions on Renewable Deployment and Power Sector Emmissions," National Renewable Energy Laboratory, Golden, CO, 2016.

[13] J. Durkay, "State Renewable Portfolio Standards and Goals," National Conference of State Legislatures, 23 March 2016. [Online]. Available: http://www.ncsl.org/research/energy/renewable-portfolio-standards.aspx.

[14] J. Weiner, "Price of Solar Energy in the United States Has Fallen to $5 \phi / \mathrm{kWh}$ on Average," Lawrence Berkeley National Laboratory, 30 September 2015. [Online]. Available: http://newscenter.lbl.gov/2015/09/30/price-of-solar-energy-in-the-united-states-has-fallen- 
to-5\% $2 \%$ A2kwh-on-average/.

[15] Office of Energy Efficiency \& Renewable Energy, "Next-Generation Wind Technology," U.S. Department of Energy, 2014. [Online]. Available: http://energy.gov/eere/nextgeneration-wind-technology.

[16] U.S. Energy Information Administration, "Today in Energy: Fewer wind curtailments and negative power prices seen in Texas after major grid expansion," 24 June 2014. [Online]. Available: http://www.eia.gov/todayinenergy/detail.cfm?id=16831\#tabs_SpotPriceSlider1.

[17] Z. Zhou, T. Levin and G. Conzelmann, "Survey of U.S. Ancillary Markets," Argonne National Laboratory, Argonne, IL, 2016.

[18] F. J. de Sisternes, J. D. Jenkins and A. Botterud, "The value of energy storage in decarbonizing the electricity sector," Applied Energy, vol. 175, pp. 368-379, 2016.

[19] U.S. Department of Energy, "Grid Energy Storage," 2013.

[20] International Energy Agency, "Technology Roadmap: Energy Storage," Paris, France, 2014.

[21] A. A. Akhil, G. Huff, A. B. Currier, B. C. Kaun, D. M. Rastler, S. B. Chen, A. L. Cotter, D. T. Bradshaw and W. D. Gauntlett, "DOE/EPRI 2013 Electricity Storage Handbook in Collaboration with NRECA," Sandia National Laboratory, Albuquerque, NM.

[22] M. Beaudin, H. Zareipour, A. Schellenberglabe and W. Rosehart, "Energy storage for mitigating the variability of renewable electricity sources: An updated review," Energy for Sustainable Development, vol. 14, pp. 302-314, 2010.

[23] International Energy Agency, "Technology Roadmap: Hydrogen and Fuel Cells," Paris, France, 2015.

[24] IRENA and IEA-ETSAP, "Thermal Energy Storage: Technology Brief," 2013.

[25] D. Bhatnagar, A. Currier, J. Hernandez, O. Ma and B. Kirby, "Market and Policy Barriers to Energy Storage Deployment: A Study for the Energy Storage Systems Program," Sandia National Laboratory, Albuquerque, NM, 2013.

[26] DOE Office of Electricity Delivery \& Energy Reliability, "DOE Global Energy Storage Database," Sandia National Laboratories, 2016. [Online]. Available: http://www.energystorageexchange.org.

[27] National Renewable Energy Laboratory, "Issue Brief: A Survey of State Policies to Support Utility-Scale and Distributed-Energy Storage," Golden, CO, 2014.

[28] U.S. Energy Information Administration, "Today in Energy: Most states have Renewable Portfolio Standards," 3 February 2012. [Online]. Available: http://www.eia.gov/todayinenergy/detail.cfm?id=4850.

[29] U.S. Environmental Protection Agency, "Fact Sheet: Overview of the Clean Power Plan," 27 June 2016. [Online]. Available: https://www.epa.gov/cleanpowerplan/fact-sheetoverview-clean-power-plan.

[30] C. Russell, "Honda Introduces Bipartisan Energy Storage Tax Relief," 2 June 2016. [Online]. Available: https://honda.house.gov/news/press-releases/honda-introducesbipartisan-energy-storage-tax-relief.

[31] P. Denholm, E. Ela, B. Kirby and M. Milligan, "The Role of Energy Storage with Renewable Electricity Generation," National Renewable Energy Laboratory, Golden, CO, 
2010.

[32] M. Kinter-Meyer, P. Balducci, W. Colella, M. Elizondo, C. Jin, T. Nguyen, V. Viswanathan and Y. Zhang, "National Assessment of Energy Storage for Grid Balancing and Arbitrage," Pacific Northwest National Laboratory, Richland, WA, 2012.

[33] J. Eyer and G. Corey, "Energy Storage for the Electricity Grid: Benefits and Market Potential Assessment Guide," Sandia National Laboratory, Albuquerque, NM, 2010.

[34] U.S. Energy Information Administration, "Energy in Brief: What is the electric power grid and what are some challenges it faces?," 22 December 2015. [Online]. Available: http://www.eia.gov/energy_in_brief/article/power_grid.cfm.

[35] ERCOT, "Maps," 2016. [Online]. Available: http://www.ercot.com/news/mediakit/maps/.

[36] International Energy Agency, "Energy Storage Technology Roadmap: Technology Annex," Paris, France, 2014.

[37] U.S. Energy Information Administration, "Today in Energy: Coal made up more than $80 \%$ of retired electricity generating capacity in 2015," 8 March 2016. [Online]. Available: https://www.eia.gov/todayinenergy/detail.cfm?id=25272.

[38] U.S. Energy Information Administration, "Today in Energy: Proposed Clean Power Plan would accelerate renewable additions and coal plant retirements," 5 June 2015. [Online]. Available: https://www.eia.gov/todayinenergy/detail.cfm?id=21532.

[39] U.S. Environmental Protection Agency, "Fact Sheet: Clean Power Plan - Opportunities for Nuclear Power," 3 December 2015. [Online]. Available:

https://www.epa.gov/cleanpowerplan/fact-sheet-clean-power-plan-opportunities-nuclearpower.

[40] U.S. Energy Information Administration, "Today in Energy: Under the proposed Clean Power Plan, natural gas, then renewables, gain generation share," 27 May 2015. [Online]. Available: http://www.eia.gov/todayinenergy/detail.cfm?id=21392.

[41] W. M. Warwick, "A Primer on Electric Utilities, Deregulation, and Restructuring of U.S. Electricity Markets," Pacific Northwest National Laboratory, Richland, WA, 2002.

[42] I. Council, "2009 State of the Markets Report," 2009.

[43] Federal Energy Regulatory Commission, "Energy Primer: A Handbook of Energy Market Basics," 2015.

[44] Federal Energy Regulatory Commission, "Electric Power Markets: National Overview," 29 February 2016. [Online]. Available: http://www.ferc.gov/market-oversight/mktelectric/overview.asp.

[45] J. Logan, K. B. Medlock III and W. C. Boyd, "A Review of Sector and Regional Trends in U.S. Electricity Markets: Focus on Natural Gas," National Renewable Energy Laboratory, Golden, CO, 2015.

[46] ISO New England, "2016 Regional Electricity Outlook," 2016.

[47] W. A. Braff, J. M. Mueller and J. E. Trancik, "Value of storage technologies for wind and solar energy," Nature Climate Change, vol. 10, no. 1038, 2016.

[48] MIT Electric Vehicle Team, "A Guide to Understanding Battery Specifications," December 2008. [Online]. Available: http://web.mit.edu/evt/summary_battery_specifications.pdf. 
[49] U.S. Environmental Protection Agency, "Electricity Storage," 30 September 2015. [Online]. Available: https://www.epa.gov/energy/electricity-storage\#impacts.

[50] Canadian Centre for Occupational Health and Safety, "OSH Answers Fact Sheets: Battery Charging," 20 November 2009. [Online]. Available: https://www.ccohs.ca/oshanswers/safety_haz/battery-charging.html.

[51] Business and Legal Resources, "Flywheel explosion teaches lessons in machine safety," 25 February 2016. [Online]. Available: http://safety.blr.com/workplace-safetynews/equipment-and-process-safety/machine-safety/Machine-safety-Flywheel-explosionteaches-lessons-/.

[52] National Renewable Energy Laboratory, "Role of Storage and Demand Response," Golden, CO, 2015.

[53] Office of Electricity Delivery and Energy Reliability, "Time Based Rate Programs," [Online]. Available:

https://www.smartgrid.gov/recovery_act/time_based_rate_programs.html.

[54] Baldor Electric Company, "Energy Management Best Practices: Peak Shaving Generators," September 2005. [Online]. Available: http://www.sustainableplant.com/assets/WP00010.pdf.

[55] International Atomic Energy Agency, "Status of design concepts of nuclear desalination plants," Vienna, Austria, 2002.

[56] International Atomic Energy Agency, "Advances in Nuclear Power Process Heat Applications," Vienna, Austria, 2012.

[57] C. Forsberg, "Production of Hydrogen Using Nuclear Energy," Oak Ridge National Laboratory, Oak Ridge, TN, 2003.

[58] M. Milligan, B. Kirby and S. Beuning, "Potential Reductions in Variability with Alternative Approaches to Balancing Area Cooperation with High Penetrations of Variable Generation," National Renewable Energy Laboratory, Golden, CO, 2010.

[59] World Nuclear Association, "Nuclear Power Reactors," July 2016. [Online]. Available: http://www.world-nuclear.org/information-library/nuclear-fuel-cycle/nuclear-powerreactors/nuclear-power-reactors.aspx.

[60] CLP Holdings Ltd., "Pressurised Water Reactor Vs Boiling Water Reactor," 2013. [Online]. Available: https://www.clpgroup.com/NuclearEnergy/Eng/power/power4_1_2.aspx.

[61] U.S. Department of Energy, "Technology Readiness Assessment Guide," Washington, DC, 2011.

[62] R. Smith, "Pumped Up: Renewables Growth Revives Old Energy-Storage Method," Wall Street Journal, 22 July 2016.

[63] U.S. Department of Energy, "Hydropower Vision: A New Chapter for America's 1st Renewable Energy Source," Washington, DC, 2016.

[64] ARUP, "Pumped storage hydropower review," 2015. [Online]. Available: http://www.arup.com/projects/pumped_storage_hydropower_review.

[65] NHA - Pumped Storage Development Council, "Challenges and Opportunities for New Pumped Storage Development," National Hydropower Association, Washington, DC, 2012. 
[66] J. I. San Martin, I. Zamora, J. J. San Martin, V. Aperribay and P. Eguia, "Energy Storage Technologies for Electric Applications," in International Conference on Renewable Energies and Power Quality, Las Palma de Gran Canaria, Spain, 2011.

[67] National Energy Technology Laboratory, "Final Environmental Assessment for the Pacific Gas and Electric Company (PG\&E) Compressed Air Energy Storage (CAES) Compression Testing Phase Project, San Joaquin County, California," U.S. Department of Energy, Morgantown, WV, 2014.

[68] R. B. Schainker and A. Rao, "Compressed Air Energy Storage (CAES) Scoping Study for California, USA," California Energy Commission, PIER Energy-Related Environmental Research Program, 2008.

[69] C. Pieper and H. Rubel, "Revisiting Energy Storage: There Is a Business Case," The Boston Consulting Group, 2011.

[70] J. Intrator, E. Elkind, S. Weissman, M. Sawchuk, E. Bartlett, A. R. Abele, B. S. Dunn, T.C. Tsao, R. Blaik, C. Lim, D. Luong, L. Smith and B. Washom, "2020 Strategic Analysis of Energy Storage in California," Public Interest Energy Research (PIER) Program, 2011.

[71] Beacon Power, LLC., "Carbon Fiber Flywheels," 2014. [Online]. Available: http://beaconpower.com/carbon-fiber-flywheels/.

[72] X. Luo, J. Wang, M. Dooner and J. Clarke, "Overview of current development in electrical energy storage technologies and the application potential in power system operation," Applied Energy, vol. 137, pp. 511-536, 2015.

[73] D. Rastler, "Electric Energy Storage Technology Options: A White Paper Primer on Applications, Costs, and Benefits," Electric Power Research Institute, Palo Alto, CA, 2010.

[74] Murata Manufacturing Co., "The Structure and Principle of Electric Double Layer Capacitor," [Online]. Available: http://www.murata.com/products/capacitor/edlc/techguide/principle.

[75] M. G. Molina, "Dynamic Modelling and Control Design of Advanced Energy Storage for Power Systems Applications," in Dynamic Modelling, A. V. Brito, Ed., InTech, 2010.

[76] H. Chen, T. N. Cong, W. Yang, C. Tan, Y. Li and Y. Ding, "Progress in electricity storage system: A critical review," Progress in Natural Science, vol. 19, no. 3, pp. 291-312, 2009.

[77] S. Schoenung, "Energy Storage Systems Cost Update: A Study for the DOE Energy Storage Systems Program," Sandia National Laboratory, Albuquerque, NM, 2011.

[78] Z.-S. Wu, K. Parvez, X. Feng and K. Mullen, "Graphene-based in-plane microsupercapacitors with high power and energy densities," Nature Communications, vol. 4, no. 2487, 2013.

[79] D. Pech, M. Brunet, H. Durou, P. Huang, V. Mochalin, Y. Gogotsi, P.-L. Taberna and P. Simon, "Ultrahigh-power micrometre-sized supercapacitors based on onion-like carbon," Nature Nanotechnology, vol. 5, pp. 651-654, 2010.

[80] M. Brain, "How Lithium-ion Batteries Work," HowStuffWorks, 2006. [Online]. Available: http://electronics.howstuffworks.com/everyday-tech/lithium-ion-battery1.htm.

[81] J. Zacune, "Lithium," GLOBAL 2000, Vienna, Austria, 2013.

[82] A. F. Blum and R. T. Long Jr., "Hazard Assessment of Lithium Ion Battery Energy Storage Systems," Fire Protection Research Foundation, Quincy, MA, 2016.

[83] I. Tutore, M. Ferretti and M. Simoni, "Overcoming the barriers to the innovations diffusion 
through diffusion-oriented policies. The case of Li-Ion Battery for Electric Vehicles," in XXV Convegno Annuale di Sinergie, 2013.

[84] B. Dunn, H. Kamath and J.-M. Tarascon, "Electrical Energy Storage for the Grid: A Battery of Choices," Science, vol. 334, no. 6058, pp. 928-935, 18 November 2011.

[85] NGK Insulators, Ltd., "NGK's Sodium Sulfur (NAS) Battery: The Vendor's Perspective on Barriers \& Issues Encountered in U.S. Deployment," 2009.

[86] R. A. Burns, Fundamentals of Chemistry (4th Edition), Prentice Hall, 2002.

[87] Wiley Rein LLP, "Lead-Acid Battery Stewardship Bill Introduced in California," April 2016. [Online]. Available: http://www.wileyrein.com/newsroom-newsletters-item-LeadAcid-Battery-Stewardship-Bill-Introduced-in-California.html.

[88] OpenStax, "Batteries and Fuel Cells," Rice University, 2016. [Online]. Available: http://cnx.org/contents/ykqdjdED@4/Batteries-and-Fuel-Cells.

[89] V. G. Lacerda, A. B. Mageste, I. J. B. Santos, L. H. Mendes da Silva and M. d. C. Hespanhol da Silva, "Separation of $\mathrm{Cd}$ and Ni from Ni-Cd batteries by an environmentally safe methodology employing aqueous two-phase systems," Journal of Power Sources, vol. 193, pp. 908-913, 2009.

[90] M. C. McManus, "Environmental consequences of the use of batteries in low carbon systems: The impact of battery production," Applied Energy, vol. 93, pp. 288-295, 2012.

[91] Industrial Economics, Inc., "Evaluation of Three RCRA Regulations Designed to Foster Increased Recycling," Cambridge, MA, 2004.

[92] S. McCluer and J.-F. Christin, "Comparing Data Center Batteries, Flywheels, and Ultracapacitors," Schneider Electric, 2011.

[93] W. G. Manuel, "Energy Storage Study 2014," California Energy Commission, 2014.

[94] Bromine Science Environmental Forum, "Innovation \& Science: Bromine in Innovative Technologies," 2013. [Online]. Available: http://bsef.com/innovation-science/.

[95] G. P. Corey, "An Assessment of the State of the Zinc-Bromine Development Effort," RedFlow Limited, Brisbane, Queensland, Australia, 2010.

[96] C. J. Rydh, "Environmental assessment of vanadium redox and lead-acid batteries for stationary energy storage," Journal of Power Sources, vol. 80, pp. 21-29, 1999.

[97] G. Kear, A. A. Shah and F. C. Walsh, "Development of the all-vanadium redox flow battery for energy storage: a review of technological, financial and policy aspects," International Journal of Energy Research, vol. 10, no. 1002, 2011.

[98] D. Ferrero, A. Lanzini, M. Santarelli and P. Leone, "A comparative assessment on hydrogen production from low- and high-temperature electrolysis," International Journal of Hydrogen Energy, vol. 38, pp. 3523-3536, 2013.

[99] McPhy Energy S. A., "Hydrogen energy," 2016. [Online]. Available: http://www.mcphy.com/en/markets/hydrogen-energy/.

[100] M. E. Webber, Energy 101, Austin, TX: University of Texas Press - Tower Books, 2016.

[101] U.S. Energy Information Administration, "Today in Energy: Few transportation fuels surpass the energy densities of gasoline and diesel," 14 February 2013. [Online].

Available: http://www.eia.gov/todayinenergy/detail.cfm?id=9991.

[102] U.S. Energy Information Administration, "May 2016 Monthly Energy Review," 2016. 
[103] Alternative Fuels Data Center, "Fuel Properties Comparison," U.S. Department of Energy, 2014.

[104] F. Wang, M. G. G., A. Ford, N. Barker and J. F. Missenden, "Impeccable Source," 5 June 2007. [Online]. Available: http://www.building.co.uk/impeccable-source/3088490.article.

[105] M. Bonte, P. J. Stuyfzand, A. Hulsmann and P. Van Beelen, "Underground Thermal Energy Storage: Environmental Risks and Policy Developments in the Netherlands and European Union," Ecology and Society, vol. 16, no. 1, 2011.

[106] W.-D. Steinmann and M. Eck, "Buffer storage for direct steam generation," Solar Energy, vol. 80, pp. 1277-1282, 2006.

[107] Stanford Energy System Innovations, "General Information," 2015. [Online]. Available: http://sustainable.stanford.edu/sites/default/files/documents/Stanford_SESI_General_ Information_Brochure.pdf.

[108] J. Collins, "Austin Energy's District Cooling Program," Austin Energy Utility Oversight Committee, Austin, TX, 2016.

[109] M. Kintner-Meyer, J. C. Molburg, K. Subbarao, J. Wang, N. Prakash Kumar, F. Zhao, G. Bandyopadhyay, L. Brackney, F. C., A. Florita and V. S. Koritarov, "The Role of Energy Storage in Commercial Building: A Preliminary Report," Pacific Northwest National Laboratory, Richland, WA, 2010.

[110] D. Laing, C. Bahl, T. Bauer, M. Fiss, N. Breidenbach and M. Hempel, "High-Temperature Solid-Media Thermal Energy Storage for Solar Thermal Power Plants," Proceedings of the IEEE, vol. 100, no. 2, pp. 516-524, February 2012.

[111] D. C. Stack and C. Forsberg, "Improving Nuclear System Economics Using Firebrick Resistance-Heated Energy Storage (FIRES)," in American Nuclear Society Annual Meeting, San Antonio, TX, 2015.

[112] C. W. Forsberg, "Gigawatt-Year Geothermal Energy Storage Coupled to Nuclear Reactors and Large Concentrated Solar Thermal Systems," in Thirty-Seventh Workshop on Geothermal Reservoir Engineering, Stanford, CA, 2012.

[113] Office of Energy Efficiency \& Renewable Energy, "Project Profile: Development and Performance Evaluation of High Temperature Concrete for Thermal Energy Storage for Solar Power Generation," U.S. Department of Energy, 2013. [Online]. Available: http://energy.gov/eere/sunshot/project-profile-development-and-performance-evaluationhigh-temperature-concrete.

[114] K. Gaine and A. Duffy, "A life cycle cost analysis of large-scale thermal energy storage technologies for buildings using combined heat and power," in Zero Emission Buildings Proceedings of Renewable Enregy Conference, Trondheim, Norway, 2010.

[115] L. F. Cabeza, I. Martorell, L. Miro, A. I. Fernandez and C. Barreneche, "Introduction to thermal energy storage (TES) systems," Elsevier Ltd., 2015.

[116] A. H. Abedin and M. A. Rosen, "A Critical Review of Thermochemical Energy Storage Systems," The Open Renewable Energy Journal, vol. 4, pp. 42-46, 2011.

[117] D. Stauth, "Storage advance may boost solar thermal energy potential," Oregon State University, 3 November 2015. [Online]. Available: http://oregonstate.edu/ua/ncs/archives/2015/nov/storage-advance-may-boost-solar-thermalenergy-potential. 
[118] International Energy Agency, "Technology Roadmap: Concentrating Solar Power," Paris, France, 2010.

[119] J. T. Adeoye, Y. M. Amha, V. V. Poghosyan, K. Torchyan and H. A. Arafat, "Comparative LCA of Two Thermal Energy Storage Systems for Shams1 Concentrated Solar Power Plant: Molten Salt vs. Concrete," Journal of Clean Energy Technologies, vol. 2, no. 3, pp. 274-281, 2014.

[120] G. Brett and M. Barnett, "The application of liquid air energy storage for large scale long duration solutions to grid balancing," in EPJ Web of Conferences, London, UK, 2014.

[121] Highview Power Storage, "Liquid Air Energy Storage (LAES)," Highview Enterprises Ltd., London, U.K., 2015.

[122] A. Sharma, V. Tyagi, C. Chen and D. Buddhi, "Review on thermal energy storage with phase change materials and applications," Renewable and Sustainable Energy Reviews, vol. 13, pp. 318-345, 2009.

[123] PCM Products Ltd., "PCM Development \& Consultancy: Product Applications," 2011. [Online]. Available: http://www.pcmproducts.net/PCM_Product_Application_Development.htm.

[124] E. Warg, "Biodegradability of phase change materials," Entropy Solutions, Inc., Plymouth, MN, 2015.

[125] R. Foran and M. Wu, "The Capabilities and Barriers of Incorporating Phase Change Material into Residential Building Design in Sydney, Australia," International Journal of Engineering Practical Research, vol. 2, no. 4, pp. 170-173, November 2013.

[126] G. Thomas, "Overview of Storage Development DOE Hydrogen Program," U.S. Department of Energy, Livermore, CA, 2000.

[127] New Mexico Energy Storage Task Force, "Federal and State Energy Storage Policies and Efforts," Sandia National Laboratory, Albuquerque, NM, 2013.

[128] U.S. Energy Information Administration, "Maps," 2016. [Online]. Available: https://www.eia.gov/consumption/residential/maps.cfm.

[129] U.S. Energy Information Administration, "Electric Power Monthly with Data for December 2015," U.S. Department of Energy, Washington, DC, 2016.

[130] Lazard, "Lazard's Levelized Cost of Storage Analysis - Version 1.0," 2015. 


\section{APPENDIX A: Developer Survey}

1. How much storage capacity is required for your application? Please provide your response in GWh.

Required Energy Storage Capacity:

2. How much power is required for your application? Please provide your response in GW.

Required Power Capacity:

3. How much space do you have available for an energy storage installation? Please provide your response in cubic meters.

Available Space:

4. Do you have any weight limitations? Please provide your maximum available weight in kilograms.

Available Weight:

5. What is the available budget for this project? Please provide your response in USD (\$).

Proposed Budget:

6. In what state will the chosen energy storage technology be installed?

7. Which grid-scale service is the most important to your application? Please mark only one.

Energy Arbitrage:

Frequency Regulation:

Load Following:

Spinning Reserves:

Non-Spinning and Supplemental Reserves:

Black Start:

Variable Supply Resource Integration:

Seasonal Storage:

Combined Heat and Power:

Waste Heat Utilization: 
8. What is the proposed timeline for this project? When will the chosen energy storage technology be installed? Please select one of the following choices.
(1) $1-5$ years
(2) 6-10 years
(3) 11-15 years
(4) 16-20 years
(5) $21-25+$ years

9. How close will this technology be located to human habitation or sensitive wildlife regions? Very close indicates that it is in the immediate vicinity and very far indicates almost no interaction. Please select one of the following choices.
(1) Very far away
(2) Far away
(3) Not very close
(4) Somewhat close
(5) Very close

10. Are there any geographic features compatible with energy storage in the immediate vicinity of the project? Please select all that apply.
$\square$ Depleted oil or natural gas reservoir
$\square$ Aquifer
$\square$ Evacuated salt cavern
$\square$ Underground cavern or pit
$\square$ Geothermal heat source
$\square$ Elevation change
$\square$ Water source 